\title{
Continuidad y cambio en la España urbana en el período de entreguerras
}





\section{Continuidad y cambio en la España urbana en el periodo de entreguerras. Análisis de una ciudad española}

Jesús Mirás Araujo 


\section{CONTINUIDAD Y CAMBIO EN LA ESPAÑA URBANA EN EL PERÍODO DE ENTREGUERRAS. ANÁLISIS DE UNA CIUDAD ESPAÑOLA \\ No está permitida la reproducción total o parcial de este libro, ni su tratamiento informático, ni la transmisión de ninguna forma o por cualquier medio, ya sea electrónico, mecánico, por fotocopia, por registro u otros métodos, sin el permiso previo y por escrito de los titulares del Copyright.}

\section{netbiglo}

www.netbiblo.com

DERECHOS RESERVADOS 2007, respecto a la primera edición en español, por

(C) Netbiblo, S. L.

NETBIBLO, S. L.

C/. Rafael Alberti, 6 bajo izq.

Sta. Cristina 15172 Oleiros (La Coruña) - Spain

Tlf: +34981915500 • Fax: +34981915511

editorial@netbiblo.com

ISBN: 978-84-9745-007-2

Depósito Legal: C-988-2007

Directora Editorial: Cristina Seco

Editora: Lorena Bello

Producción Editorial: Gesbiblo, S. L.

Impreso en España - Printed in Spain 


\section{Contenido}

Introducción

vii

\section{La neutralidad durante la Primera Guerra Mundial y los efectos del ajuste posbélico}

1. La evolución económica global......................................................................

2. La población coruñesa durante las dos primeras décadas del siglo XX ......... 10

3. Las actividades comerciales......................................................................... 22

3.1. El peso de las actividades comerciales................................................... 22

3.2. Las actividades comerciales en A Coruña durante la guerra mundial..................................................................... 26

3.3. Estructura de las actividades comerciales .................................................. 44

3.3.1. La importancia de las actividades de consumo básico................... $\quad 44$

3.3.2. El desigual comportamiento de las restantes actividades comerciales urbanas .................................................................. 48

3.4. La primacía de las actividades minoristas .............................................. 49

4. El sector servicios .............................................................................. $\quad 50$

4.1. Análisis de las actividades de servicios y factores caracterizadores

4.2. La crítica evolución de algunas actividades de servicios durante la guerra europea .................................................................... 53

4.3. Estructura interna de las actividades de servicios ................................... 57

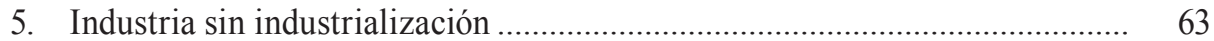

5.1. El impacto de la guerra mundial en la industria de A Coruña.................. 63

5.2. Las principales actividades industriales y estructura del sector ................ 64

\section{La "paz social" de la Dictadura de Primo de Rivera} y las transformaciones del ciclo económico, 1923-1930

1. La economía de A Coruña se adentra por una senda inestable

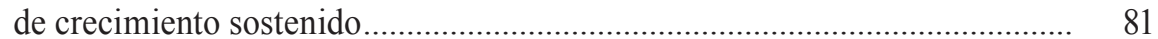

2. La culminación de la modernización demográfica .......................................... 85

3. El heterogéneo crecimiento de la función comercial...................................... 91

3.1. El avance del comercio sin modificaciones significativas

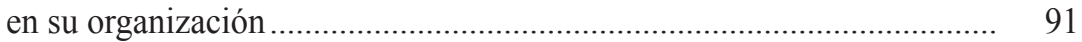

3.2. La dicotomía de las actividades comerciales ........................................ $\quad 92$

3.2.1. Las actividades comerciales básicas

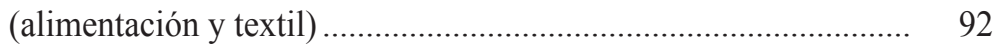

3.2.2. El resto de los sectores ................................................................ 94 
4. Los servicios expanden de manera creciente su protagonismo ...................... 97

4.1. Factores diferenciales del desarrollo de la función terciaria urbana ....... 97

4.2. El crecimiento de las funciones tradicionales y la expansión de los servicios modernos .................................................... 98

5. Un crecimiento industrial con desaceleración del impulso inicial................. 120

5.1. Las principales actividades industriales y su significación en la economía urbana

\section{El impacto de la crisis internacional en la Segunda República} española. Su incidencia en A Coruña, 1931-1936

1. La evolución económica global internacional y nacional.............................. 135

2. La coyuntura económica en la ciudad de A Coruña ...................................... 139

3. Una población afectada por los efectos de la crisis ..................................... 146

4. El sector comercial y su crecimiento comparativo ....................................... 153

4.1. Estructura de las actividades comerciales .......................................... 153

4.2. Las actividades minoristas sobreviven en un difícil entorno ................. 158

5. El sector servicios y el impacto negativo de la crisis de los negocios marítimos.................................................................... 160

6. La crisis industrial nacional e internacional deja su huella en un sector insuficientemente asentado en la ciudad

6.1. Los problemas de contracción de la demanda dominan el panorama interindustrial

\section{Fuentes y bibliografía}

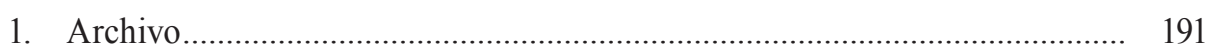

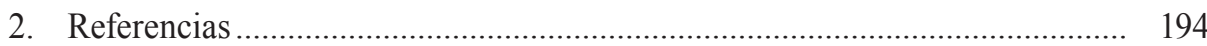




\section{INTRODUCCIÓN}

La historia urbana es una disciplina que ha venido gozando de una notoria vitalidad a nivel internacional durante los últimos años. En España, la literatura sobre la historia de las ciudades ha seguido un rumbo marcado por la irregularidad (de Terán, 1996; Monclús, 1993; Oyón, 1993; Monclús, 1992; Bonet, 1991, 1989a). Los estudios de historia urbana se iniciaron aproximadamente en los años anteriores a la Guerra Civil, aunque de una manera todavía muy fragmentaria (Bonet, 1989b: 41). No será hasta mediados de los años setenta y principios de los ochenta cuando se desarrollen los primeros intentos serios de análisis con una metodología propia y diferenciada (de Terán, 1996: 87, 1989; Monclús, 1995, 1992; Oyón, 1993: 37). Sin embargo, el interés hacia el estudio de las ciudades desde un punto de vista histórico ha experimentado un considerable crecimiento en fechas recientes, con progresos especialmente sobresalientes durante los años noventa (Núñez, 2001: 252; Claverol y Vilagrasa, 1989), generando así un amplio abanico de publicaciones que ha permitido recabar un creciente volumen de información sobre las ciudades españolas contemporáneas (Guàrdia, Monclús y Oyón, 1994).

La progresiva aceleración acaecida desde los años noventa se contextualiza dentro la paulatina configuración de la historia urbana a nivel internacional como "un campo de confluencia de orientaciones disciplinares diversas" (Guàrdia, Monclús y Oyón, 1994: xiii). Sin embargo, la historiografía española todavía no ha cobrado carta de naturaleza propia (Monclús, 1993: 115). La disciplina no ha desarrollado una metodología propia (Bonet, 1987), encontrándose dominada por contribuciones dispersas e individuales, y por la excesiva presencia de monografías urbanas, sin formulaciones teóricas globales. Además, a pesar de que las tendencias dentro de la historia urbana en el mundo desarrollado transitan en la línea de una metodología comparativa (Guàrdia, Monclús y Oyón, 1994: xiii), este camino aún no ha sido suficientemente hollado en España (Monclús, 1992: 7).

Una de las carencias más graves en la aproximación histórica al estudio de las ciudades se encuentra en la historia económica, que tradicionalmente ha prestado una escasa atención comparada a la ciudad como una categoría analítica específica. A pesar de que se han publicado investigaciones que examinan el desarrollo urbano a escala global (Núñez, 2001; del Val, 1997; Gelabert, 1995; Reher, 1994), los estudios de caso individuales de carácter comparativo y contextualizado han sido menos comunes. Además, los análisis sobre el período moderno y sobre el siglo XIX han predominado sobre el resto, concentrándose la investigación en las áreas más desarrolladas del país. La combinación de estos elementos dificulta el hallazgo de referentes comparativos para el estudio que aquí se plantea.

El trabajo que se desarrolla a lo largo de las páginas que siguen pretende analizar determinados aspectos de la economía de la ciudad de A Coruña durante un período 
que la historiografía española y gallega han señalado como clave, y que lo habría sido en mayor medida de no haber mediado las circunstancias que condujeron a la Guerra Civil y al posterior período de involución democrática que supuso el franquismo ${ }^{1}$. El propósito inicial es enmarcar la economía urbana dentro de las tendencias de la economía española y del sistema de ciudades nacional, a pesar de que resulta extremadamente complicado establecer una comparación adecuada, dado que las fuentes y enfoques empleados en los estudios difieren sustancialmente, motivo por el cual sólo es posible comparar tendencias evolutivas.

El período cronológico en el que se encuadra el estudio, comúnmente conocido como etapa de entreguerras, fue una etapa especialmente convulsa para la economía internacional. La Primera Guerra Mundial generó una profunda ruptura, que permite desgajar la historia contemporánea en un antes y un después de 1914. Las dislocaciones causadas por el conflicto transformaron radicalmente la economía, la política y la sociedad mundiales, con unos efectos especialmente perceptibles en Europa, aunque el conjunto de la economía del planeta no pudo mantenerse al margen de los trastornos. Posteriormente, los años veinte fueron testigo del surgimiento de movimientos políticos totalitarios, a los que España no fue ajena, y que se desenvolvieron en un contexto de inestabilidad, en donde el crecimiento macroeconómico parece haber constituido una ilusión que ocultaba deficiencias y fallos de amplio alcance en el sistema capitalista.

Con este escenario como fondo, existe un consenso ampliamente admitido en reconocer que, aun con sus carencias, deficiencias, limitaciones, lentitudes, etc., el primer tercio del siglo XX supuso para la economía española un período de crecimiento, tal vez insuficiente como para permitir una comparación en plano de igualdad con el entorno occidental más desarrollado. Pero, como han señalado numerosos autores, crecimiento al fin y al cabo.

A nivel regional, la historiografía gallega ha acometido durante los últimos años un decidido esfuerzo para superar la tradicional visión ruralista de nuestra sociedad, prestando una atención especial a otros aspectos de su economía (Carmona, 2001b; Villares, 1996b). Las investigaciones desarrolladas a lo largo de los últimos años sobre la economía de Galicia han permitido caracterizar a este período como el del inicio de las transformaciones que habrían de conducir al extremo noroccidental del país por el camino de la modernización.

La economía de la ciudad de A Coruña, por su parte, no puede analizarse independientemente de los acontecimientos socioeconómicos y políticos que marcaron esta etapa, tanto a nivel internacional como nacional. Varios factores nos han llevado a reflexionar y deducir que el período estudiado ha sido especialmente significativo para

\footnotetext{
1 El trabajo sintetiza las aportaciones recogidas en la tesis doctoral del autor que, bajo el título Una modernización inconclusa. Estructura y transformaciones económicas en una ciudad española de tipo medio. A Coruña, 1914-1935, y dirección del profesor doctor Alberte Martínez López, fue defendida en la Facultad de Ciencias Económicas y Empresariales de la Universidade da Coruña, en diciembre de 2004, mereciendo la calificación de sobresaliente cum laude por unanimidad por parte del tribunal compuesto por Luis Alonso Álvarez (presidente), Rubén Camilo Lois González (secretario), Javier Vidal Olivares, Jesús María Valdaliso Gago y John Kimmons Walton.
} 
la caracterización socioeconómica de la ciudad, sin por ello caer en una mimetización de las cronologías al uso trazadas por la historiografía económica española.

La profusión de investigaciones sobre historia, geografía, economía o sociología urbanas en nuestro país durante las últimas décadas ha puesto de manifiesto el carácter unitario y específico de este período. En la mayoría de ciudades españolas, se produjo la transición entre un crítico final de siglo XIX y los intentos por modernizar las estructuras económicas, políticas, sociales y urbanísticas. A lo largo de todo el país los síntomas de una crisis de la sociedad de la Restauración se repiten siguiendo parámetros similares. Y, en la mayoría de los casos, la guerra europea actuó como el detonante de procesos totalmente nuevos, que marcaron el destino de los núcleos urbanos, aunque con muy distinta fortuna.

A pesar de que existen todavía lagunas en el análisis global del fenómeno urbano español, las síntesis de las que disponemos indican que este período fue el que marcó la evolución futura de nuestras ciudades ${ }^{2}$. En función de su capacidad de respuesta a los acontecimientos que definen esta etapa, las ciudades aprovecharon de manera distinta sus oportunidades. A nivel nacional, la ruptura que tuvo lugar tras la guerra europea supuso la consolidación definitiva del predominio urbano, del cual se vieron beneficiadas las localidades por encima del umbral de los 100.000 habitantes, lo que acarreó una creciente urbanización del país.

Por un lado, el grupo de las ciudades que, bien desde el siglo XIX, bien durante este período, se adentraron decididamente por la senda de la modernización. A pesar de que hoy no se identifica con tanta claridad ciudad e industrialización, y a pesar de que la actividad industrial no parece haber tenido un papel tan determinante sobre el proceso de urbanización español en su conjunto (Racionero, 1978; Capel, 1974), las ciudades que experimentaron un mayor crecimiento fueron aquéllas en las que la industrialización dejó su impronta. Aunque no consiguieron desembarazarse completamente de la inercia de las actividades terciarias, primero ciudades como Bilbao o Barcelona, y más tarde otras como Zaragoza, Madrid, e incluso Valencia, Sevilla, Gijón, Cartagena, etc. encontraron en el desarrollo industrial el motor de su crecimiento (González Portilla et al., 2001; Oyón et al., 1998; Almuedo, 1996; Fernández Clemente y Forcadell, 1992; García Delgado, 1992; Sorribes, 1992; García Merino, 1987; Pérez Rojos, 1986; Alvargonzález, 1977).

Por otro lado, descubrimos los casos de las ciudades medianas (aquéllas de rango jerárquico próximo al de A Coruña). Ejemplos de ello serían ciudades como Oviedo, Albacete, León, etc., y la categoría específica de las ciudades portuarias (Cádiz, Alicante, Málaga, San Sebastián, Tarragona, Las Palmas de Gran Canaria, Santa Cruz de Tenerife, etc.), núcleos eminentemente comerciales, y en las que dicho sector jugó un

2 De Terán (1999). El crecimiento urbano español corrió paralelo, aunque a un ritmo algo inferior, al que experimentaron otros países desarrollados (Reher, 1989), en los que el período que transcurre entre el final de la Primera Guerra Mundial y la depresión de los años treinta presenta elevadas tasas de crecimiento de sus índices de urbanización. Ese proceso fue más acelerado en los países que consiguieron mantenerse al margen del conflicto bélico (Bairoch, 1988: 302-303). 
papel decisivo (García Martínez, 1995; Gómez Cruz, 1994; Morilla, 1992; Trespalacios, 1992; Fernández Cuenca, 1991; Pérez Serrano, 1991; González González, 1987; Cáceres, 1980). Durante el primer tercio del siglo, se correspondían con ciudades en torno a una franja entre 30.000 y 50.000 habitantes, que en 1900 apenas representaban el 3\% de la población nacional, pero en 1930 habían multiplicado por tres su población total y duplicado su participación relativa (Martínez Cuadrado, 1974: 119).

Finalmente, el grupo de las ciudades pequeñas, en las cuales no se produjeron cambios significativos en sus estructuras socioeconómicas y, por tanto, caminaron siempre a un ritmo inferior al de la lenta pero inexorable modernización de las áreas más dinámicas del país. Estas ciudades generalmente fracasaron a la hora de engancharse al tren de la industrialización. En consecuencia, pueden caracterizarse por el excesivo predominio de sus funciones terciarias, de escasa sofisticación, con un elevado peso del comercio (sobre todo, de aquél destinado a satisfacer las necesidades básicas de la población) y del empleo en la administración. Ejemplos de ello son ciudades como Lugo, Lleida, Teruel, Segovia, Ciudad Real, Cuenca, Jaén y otras capitales de provincia, algunas de las cuales cristalizaron como "agrociudades" rectoras de amplias comarcas rurales en sus respectivas provincias (Vicedo et al., 1999; López González, 1999; Arroyo et al., 1992; Armas, 1990; Rodríguez Lestegás, 1989; Pillet, 1984; Troitiño, 1984; García Márquez, 1983; Martínez de Pisón, 1976). Con todo, este perfil no debe ocultarnos que, con mayores o menores traumatismos, también estas ciudades experimentaron una cierta transformación de sus estructuras socioeconómicas.

La metodología adoptada en el trabajo parte de la utilización de una fuente empleada con profusión en la historia económica española, la contribución industrial y de comercio. Entre los argumentos que avalan la utilización de esta fuente, destaca su aplicación a ámbitos territoriales y a propósitos muy heterogéneos. Sin embargo, ha dominado su aplicación al estudio de la estructura industrial del país, bajo enfoques nacionales o regionales. Por este motivo, la principal novedad del enfoque del trabajo reside en su tratamiento en un estudio económico urbano concreto.

El objetivo es determinar el comportamiento de la economía de la ciudad, intentando establecer cuáles fueron las etapas evolutivas por las que discurrió. La estrategia seguida ha consistido en el tratamiento estadístico de varios años censales, mediante cortes temporales que determinasen las transformaciones en la estructura económica local. El enfoque es de carácter macroeconómico. Por tanto, se trata de retratar los principales sectores económicos urbanos y sus rasgos globales, sin descender al detalle de empresas concretas (excepto en casos puntuales, y con el objeto de ilustrar comportamientos sectoriales), ya que la complejidad de la vida urbana hace necesario acotar el área de estudio, aunque siempre dentro del marco de necesaria multidisciplinariedad metodológica que requiere un estudio de historia económica urbana.

Subsidiariamente, se ha recurrido a una fuente complementaria de la anterior, la contribución sobre las utilidades de la riqueza mobiliaria, gracias a la que se ha podido disponer de información concreta sobre algunas de las sociedades que integraban el entramado económico local. En este sentido, esta fuente permite descender un peldaño 
en el nivel de análisis, acercándonos a un enfoque microeconómico que, sin embargo, no es el dominante en el estudio.

La hipótesis fundamental que se intenta demostrar es la consolidación de A Coruña como una economía terciaria, comercial y de servicios. Si se ha de señalar un motor de la economía de la ciudad durante el primer tercio del siglo XX, éste fue indudablemente el puerto, elemento decisivo desde épocas antiguas. La situación portuaria de A Coruña ha sido el factor principal que ha determinado su crecimiento, a través del comercio marítimo, tanto de pasajeros como de mercancías, y a través de la pesca y derivados. El reciente desarrollo de la historia marítima y, en particular, de la historia portuaria ha permitido descubrir fenómenos similares en otras ciudades litorales y portuarias.

La mayoría de investigadores gallegos ha coincidido asimismo en señalar que la pesca ha sido un factor clave en el desarrollo socioeconómico regional. Los puertos gallegos destacaron por los capítulos pesca y emigración, aunque tal especialización revelaba el posicionamiento gallego en pie de desigualdad en el mercado mundial. Los puertos de A Coruña y Vigo desempeñaron un papel de centros de conexión con el exterior, de puntos de llegada de las innovaciones, de focos dinámicos y de progreso, aunque la carencia de una estructura regional avanzada e integrada en los mercados y en las corrientes culturales mundiales, limitó su papel al de puntos de salida de los recursos naturales y humanos (Precedo, 1998: 26).

Como consecuencia de ello, durante la mayor parte del siglo XX esta actividad ha sido el otro factor preponderante de la economía de A Coruña, al posibilitar el asiento de una de las más potentes flotas pesqueras nacionales, facilitando el nacimiento y desarrollo de numerosas actividades derivadas, industriales y terciarias, que conformaron la base económica urbana (Mirás, 2003a, b). Por consiguiente, la evolución del tráfico portuario y, a su lado, de la pesca y actividades vinculadas (conservas, hielo, industrias metalográficas, combustibles, etc.) ha sido uno de los hilos conductores más repetidos en la exposición. La historia del puerto es la historia de la ciudad y, en este sentido, las coyunturas por las que atravesó el puerto coinciden plenamente con las que experimentó el conjunto de la economía urbana, especialmente aquellos segmentos del sector terciario más dependientes del movimiento portuario. 



\section{1}

\section{La neutralidad durante la}

Primera Guerra Mundial y los efectos del ajuste posbélico 



\section{LA EVOLUCIÓN ECONÓMICA GLOBAL}

Con el estallido de la guerra europea, el ciclo expansivo que había dominado el mundo occidental durante los primeros años del siglo XX tocó a su fin (Aldcroft, 1985). La guerra significó la consolidación de numerosas dificultades y tensiones en las relaciones económicas y financieras entre países, surgidas en los decenios previos (Renouvin et al., 1995), que sólo habrían de tener solución tras la nueva reorganización internacional que se produjo tras el conflicto (Tortella, 2000).

En términos comparativos, el inicio del siglo fue uno de los períodos más desfavorables en el desarrollo económico español a largo plazo (Prados, 2003). La crisis colonial trajo consigo vientos de cambio, iniciándose así un viraje en la trayectoria del capitalismo español. En algunas capitales españolas, el ciclo económico se encontraba en una fase alcista desde el tránsito entre los siglos XIX y XX, circunstancia que convencionalmente se ha asociado a la repatriación de capitales antillanos, lo que derivó en un auge de las inversiones industriales (Bueno, 2000: 49; Alvargonzález, Fernández y Tomé, 1992: 152; Rivera, 1985: 43; Alvargonzález, 1977: 32). Pero ese crecimiento industrial no siempre tuvo continuidad durante los años que antecedieron a la guerra mundial, si se exceptúan casos puntuales como Bilbao, Zaragoza o Barcelona (Oyón et al., 1998; García Merino, 1992: 101; Fernández Clemente y Forcadell, 1992: 440-441).

Sin embargo, a la altura de la guerra, la economía española presenta signos de agotamiento, excesivamente dependiente de los parámetros que la definían desde finales del siglo XIX: proceso de industrialización insuficientemente consolidado, mercado interior estrecho (condicionado por una agricultura pobre y poco diversificada, con las consiguientes limitaciones de demanda que ello implicaba), bajo nivel de formación de capital, descompensada estructura social y política exterior marcadamente proteccionista (García Delgado y Jiménez, 1998; Carreras y Fontana, 1997: 53; García Delgado, 1991; Maluquer, 1991; Nadal, 1987a, b; Palafox, 1986; Muñoz, Roldán y Serrano, 1978).

Tradicionalmente se consideraba que la guerra había constituido un período excepcionalmente próspero para España, toda vez que el aumento de las exportaciones y la caída de las importaciones habían repercutido en un crecimiento del producto interior (Sudrià, 1990: 363). Prueba de ello es el indicador de constitución de sociedades, que en el período bélico registra su mayor dinamismo desde el impulso que experimentara a principios de siglo, gracias a la aludida repatriación de capitales coloniales (García Delgado y Jiménez, 1998: 261-262).

Las estimaciones del producto nacional y del comercio realizadas durante los años ochenta relativizaron esa imagen optimista (Carreras, 1990, 1984; Tena, 1985;, al puntualizar que la influencia de la contienda había sido indirecta, y que las cifras favorables de la economía española en comparación con el entorno europeo se debían al empeoramiento de los resultados de estos últimos países (Carreras, 1991: 286). En lugar de abrir la economía española a nuevas oportunidades en el exterior, el principal impacto de la guerra fue un cambio en los precios relativos y una fuerte inflación, dando origen a un crecimiento de la producción y la tasa de ahorro basados principalmente 
en la reducción de los salarios reales y la redistribución del ingreso interior (Alcalá y Sudrià, 1989: 13), lo que impidió un crecimiento del mercado doméstico.

España salió derrotada del conflicto en términos de coste de oportunidad. Varios sectores obtuvieron pingües beneficios en un entorno económico especulativo, que se realizó, en su mayor parte, a costa de los asalariados y, por tanto, en abierto antagonismo con el crecimiento del consumo interno (García Delgado, 1983b: 548; Fontana y Nadal, 1980: 105). Además, los beneficios se consiguieron sin una modernización de la estructura productiva del país, ya que lo más frecuente fue el aprovechamiento al máximo de la capacidad productiva instalada, sin inversión de los beneficios (Carreras, 1990: 158).

El crecimiento no fue cronológica ni sectorialmente uniforme. Se detectan dos ciclos en la economía española. El primero, entre 1914 y 1915, en el que predominó el impacto negativo de la guerra, y el segundo, entre 1916 y 1918 (García Delgado, 1981, lo retrotrae a 1915), en el que la actividad económica registró un importante crecimiento (Carreras, 1990: 48).

El crecimiento de los años de guerra tuvo su contrapartida en las dificultades de los años posteriores (García Delgado, 1981: 425), ya que el período 1919-22 fue testigo de un duro ajuste (García Delgado, 1983b). La crisis socioeconómica afectó primero al medio rural y más tarde a las zonas industriales (Harrison, 1988: 137). Hacia 1920 los efectos de la recesión se habían extendido a todo el país y a la mayoría de sectores (García Delgado, 1983b: 577), prolongándose hasta la segunda mitad 1922, cuando la situación económica comenzó a mejorar (Malerbe, 1979: 75). Uno de los indicadores que mejor había evolucionado, la constitución de sociedades, entró en una coyuntura crítica, como consecuencia de un empeoramiento de las expectativas empresariales (García Delgado, 1983b: 541). Las empresas nacidas al calor de la demanda bélica, muchas de ellas marginales, perdieron su razón de ser (García Delgado, 1986: 118).

Las respuestas para intentar salvaguardar la frágil estructura industrial creada durante la guerra se encaminaron en dos direcciones. Por un lado, una política de nacionalismo económico, concretada en planes de fomento y defensa de la riqueza nacional, nacionalización de los ferrocarriles y una aceleración de las obras públicas (Tortella y Palafox, 1984: 89). Por otro, un endurecimiento del ya tradicionalmente elevado proteccionismo. Durante los años 1919-21 el proteccionismo se acentuó, pero en 1922-23 el objetivo fue la recomposición del mercado exterior español, mediante la firma de tratados comerciales (Serrano, 1986: 201).

Hacia 1900, Galicia ocupaba la peor situación relativa de su historia en términos de participación en la producción industrial española ${ }^{1}$. Sin embargo, los años de cambio de siglo constituyen uno de los períodos más expansivos en la historia contemporánea gallega (Carmona, 2001a; Carmona y García Lombardero, 1985: 443), circunstancia

Carmona (1990b: 25). Según una estimación realizada por Parejo (2001), en 1900 Galicia ocupaba la penúltima posición en términos de coeficiente de intensidad industrial, mientras que en 1850 se situaba la $4^{\mathrm{a}}$ por la cola, lo que demuestra la pérdida de posiciones en el conjunto nacional en la segunda mitad del siglo XIX. "Apéndice estadístico", en Germán et al. (eds.), p. 579, tomado de Parejo (2001). 
perceptible a través de la creación de nuevas sociedades, indicador en el que Galicia siguió un patrón similar al español ${ }^{2}$. Las transformaciones se sucedieron con lentitud, debido a la necesidad de superación de numerosos obstáculos naturales, institucionales o sociales, entre otros, que bloqueaban una incorporación más acelerada del país a los parámetros que desde el siglo XIX han definido la modernización (Carmona, 2001a; Villares, 1991: 148). Con todo, Galicia fracasó en la formación de un auténtico tejido industrial. Las excepciones dentro del panorama industrial gallego fueron el sector conservero y la construcción naval. Las demás iniciativas (minería, servicios públicos urbanos, agroindustria) complementan este panorama.

La guerra sirvió de escenario a una nueva fase alcista de la economía regional. Durante el conflicto se produjo un aumento del número de sociedades registradas y de su capital, a pesar de que las sociedades creadas surgieron al amparo de una coyuntura especulativa, de manera similar a lo ocurrido en España (Abreu, 1992: 256-267). Amparadas en unas perspectivas de beneficio a corto plazo, no estaban suficientemente preparadas para el desafío que significaba el crecimiento de la demanda exterior (IRS, 1919a, 2: 98-99). Sin embargo, el crecimiento se interrumpió coyunturalmente en la posguerra, aunque fue retomado en los años veinte (Villares, 1991: 148).

\section{Gráfico 2.1. Número de sociedades constituidas en Galicia (por provincias), 1910-36.}

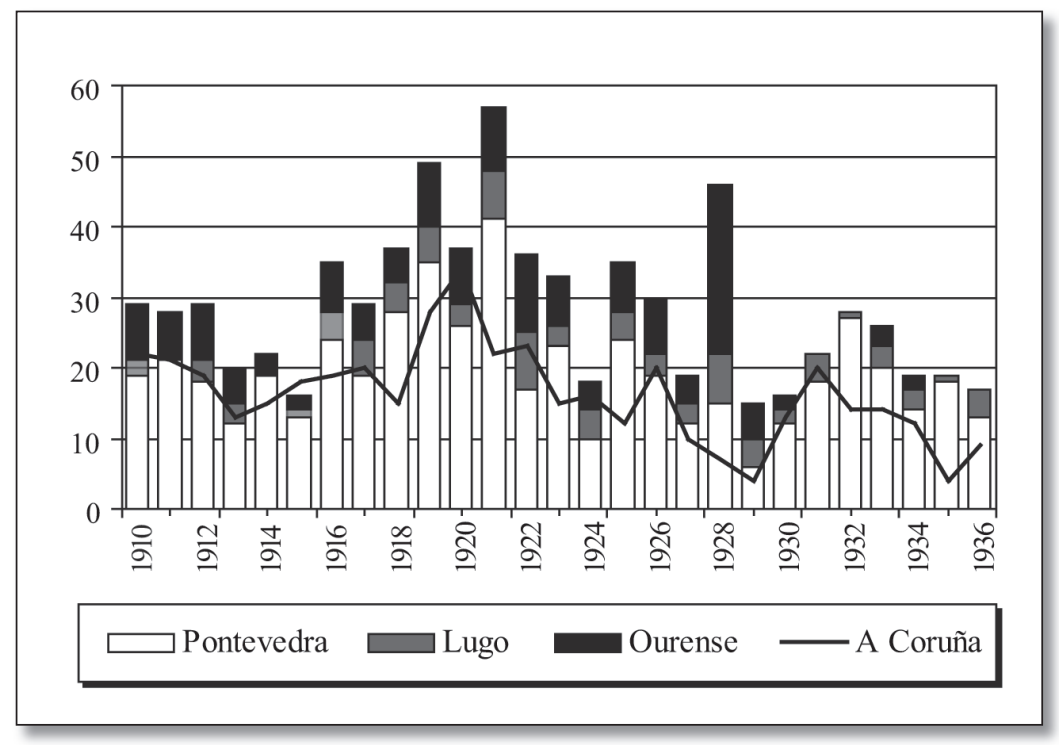

Fuente: Anuarios de la Dirección General de los Registros $y$ del Notariado. Elaboración propia.

\footnotetext{
2 Abreu (1992: 254). El avance fue comparativamente más rápido en Galicia que en el conjunto español. Sin embargo, parece más prudente conjeturar que este comportamiento tuvo su raíz en el proceso de industrialización vinculado a la pesca y las conservas que se estaba llevando a cabo en la provincia de Pontevedra y, en particular, en Vigo (Abreu, 2002: 16).
} 
Por lo que respecta a la ciudad de A Coruña, la economía venía experimentando una evolución positiva. La última década del siglo XIX y los primeros años del XX fueron uno de los períodos más dinámicos de su historia (Lindoso, 1999). Aunque no se trate de un proceso industrializador en toda regla, durante este período tuvo lugar el despegue industrial coruñés, "modesto si lo comparamos con otras zonas de España, pero relevante en relación con la economía gallega" (Lindoso, 2003: 46-48, 1999; Lindoso y Mirás, 2001: 32).

\section{Gráfico 2.2. Capital nominal de las sociedades} constituidas en Galicia, 1910-36 (pts. corrientes).

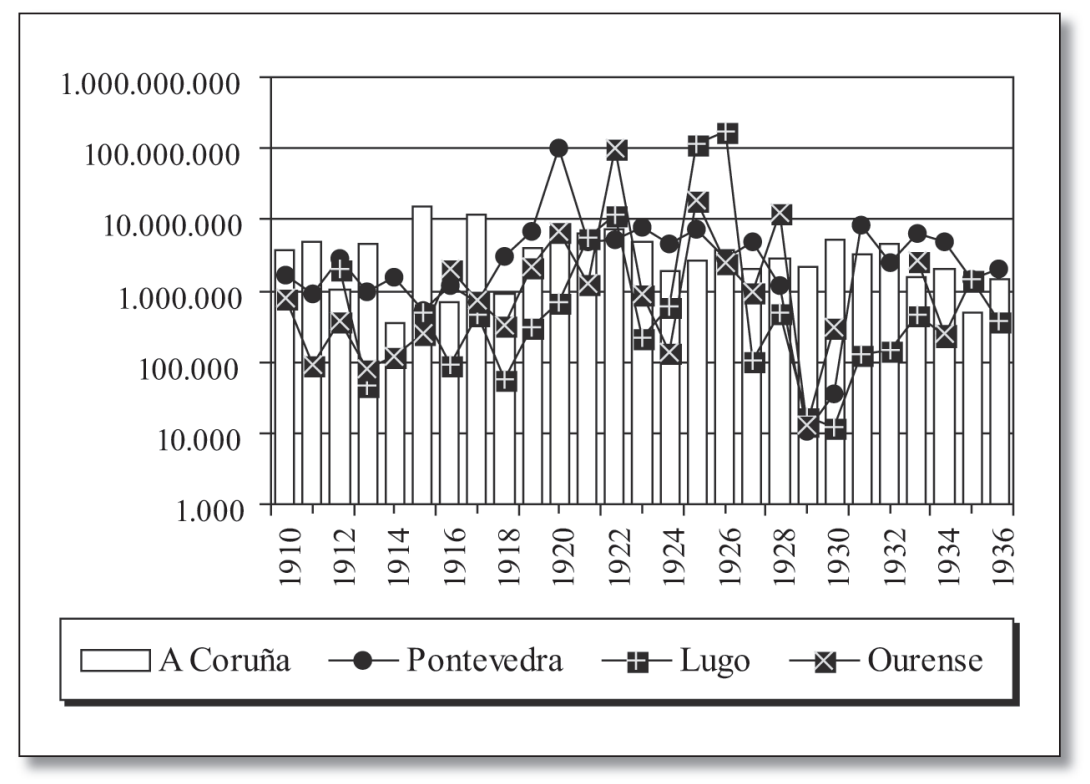

Fuente: Anuarios de la Dirección General de los Registros y del Notariado. Elaboración propia.

Con anterioridad a la guerra, la constitución de sociedades presenta una clara tendencia descendente en la provincia de A Coruña, aunque el despegue en el conjunto de Galicia tuviese lugar con un cierto retraso con respecto al conjunto de España (Abreu, 1992: 256). En realidad, el principal factor responsable de este negativo comportamiento fue la transformación en las formas societarias. Por un lado, se registró una notable caída en la constitución de empresas bajo formas personalistas (principales instrumentos jurídicos de las empresas españolas durante las primeras décadas del siglo $\mathrm{XX})^{3}$, como las sociedades colectivas, mientras que la sociedad anónima comenzaba a ganar

\footnotetext{
3 El proceso de sustitución de formas jurídicas personalistas iniciado en Galicia en los años veinte se concretó en la hegemonía de la sociedad limitada como forma mayoritaria en la asociación de capitales hasta los años setenta. En cambio, la penetración de la sociedad anónima en la economía gallega fue lenta y tardía (Abreu, 1992: 259-262).
} 
presencia, aunque sin llegar a ser todavía dominante (Gráfico 2.1) ${ }^{4}$. La tendencia de la provincia de Pontevedra fue muy similar a la coruñesa, aunque el capital empleado fuese el doble en la provincia de A Coruña.

La incidencia de la guerra a nivel provincial fue, sin embargo, tremendamente irregular. Mientras en España el número de nuevas sociedades se duplicaba entre 1913 y 1918, en A Coruña el número se mantuvo bastante estable (de 13 a 15), con una suave tendencia ascendente (IRS, 1919a, 2: 232). Resulta sintomático que los mayores picos en la creación de empresas se hallen en la posguerra.

Por su parte, la serie de capitales sufrió violentas oscilaciones, con máximos en los años 1915 y 1917 (los más elevados de todo el período), seguidas de fuertes caídas en 1916 y 1918, además de la de 1914 (Gráfico 2.2). Estos picos coinciden con la tendencia española (García Delgado, 1981: 427). Nuevamente, las formas personalistas fueron las que más incidieron en la tendencia general del número de sociedades constituidas, lo que reafirma la reducida dimensión de las nuevas empresas creadas durante la guerra. Pero las responsables de los intensos movimientos de capitales fueron exclusivamente las sociedades anónimas. La serie está condicionada por la presencia de algunas sociedades anónimas creadas durante la guerra en Lugo y Ourense, al amparo de la revitalización de la minería, aunque en estas provincias dominasen las formas personalistas. Además, en A Coruña las nuevas sociedades se acogían a la forma anónima, lo que explica que el capital medio de las empresas creadas fuese algo más elevado que en Pontevedra (Gráfico 2.3).

La guerra europea tuvo efectos contradictorios en la economía de la ciudad de A Coruña. Al contrario de lo que ocurría en otras áreas del país, la ciudad no pudo sacar provecho adecuadamente de la favorable coyuntura bélica ${ }^{5}$. Tampoco los escasos sectores favorecidos por el entorno derivado de la guerra extrajeron una ventaja suficientemente sólida de la situación, aprovechando para modernizar sus estructuras productivas, y garantizar así una mayor competitividad una vez finalizado el conflicto (IRS, 1919a, 2: 158).

En realidad, aunque hubo un cierto crecimiento en la constitución de algunas industrias, creadas al amparo del efecto invernadero, predominó el impacto negativo ocasionado por la disminución de las importaciones en una ciudad netamente comercial y mercantil. La ralentización de la actividad mercantil, industrial y portuaria, perjudicó a un amplio abanico de actividades económicas urbanas, en especial dentro

\footnotetext{
$4 \quad$ García Delgado (1981: 432-433) señala que la inversión en sociedades no anónimas durante la guerra en España tuvo un escaso dinamismo. En cambio, la inversión en sociedades anónimas aumentó enormemente. Por el contrario, en 1919-23 se produjo un acelerado proceso de disolución de sociedades, que fue paralelo a un aumento de la inversión en fincas, particularmente urbanas. Esto demuestra el caracter especulativo de la acumulación de capital a lo largo de la guerra (Tortella y Palafox, 1983).

5 Como tampoco lo hicieron dentro de la provincia ni Santiago ni Ferrol. En el primer caso, por carecer de producciones competitivas, por lo que se vio afectada por los problemas de incremento de los precios y por la insuficiencia de recursos alimenticios. La ciudad no consiguió liberarse de esta paralización en todo el período 1914-22. En el segundo, por la excesiva dependencia de los programas navales, una vez agotado el esfuerzo de la política promulgada en 1907 (Bascoy, 1985: 119-120).
} 
del sector terciario ${ }^{6}$. La industria y el comercio resistieron mejor, dadas sus características estructurales, ya que el sector estaba dominado por empresas de pequeñas dimensiones, que atendían a un mercado local o regional, y que eran menos sensibles a las coyunturas externas. Pero esta estrategia impidió un desarrollo más acelerado de la ciudad.

\section{Gráfico 2.3. Capital medio de las sociedades constituidas en Galicia, 1910-36 (pts. corrientes).}

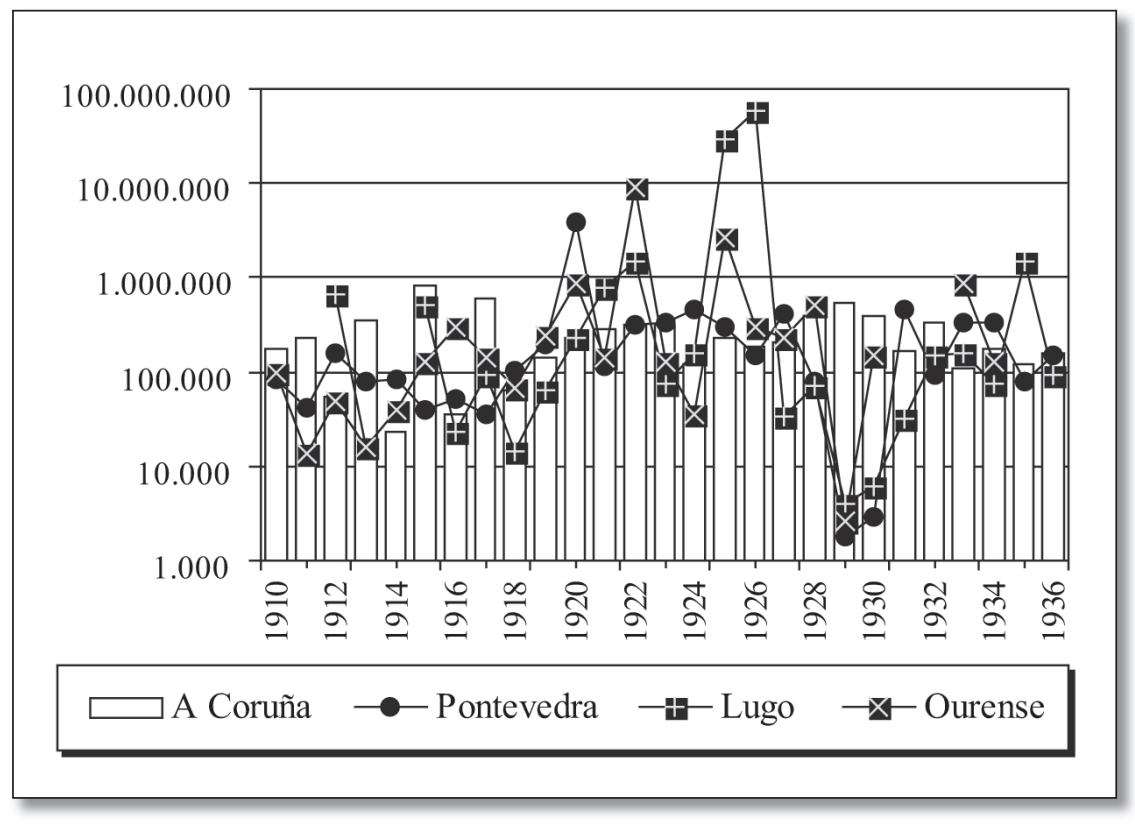

Fuente: Anuarios de la Dirección General de los Registros y del Notariado. Elaboración propia.

De este modo, A Coruña pasó a formar parte del grupo de áreas y sectores perjudicados por el conflicto, porque durante la guerra se constata una ralentización de las actividades económicas urbanas ${ }^{7}$. De la intensidad de su marca habla con claridad el estancamiento e incluso descenso del número de empresas registradas en la matrícula industrial, aunque el impacto fuese distinto según los sectores. En este sentido,

\footnotetext{
6 Según la Cámara de Comercio, "en La Coruña la producción industrial no ha aumentado, ni tampoco la actividad mercantil, en general, desde el comienzo de la guerra. La causa principal, las carencias de los transportes". Suárez Pumariega, G. y Valcárcel, A. "Informe que la Cámara de Comercio, Industria y Navegación de La Coruña, eleva a la Dirección General de Comercio, Industria y Trabajo, acerca de las causas y de los remedios de la crisis de los transportes ferroviarios en esta localidad", Boletín de la Cámara Oficial de Comercio, Industria y Navegación de La Coruña (COCINC), n 7, diciembre de 1916, p. 11.

7 Según el cónsul británico en A Coruña, poco antes de la guerra mundial, se apreciaban ya algunos signos de estancamiento en determinados segmentos de la actividad económica en la provincia de A Coruña, por ejemplo, en la actividad comercial, tanto interior como exterior, en los años 1912 y 1913. Diplomatic and Consular Reports. Spain. Report for the Year 1912, p. 5.
} 
compartió la pauta evolutiva de ciudades afectadas por la guerra, como Las Palmas, Valencia, Sevilla, Gijón, Palma, Alicante, Cartagena o Ferrol, todas ellas ciudades portuarias, muy castigadas por la crisis del tráfico mercantil (Escartín, 2001: 25; Arenas, 1995: 102; Precedo, 1995: 47; Carnero, 1992: 191; Pérez García y Noreña, 1992: 465; Casariego, 1987: 27; Gozálvez, 1987: 37; Pérez Rojos, 1986: 24; Cáceres, 1980: 27, 36; Alvargonzález, 1977: 57). En algunas de estas ciudades, se observa que algunos grupos sociales realizaron grandes negocios derivados de la comercialización hacia los países contendientes, aunque el transcurrir de la guerra terminó por hundir algunas de las exportaciones, sobre todo a partir de 1916-17. Por el contrario, ciudades como Bilbao, Cádiz, Vigo, San Sebastián, Málaga o Zaragoza progresaron, gracias al desarrollo de sectores industriales, comerciales o navales impulsados por la demanda bélica (Carmona, 2003: 43; Trinidad, 2001: 17; Fernández Clemente y Forcadell, 1992: 441; García Merino, 1992: 103-104; Morilla, 1992: 338; Sánchez Jiménez, 1992: 371; Luengo, 1990: 169; Precedo et al., 1988: 117), mientras que ciudades como Oviedo se apoyaban en el sector terciario (Alvargonzález, Fernández y Tomé, 1992: 152).

Durante el bienio 1919-20, se observa que la serie de sociedades presenta un pico a nivel provincial, concentrado en la creación de sociedades colectivas $\mathrm{y}$, en menor medida, anónimas. La mayor parte de las empresas tenía su sede en A Coruña ciudad, en donde sobresale la creación de las Fábricas Coruñesa de Gas y Electricidad (1919). Sin embargo, la mayor parte de las sociedades pertenecían al comercio, los servicios y la pesca, casi todas ellas con un capital nominal reducido, lo que avala la hipótesis de que la coyuntura especulativa había tocado a su fin y se estaba retornando a la normalidad empresarial.

Abreu (1992: 256) sostiene que la constitución de sociedades experimentó una acentuada caída en Galicia, que refleja la crisis de posguerra. En todo caso, la caída se produjo a partir de 1921, en paralelo a la crisis industrial que sufrían numerosas capitales de provincia españolas. Los años 1921-22 coinciden con la crisis económica padecida al desaparecer las condiciones favorables creadas por la guerra en la industria y el comercio ${ }^{8}$. Salvo excepciones, hacia 1923 la mayoría de los sectores industriales habían superado el bache.

Como contrapartida, durante los primeros años veinte, la dimensión de las sociedades creadas fue mayor, gracias a la consolidación de la industrialización ligada a la pesca, las actividades comerciales vinculadas, y el desarrollo de los servicios públicos urbanos, principalmente la electricidad, que movilizaron cifras elevadas de capital autóctono. Por ello, la tendencia fue muy similar a la de Pontevedra (Gráfico 2.1).

En vísperas de la Dictadura de Primo de Rivera, la estructura empresarial local no había experimentado mutaciones profundas, sino que continuaba estando dominada por empresas de pequeño tamaño. En 1923, el ranking de las empresas más destacadas estaba constituido únicamente por una sociedad anónima bancaria, tres sucursales de

\footnotetext{
8 De la crisis salieron relativamente bien libradas ciudades como Santiago, como resultado de una evolución más lineal en el conjunto del período 1914-22 (Bascoy, 1985: 122).
} 
otras tantas sociedades anónimas bancarias, las tres empresas eléctricas, la compañía de tranvías, la de abastecimiento de agua, y las fábricas de hielo y gas ${ }^{9}$.

\section{LA POBLACIÓN CORUÑESA DURANTE LAS DOS PRIMERAS DÉCADAS DEL SIGLO XX}

Globalmente, A Coruña experimentó un notable crecimiento demográfico durante el primer tercio del siglo, hasta situarse de forma destacada como la primera ciudad gallega (Cuadro 2.2) ${ }^{10}$. Durante la primera década, la población coruñesa creció a un ritmo del 0,91\% anual, la tasa de crecimiento más baja del período (índice $=109$ en 1910), frente a incrementos más acelerados durante la segunda y, sobre todo, la tercera década, gracias, en el primer caso, a la anexión en 1912 del municipio de Santa María de Oza (Cuadro 2.1) ${ }^{11}$. A nivel regional, su ritmo de crecimiento no ocupó más que una posición intermedia, sobrepasada por la fuerte progresión relativa de Vigo y Lugo (Cuadro 2.2).

\section{Cuadro 2.1. Población de hecho y densidad por km² de A Coruña, 1900-40.}

\begin{tabular}{lccccc}
\hline & $\mathbf{1 9 0 0}$ & $\mathbf{1 9 1 0}$ & $\mathbf{1 9 2 0}$ & $\mathbf{1 9 3 0}$ & $\mathbf{1 9 4 0}$ \\
\hline Población & 43.971 & 47.984 & 62.022 & 74.132 & 104.220 \\
\hline Índice & 100 & 109 & 141 & 169 & 237 \\
\hline Tasa crecto. anual & - & 0,91 & 2,93 & 1,95 & 4,06 \\
\hline Hombres & 19.597 & 21.429 & 28.806 & 34.494 & 50.086 \\
\hline Índice & 100 & 109 & 147 & 176 & 256 \\
\hline Mujeres & 24.374 & 26.555 & 33.216 & 39.638 & 54.134 \\
\hline Índice & 100 & 109 & 136 & 163 & 222 \\
\hline Superficie Km ${ }^{2}$ & 7,85 & 7,85 & 36,84 & 36,84 & 36,84 \\
\hline Densidad por Km $^{2}$ & 5.601 & 6.112 & 1.683 & 2.012 & 2.829 \\
\hline Crecto. capitales provincia & & 1,00 & 1,72 & 2,48 & 2,41 \\
\hline
\end{tabular}

Fuente: I.N.E. Censos de la población de España. A partir de 1912, los datos incluyen el municipio anexionado de Santa María de Oza.

9 Breve estudio de la economía mercantil e industrial coruñesa, y principales aspiraciones de aquélla (Informe pedido para el Ministerio de Trabajo, por el Excmo. Sr. Gobernador de la provincia), A Coruña, 15 de diciembre de 1923, en Las Cámaras de Comercio. Labor de la de La Coruña hasta fin de 1923, La Coruña, COCINC, 1924, p. 337.

10 A mediados del siglo XIX A Coruña pasó a ocupar el primer puesto, desplazando a Santiago. Y se mantuvo en esa posición hasta la década de 1950, cuando Vigo se situó en el primer lugar del ranking regional. No obstante, A Coruña continuará siendo uno de los dos grandes centros rectores (junto con Vigo) constituyendo así un eje de desarrollo y de crecimiento a lo largo del arco atlántico.

11 El crecimiento de A Coruña en 1900-10 fue el 28 más rápido de las capitales españolas, mientras en 1920-30 fue el $26^{\circ}$. Sin embargo, en 1930-40 ocupaba el 16º lugar y en 1910-20 fue el quinto más acelerado del país. Por su parte, el porcentaje de población de la ciudad respecto al total provincial experimentó un constante aumento. En 1900, se situaba en el 6,73\%, aumentando de manera uniforme hasta 1930 $(1910=7,1 \% ; 1920=8,8 \% ; 1930=9,7 \% ; 1940=11,8 \%)$. Vid. Mirás (2005a). 
Cuadro 2.2. Población de las principales ciudades gallegas, 1900-40.

\begin{tabular}{lccccccc}
\hline & A Coruña & Ferrol & Lugo & Ourense & Pontevedra & Santiago & Vigo \\
\hline $\mathbf{1 9 0 0}$ & 43.971 & 25.281 & 26.959 & 15.194 & 22.330 & 24.120 & 23.259 \\
\hline Índice & 100 & 100 & 100 & 100 & 100 & 100 & 100 \\
\hline $\mathbf{1 9 1 0}$ & 47.984 & 26.331 & 35.726 & 15.998 & 24.222 & 24.637 & 41.213 \\
\hline Índice & 109,1 & 104,2 & 132,5 & 105,3 & 108,5 & 102,1 & 177,2 \\
\hline $\mathbf{1 9 2 0}$ & 62.022 & 30.350 & 28.346 & 17.581 & 25.870 & 37.786 & 53.100 \\
\hline Índice & 141,1 & 120,1 & 105,1 & 115,7 & 115,9 & 156,7 & 228,3 \\
\hline $\mathbf{1 9 3 0}$ & 74.132 & 35.563 & 31.137 & 21.579 & 30.821 & 38.270 & 65.012 \\
\hline Índice & 168,6 & 140,7 & 115,5 & 142,0 & 138,0 & 158,7 & 279,5 \\
\hline $\mathbf{1 9 4 0}$ & 104.220 & 59.829 & 42.805 & 28.397 & 36.968 & 49.191 & 85.272 \\
\hline Índice & 237,0 & 236,7 & 158,8 & 186,9 & 165,6 & 203,9 & 366,6 \\
\hline
\end{tabular}

Fuente: I.N.E. Censos de la población de España.

La ciudad mantuvo una dinámica poblacional positiva. Sin embargo, contrariamente a lo que ocurrirá durante el resto del siglo, el crecimiento demográfico se sostuvo sobre el crecimiento vegetativo (Cuadro 2.3). Durante la primera década la diferencia entre éste y el incremento absoluto arroja un saldo negativo, lo que demuestra que apenas existió inmigración hacia la ciudad durante esos años concretos (Mirás, 2005a).

Durante el primer tercio del siglo, A Coruña absorbió una proporción reducida del excedente demográfico regional, manteniendo de paso un cierto comportamiento dual. Por un lado, la ciudad actuó como foco de atracción de población rural expulsada de su medio, de manera que su comportamiento encaja con las actitudes normales en las poblaciones rurales en su migración hacia los mercados de trabajo urbanos. Por otro lado, el mercado de trabajo de A Coruña se hallaba relativamente saturado ${ }^{12}$, de manera que el crecimiento económico urbano era incapaz de descongestionarlo, por lo que le seguía un proceso de expulsión de mano de obra que acompañaba al que generaba el medio rural, y que se resolvía mediante la emigración ultramarina. Se puede derivar la conclusión de que el crecimiento de la población urbana no era el resultado del influjo ejercido por el medio urbano sobre el rural como activador de cambios socioeconómicos a nivel regional. Por tanto, únicamente existía una atracción sobre una mínima parte de los que se veían impelidos a huir de un medio que ofrecía escasas garantías para poder subsistir con dignidad, circunstancia que encaja con el comportamiento de otras ciudades medias españolas, e incluso con algunas de mayor tamaño ${ }^{13}$.

\footnotetext{
12 Martínez, A. (1913), “A jornada larga, salario corto”, El Dependiente Español, 6-5-1913.

13 Según García Barbancho (1967: 89), parece existir una relación estrecha entre el tamaño de la población de un núcleo y su fuerza de atracción de inmigrantes, por lo que una ciudad como A Coruña tenía una capacidad de atracción menor que las ciudades que la precedían en la jerarquía urbana.
} 


\section{Cuadro 2.3. Crecimiento vegetativo, crecimiento absoluto y saldo migratorio en A Coruña, 1900-40.}

\begin{tabular}{rccc}
\hline Período & Crecimiento absoluto & Crecimiento vegetativo & Saldo migratorio \\
\hline $1900-1910$ & 4.013 & 4.119 & -106 \\
\hline $1910-1920$ & 14.038 & 3.965 & 10.073 \\
\hline $1920-1930$ & 12.110 & 7.067 & 5.043 \\
\hline $1930-1940$ & 30.088 & 5.268 & 24.820 \\
\hline
\end{tabular}

Fuente: I.N.E. Censos de la población de España e I.N.E. Movimiento natural de la población.

Con todo, la ciudad constituía un enclave atractivo, que recondujo parcialmente el flujo demográfico regional y del hinterland. Alrededor de 1900 sólo el 52,16\% de la población urbana había nacido en la capital. La influencia de la ciudad se extendía hacia el hinterland próximo, de manera que los principales flujos migratorios procedían de los municipios más cercanos, en especial del antiguo municipio de Santa María de Oza. Pero su influjo se extendía hacia el resto de la provincia (en donde había nacido el 28,34\% de la población urbana), e incluso hacia el resto de la región (Blanco, 1996: 149-151).

El crecimiento de la ciudad fue pobre en términos comparativos, ya que A Coruña perdió posiciones en el ranking de capitales provinciales ${ }^{14}$. En conjunto, en España se asiste al inicio de la transición demográfica, gracias al cambio de un patrón demográfico preindustrial, basado en una agricultura de carácter extensivo, a un patrón moderno, basado en el trabajo asalariado en la industria y el terciario. En cambio, Galicia transitó por parámetros algo distintos a los del resto de España y el entorno europeo (Fernández y López, 2000: 46), ya que el crecimiento demográfico fue menor que en otras regiones (de Juana y Castro, 1998: 7). Esto está relacionado con el peculiar discurrir de la transición demográfica y con la influencia de la emigración exterior.

La segunda década del siglo sí registró un fuerte crecimiento demográfico, gracias a la anexión de Santa María de Oza, con una tasa anual del 2,92\%, la segunda más elevada del primer tercio de siglo. Comparativamente, la posición de la ciudad como principal ciudad regional se vio fortalecida. Lo que ocurrió fue que la emigración regional padeció un bloqueo, debido a las difíciles condiciones de la navegación marítima. Pero, además, se produjo un aumento de la demanda de mano de obra en las zonas industriales y de servicios, de manera que el flujo migratorio se dirigió temporalmente

14 El período 1900-30 fue testigo de un fuerte crecimiento de las capitales de provincia, que se concentró en aquéllas que tuvieron un temprano proceso de industrialización (Rodríguez Osuna, 1985: 153). La evolución de la posición de A Coruña dentro del ranking de capitales de provincia fue la siguiente: $1900=19 ; 1910=21 ; 1920=18 ; 1930=18 ; 1940=14$. 
hacia las principales ciudades gallegas, dentro de un contexto caracterizado por la fuerte acumulación de mano de obra en los procesos industriales españoles (García Barbancho, 1967). Las difíciles condiciones que vivió la agricultura en esta etapa, según gran número de testimonios, nos permiten conjeturar que predominaron los factores de expulsión, combinados con la atracción derivada de los efectos beneficiosos sobre algunos (pocos) sectores económicos urbanos.

Por tanto, la emigración se reveló como la principal responsable del crecimiento demográfico urbano, lo que coincidía con el patrón de la mayoría de las ciudades pequeñas y medias. En general, se distinguen dos tipos de situaciones. Por un lado, el comportamiento de un número restringido de capitales, capaces de albergar a un importante contingente migratorio de la propia provincia e incluso de otras aledañas. Por otro, el conjunto más numeroso de capitales que únicamente acogieron a una parte reducida de los emigrantes provinciales (Delgado, 1995: 78). A Coruña encaja en este perfil, dado que los emigrantes que salían hacia el exterior eran muy superiores a los que se dirigían a la ciudad ${ }^{15}$. Por tanto, este movimiento demográfico favoreció a las ciudades industriales, es decir, a los núcleos que se encontraban operando al máximo de sus posibilidades productivas, para hacer frente a la demanda de los países beligerantes.

El crecimiento demográfico durante los primeros años del siglo se vio dificultado por el comportamiento de las variables que determinaban el crecimiento natural de la población urbana. Las tasas de natalidad y de mortalidad hasta la guerra europea mantuvieron una pauta más propia del siglo XIX que del nuevo siglo ${ }^{16}$. En este sentido, se ajusta relativamente bien al patrón general de la población española. En España, en 1900-18 se produjo una paulatina disminución de la mortalidad, inducida por progresos en la medicina, una mejor distribución relativa de los recursos, una mejor higiene y sanidad pública, etc., con un descenso casi análogo de la natalidad, manteniéndose casi inalterada la razón entre ambas tasas ${ }^{17}$.

Con el inicio de la guerra, se produjo un repunte de la natalidad (Gráfico 2.4), ligado a la llegada de inmigrantes rurales, tradicionalmente caracterizados por unos comportamientos más prolíficos. Pero, sobre todo, entró en escena un factor distorsionador decisivo: la anexión del municipio semirrural de Santa María de Oza (1912), responsable principal del ascenso de la tasa de natalidad y del número absoluto de nacimientos experimentado en 1913, lo que rompió brevemente la tendencia anterior.

\footnotetext{
15 Con todo, en las ciudades medias "la responsabilidad exclusiva del aumento de la población [...] recayó en la inmigración", lo que revela unas pautas de comportamiento biológico propias de un régimen demográfico primitivo hasta al menos la segunda década del siglo XX (Delgado, 1995: 77).

16 A Coruña formaba parte de un área de alta natalidad, constituida por las capitales gallegas, junto con algunas capitales andaluzas y de la fachada norte peninsular. En 1911, A Coruña era la capital española con una tasa de natalidad más elevada. Anuario Estadístico de España, 1917.

17 Rodríguez Osuna (1985: 27). No obstante, las tasas eran más elevadas que los estándares europeos, lo que resulta coherente con el menor grado de modernización demográfica de la sociedad española respecto de la Europa occidental, a pesar del espectacular avance posterior, que permitió que el modelo demográfico español se aproximase al de los países más avanzados (Vidal Bendito, 1991: 37).
} 


\section{Gráfico 2.4. Evolución de los factores del crecimiento vegetativo en A Coruña, 1900-36.}

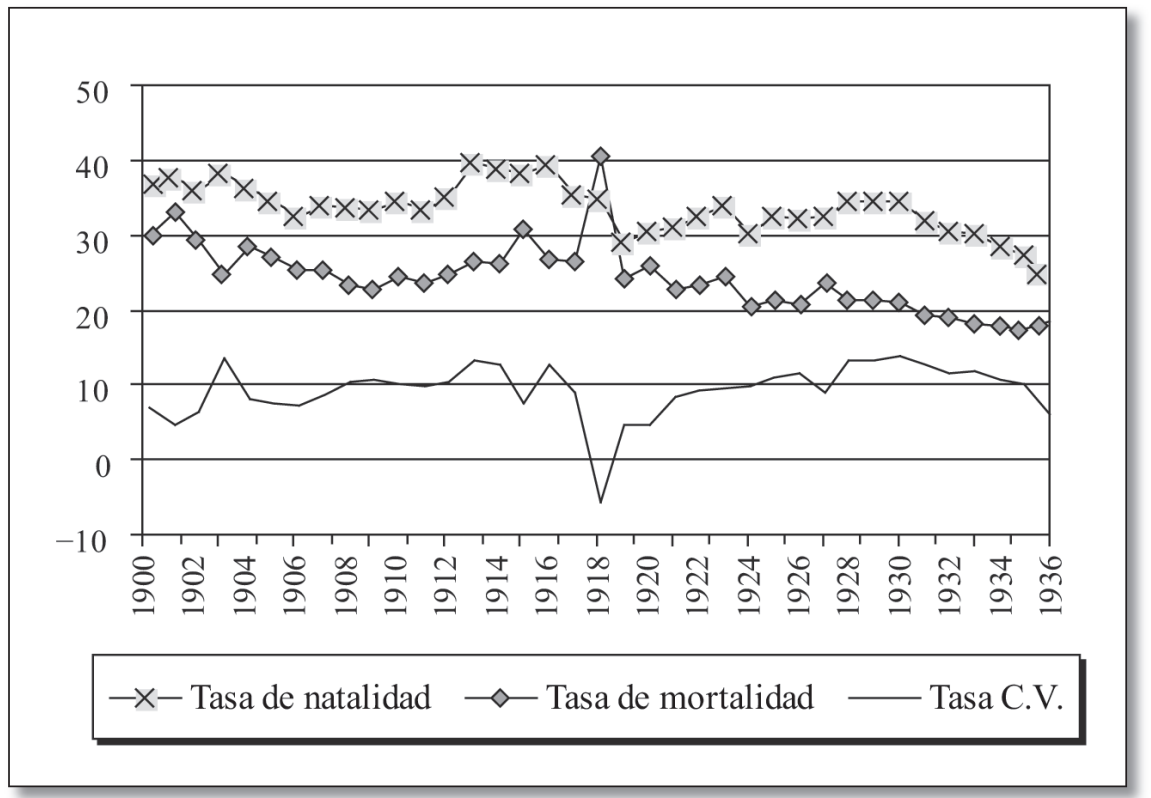

Fuente: I.N.E., Movimiento natural de la población.

Aunque es arriesgado vincular las coyunturas económicas a corto plazo con la evolución de las indicadores poblacionales básicos, hacia 1917 encontramos un primer indicio de que la economía urbana estaba atravesando una situación delicada. La situación social se deterioró paulatinamente durante la guerra, y la población frenó sus niveles reproductivos, hasta el punto de que el ciclo se mantuvo, al menos, hasta 1919 (momento en el que se alcanzó la tasa de natalidad más baja hasta 1934, y la tercera más reducida de todo el período). La situación continuó siendo delicada al acabar la guerra ${ }^{18}$.

La tasa de mortalidad muestra un perfil similar al de la natalidad ${ }^{19}$. Esto prueba que A Coruña todavía no había entrado suficientemente en la primera fase de la transición demográfica, caracterizada por un descenso de la mortalidad y un sostenimiento de la natalidad que provoca el consiguiente despegue demográfico ${ }^{20}$. Las tasas de A Coruña

\footnotetext{
18 En España, la fecundidad muestra una tendencia decreciente desde el inicio del siglo XX, que se prolonga de manera sistemática hasta la Guerra Civil (Rodríguez Osuna, 1985: 35).

19 Excepto por el brusco incremento de los fallecimientos que tuvo lugar en el año 1918, como resultado de la epidemia de gripe, que elevó la tasa de mortalidad hasta el 40,7 \%o (al año siguiente había descendido hasta el 24,3\%). Batanero (1976: 71) señala que el aumento de la mortalidad fue considerablemente más acentuado que en el resto del país. A este último factor hay que atribuir también el descenso de la natalidad, y no únicamente a la situación socioeconómica.

20 Revenga (1980). El cambio coincidió, generalmente, con el advenimiento del proceso de industrialización. Gracias a ello, salvadas las primeras fases de empeoramiento de las condiciones objetivas de mortalidad, al menos en el Reino Unido (Williamson, 1982), se produjo un descenso paulatino de esta variable, con el consiguiente aumento en los promedios de esperanza de vida.
} 
no resistían la comparación con el entorno occidental, lo mismo que ocurría con la población española ${ }^{21}$. En definitiva, la distancia entre la natalidad y la mortalidad guarda un perfil similar al del conjunto de la población española (Nadal, 1988; Pérez Moreda, 1985), caracterizadas ambas por la reducida diferencia entre las dos principales tasas vitales, lo que tuvo como consecuencia el reducido crecimiento vegetativo durante las dos primeras décadas del siglo (Gráfico 2.4).

\section{Cuadro 2.4. Nivel de actividad de la población de A Coruña, 1900-40 (porcentaje).}

\begin{tabular}{lccccccc}
\hline & \multicolumn{2}{c}{ Población activa } & \multicolumn{2}{c}{ Población inactiva } & Total \\
\cline { 2 - 7 } & Hombres & Mujeres & Total & Hombres & Mujeres & Total & \\
\hline $\mathbf{1 9 0 0}$ & 59,28 & 30,09 & 43,28 & 40,72 & 69,91 & 56,72 & 100 \\
\hline $\mathbf{1 9 1 0}$ & 58,18 & 25,17 & 40,08 & 41,82 & 74,83 & 59,92 & 100 \\
\hline $\mathbf{1 9 2 0}$ & 59,12 & 16,85 & 36,44 & 40,88 & 83,15 & 63,56 & 100 \\
\hline $\mathbf{1 9 3 0}$ & 59,61 & 21,37 & 39,16 & 40,39 & 78,63 & 60,84 & 100 \\
\hline $\mathbf{1 9 4 0}$ & 63,66 & 16,15 & 38,99 & 36,34 & 83,85 & 61,01 & 100 \\
\hline
\end{tabular}

Fuente: I.N.E. Censos de la población de España.

La población inactiva superaba ampliamente a la activa (Cuadro 2.4). El diferencial, además, era creciente, salvo un ligero retroceso en 1930. La disminución de la población activa se explica, principalmente, por la extensión de la escolarización, que sustraía individuos del mercado laboral, y por un lento envejecimiento de la población. Este rasgo guarda relación con la estructura por sexo y edades de la población, ya que A Coruña se caracterizaba por poseer una población joven y por un predominio de las mujeres sobre los hombres ${ }^{22}$.

En general, la población masculina mostró porcentajes de actividad superiores a los de inactividad, y eran las mujeres las responsables principales de la baja tasa de actividad $^{23}$, circunstancia coherente con el nivel de desarrollo socioeconómico existente entonces ${ }^{24}$. Existía una división por sexos en función de la actividad realizada: predominio masculino en las actividades de mayor cualificación, y preponderancia femenina

\footnotetext{
21 Nadal (1988: 15-17). A pesar de todo, A Coruña tenía un nivel de mortalidad aceptable, pues en 1910 era la $35^{\mathrm{a}}$ capital de provincia con mayor mortalidad, y en 1914 la 23 ${ }^{\mathrm{a}}$. Anuario Estadístico de España, 1917.

22 Un tratamiento detallado en Mirás (2004a).

23 Mirás (2005b). Entre los hombres, el porcentaje de activos se situó muy cercano al 60\%, mientras que entre las mujeres apenas superaba el $40 \%$.

24 En Galicia, la tasa de actividad femenina era más elevada que en A Coruña, debido al cómputo de las mujeres en el sector primario, que históricamente presentaba unas elevadas tasas de actividad (Beiras, 1970). En España, la tasa de actividad ha sido tradicionalmente baja, aunque mayor en las zonas urbanas, tanto para hombres como para mujeres (Sáez, 1975).
} 
en las no cualificadas, a excepción de algunas industrias (tabaco, derivados de la pesca, etc.). La población económicamente activa era relativamente joven en la ciudad, con una distribución que induce a pensar que A Coruña era todavía una sociedad fundamentalmente tradicional.

Cuadro 2.5. Distribución de la población de A Coruña por sectores económicos, 1900-40 (porcentaje).

\begin{tabular}{llccccc}
\hline \multirow{2}{*}{ Primario } & & $\mathbf{1 9 0 0}$ & $\mathbf{1 9 1 0}$ & $\mathbf{1 9 2 0}$ & $\mathbf{1 9 3 0}$ & $\mathbf{1 9 4 0}$ \\
\cline { 2 - 7 } & Hombres & $\mathbf{2 3 , 6 8}$ & $\mathbf{2 3 , 5 9}$ & 11,02 & 2,60 & 6,23 \\
\cline { 2 - 7 } & Mujeres & 9,56 & 7,87 & 1,09 & 3,09 & 4,05 \\
\hline \multirow{2}{*}{ Secundario } & Total & 18,27 & 18,16 & 8,28 & 2,74 & 5,74 \\
\cline { 2 - 7 } & Hombres & 23,81 & 23,86 & 43,17 & 50,13 & 40,84 \\
\cline { 2 - 7 } Terciario & Total & 31,94 & 41,35 & 51,71 & 40,42 & 32,65 \\
\cline { 2 - 7 } & Mombres & 52,50 & 52,55 & 45,82 & 47,28 & 52,93 \\
\cline { 2 - 7 } Total & Total & 48,50 & 50,78 & 47,20 & 56,49 & 63,30 \\
\hline \multirow{2}{*}{ Mujes } & 50,97 & 51,94 & 46,20 & 50,03 & 55,24 \\
\hline
\end{tabular}

Fuente: I.N.E. Censos de la población de España.

Con anterioridad a la guerra el sector dominante era el terciario, que en 1900 ocupaba un 50,97\% de la población activa urbana, y en 1910 el 51,94\%, manteniendo un patrón económico decimonónico (Cuadro 2.5). En términos comparativos, A Coruña formó parte del grupo de ciudades que durante la segunda mitad del siglo XIX no lograron transformar su base económica, cristalizando como ciudades terciarias de medio o pequeño tamaño, diferenciándose de este modo de los núcleos urbanos de mayor rango funcional y demográfico (Delgado, 1995: 24).

Si prescindimos de los inactivos, el tipo de actividad más importante era el del conjunto de actividades industriales, que el censo agrupaba bajo la denominación Industrias clasificadas según el género de las necesidades a que se aplican $(11,9 \%$, con una participación muy similar para hombres y mujeres). Por el contrario, las industrias clasificadas por el censo según la naturaleza de la materia utilizada, y las industrias no clasificadas, tenían un peso sustancialmente inferior. Agricultura y pesca $(7,9 \%)$, servicios domésticos y personales $(6,4 \%)$, fuerzas del orden $(5,0 \%)$, debido al carácter de plaza militar de la ciudad, comercio $(4,2 \%)$ y los transportes marítimos, urbanos y fluviales $(2,1 \%)$ ocupaban los escalafones inmediatamente inferiores. 


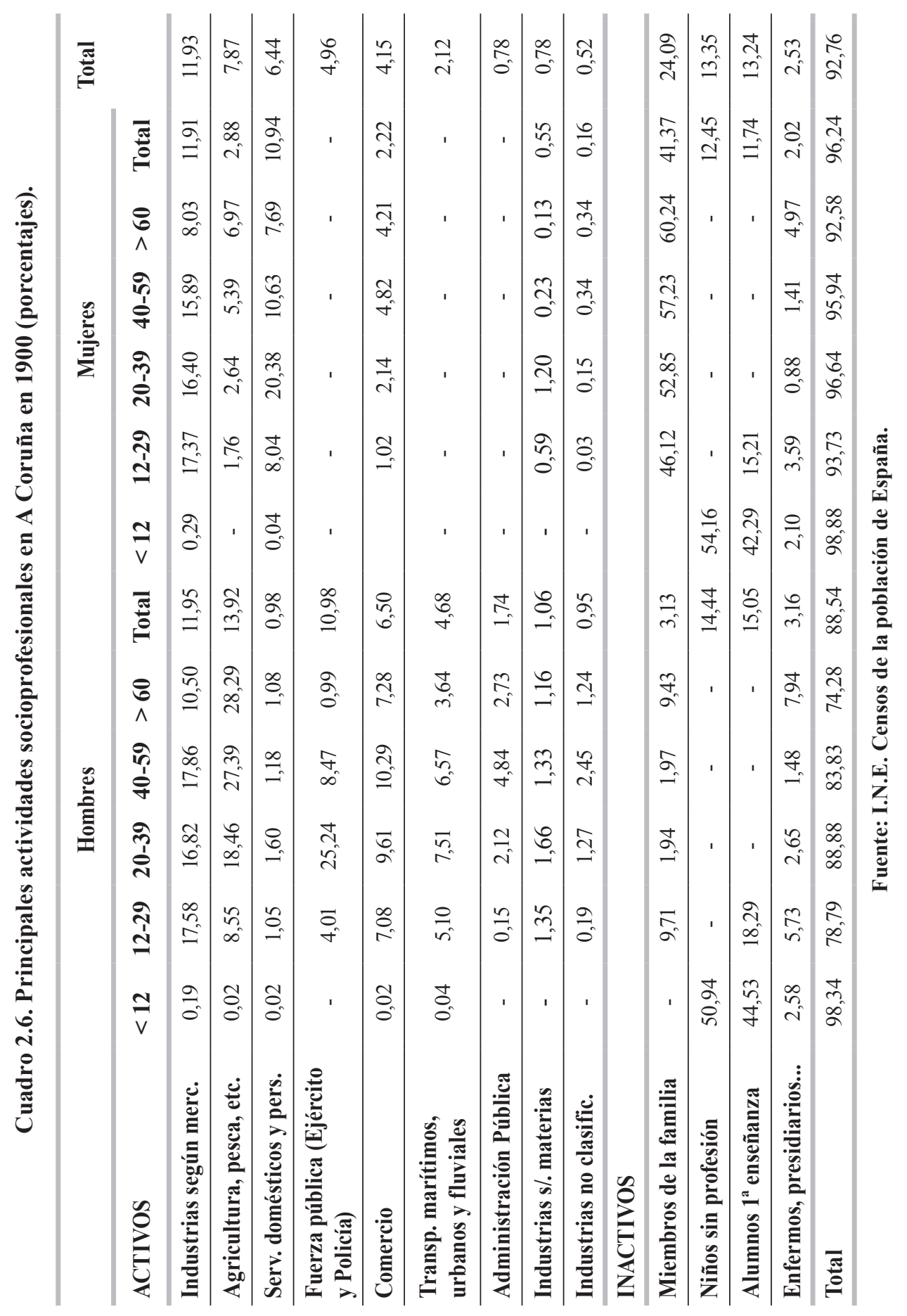


El protagonismo del sector terciario tiene su raíz en el denominado terciario portuario $\mathrm{y}$, dentro de éste, en el tráfico pesquero y actividades asociadas, en donde la presencia masculina era dominante ${ }^{25}$. En otras ciudades costeras ocurrió un fenómeno similar, pero fue más perceptible en los casos en que, desde la segunda mitad del XIX, se aprovecharon las ventajas de la reforma y ampliación de las infraestructuras portuarias, lo que permitió una mayor conexión con el comercio internacional ${ }^{26}$.

En los primeros años del siglo se consolidaron otras actividades terciarias de baja cualificación. Por un lado, las actividades comerciales dirigidas al mercado urbano. Por otro, aquellos servicios en los que la participación femenina era abrumadora (servicio doméstico y similares). Además, sobresalían otras funciones urbanas tradicionales, que se repetían con mayor o menor intensidad en el territorio español (administrativa, militar, hostelera). Las ciudades gallegas, en general, se caracterizaban por un escaso número de funciones especializadas pero, aunque la mayoría de dichas funciones estaban vinculadas de uno u otro modo al terciario ${ }^{27}$, el principal motor de su funcionamiento residía en actuar como centros administrativos, especialmente tras la división administrativa de 1833 (Colino y Grandío, 1994: 11). Esto ha llevado a González Laxe (1992: 22-23) a afirmar que la perpetuación de un elevado aparato burocrático institucional provocó una hipertrofia del sector terciario. En el caso de A Coruña, la función como capital administrativa y burocrática reforzó notablemente su papel institucional, generando efectos inducidos sobre otras funciones terciarias ${ }^{28}$.

También existían servicios avanzados, como los financieros, las actividades profesionales, etc., en los que la presencia masculina era prácticamente absoluta. Por tanto, la base económica urbana se cimentaba sobre unos pilares similares a otras ciudades de carácter terciario: comercio, fuerza pública, administración, servicio doméstico, etc., a los que se añadía la función portuaria.

Por su parte, el tejido industrial constituía el arquetipo de sector insuficientemente consolidado, dominado por industrias de pequeño tamaño y escasa proyección exterior. El nacimiento de esos negocios partió principalmente del aumento de la

\footnotetext{
25 Mirás (2003b). El terciario portuario es el conjunto de las empresas de servicios cuya existencia está ligada esencialmente a las actividades portuarias, y por lo tanto no tendrían razón de existir si desapareciera el puerto (Tobal, 1997: 704).

26 Hernández Borge (1997: 815). Algunos ejemplos de esta dinámica los encontramos en Las Palmas (Casariego, 1987), Valencia (Teixidor, 1982), Alicante (Ramos Hidalgo, 1987), San Sebastián (Luengo, 1990), Cádiz (Pérez Serrano, 1991), etc. Excepciones a este comportamiento han sido las ciudades industriales, como Gijón (Llordén, 1994), Cartagena (Pérez Rojos, 1986), Vigo (Precedo et al., 1988), Ferrol (Clemente, 1984), etc.

27 Lois (1996). Esta circunstancia encaja con el modelo clásico de inserción de las ciudades europeas en los nuevos sistemas de mercado donde la industrialización no llegó a consolidarse (Precedo, 1990b: 257). Sólo el modesto desarrollo industrial de finales del siglo XIX en algunos núcleos quebró parcialmente esta dinámica. Pero únicamente fue responsable del crecimiento en algunas ciudades (Vigo y Ferrol).

28 En 1833 A Coruña fue designada como capital de una de las cuatro provincias en que se estructuró la región noroeste, decisión que reforzó su papel institucional, en detrimento de la ciudad hasta entonces más importante, Santiago de Compostela. Pero en las demás capitales esto significó también un fortalecimiento de sus funciones terciarias (Pose, 1992; Precedo et al., 1991; Pérez Iglesias, 1985). Además, A Coruña fue designada posteriormente cabeza de la VIII Región Militar. De este modo, sus funciones institucionales, burocráticas y militares se afianzaron, condicionando su evolución futura.
} 
demanda originado por el crecimiento urbano, respondiendo más a una política de sustitución de importaciones y a una legislación proteccionista que a una industrialización global. En consecuencia, la mayoría de empresas se definía por sus reducidas dimensiones y por estar orientadas hacia el mercado urbano, rasgos que, por otra parte, compartían la mayoría de las capitales de provincia españolas (Delgado, 1995: 60). Al igual que ocurría en el comercio, existía una numerosa presencia de pequeños talleres en el tejido productivo coruñés.

Finalmente, el peso del sector primario se explica por el protagonismo de la actividad pesquera. Paralelamente, en la periferia urbana, existía una cierta presencia de distintas actividades agrarias, cuyo mercado era el área urbana. La trascendencia de este sector era mayor si tenemos en cuenta que existía una cierta simbiosis entre algunas actividades industriales o de servicios y las agrarias (Carré, 1929).

Ante la ausencia de un cambio de rumbo significativo en la economía urbana y regional, en 1910 la situación no había experimentado una variación significativa (Cuadro 2.7). Los principales cambios apuntan en la dirección de una relativa consolidación del sector industrial (industrias no clasificadas e industrias clasificadas según la naturaleza de la materia utilizada). Pero, por el contrario, las industrias clasificadas según el género de las necesidades experimentaron un pronunciado descenso. Por tanto, en la práctica, la participación de la industria manufacturera no experimentó una transformación sustancial.

Con todas las precauciones derivadas del cambio de criterios de clasificación, se aprecia que, agregando los principales subsectores industriales urbanos, en 1920 éstos totalizaban aproximadamente un $14,2 \%$ de la población de la ciudad, frente al aproximadamente $10,4 \%$ de 1910 (Cuadro 2.8). Por tanto, se detecta un significativo crecimiento del conjunto del sector industrial-manufacturero, pues los principales sectores incrementaron su número de efectivos, representando un porcentaje netamente superior al de principios de siglo, lo que parece confirmar el inicio del despegue del sector, que se había detectado en los años finales del siglo XIX (Lindoso, 1999).

Ahora bien, el aumento de la población industrial registrado entre 1910 y 1920 se ha observado también en la mayoría de ciudades intermedias españolas, y se debe probablemente a la vaguedad del concepto industrias varias, en donde se agrupaba un elevado porcentaje de la población industrial local. Esto distorsiona el análisis de la composición interna del sector. Además, sus características estructurales no experimentaron una modificación sustancial, pues algunas de las empresas creadas en esta etapa nacieron al amparo de las condiciones creadas por la guerra.

Las restantes actividades tenían un peso individual mucho menos significativo. El segundo lugar en importancia lo ocuparon las fuerzas del orden, figurando a continuación el servicio doméstico, hacia el que se hallaba sesgada en exceso la mano de obra femenina (Mirás, 2005b), los transportes, la pesca, el comercio, la administración y las actividades agrarias. Por tanto, existía un predominio de actividades terciarias no avanzadas, aunque la administración, los transportes o las fuerzas del orden continuaban desempeñando un rol importante, como resultado de las funciones portuaria y de capitalidad. 


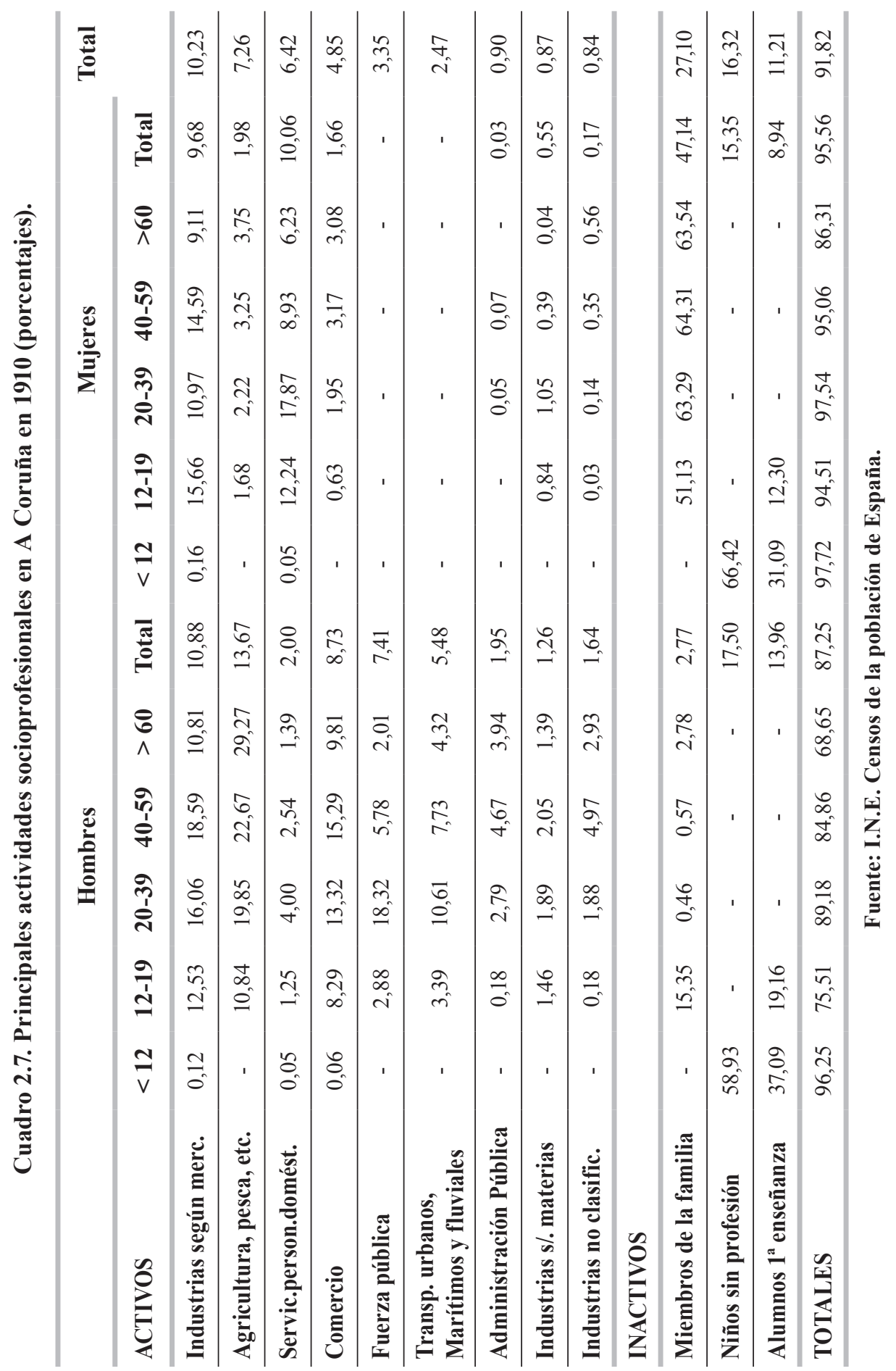




\section{Cuadro 2.8. Principales actividades socioprofesionales en A Coruña en 1920 (porcentajes).}

\begin{tabular}{|c|c|c|c|c|c|c|c|c|c|}
\hline \multirow[b]{2}{*}{ ACTIVOS } & \multicolumn{4}{|c|}{ Hombres } & \multicolumn{4}{|c|}{ Mujeres } & \multirow[t]{2}{*}{ Total } \\
\hline & $<21$ & $21-60$ & $>60$ & Total & $<21$ & $21-60$ & $>60$ & Total & \\
\hline Industrias varias o sin especificar & 5,11 & 17,12 & 12,41 & 11,51 & 0,53 & 1,22 & 0,39 & 0,87 & 5,82 \\
\hline Ejército & 1,89 & 14,35 & 1,77 & 8,19 & - & - & - & - & 3,80 \\
\hline Sirvientes domésticos & 0,20 & 1,11 & 0,46 & 0,67 & 3,97 & 8,41 & 2,74 & 6,14 & 3,60 \\
\hline Industria del vestido & 0,57 & 1,54 & 1,23 & 1,09 & 3,30 & 4,02 & 0,86 & 3,49 & 2,38 \\
\hline Industria química & 0,11 & 0,56 & 0,85 & 0,37 & 0,11 & 5,62 & 9,89 & 3,61 & 2,10 \\
\hline Comercio & 2,10 & 4,84 & 12,64 & 3,96 & 0,01 & 0,28 & 0,43 & 0,18 & 1,94 \\
\hline Transportes & 0,94 & 6,59 & 2,24 & 3,85 & 0,12 & 0,32 & 0,09 & 0,22 & 1,91 \\
\hline Pesca & 0,84 & 5,50 & 1,39 & 3,22 & 0,09 & 0,53 & 0,26 & 0,33 & 1,67 \\
\hline Individuos sin profesión & 1,87 & 3,30 & 2,47 & 2,62 & - & - & - & - & 1,22 \\
\hline Propietarios inmuebles & 0,06 & 2,91 & 11,41 & 2,02 & 0,01 & 0,16 & 0,73 & 0,14 & 1,01 \\
\hline Industria (patronos) & 0,95 & 2,04 & 7,63 & 1,81 & - & 0,33 & 0,98 & 0,24 & 0,97 \\
\hline Industria de la construcción & 0,68 & 3,35 & 1,31 & 2,06 & - & - & - & - & 0,96 \\
\hline Forestales y agrícolas & 0,69 & 2,96 & 2,54 & 1,92 & 0,07 & 0,12 & 0,04 & 0,09 & 0,94 \\
\hline Administración & 1,19 & 2,33 & 4,70 & 1,92 & - & 0,02 & - & 0,01 & 0,90 \\
\hline Profesión desconocida & 0,27 & 2,97 & 0,46 & 1,64 & 0,13 & 0,08 & - & 0,10 & 0,82 \\
\hline Industria de la madera & 0,65 & 2,17 & 2,08 & 1,48 & - & - & - & - & 0,69 \\
\hline Profesiones de la enseñanza & 0,02 & 1,73 & 0,93 & 0,93 & 0,07 & 0,77 & 0,17 & 0,43 & 0,66 \\
\hline Indiv. temporalmente sin ocupación & 0,24 & 2,44 & 1,70 & 1,42 & - & - & - & - & 0,66 \\
\hline Rentistas & 0,02 & 2,48 & 2,08 & 1,35 & 0,01 & 0,02 & 0,26 & 0,03 & 0,65 \\
\hline Trabajo del hierro y metales & 0,97 & 1,74 & 0,62 & 1,34 & - & - & - & - & 0,62 \\
\hline \multicolumn{10}{|l|}{ INACTIVOS } \\
\hline Miembros de la familia & - & - & - & - & 18,06 & 75,81 & 73,89 & 51,40 & 27,53 \\
\hline Alumnos $1^{\text {a }}$ enseñanza & 37,99 & - & - & 17,05 & 35,43 & - & - & 14,89 & 15,89 \\
\hline Niños sin profesión & 32,00 & - & - & 14,36 & 33,62 & - & - & 14,13 & 14,24 \\
\hline Estudiantes & 5,20 & 1,21 & - & 2,95 & 2,46 & 0,11 & - & 1,09 & 1,95 \\
\hline Acogidos hospicios y hospitales & 2,90 & 0,51 & 7,71 & 1,91 & 1,70 & 0,18 & 6,29 & 1,25 & 1,56 \\
\hline TOTALES & 97,45 & 83,74 & 78,63 & 89,63 & 99,61 & 97,62 & 96,85 & 98,40 & 94,36 \\
\hline
\end{tabular}

Fuente: I.N.E. Censos de la población de España. Sólo se han incluido aquellas actividades con una cierta presencia, dado que el número total de categorías en el censo de 1920 era de 80. 
En las actividades profesionales se aprecia una lenta y desigual incorporación femenina al mercado laboral. Entre los empresarios industriales se observa un elevado peso de las actividades ya señaladas, aunque con pequeñas diferencias. Lo mismo ocurre en el sector comercial, aunque con una fuerte concentración en el sector alimentación, que se une a las industrias textiles, para dar como resultado una estructura comercial polarizada en actividades de satisfacción de necesidades básicas (Cuadro 2.8). En todo caso, el número de mujeres que no trabajaban o estaban dedicadas a labores domésticas era muy elevado ${ }^{29}$. La explicación de esta disfunción se encuentra en el hecho de que la mujer estuvo sometida a una discriminación en razón de su sexo (Capel, 1989), no habiendo alcanzado todavía, por tanto, un estatus laboral equiparable al hombre, aunque el trabajo femenino fuese muy importante para el sostenimiento de las unidades familiares.

\section{LAS ACTIVIDADES COMERCIALES}

\subsection{El peso de las actividades comerciales}

El aparato de la distribución comercial cumple dentro de una economía urbana una función vital, al configurarse como el conjunto de operaciones cuya misión consiste en actuar de puente entre la producción de bienes y servicios y su consumo (Casares, 1987: 17). No obstante, la importancia de la distribución no ha sido la misma en todos los sistemas socioeconómicos, sino que con el desarrollo del capitalismo ha alcanzado su máxima expresión, debido a que las decisiones relativas a la asignación de los recursos se manifiestan en forma de flujos diversos (Moreno y Escolano, 1992: 102).

El comercio ha estado fuertemente influido por factores económicos, sociales y culturales propios de cada país. Por este motivo, la experiencia comercial española, a pesar de integrarse en el contexto occidental, ha sido históricamente distinta. En España, se puede establecer una división entre el período 1900-59, en el que el comercio mantuvo unas estructuras predominantemente tradicionales, y el período posterior a 1959, en el que empezaron a manifestarse de manera relevante nuevos planteamientos en la organización, gestión y tecnología comercial (Casares y Briz, 1987: 94). La etapa 1900-59 constituye un conjunto relativamente homogéneo, en el que el comercio español intentó adaptarse lentamente a las nuevas necesidades de una sociedad cambiante. Del sistema gremial que caracterizaba a la época medieval, se pasó a la progresiva aparición de un modelo de mercado que trataba de abastecer las necesidades básicas de la población, con una serie de negocios de tipo particular, polivalentes en las pequeñas poblaciones, y que debían cubrir todas las necesidades materiales básicas.

Sin embargo, los cambios demográficos que estaba experimentando la sociedad española provocaron transformaciones en las estructuras comerciales. Por ello, este período de comercio tradicional, se puede subdividir en tres etapas: 1. un período cuasigremialista, que abarca desde principios de siglo a 1936; 2 . la etapa de la guerra y la posguerra; y 3 . la consolidación del "tradicionalismo monovalente", que se prolonga desde 1950 hasta 1959 (Casares y Briz, 1987: 94-95).

29 Mirás (2005b). Las mujeres casadas formaban el grupo al que la sociedad ponía mayores trabas para el trabajo extradoméstico (Nielfa, 1984: 164). 
Durante el primer tercio del siglo, el problema era el aprovisionamiento de bienes primarios. El comercio solía ser de carácter tradicional, aunque en las ciudades de mayor tamaño reunía diversas peculiaridades. Así, en el comercio no alimentario comenzaron a desarrollarse al final del período algunos bazares populares, es decir, almacenes de precios únicos de dimensiones relativamente reducidas. De todos modos, esta fue una etapa de escasas innovaciones en tecnología y organización comercial, en un contexto de leve presión desde la oferta y la demanda, al tratarse de una sociedad predominantemente rural y de bajo poder adquisitivo (Casares y Briz, 1987: 95-96).

A Coruña ha sido tradicionalmente una ciudad caracterizada por un notable tráfico mercantil, lo que ha permitido que la función comercial haya penetrado con fuerza en su base económica. Diversas investigaciones desarrolladas desde la geografía a partir de los años sesenta sobre la estructura funcional de las ciudades españolas han puesto de manifiesto la especialización de A Coruña como centro comercial y de servicios (Precedo, 1987a, b; Racionero, 1978; Díez Nicolás, 1972; Capel, 1968).

Este rasgo no era exclusivo de A Coruña. Un elevado número de ciudades españolas poseía una estructura funcional en la que predominaba el sector terciario y el comercio. Además, los rasgos básicos del sector muestran notables paralelismos. Dentro del conjunto urbano español, se distinguían al menos dos grupos de comportamientos. Por un lado, el de las pequeñas ciudades, que en esos años apenas experimentaron transformaciones en sus estructuras socioeconómicas, y se quedaron a la zaga en el lento pero efectivo proceso de modernización del país. Estas ciudades fracasaron a la hora de engancharse al tren de la industrialización y, en consecuencia, se definían por el predominio del terciario, con un fuerte peso del comercio y de los empleos ligados a la administración. Ejemplos de ello fueron Teruel, Segovia, Ciudad Real, Cuenca y otras pequeñas capitales de provincia (Pillet, 1984; Troitiño, 1984; García Márquez, 1983; Martínez de Pisón, 1976), junto con las ciudades medias de tipo monofuncional, como Oviedo, San Sebastián, Albacete o León (Magán, 1997; García Martínez, 1995; Trespalacios, 1992; Luengo, 1990; González, 1987).

Sin embargo, a diferencia de los núcleos del interior, en A Coruña el origen de la actividad comercial hay que buscarlo en el puerto (Mirás, 2004b, 2003b). Por ello, los paralelismos con otras ciudades portuarias españolas han sido aún más evidentes: Cádiz, Alicante, Málaga, San Sebastián e incluso Valencia (Larrinaga, 1997; Morilla, 1992; Sorribes, 1992; Fernández Cuenca, 1991; Pérez Serrano, 1991; Vidal, 1987), además de las capitales insulares — Las Palmas o Santa Cruz de Tenerife - (Cáceres, 1980).

Este proceso de desarrollo de la función comercial se enmarca dentro de otro de terciarización de la economía urbana, circunstancia que se consolidó durante el siglo XX. Esta última característica ha sido común a otras economías urbanas y ha caminado en paralelo al propio proceso de terciarización que ha caracterizado a la mayoría de las economías occidentales (Romero, 1995; Bairoch, 1988), y al que España no ha sido ajena.

Las características de la economía española condicionaron la adopción de innovaciones comerciales, que generalmente se aplicaron con retraso en relación con el entorno occidental. Pero, además, la conjunción de otros diversos factores bloqueó una progresión normal del comercio en A Coruña. Entre éstos destacaron el bajo poder 
adquisitivo de la población urbana y regional, las dificultades para la movilidad de la población (lo que reducía el área de influencia comercial de la ciudad), la posición periférica de A Coruña en la economía española y mundial, la debilidad de sus estructuras productivas, la relativa insuficiencia de capital, la escasa apertura del país respecto al exterior, etc. A pesar de ello, A Coruña sí se constituyó en el principal centro económico y financiero regional, así como en su principal mercado consumidor, lo que le permitió convertirse en un espacio preferente en Galicia para el desarrollo de las nuevas formas comerciales que por entonces comenzaban a nacer en España.

La organización del comercio coruñés en esos años arranca en muchos aspectos del siglo XIX. El principal rasgo definitorio era la permanencia de unas estructuras de tipo tradicional ${ }^{30}$. Con anterioridad a la guerra mundial, este sector experimentó un prolongado período de crecimiento. Uno de los factores más destacados fue el auge de las remisiones de productos primarios gallegos hacia el mercado interior peninsular (Barreiro Gil, 1983), gracias a una mejora de los medios de comunicación (principalmente, el ferrocarril) y comercialización, así como el aumento de las importaciones de determinados inputs agrícolas (abonos químicos, maquinaria, etc.). Asimismo, el puerto constituía uno de sus principales vehículos de entrada y de salida.

\section{Cuadro 2.9. Distribución de las actividades económicas de A Coruña en 1910 (\% de población activa).}

Industrias de la alimentación, vestido, construcción, gas, electricidad, artes gráficas

Agricultura, ganadería, pesca, silvicultura $18,11 \%$

Servicios personales y domésticos $16,02 \%$

Comercio $12,11 \%$

Fuerzas públicas $8,35 \%$

Transporte marítimo y fluvial $6,17 \%$

Administración Pública $2,24 \%$

Industrias textiles, pieles, madera, metalurgia, cerámica, productos químicos $\quad 2,17 \%$

Otras Industrias $2,09 \%$

Total $92,78 \%$

Fuente: I.N.E. Censo de la Población de España.

\footnotetext{
30 Gámir (1975) distingue tres tipos de sistemas de distribución: 1. el comercio tradicional, caracterizado por una intensidad relativa muy alta en trabajo humano, un elevado capital circulante, reducido capital fijo y pequeñas dimensiones, elementos que, como iremos comprobando se ajustaban al patrón del comercio en A Coruña; 2. las nuevas formas de comercio, que sustituyen trabajo por capital y espacio; 3 . y una forma intermedia, el gran almacén, con una intensidad factorial mixta.
} 
Según los datos proporcionados por los Censos de Población, el comercio se constituía como una de las principales actividades económicas en vísperas de la guerra (Cuadro 2.9). Asimismo, de acuerdo con los datos procedentes de la contribución industrial, el comercio se constituía en la actividad económica urbana más numerosa.

Cuadro 2.10. Distribución de las actividades económicas, 1914-35 (porcentaje sobre total de contribuyentes).

\begin{tabular}{cccccc}
$\begin{array}{c}\text { Ejercicio } \\
\text { fiscal }\end{array}$ & Comercio & Servicios & Industria & $\begin{array}{c}\text { Actividades } \\
\text { artesanales }\end{array}$ & Total \\
\hline 1914 & 39,6 & 16,7 & 24,1 & 19,7 & 100 \\
\hline 1916 & 36,4 & 17,4 & 25,7 & 20,5 & 100 \\
\hline 1917 & 38,5 & 13,8 & 24,3 & 23,5 & 100 \\
\hline 1918 & 39,5 & 14,2 & 24,2 & 22,0 & 100 \\
\hline 1919 & 39,8 & 14,5 & 24,1 & 21,6 & 100 \\
\hline 1920 & 41,8 & 13,0 & 25,4 & 19,8 & 100 \\
\hline 1921 & 36,5 & 18,0 & 27,3 & 18,2 & 100 \\
\hline 1922 & 35,0 & 19,9 & 27,3 & 17,8 & 100 \\
\hline 1923 & 32,2 & 23,0 & 29,3 & 15,5 & 100 \\
\hline 1924 & 32,3 & 24,3 & 25,9 & 17,6 & 100 \\
\hline 1927 & 35,1 & 14,3 & 27,7 & 22,9 & 100 \\
\hline 1929 & 30,6 & 24,1 & 25,6 & 19,7 & 100 \\
\hline 1931 & 51,5 & 20,9 & 16,5 & 11,1 & 100 \\
\hline 1933 & 52,0 & 19,0 & 12,3 & 16,7 & 100 \\
\hline 1935 & 56,6 & 17,9 & 14,0 & 11,5 & 100 \\
\hline
\end{tabular}

Fuente: Elaboración propia en base a las Estadísticas de la Matrícula industrial. COCINC.

En 1914 la cuota por contribución industrial satisfecha por el comercio local ascendía a 200.407 pts. (un 63,3\% del total), elevándose el total de comerciantes coruñeses a 322 (39,6\%) (Cuadro 2.10 y Cuadro 2.11). El comercio representaba aproximadamente 6,71 establecimientos por cada 1.000 habitantes. A este tejido comercial de base se le deberían añadir las actividades no sedentarias, constituidas por los feriantes y un significativo número de vendedores ambulantes, que desgraciadamente resultan imposibles de cuantificar de manera fiable. 


\section{Cuadro 2.11. Distribución de las actividades económicas, 1914-35 (porcentaje sobre total de cuotas).}

\begin{tabular}{cccccc}
\hline $\begin{array}{c}\text { Ejercicio } \\
\text { fiscal }\end{array}$ & Comercio & Servicios & Industria & $\begin{array}{c}\text { Actividades } \\
\text { artesanales }\end{array}$ & Total \\
\hline 1914 & 63,3 & 17,1 & 13,2 & 6,4 & 100 \\
\hline 1916 & 59,4 & 19,1 & 14,1 & 7,4 & 100 \\
\hline 1917 & 65,7 & 12,9 & 13,4 & 8,0 & 100 \\
\hline 1918 & 60,8 & 18,8 & 12,8 & 7,6 & 100 \\
\hline 1919 & 64,7 & 15,2 & 13,1 & 7,0 & 100 \\
\hline 1920 & 62,9 & 16,9 & 13,7 & 6,6 & 100 \\
\hline 1921 & 55,7 & 22,8 & 15,2 & 6,3 & 100 \\
\hline 1922 & 54,1 & 25,0 & 14,5 & 6,4 & 100 \\
\hline 1923 & 52,8 & 25,2 & 16,0 & 6,1 & 100 \\
\hline 1924 & 58,9 & 19,1 & 15,6 & 6,4 & 100 \\
\hline 1927 & 61,9 & 17,7 & 12,2 & 8,2 & 100 \\
\hline 1929 & 60,4 & 18,3 & 13,3 & 8,0 & 100 \\
\hline 1931 & 69,7 & 14,6 & 9,8 & 5,9 & 100 \\
\hline 1933 & 66,5 & 17,1 & 9,8 & 6,6 & 100 \\
\hline 1935 & 71,6 & 12,5 & 9,0 & 6,9 & 100 \\
\hline & & & & & \\
\hline
\end{tabular}

Fuente: Elaboración propia en base a las Estadísticas de la Matrícula industrial. COCINC.

\subsection{Las actividades comerciales en A Coruña durante la guerra mundial}

La economía española vivió una fase inicial de desconcierto y desorganización, que en los países beligerantes se había prolongado hasta bien entrado el primer semestre de 1915, pero en España se acortó sensiblemente para varios sectores económicos, llegando hasta finales de 1914 (García Delgado, 1981: 425). Una segunda fase, caracterizada por un verdadero auge y expansión, se prolongó hasta 1917-18, e incluso en algunos sectores productivos hasta 1919 (Carreras, 1985b).

Sin embargo, en A Coruña las actividades comerciales experimentaron un descenso muy importante en el año 1916, con una muy ligera recuperación en 1917-18, en donde se aprecia que el porcentaje dentro del total de actividades no se vio excesivamente afectado, aunque esto fuese como consecuencia de un descenso similar en el resto de los sectores. Las causas de esta situación se encuentran en las dificultades del contexto internacional. La guerra tuvo un negativo impacto en los negocios de la ciudad, que dependían en alto grado del puerto ${ }^{31}$. Muchas actividades estaban ligadas al tráfico

31 Las actividades comerciales se analizan en detalle en Mirás (2007). 
portuario, aunque algunos empresarios locales desviaron en parte sus inversiones hacia negocios especulativos, de manera análoga a lo observado en Vigo (Souto, 1990: 50).

El tráfico portuario sufrió pronto una visible ralentización, debido a la fuerte disminución de las entradas de buques extranjeros, tanto mercantes como de pasajeros, lo que pronto comenzó a transmitir distorsiones hacia otros sectores económicos urbanos y regionales. El comercio resultó dañado por la menor disponibilidad de mercancías con las que comerciar en el mercado local y en el hinterland.

Además, se multiplicaron las dificultades para el movimiento de pasajeros en dirección a Europa y especialmente hacia América Latina, debido al bloqueo naval en aguas europeas y a las dificultades económicas que atravesaban los países de destino (Villares, 1996a: 108). La situación se deterioró notablemente desde 1916-17, coincidiendo con el bloqueo marítimo impuesto por la flota alemana, lo que motivó que gran parte de las compañías de los países beligerantes e incluso las españolas interrumpiesen sus líneas o evitasen hacer escala en Galicia ${ }^{32}$.

El movimiento de mercancías también se vio afectado. Éste había experimentado un continuo crecimiento desde finales del siglo XIX, pero durante la primera década del XX atravesó un período excepcionalmente próspero (Gráfico 2.5), gracias a la favorable evolución económica regional (Mirás, 2004c). De todos modos, A Coruña ocupó una posición intermedia en la jerarquía portuaria española, tanto dentro del tráfico de cabotaje como con el exterior. Además, era un puerto fundamentalmente importador (Gráfico 2.16) ${ }^{33}$, circunstancia que ha estado determinada por el bajo nivel de desarrollo regional y de su hinterland. Finalmente, el tráfico portuario tuvo que soportar una crónica inadecuación de las instalaciones, una circunstancia común a otros puertos españoles.

En España, los efectos económicos de la guerra fueron divergentes. Algunas regiones costeras y sus puertos aprovecharon la neutralidad para incrementar sus exportaciones, en especial aquéllos con situación continental, que se beneficiaron de la mayor disponibilidad de comunicaciones terrestres y una actividad naviera más desarrollada (Guimerá, 1996: 131).

En A Coruña, sin embargo, la importancia de la flota mercante era secundaria, y esta circunstancia se agravó con el desarrollo del conflicto ${ }^{34}$. Además, el tipo de tráfico que atendía la flota era exclusivamente de cabotaje, especialmente dentro

\footnotetext{
32 Vázquez González (2000a: 741). Actas del Pleno de la Cámara de Comercio, Industria y Navegación de La Coruña (en adelante, ACTAS Pleno COCINC).

33 La provincia de A Coruña, fuertemente condicionada por el peso del puerto herculino, ocupaba años más tarde, en 1914, el $7^{\circ}$ lugar dentro de las 21 provincias marítimas españolas, en términos de entradas por cabotaje en peso, siendo Pontevedra la $9^{\mathrm{a}}$. Por el contrario, en las salidas sólo ocupaba la $12^{\mathrm{a}}$ posición, y Pontevedra la $13^{\mathrm{a}}$. Por lo que respecta al valor de las entradas, A Coruña era la $6^{\mathrm{a}}$ provincia en 1914 (inmediatamente superada por Pontevedra). Anuario Estadístico de España, 1915.

34 El número de buques mercantes mayores de 50 toneladas de registro total matriculados en el puerto en el año 1913 era de 55, sólo superado por Bilbao y Barcelona. Pero la flota todavía mantenía un fuerte sesgo hacia los buques de vela, en los que A Coruña era el tercer puerto español, mientras la flota de vapor era sólo la séptima del país. Para 1914, con sólo 44 buques, se había visto superado por los puertos de Sevilla y Palma de Mallorca, aunque se había producido una fuerte caída de las embarcaciones a vela y una progresiva sustitución por buques de vapor. En 1915 A Coruña había descendido al séptimo puesto, superada, además, por Cádiz y San Sebastián. "Estadística del número de buques mayores de 50 toneladas de registro total que componían la Marina mercante española en los años 1913, 1914 y 1915”. Anuario Estadístico de España, 1915.
} 
de la propia región o de la provincia, y el tonelaje individual de los buques era muy reducido ${ }^{35}$. Por otra parte, la guerra provocó un fuerte descenso de las importaciones españolas en términos físicos, aunque no en su valor, debido al aumento de los precios en los mercados internacionales (García Delgado, 1983b: 543). Para un puerto importador como A Coruña, el efecto de esta disminución fue dramático (IRS, 1919a, 2: 227 y ss.).

\section{Gráfico 2.5. Tráfico mercantil a través del puerto de A Coruña, 1904-36 (tms).}

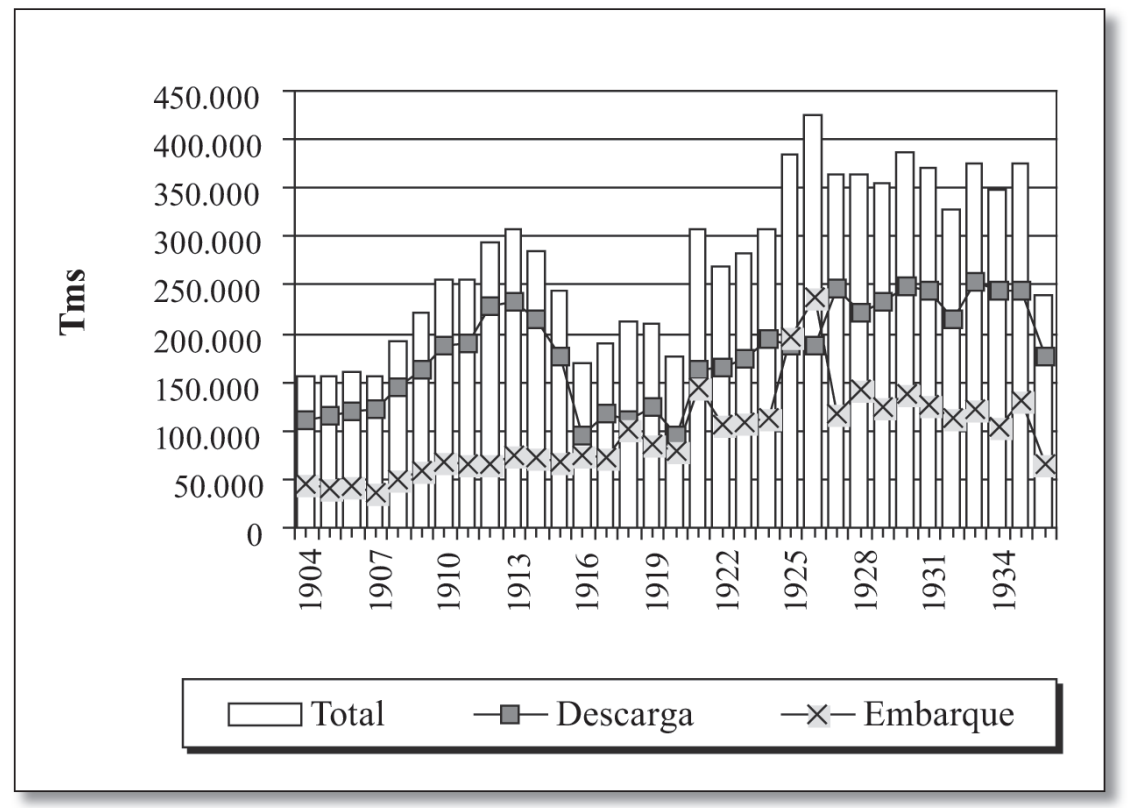

Fuente: Para 1904-15, Valcárcel (1923). Para 1916-39, Memorias de la Junta de Obras del Puerto de La Coruña. No incluye el tráfico pesquero.

El aumento desencadenado en los fletes tuvo especial significación ${ }^{36}$. Los fletes antes de la guerra eran más elevados en los puertos del Levante que en los del norte. Sin embargo, durante 1911-12 experimentaron un considerable incremento, que afectó a todos los puertos. Los años 1913-14 fueron testigos de un abaratamiento de los fletes, que no alteró sustancialmente las diferencias en su distribución geográfica. Ahora bien, a partir de 1915 se inició una fuerte espiral alcista, que continuó durante el siguiente año, y que condujo a los fletes a multiplicarse por siete en ese breve lapso de tiempo (Cuadro 2.12).

\footnotetext{
35 Los buques de vela tenían una media de 86,14 toneladas por buque en 1913, mientras los buques de vapor alcanzaban sólo 225,15 toneladas por buque, lo que situaba al puerto coruñés en el $18^{\circ}$ lugar dentro del ranking nacional por ambos conceptos. En 1915 la situación había empeorado, ya que las 204,39 toneladas por buque de vapor situaban A Coruña en el $21^{\circ}$ lugar a nivel español. Ibíd.

36 Boletín COCINC, n 9, febrero de 1917, p. 8.
} 
Cuadro 2.12. Incremento de los fletes de vapores con origen en los puertos ingleses con destino a los principales puertos españoles, 1910-16, en chelines y peniques.

Bilbao Barcelona Valencia Cartagena Málaga Cádiz Sevilla Santander Canarias

\begin{tabular}{|c|c|c|c|c|c|c|c|c|c|c|}
\hline \multirow{2}{*}{1910} & Ch.* & 4,8 & 6,7 & 6,9 & 6,6 & 6,5 & 5,8 & 6,4 & \multicolumn{2}{|l|}{5,2} \\
\hline & Pens. & & $1 / 4$ & $3 / 4$ & $1 / 2$ & $1 / 2$ & $1 / 4$ & $1 / 2$ & & \\
\hline \multirow{2}{*}{1911} & Ch. & 6,2 & 8,8 & 7,7 & 8,0 & 7,3 & 7,9 & 7,10 & 6,0 & \\
\hline & Pens. & $1 / 4$ & & $1 / 4$ & $1 / 4$ & $1 / 3$ & $1 / 4$ & $1 / 4$ & & \\
\hline \multirow{2}{*}{1912} & Ch. & 7,2 & 11,9 & 11,4 & 11,4 & 10,1 & 11,0 & 10,8 & 7,8 & \\
\hline & Pens. & & $3 / 4$ & & $1 / 4$ & $1 / 2$ & $3 / 4$ & & & \\
\hline \multirow{2}{*}{1913} & Ch. & 7,8 & 9,7 & 9,1 & 10,7 & 10,1 & 9,0 & 9,4 & 7,8 & 9,0 \\
\hline & Pens. & $1 / 2$ & & & $1 / 4$ & $1 / 2$ & $1 / 4$ & $3 / 4$ & & $1 / 2$ \\
\hline \multirow{2}{*}{1914} & Ch. & 6,2 & 10,0 & 9,7 & 9,6 & 9,2 & 9,2 & 8,6 & 6,5 & 8,7 \\
\hline & Pens. & & $1 / 2$ & $3 / 4$ & $1 / 4$ & & $1 / 2$ & & & $1 / 4$ \\
\hline \multirow{2}{*}{1915} & Ch. & & 82,11 & 28,4 & & 31,8 & 26,8 & 25,6 & & 24,9 \\
\hline & Pens. & & $1 / 2$ & & & & & & & \\
\hline \multirow{2}{*}{1916} & Ch. & 44,0 & 68,8 & 68,9 & 68,6 & 66,2 & 63,2 & & & 40,8 \\
\hline & Pens. & $3 / 4$ & $1 / 2$ & & & $1 / 2$ & & & & $3 / 4$ \\
\hline
\end{tabular}

${ }^{*}$ Ch. $=$ Chelines. Pens. $=$ Peniques.

Fuente: Boletín de la Cámara Oficial de Comercio, Industria y Navegación de La Coruña, no 9, 28 de febrero de 1917, p. 9.

A pesar de lo dicho, la principal responsabilidad del descenso del tráfico recayó sobre los embarques de mercancías, mientras las descargas decaían a un ritmo menor. A Coruña no contaba a su favor con un hinterland capaz de satisfacer la demanda de los países beligerantes, factor fundamental para garantizar su desarrollo (de la Puerta, 1994: 42). La caída del tráfico se hizo más pronunciada en 1915, cuando la escasez de buques, la carestía de los fletes y del carbón y los peligros de la navegación de altura y de gran cabotaje ocasionaron una reducción general del tráfico marítimo ${ }^{37}$. En conjunto, el período más crítico transcurrió entre 1914 y 1916 cuando la actividad portuaria cayó un $71,3 \%(-7,0 \%,-14,6 \%$ y $-30,3 \%$, respectivamente).

Otro factor que actuaba en contra de la economía de la ciudad era su dependencia de compañías navieras extranjeras o nacionales para el transporte de viajeros

$37 \quad$ El bloqueo decretado por Alemania y la guerra en el mar, primero desde 1915 y con mayor intensidad desde 1917, fueron los principales factores que dificultaron el tráfico marítimo (IRS, 1916: 108). 
y mercancías ${ }^{38}$. La conclusión, por tanto, es clara. A Coruña no formó parte de los espacios que aprovecharon las ventajas exportadoras creadas por la guerra, y que, en todo caso, esas ventajas se restringieron a sectores muy puntuales.

Sólo se aprecia una recuperación hacia el final de la guerra, en 1917-18. En realidad, el crecimiento de 1918 fue ficticio, puesto que la serie corresponde al tráfico total, es decir, cabotaje, exterior y bahía ${ }^{39}$, y el incremento estuvo muy condicionado por el aumento de los embarques de carbón mineral con destino a la flota pesquera local $\mathrm{y}$, en menor medida, a las operaciones de carboneo ${ }^{40}$. Algo parecido ocurrió con los embarques correspondientes al servicio de aguada ${ }^{41}$.

Gráfico 2.6. Tráfico de bahía, cabotaje y exterior

en el puerto de A Coruña. Descarga, 1916-36 (tms).

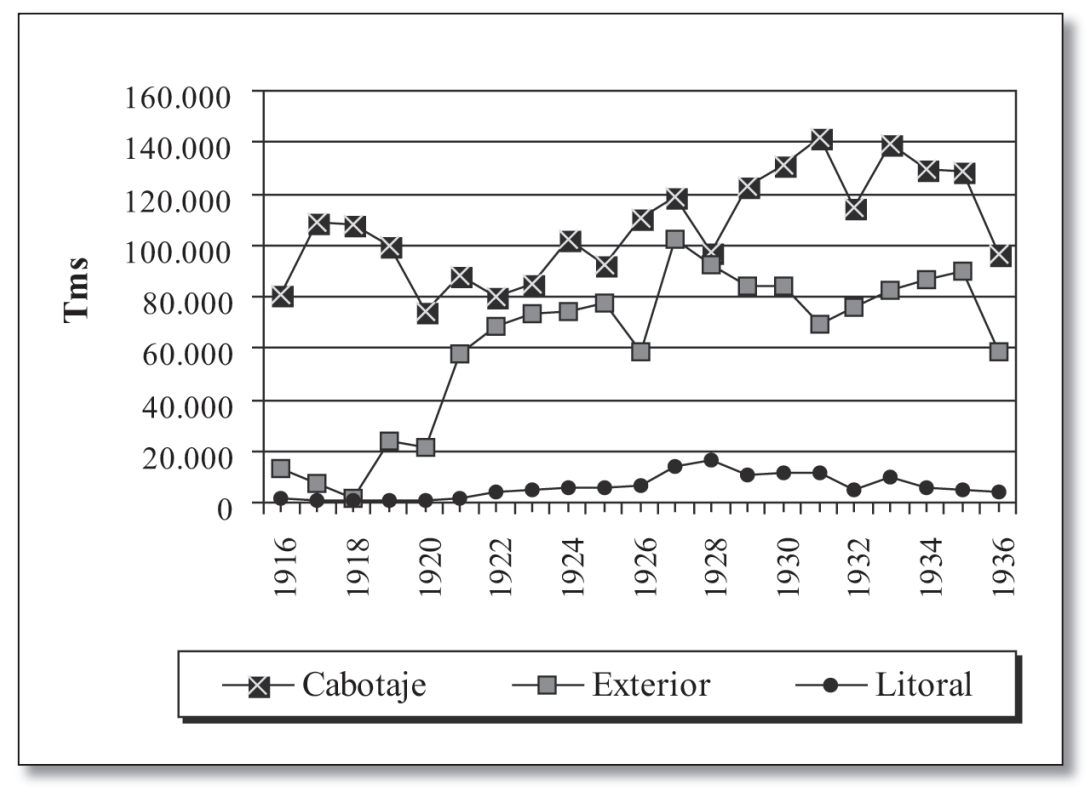

Fuente: Memorias de la Junta de Obras del Puerto de La Coruña.

\footnotetext{
38 El Anuario Financiero y de Valores Mobiliarios, 1917, Madrid, año II, señala que entre las principales compañías navieras españolas, sólo sobresalía Dionisio Tejero, que disponía de 4 vapores: Coruña (de 960 tms), Cantabria (573 tms), Hernani (420 tms), Galicia (278 tms). El mismo Anuario, en 1916, señalaba que no existía ninguna naviera importante en A Coruña, con la excepción de la Compañía Herculina Ferrola$n a$, con un capital social de 350.000 pts. En 1919 existían en la provincia coruñesa 4 sociedades anónimas navieras, La Herculina Ferrolana, con un capital de 192.000 pts., La Necesaria (125.000), Progreso de Riveira (65.000), La Esperanza (42.000). Anuario Financiero y de Sociedades Anónimas, 1919, p. 668.

39 El tráfico de bahía tenía una notable importancia en el puerto de A Coruña, de manera semejante a lo que ocurría en el resto de Galicia (Espárrago, 1944: 110).

40 El movimiento de carbón mineral en el puerto representaba más del 30\% del total de descargas, y en algunos años llegó a suponer cerca del 50\%. El puerto ejercía una función redistribuidora hacia los buques pesqueros, porque los embarques de ese mismo carbón mineral supusieron porcentajes variables, entre el 20 y $50 \%$ en los años de la guerra y la inmediata posguerra.

41 Martínez López et al. (2004). El agua, por su parte, acaparaba porcentajes próximos casi siempre superiores al $50 \%$ de los embarques totales realizados en el puerto.
} 
A favor de A Coruña jugó el hecho de que se trataba de un puerto con una situación periférica a nivel europeo, un nivel de relaciones exteriores poco significativo y un peso considerable del comercio de cabotaje (Gráfico 2.6 y Gráfico 2.7), característica fortalecida durante la guerra, lo que significa que sus exportaciones tal vez no aumentaron, pero las importaciones del exterior ya de por sí eran cuantitativamente poco importantes. El tráfico mercantil gallego se encontraba asimismo dominado por el comercio de cabotaje $\mathrm{y}$, circunstancialmente, por algunas partidas del comercio exterior, vinculadas principalmente a la exportación de ciertas manufacturas por el puerto de Vigo.

El comercio de cabotaje pudo constituir una excelente alternativa para el puerto, ante las dificultades del comercio exterior. Sin embargo, el puerto no figura en ninguna de las categorías que distingue Guimerá (1996: 132), para quien el sistema portuario español se caracterizó por la existencia de puertos especializados en exportación de materias primas como hierro, carbón u otros minerales (Gijón, Huelva o Almería) y la hegemonía de los puertos de mayor desarrollo vinculado a la industrialización y urbanización, con mayor demanda y capacidad adquisitiva de su hinterland (Barcelona y Bilbao). Esto indudablemente limitó el rol de A Coruña como puerto de cabotaje.

A finales del siglo XIX, A Coruña ocupaba una posición intermedia entre los puertos de cabotaje españoles ${ }^{42}$. Ahora bien, la guerra tuvo un impacto negativo sobre el tráfico de cabotaje coruñés, tanto en embarques como en importaciones, cuya única excepción fue el aumento de las expediciones en tonelaje de algunas mercancías. Este comportamiento se inserta dentro de la fase de crisis que atravesó la navegación de cabotaje en España desde el segundo año de la guerra. El descenso afectó tanto a los embarques como a las entradas, si bien fue ligeramente más pronunciado en los primeros. Por tanto, la influencia exterior de la guerra no se vio compensada con una mejoría de las relaciones comerciales con el espacio litoral español (Cuadro 2.13) ${ }^{43}$.

Para una economía como la analizada, con una función de tránsito especialmente acentuada, el problema de los transportes tuvo tintes calamitosos. Las dos causas principales eran la insuficiencia de tonelaje en los transportes marítimos y la falta de material en los transportes ferroviarios. La falta de tonelaje marítimo se transmitió hacia el transporte terrestre, porque parte del tráfico marítimo demandó la vía terrestre. La orientación del tráfico de cabotaje hacia el transporte ferroviario acarreó un importante aumento en este último (Gráfico 2.8) ${ }^{44}$. El problema se agravó por la decisión del Gobierno de establecer en 1917 unas tarifas de cabotaje que elevaban los fletes ${ }^{45}$, cuando hasta entonces apenas había intervenido en su fijación (Valdaliso, 1997), circunstancia que fue seguida de una subida de las tarifas del transporte ferroviario ${ }^{46}$.

\footnotetext{
$\overline{42}$ El hecho de que A Coruña mantuviese un comportamiento más sólido en los embarques que en las entradas en valor sólo sugiere que en España el número de puertos exportadores de mercancías de elevado valor añadido era reducido. Además, las salidas en valor eran mucho más importantes comparativamente que las salidas en peso, lo que se explica por la presencia dominante de los puertos exportadores de minerales y de las zonas industriales españolas (puertos del norte, Barcelona y algunos puertos andaluces).

43 Suárez Pumariega y Valcárcel, op. cit., pp. 9-10.

44 El problema de los transportes. Informe remitido a la Dirección General de Comercio, A Coruña, 10 de noviembre de 1917, en Las Cámaras de Comercio. Labor de la de La Coruña hasta fin de 1923, La Coruña, COCINC, 1924, pp. 197-199.

45 Boletín COCINC, no 18 , noviembre de 1917, pp. 1-3.

46 Anuario Estadístico de España, 1918.
} 


\section{Cuadro 2.13. Posición de A Coruña en el ranking} del tráfico de cabotaje, 1891-1920.

\begin{tabular}{cccc}
\hline $\begin{array}{c}\text { Importación } \\
\text { (en valor) }\end{array}$ & $\begin{array}{c}\text { Posición en el } \\
\text { ranking }\end{array}$ & $\begin{array}{c}\text { Importación } \\
\text { (en tonelaje) }\end{array}$ & $\begin{array}{c}\text { Posición en el } \\
\text { ranking }\end{array}$ \\
\hline $1891-1895$ & $10^{\circ}$ & $1891-1895$ & $11^{\circ}$ \\
\hline $1896-1900$ & $7^{\circ}$ & $1896-1900$ & $11^{\circ}$ \\
\hline $1901-1905$ & $11^{\circ}$ & $1901-1905$ & $12^{\circ}$ \\
\hline $1906-1910$ & $11^{\circ}$ & $1906-1910$ & $8^{\circ}$ \\
\hline $1911-1915$ & $10^{\circ}$ & $1911-1915$ & $8^{\circ}$ \\
\hline $1916-1920$ & $12^{\circ}$ & $1916-1920$ & $11^{\circ}$ \\
\hline Exportación & & $\begin{array}{c}\text { Exportación } \\
\text { (en tonelaje) }\end{array}$ & $17^{\circ}$ \\
\hline (en valor) & & $1891-1895$ & $17^{\circ}$ \\
\hline $1891-1895$ & $6^{\circ}$ & $1896-1900$ & $18^{\circ}$ \\
\hline $1896-1900$ & $8^{\circ}$ & $1901-1905$ & $22^{\circ}$ \\
\hline $1901-1905$ & $9^{\circ}$ & $1906-1910$ & $21^{\circ}$ \\
\hline $1906-1910$ & $11^{\circ}$ & $1911-1915$ & $18^{\circ}$ \\
\hline $1911-1915$ & $11^{\circ}$ & $1916-1920$ & \\
\hline $1916-1920$ & $12^{\circ}$ &
\end{tabular}

Fuente: Frax (1981).

Gráfico 2.7. Tráfico de bahía, cabotaje y exterior en el puerto de A Coruña. Embarque, 1916-36 (tms).

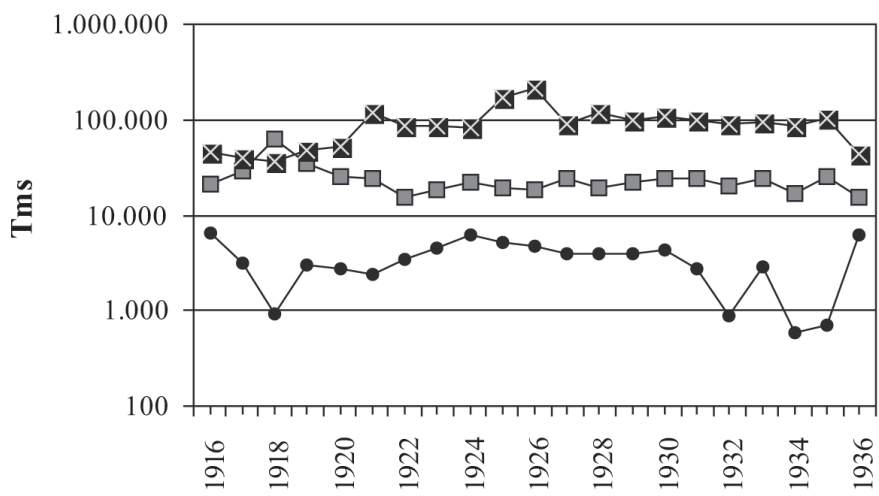

$\rightarrow \square-$ Cabotaje $\rightarrow$ Exterior $\rightarrow \mathrm{z}$ - Litoral

Fuente: Memorias de la Junta de Obras del Puerto de La Coruña. 
Gráfico 2.8. Tráfico mercantil. Estación ferroviaria de A Coruña, 1901-30 (tms).

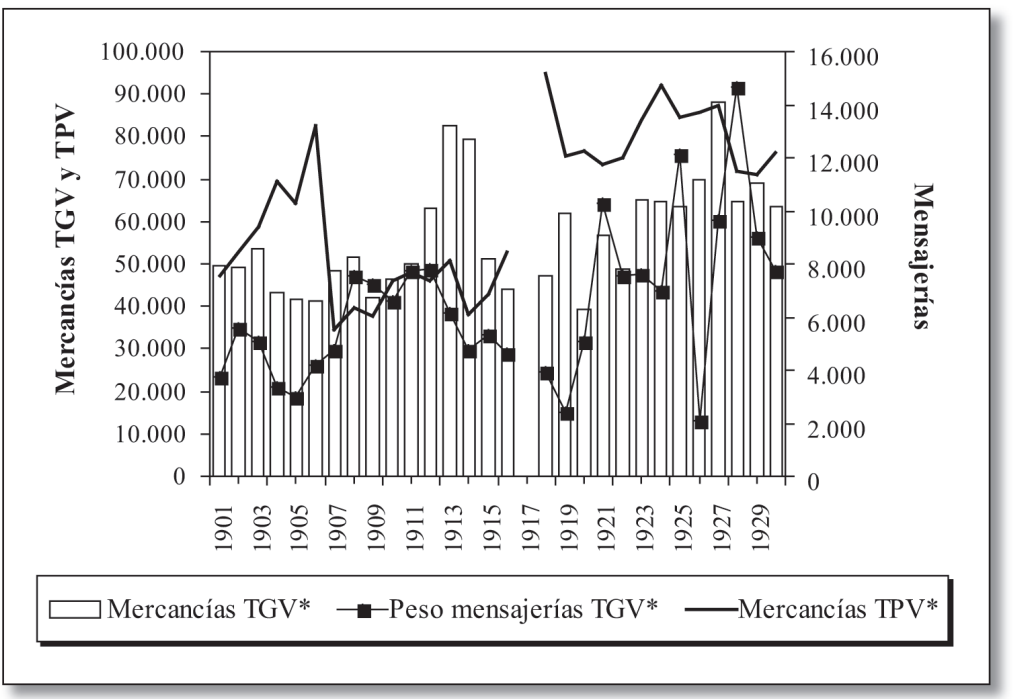

* TGV: Transportes de Gran Velocidad. TPV: Transportes de Pequeña Velocidad. Mensajerías: géneros frescos.

Fuente: Memoria de la Compañía de los Caminos de Hierro del Norte de España (estaciones de Galicia), cedido por Francisco López Abuín.

Gráfico 2.9. Distribución de las mercancías embarcadas en el puerto de A Coruña, 1916-36 (tms).

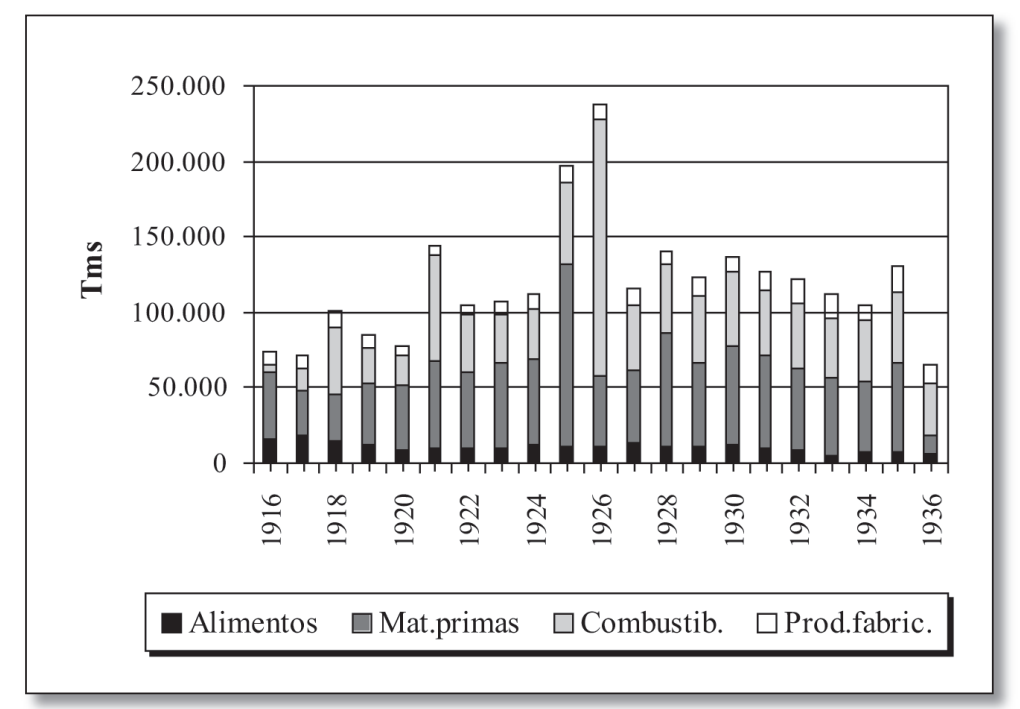

Fuente: Memorias de la Junta de Obras del Puerto de La Coruña. 
La estación de ferrocarril de A Coruña era más expedidora que receptora, y las mercancías quedaban detenidas en ella largo tiempo sin poder expedirse al mercado interior, provocando una verdadera congestión ${ }^{47}$. El problema era de falta de carga, de escasez de medios de transporte y de falta de almacenes e instalaciones ${ }^{48}$.

Gráfico 2.10. Distribución de las mercancías descargadas en el puerto de A Coruña, 1916-36 (tms).

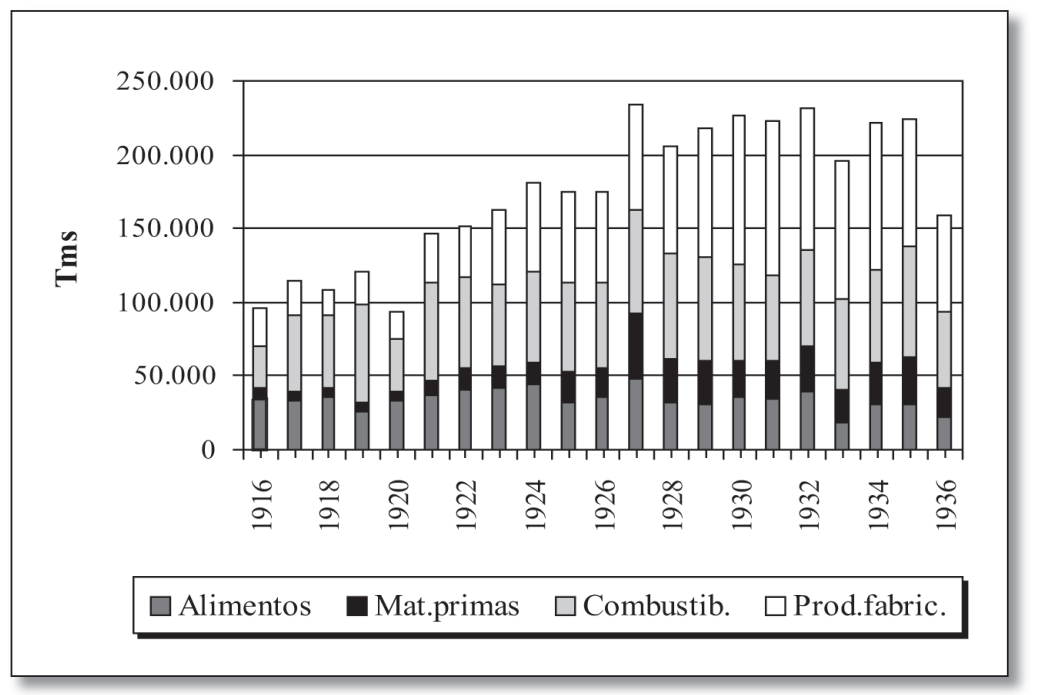

Fuente: Memorias de la Junta de Obras del Puerto de La Coruña.

Siguiendo la metodología empleada por de la Puerta (1994: 128 y ss.), se ha agregado el tráfico mercantil en cuatro categorías (Gráfico 2.9, Gráfico 2.10 y Gráfico 2.11). Inicialmente, el dominio correspondía a los alimentos (aceite de oliva, azúcar, maíz, harinas, sal, vinos, trigo, etc.), lo que se explica por los rasgos dominantes en Galicia: una sociedad tradicional que exportaba bienes primarios, importando bienes manufacturados, para los que no existía suficiente capacidad productiva. Se trataba de productos de consumo ordinario, enviados hacia otras áreas del país, y, sobre todo, de importación, mostrando un escaso desarrollo de las industrias exportadoras locales.

La influencia de la guerra se manifestó en la entrada de algunas de las partidas más importantes de este grupo. Por ejemplo, en el trigo, en el que la provincia era deficitaria, teniendo que importarlo o comprarlo en el interior ${ }^{49}$. Una parte se destinaba al abastecimiento local, debido a su elevada demanda. La delicada coyuntura provocada por la guerra impidió su importación, mientras que las entradas de cabotaje no experimentaron un significativo incremento, pues la agricultura castellana no era capaz de cubrir las necesidades del mercado nacional.

El problema de los transportes, op. cit, p. 199. Boletín COCINC, no 15, agosto de 1917, p. 3.

48 Suárez Pumariega y Valcárcel, op. cit., p. 11. Boletín COCINC, no 18, noviembre de 1917, p. 2.

49 Archivo COCINC. Legajo A.D./220, carpeta "Depósito de cereales (silos)". 


\section{Gráfico 2.11. Distribución sectorial del tráfico total registrado por el puerto de A Coruña, 1916-36 (tms).}

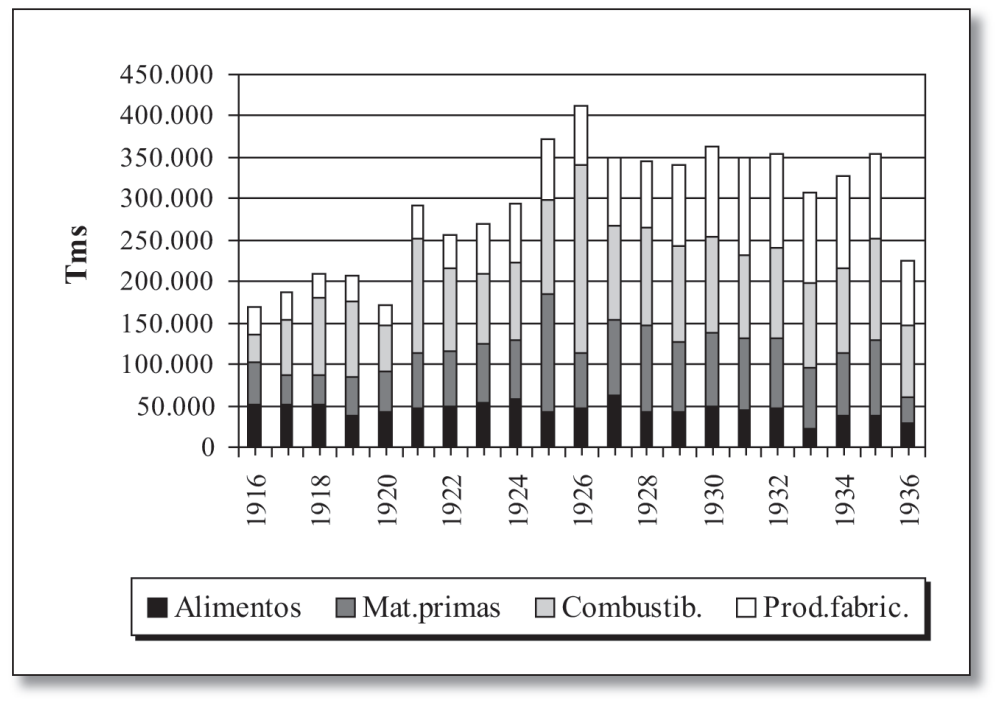

Fuente: Memorias de la Junta de Obras del Puerto de La Coruña.

El capítulo correspondiente a los combustibles tenía una fuerte participación, debido a la importación de elevados volúmenes de carbón mineral (Cuadro 2.15). Su principal destinatario era la flota pesquera local, además de ciertos procesos industriales urbanos y la redistribución hacia otros puntos del litoral. La procedencia del carbón era mayoritariamente británica, con una fuerte concentración en el puerto de Cardiff, llegando en ocasiones a acaparar la práctica totalidad de los envíos.

Durante la guerra, el precio de los fletes del carbón se disparó, lo que redujo su importación. Por su parte, el suministro de carbón español había tenido una importancia marginal. Además, el carbón asturiano también sufrió considerables aumentos de precio. Sin embargo, debido a la cercanía respecto de los puertos asturianos, pasó a ser adquirido vía cabotaje. Asimismo, la producción minera de la cuenca leonesa aumentó, gracias a la puesta en funcionamiento de minas hasta entonces sin explotar, aunque este carbón llegó al puerto, vía ferrocarril, durante los últimos años de la contienda. De todos modos, el carbón español era generalmente poco apreciado, por su menor poder calorífico y por la incapacidad de utilización en los buques pesqueros, por ser de peor calidad ${ }^{50}$.

En cuanto a los productos fabricados, de los que la economía coruñesa tenía una fuerte dependencia del exterior y, sobre todo de cabotaje, la caída de algunas partidas fue muy acusada: cemento, abonos, tabaco, materiales de construcción, jabón, hierros y aceros, gasolina, hojalata, tejidos, envases vacíos, productos químico-farmacéuticos, etc. Se trataba de mercancías destinadas a la construcción urbana, artículos que satisfacían la

\footnotetext{
$50 \quad$ El transporte del carbón de la cuenca leonesa, a La Coruña. Informe enviado al Ministro de Fomento, La Coruña, 1922, en Las Cámaras de Comercio. Labor de la de La Coruña hasta fin de 1923, La Coruña, COCINC, 1924, p. 243.
} 
demanda del hinterland y del proceso de modernización agrícola, productos que cubrían las limitaciones de la industria local, y artículos de industrias que suministraban inputs a instalaciones urbanas, o destinaban parte de su producción al mercado nacional.

\section{Cuadro 2.14. Principales mercancías del tráfico portuario total, 1916-40 (porcentaje sobre tonelaje).}

\begin{tabular}{lcccccc}
\multicolumn{1}{c}{ Mercancías } & $\mathbf{1 9 1 6}$ & $\mathbf{1 9 2 0}$ & $\mathbf{1 9 2 5}$ & $\mathbf{1 9 3 0}$ & $\mathbf{1 9 3 5}$ & $\mathbf{1 9 4 0}$ \\
\hline Carbones minerales & 19,5 & 31,0 & 30,6 & 31,2 & 33,8 & 44,8 \\
\hline Agua común & 24,1 & 22,0 & 31,9 & 16,4 & 16,1 & 12,5 \\
\hline Aceites pesados motores & & & & 3,3 & 3,3 & 4,4 \\
\hline Sal & 8,1 & 6,2 & 3,6 & 4,7 & 4,5 & 3,5 \\
\hline Cemento & 2,6 & 2,0 & 2,4 & 6,7 & 4,4 & 4,2 \\
\hline Abonos & 3,1 & 1,1 & 4,2 & 4,9 & 1,8 & 3,3 \\
\hline Madera sin labrar & 2,5 & 2,8 & 3,0 & 3,2 & 2,5 & 3,2 \\
\hline Gasolina y bencina & 0,3 & 0,0 & 1,1 & 5,0 & 4,5 & 0,7 \\
\hline Fosfato de cal & & & & & 5,8 & 3,2 \\
\hline Tabaco & 2,2 & 1,2 & 2,9 & 1,4 & 2,2 & 0,9 \\
\hline Maíz & 2,2 & 6,4 & 1,2 & 0,5 & 0,1 & 0,0 \\
\hline Hierros y aceros & 1,4 & 1,2 & 2,1 & 1,3 & 0,8 & 1,5 \\
\hline Total & 66,0 & 73,9 & 83,0 & 78,6 & 79,8 & 82,2 \\
\hline
\end{tabular}

Fuente: Memorias de la Junta de Obras del Puerto de La Coruña.

En las materias primas predominaban los embarques (de minerales y bienes agrícolas), estando integradas por unas cuantas partidas esenciales, que mostraron, en general, un gran equilibrio. Las principales, agua común, arena o madera sin labrar, totalizaban un elevado porcentaje. Estos artículos se destinaban a la construcción urbana o proporcionaban inputs para industrias locales, subsidiarias de la pesca y la conserva. Su evolución, en conjunto, fue más positiva que la de los productos fabricados.

Capítulo aparte merece la pesca. En Galicia, el tránsito entre siglos coincidió con el inicio de las transformaciones y modernización del sector (Giráldez, 1996), gracias a la introducción del vapor, tecnología que supuso una notable movilización de capitales que dinamizó a determinados segmentos de la clase empresarial del litoral gallego ${ }^{51}$. Esta innovación técnica, junto con el aumento del tamaño de los buques, permitió

51 Según Valdaliso (2003), en España la introducción del vapor y el arrastre en el sector pesquero trajo consigo la entrada de capitales procedentes del comercio. En Galicia, en 1904 existían 138 vapores pesqueros, de los que 108 estaban matriculados en Vigo, 24 en A Coruña y 6 en Ferrol. Eran pequeños, con un arqueo medio de unas 30 TRB, montadas con máquinas de vapor inglesas de unos 48 caballos de vapor, y cascos de madera construidos en Vigo (Giráldez, 1997b: 243). 
un incremento de los rendimientos pesqueros e incrementó el radio de acción de los buques y la duración de los períodos de pesca. Las transformaciones en los medios de extracción, tanto artes (cercos de jareta, parejas, palangres y artes de arrastre) como embarcaciones (sustitución de madera por acero en los cascos, mejora de los equipos de captura, aumento del tamaño de las unidades y su autonomía), la estructura organizativa del sector y las actividades derivadas, el descubrimiento de nuevos caladeros, etc., fueron elementos que favorecieron el desarrollo de esta actividad (Carmona, 1990a).

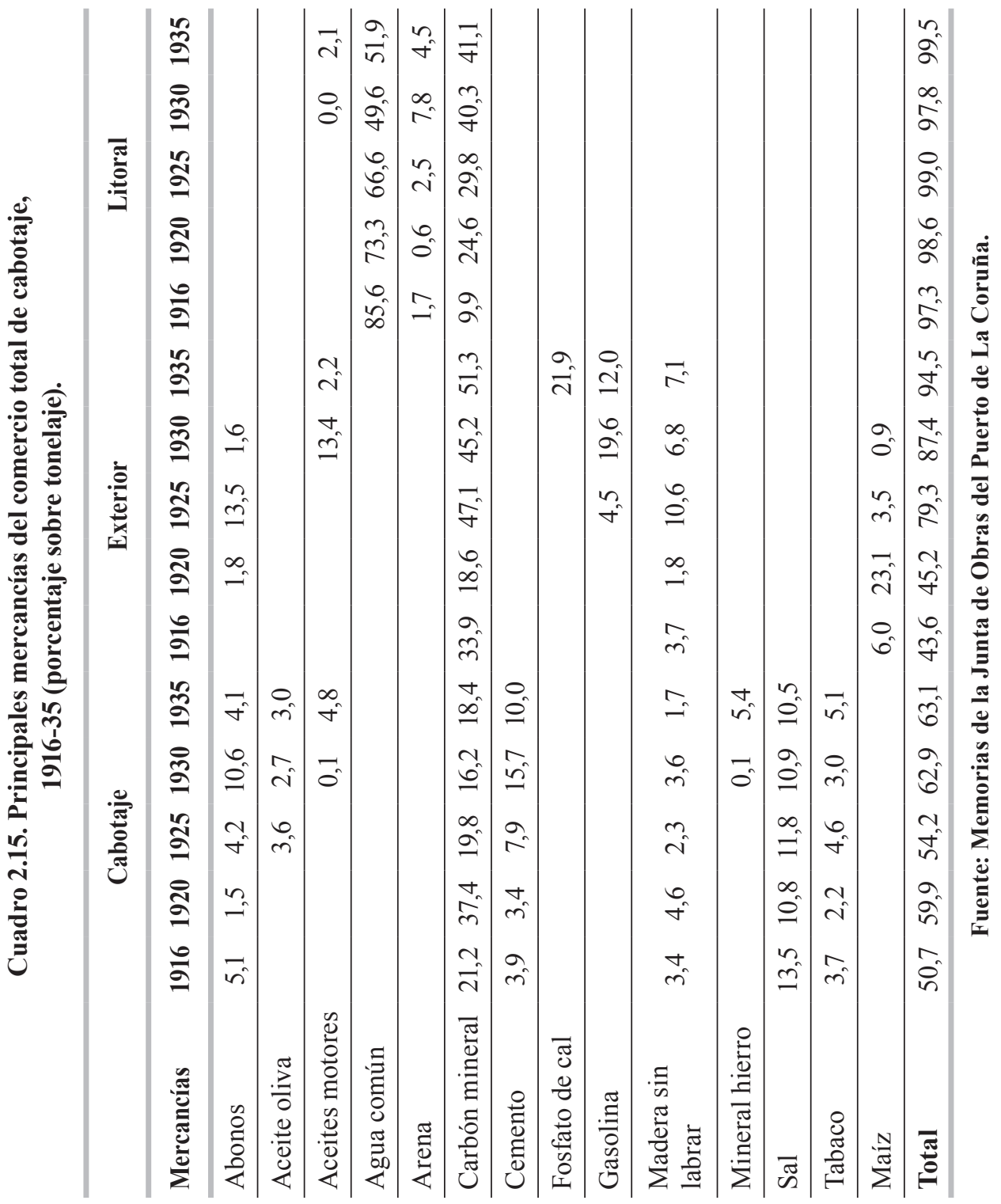


Estas innovaciones técnicas simbolizan el afianzamiento de la pesca industrial, en Vigo y A Coruña, lo que favoreció la penetración de nuevos tipos de técnicas y de relaciones industriales (Pereira, 1992b: 154). La modernización del sector permitió asimismo una transformación de la actividad comercializadora. Las formas tradicionales de distribución existentes desde finales del siglo XIX, personalizadas en la cadena armador-negociante mayorista-asentador, se vieron complementadas con la aparición de nuevas empresas integradas verticalmente, caso de la firma Pescaderías Coruñesas, S.A. Esta sociedad agrupaba la fase de producción (con su propia flota), el transporte y la comercialización hasta su venta al por menor, en expendurías propias. Sin embargo, este tipo de empresas, con excepción de la citada, quebraron o se reestructuraron con la crisis de los años treinta (Giráldez, 1997a: 19, 66, 68).

Como resultado, la población empleada en las faenas pesqueras creció significativamente en Galicia y en A Coruña (Pereira, 1992b: 156-154). Esto permitió que el puerto comenzase a ocupar los primeros puestos del ranking pesquero, aunque a cierta distancia de Vigo (principal puerto pesquero nacional) en cuanto a volumen de capturas (Gráfico 2.12 y Gráfico 2.14), con un porcentaje de participación dentro del conjunto español que se mantuvo en torno al 4-7\% del total de capturas. Las diferencias, en cambio, han sido menores respecto al valor (Gráfico 2.13), debido al elevado peso que tenía en Vigo la pesca de la sardina, especie ésta de menor valor unitario (Giráldez, 1996: 105).

Gráfico 2.12. Volumen de las capturas de pesca en A Coruña y Vigo, 1910-36 (tms).

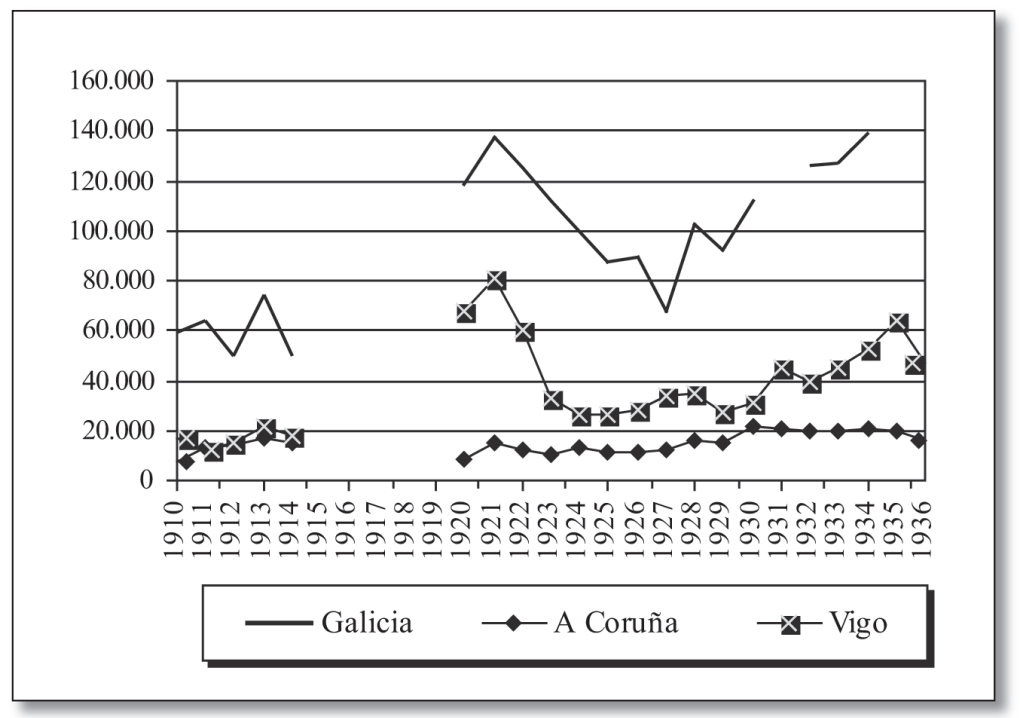

Fuente: Para el período 1910-20, el agregado gallego total y Vigo, Giráldez (1996). Para A Coruña, a partir de 1920, Memorias de la Junta de Obras del Puerto de La Coruña, cuyos datos correspondientes a la pesca se recogen por primera vez a partir de esa fecha. 
Gráfico 2.13. Valor de la pesca capturada en A Coruña y Vigo, 1910-36 (pts. constantes de 1913).

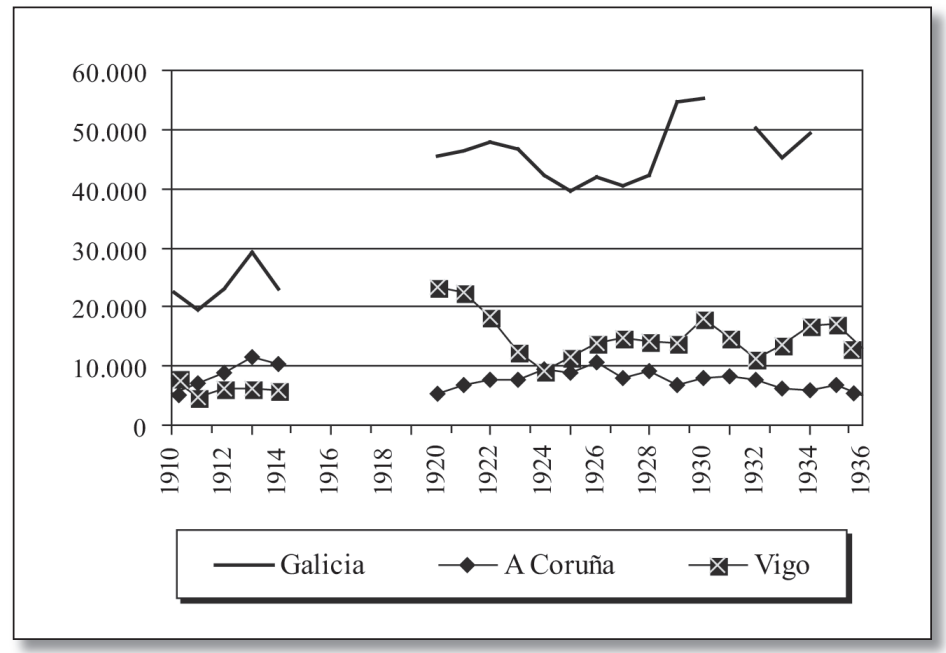

Fuente: Vid. Gráfico 2.12.

\section{Gráfico 2.14. Participación de A Coruña y Vigo en el total pesquero español.}

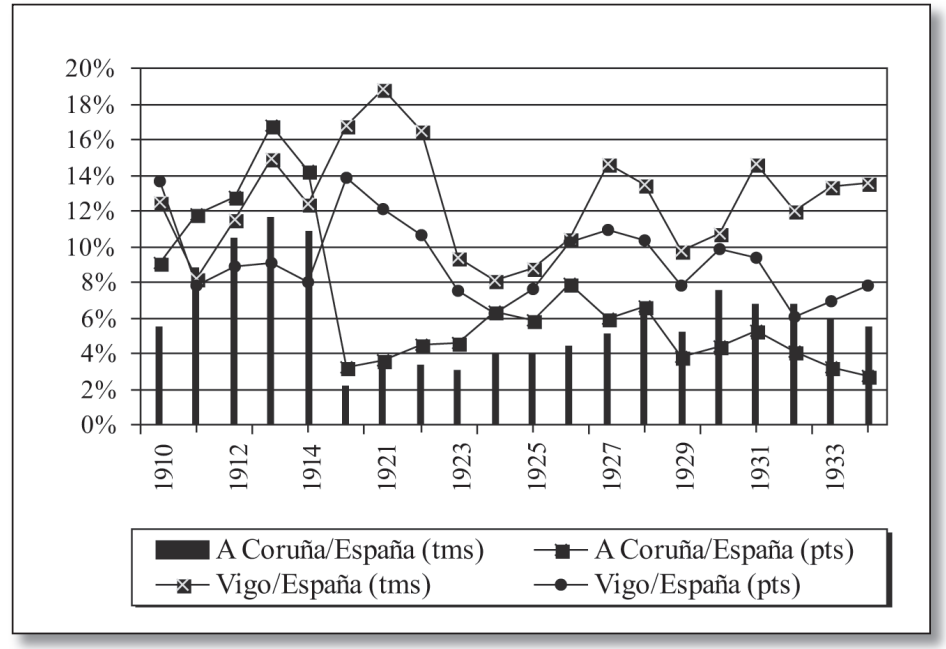

Fuente: Vid. Gráfico 2.12.

Sin embargo, la guerra afectó de forma negativa a la actividad pesquera coruñesa, de manera semejante al sector pesquero español y a otros sectores de la economía nacional. Concurrieron varios factores que repercutieron en una relativa paralización, tanto del sector como del conjunto de la economía urbana. En primer lugar, se produjo un fuerte aumento de los costes empresariales, vía aumentos de precios de materias 
primas y combustibles, que afectó a la pesca y sectores vinculados y a numerosos sectores industriales (Bernárdez, 1917a).

El mayor crecimiento correspondió al capítulo materias primas, en especial el carbón, que se vino a sumar a los graves problemas para el abastecimiento de combustible propios del conflicto. La carestía del carbón procedente de Cardiff entorpecía la industria pesquera, en unos momentos en los que el suministro del exterior no encontraba una respuesta elástica en la producción nacional. Ello tuvo su traducción en un estrangulamiento de la oferta pesquera. El problema del carbón se presentó varias veces. En 1916 alcanzó cotas serias, hasta el punto de desembocar en una huelga de buques pesqueros, que se inició en primavera y se prolongó por espacio de varios meses. Pero al año siguiente, el problema continuaba sin resolver ${ }^{52}$.

Otros capítulos destacados fueron el aceite, cables de acero, redes, cuerdas y otros pertrechos, que compartieron una tendencia inflacionista especialmente virulenta de las principales subsistencias (IRS, 1919a, 2; Bernárdez, 1917b). Asimismo, las dificultades para la importación de determinados inputs y de maquinaria se multiplicaron y, lo que es más grave, se observa una contracción en el volumen de capturas, con los consiguientes efectos sobre las actividades vinculadas (Giráldez, 1997a: 21-22). Como resultado, las empresas pesqueras sufrieron las consecuencias en sus resultados ${ }^{53}$.

Finalmente, la pesca asistió impotente a las dificultades financieras de las compañías ferroviarias, que obligaron a una fuerte subida de las tarifas ${ }^{54}$. Las remisiones de pescado eran origen de frecuentes conflictos entre los productores coruñeses y la Compañía de los Ferrocarriles del Norte ${ }^{55}$. En ocasiones, se trataba de divergencias en torno al horario de los trenes pescaderos, que debían llegar a su destino a determinadas horas, pero era aún más habitual que la compañía amenazase con la supresión de los trenes. En contrapartida, la demanda de pescado en el mercado español se incrementó, lo que unido a la subida del coste de la vida, provocó una fuerte subida de los precios del pescado (Martínez López, 2000a: 359-360; Giráldez, 1996: 165-167, 195).

Al finalizar la guerra, la economía local retornó lentamente a la normalidad, y el ritmo empresarial comenzó a normalizarse, permitiendo una leve recuperación de la actividad comercial en su conjunto hacia 1919. A pesar de que algunas de las secuelas del conflicto todavía se hacían notar, el país había entrado en la etapa de posguerra y los principales factores que guiaron la coyuntura bélica comenzaron a cambiar de signo.

El número de comerciantes matriculados se incrementó sólo un 3,7\% entre 1917 y 1919, mientras que las cuotas apenas aumentaron un 2,2\%. El sector, por tanto, todavía no había tenido tiempo suficiente para recuperarse del impacto bélico sobre el mercado y el consumo urbanos, pues la caída respecto a 1914 era del 5,6\% en el número de contribuyentes, y del 8,1\% en el total de las cuotas del sector.

\footnotetext{
52 Memoria de la Cámara de Comercio, Industria y Navegación de La Coruña del año 1916.

53 Por ejemplo, La Pesquería Gallega, S.A., que entre 1913 y 1916 tuvo pérdidas. ARG-DHC (Hacienda). Intervención de Hacienda. Auxiliar de cuentas corrientes por Contribución sobre Utilidades de la Riqueza Mobiliaria con los Bancos y Sociedades por los beneficios que obtienen. Presupuestos de 1914-1920. Libros 4535-4538.

54 Boletín COCINC, $\mathrm{n}^{\circ}$ 21, febrero de 1918, p. 3

55 Suárez Pumariega y Valcárcel, op. cit., p. 10.
} 
La conclusión de la guerra ocasionó un descenso del consumo, en la línea del que sufrieron la economía española y la europea ${ }^{56}$. Sin embargo, la capacidad de respuesta del comercio mayorista (acaparadores, asentadores, negociantes, etc.) fue más sólida que la del pequeño comercio. Sus márgenes de beneficio se sostuvieron con mayor firmeza que los de los comerciantes minoristas ${ }^{57}$.

Por tanto, esta primera etapa de posguerra fue de reajuste. Las distorsiones y los estrangulamientos provocados por la contienda todavía no habían desaparecido completamente. Los países beligerantes estaban recomponiendo sus economías, sobre todo los que habían salido peor parados (Alemania, Francia, Países Bajos), que habían sido tradicionalmente espacios relacionados comercialmente con A Coruña. La producción industrial de esos países aún tardó tiempo en recuperarse, en especial la alemana, país de donde se importaban elevados volúmenes de bienes de equipo.

Por otro lado, la industria y los sectores extractivos nacionales entraban en una fase de descompresión, después del boom especulativo de la guerra. El empuje sobre la demanda de mercancías españolas con destino a los escenarios bélicos estaba tocando a su fin, de manera que numerosos sectores comenzaron a padecer las consecuencias de una desaceleración económica. La alternativa que habría podido significar el mercado interno no era una posibilidad consistente. De manera que, ante la caída de la demanda, la oferta productiva cayó, en algunos sectores muy rápidamente, incluso a niveles inferiores a los de preguerra. En consecuencia, la escasez de algunos productos y de algunas materias primas que había caracterizado el período bélico en A Coruña, se agudizó entre 1919-20, lo que dificultaba el normal desarrollo de la función comercial. Y, además, la inflación perturbó el comportamiento del consumo, tal y como había venido ocurriendo durante los cuatro años de conflicto.

Ahora bien, comparativamente, el sector comercial sobrellevó mejor el retorno a la normalidad. Las actividades más beneficiadas en A Coruña no fueron las comerciales, sino los negocios incluidos en el sector servicios, como consecuencia, fundamentalmente, del cambio de orientación de las actividades relacionadas con el mar (movimiento de pasajeros y tráfico pesquero). En cambio, es necesario tener en cuenta que las actividades industriales, y en parte también las actividades artesanales (sobre todo, aquéllas que tenían un carácter más decididamente manufacturero), experimentaron la crisis que vivió el conjunto del sector secundario en toda España (IRS, 1921a).

A pesar de todo, aunque este breve período se inscribe dentro de una coyuntura depresiva a nivel europeo e internacional, que tuvo efectos en la propia economía gallega (Barreiro Fernández, 1981: 289), no sería exacto emplear el término estancamiento (y menos aún depresión) para caracterizar en A Coruña los años que precedieron a la Dictadura de Primo de Rivera. En todo caso, es una etapa definida por su irregularidad y por la heterogeneidad de comportamiento de los distintos sectores económicos urbanos.

\footnotetext{
56 Argente, B., "La crisis económica", en Anuario Económico-Industrial de la Producción Nacional para 1924, Madrid, p. 31.

57 Villanueva, V., "La venta de carnes y la explotación del ganado vacuno en Galicia", La Voz de Galicia, 17 de marzo de 1921, en Villanueva, V., Organización del cultivo y de la sociedad agraria en Galicia y en la España Atlántica, 1984, Madrid, Xunta de Galicia-MAPA, pp. 430-432.
} 
Superada la fase bélica, la prosperidad retornó a algunos negocios. Parte de la responsabilidad de la recuperación hay que atribuirla a factores exógenos, fundamentalmente los vinculados con la evolución de las actividades marítimas. En primer lugar, el restablecimiento de la corriente migratoria con destino a América, que permitió la recuperación de las actividades terciarias en general. El tráfico de pasajeros era por entonces vital para la vida económica de la ciudad, en especial el de emigrantes ${ }^{58}$.

En segundo lugar, el despegue del sector pesquero que, coincidiendo con el final de la guerra, vivió una de sus coyunturas más prósperas, ya que fue entonces cuando verdaderamente se inició una nueva etapa en la historia de las pesquerías regionales y coruñesas. Las capturas experimentaron un notable incremento, debido a la caída de la actividad de los primeros tres años de conflicto y a la casi total paralización de la mayor parte de las flotas europeas, lo que trajo a los caladeros la necesaria recuperación tras el esfuerzo extractivo anterior. Esta etapa de expansión se prolongó, igual que en Galicia, hasta aproximadamente 1921 (Giráldez, 1996).

A partir de entonces, las actividades marítimas gallegas, además de verse afectadas por la crisis de posguerra (general a todos los negocios marítimos españoles), tropezaron con algunos problemas particulares. La principal, el hecho de que la fuerte expansión de las pesquerías en una plataforma estrecha como la gallega (Labarta, 1985: 27) comenzaba a mostrar rendimientos decrecientes, afectando a los resultados económicos de los armadores. Afortunadamente, la capitalización del sector adquirida durante la guerra les permitió implementar una política de ampliación de las áreas de pesca (Carmona, 1997: 259).

Otro grave problema era la mejora de las condiciones técnicas del transporte del pescado en fresco, puesto que un perfeccionamiento de las infraestructuras y de los materiales posibilitarían una expansión del mercado. Durante esta década comenzó a tomar posiciones la comercialización de productos pesqueros desde A Coruña, de manera que a finales de los años veinte se consolidó un grupo de grandes asentadores en los mercados centrales (Sinde, 1999).

Después de la guerra se generalizó la utilización del camión como medio de transporte para el pescado fresco, como alternativa a unas tarifas ferroviarias que se mantuvieron a un nivel elevado durante todo el primer tercio del siglo. Las referencias a los problemas del transporte ferroviario son continuas. A pesar de que el pescado era considerado mercancía preferente, los trenes pescaderos no disponían de vagones suficientes, sus horarios eran excesivamente rígidos, el material móvil se encontraba en pésimo estado, las condiciones del transporte eran inapropiadas y antihigiénicas, etc. (Sinde, 1999). Incluso la conexión con el ferrocarril desde el puerto y las propias dependencias de la estación eran inadecuadas para el servicio ${ }^{59}$. De hecho, se observa que el tráfico ferroviario de gran velocidad (donde se transportaba el pescado) presenta una evolución irregular hasta aproximadamente 1923 (Gráfico 2.8). El transporte por carretera alcanzó tal importancia

\footnotetext{
58 "El tráfico de pasajeros que más interesa a La Coruña es el de los de tercera clase que emigran o inmigran". "El puerto de La Coruña", Comercio, Industria y Navegación. Revista de los Intereses Económicos de La Coruña, año 1, $\mathrm{n}^{\circ}$ 1, abril-agosto 1924, Cámara de Comercio de La Coruña, p. xi.

59 ACTAS Pleno COCINC, mayo de 1924.
} 
que, a pesar de que a principios de siglo el ferrocarril monopolizaba las remisiones de pescado fresco, llegó a movilizar casi dos tercios de las expediciones ${ }^{60}$.

Sin embargo, en vísperas de la etapa primorriverista (aproximadamente, 1921-22), el sector pesquero comienza a presentar síntomas de agotamiento que se agudizaron y perduraron hasta los últimos años de la Dictadura. Giráldez (1996: 302) sitúa esta fase en Galicia y en España en torno a 1920. En A Coruña se puede retrasar hasta 1921, si tomamos como indicador el volumen de capturas e incluso el valor nominal de la pesca. No obstante, si empleamos el valor en pesetas constantes de 1913, todavía se aprecia un moderado crecimiento hasta mediados de la década.

La crisis de adaptación posbélica afectó más tardíamente al sector, pero la actividad pesquera en A Coruña atravesó probablemente la situación más crítica del primer tercio del siglo. Los años veinte fueron bastante duros para la pesca, debido al agotamiento de los caladeros (Giráldez, 1996: 302-303), a las rigideces de la demanda, y a la subida de los costes de producción. Esta etapa coincide con un agotamiento relativo de los caladeros situados frente a las costas del Cantábrico y Galicia, lo que dio lugar a la búsqueda de nuevas áreas de pesca con mayor poder de captura. Como consecuencia, parte de la flota de arrastre se desplazó hacia el sur, a Sevilla, Algeciras, Huelva y, sobre todo, a Cádiz, para beneficiarse de su proximidad a los casi inexplotados caladeros de Marruecos y del Banco Canario-Sahariano ${ }^{61}$.

En el capítulo de los costes, hasta los años veinte el precio del carbón no había constituido una preocupación para el sector pesquero gallego, excepto en coyunturas excepcionales como la de la guerra. Pero el coste de adquisición del carbón a principios de los años veinte comenzó a figurar de nuevo como la primera partida de gasto de las empresas pesqueras. Esto provocó que los armadores buscasen formas alternativas de abastecimiento, de manera directa, prescindiendo de los intermediarios (Giráldez, 2002: 96; Giráldez, 1996: 322 y ss.). El carbón nacional era más caro y de menor calidad, restaba espacio en el barco para otros usos, tenía un menor poder calorífico, un menor rendimiento, tardaba más tiempo en alcanzar la presión necesaria para poner en marcha las máquinas, y tenía una mayor proporción de menudos, lo que averiaba las máquinas ${ }^{62}$.

\footnotetext{
60 Hacia los años treinta estaba plenamente consolidado, habiéndose abandonado prácticamente el transporte ferroviario. Consejo de Industria, Apuntes para el momento de la industria española de 1930. Coruña, Madrid, s.f. (c. 1932). Estudio realizado para conocer las causas del decrecimiento mercantil de La Coruña, La Coruña, COCINC, 1935, p. 5.

61 Giráldez (1997a: 19; Eiroa, 1997: 72). El movimiento de armadores coruñeses hacia otros puertos, que se había iniciado durante la contienda europea y se consolidó en la posguerra y en los años veinte explica, en buena medida, la irregular evolución de la matrícula correspondiente a los buques pesqueros. La Lista Oficial de los Buques de Guerra y Mercantes de la Marina Española correspondiente a los años 1909 y 1914 muestra un crecimiento del número de buques de más de 100 TRB con respecto a principios del siglo. El número de unidades era de 14 en 1909 y 13 en 1914, con un tonelaje total de 2.412 y 2.321 tms respectivamente, cuando en 1900 apenas figuraban matriculados dos buques de estas características. Sin embargo, en 1922 sólo aparecía registrado un buque de menos de 100 TRB en A Coruña, mientras en 1925 se habían matriculado 9 buques entre 20 y 100 TRB y 5 de más de 100 TRB, con un tonelaje total de 1.205 tms. En 1930 aparecían 14 y 6 buques, respectivamente, con un tonelaje total de 2.455 tms. En 1935 y 1939 la cifra se estabilizó en 11 buques de más de 100 TRB. Se ha podido constatar un desplazamiento muy numeroso de armadores y buques hacia otros distritos marítimos, principalmente hacia San Sebastián y hacia el sur del país.

62 ACTAS Pleno COCINC, 1927. En los años treinta el problema de la calidad del carbón no sólo no se había resuelto, sino que se había agudizado. Industrias Pesqueras, 1 de febrero de 1932.
} 
El momento más delicado se vivió en los años centrales de la década. La crisis tocó fondo en 1923, cuando se registraron las cifras más bajas de producción del período. La disminución afectó principalmente a la sardina, que desapareció de las costas en 191724 (Romaní, 1981: 103). Pero las especies de arrastre también sufrieron un retroceso, provocando una de las mayores crisis del puerto. El volumen de capturas permaneció prácticamente estancado hasta 1927. La crisis no comenzó a remontar el vuelo hasta finales de los años veinte.

El tráfico portuario experimentó asimismo una desaceleración en su ritmo de crecimiento en el año 1919, que fue seguido de una intensa caída en 1920, siguiendo el ritmo de la crisis económica internacional y nacional (Gráfico 2.5). Esta caída fue probablemente la reacción al auge coyuntural inmediatamente posterior a la guerra vivido por Europa. El posterior crecimiento de 1921 estuvo, en cambio, muy condicionado por el aumento de los embarques de carbón mineral con destino a la flota pesquera coruñesa.

\subsection{Estructura de las actividades comerciales}

\subsubsection{La importancia de las actividades de consumo básico}

El tejido comercial se caracterizaba por un cierto dualismo. Coexistían elementos innovadores con otros tradicionales, pues el sector estaba dotado de unos bajos niveles de modernización (un fenómeno común a muchas ciudades españolas), y se caracterizaba por una acentuada fragmentación en un elevado número de pequeños establecimientos. Existía un destacado número de pequeñas tiendas, dedicadas a la venta de productos de elaboración propia (alimentación, textiles, maderas, etc.). Los negocios eran principalmente de tipo familiar y, en algunos casos, atendían diferentes tipos de demandas, si bien predominaban los de carácter univalente. El resultado era la reducida dimensión de los establecimientos comerciales, algunos de los cuales incluso formaban parte de la vivienda, ubicándose en la parte baja de los inmuebles. Por tanto, A Coruña seguía un modelo que en Europa occidental se había comenzado a abandonar en el siglo XIX, cuando se desencadenó la "revolución en la distribución comercial" 63 .

Al hablar de las actividades comerciales es necesario separar los sectores de consumo básico del resto, ya que alimentación y textiles suponían aproximadamente la mitad del comercio coruñés. Este es un aspecto común al aparato comercial de la mayoría de ciudades españolas, y resulta muy similar a otros patrones de comportamiento detectados en numerosas ciudades occidentales.

La primacía de ambos sectores constituye un primer rasgo estructural del comercio coruñés. Ambos conjuntamente representaban en 1914 alrededor del 61\% de los contribuyentes y del 54\% de las cuotas. En varios sentidos, eran el arquetipo de la estructura comercial urbana, toda vez que ambos sectores experimentaron un descenso análogo al del conjunto de la economía local durante la guerra.

63 Jeffreys (1954: 6). Para Jeffreys, los cien años previos a 1914, y en particular el período 1875-1914 habían sido testigo de una transformación en la distribución, de la misma manera que los sectores manufactureros los habían presenciado en los cien años anteriores. 


\section{Cuadro 2.16. Distribución de las actividades comerciales, 1914-35 (porcentaje sobre contribuyentes).}

\begin{tabular}{|c|c|c|c|c|c|c|c|c|c|c|c|c|c|c|c|}
\hline $\begin{array}{c}\text { Ejercicio } \\
\text { fiscal* }\end{array}$ & 1914 & 1916 & 1917 & 1918 & 1919 & 1920 & 1921 & 1922 & 1923 & 1924 & 1927 & 1929 & 1931 & 1933 & 1935 \\
\hline (1) & 32,3 & 32,3 & 31,7 & 31,8 & 33,9 & 32,7 & 34,2 & 34,8 & 33,6 & 35,3 & 36,1 & 32,0 & 59,3 & 61,8 & 65,2 \\
\hline (2) & 28,9 & 29,1 & 26,6 & 27,2 & 26,0 & 27,1 & 26,9 & 25,3 & 26,3 & 28,1 & 27,1 & 27,4 & 10,1 & 11,2 & 9,0 \\
\hline (3) & 10,6 & 9,5 & 8,5 & 8,9 & 7,9 & 8,5 & 7,0 & 5,8 & 6,4 & 6,5 & 6,2 & 7,7 & 5,2 & 3,7 & 3,4 \\
\hline (4) & 8,4 & 8,8 & 7,8 & 7,2 & 7,6 & 7,3 & 8,5 & 9,8 & 9,2 & 11,6 & 9,5 & 13,3 & 5,6 & 4,8 & 5,3 \\
\hline (5) & 4,3 & 5,3 & 6,8 & 4,3 & 6,9 & 3,8 & 6,0 & 6,1 & 5,5 & 4,0 & 6,2 & 6,8 & 3,6 & 4,1 & 2,9 \\
\hline (6) & 3,7 & 3,5 & 4,1 & 4,3 & 3,9 & 3,2 & 3,5 & 4,0 & 4,6 & 5,6 & 2,5 & 1,9 & 2,9 & 1,2 & 1,9 \\
\hline (7) & 3,1 & 4,9 & 3,8 & 7,2 & 3,6 & 8,5 & 6,3 & 6,7 & 6,7 & 2,3 & 5,5 & 4,8 & 0,8 & 3,6 & 1,2 \\
\hline (8) & 3,1 & 3,2 & 3,8 & 2,3 & 2,6 & 3,2 & 2,8 & 2,4 & 3,1 & 2,1 & 2,2 & 2,4 & 3,7 & 3,3 & 2,4 \\
\hline (9) & 2,8 & 2,8 & 3,4 & 6,2 & 3,9 & 5,0 & 3,5 & 3,4 & 2,8 & 2,3 & 2,0 & 1,2 & 2,9 & 3,0 & 3,4 \\
\hline (10) & 2,8 & 0,7 & 3,4 & 0,7 & 3,6 & 0,9 & 1,3 & 1,8 & 1,8 & 2,1 & 2,7 & 2,4 & 6,0 & 3,2 & 5,3 \\
\hline Total & 100 & 100 & 100 & 100 & 100 & 100 & 100 & 100 & 100 & 100 & 100 & 100 & 100 & 100 & 100 \\
\hline
\end{tabular}

\section{Fuente: Elaboración propia en base a las Estadísticas de la Matrícula industrial. COCINC.}

Dentro del sector de la alimentación se han incluido los comerciantes que tenían relación de un modo u otro con el mismo en sentido amplio. Este sector actuó como el principal responsable del comportamiento general del comercio. En él concurrían tanto los pequeños negocios de venta al público (ultramarinos, pequeñas tiendas, etc.), como los comerciantes mayoristas, algunos de ellos exportadores. Eran negocios de tipo univalente, abundando los locales de comestibles. También proliferaba el comercio detallista dedicado a la venta de productos perecederos, sobre todo, las casas de ultramarinos. Eran tiendas de carácter familiar, en las que predominaba el trabajo familiar, con escaso predominio de la mano de obra asalariada.

Los establecimientos se encontraban deficientemente equipados y se organizaban de acuerdo a métodos distributivos poco económicos, con mínimos conocimientos técnicos, pues escaseaban los trabajadores especializados, directores, gerentes, etc., y muchos de los existentes carecían de una formación especializada. Ante la reducida escala de operaciones, la retribución del trabajo suponía uno de los costes más elevados, y esto puede explicar el predominio de la mano de obra familiar, para intentar alcanzar una mayor rentabilidad. Aunque los rasgos citados eran extensibles al conjunto del comercio, resultaban algo más acusados en el sector de la alimentación. 
El resultado eran unas instalaciones en muchos casos escasamente dotadas, lo que disminuía las posibilidades derivadas de la adquisición de grandes volúmenes de mercancías y restringía la renovación de stocks, el nivel óptimo de almacén, el surtido de productos, etc. Los establecimientos se veían perjudicados, además, por el reducido nivel de financiación, lo que entorpecía el camino hacia la renovación de las mercancías y del negocio. Otra consecuencia era, en ocasiones, la dificultad para alcanzar unos umbrales mínimos de venta que permitiesen a los establecimientos seguir en actividad.

\section{Cuadro 2.17. Distribución de las actividades comerciales, 1914-35 (porcentaje sobre total de cuotas).}

\begin{tabular}{ccccccccccccccccccc}
\hline $\begin{array}{c}\text { Ejercicio } \\
\text { fiscal }\end{array}$ & $\mathbf{1 9 1 4}$ & $\mathbf{1 9 1 6}$ & $\mathbf{1 9 1 7}$ & $\mathbf{1 9 1 8}$ & $\mathbf{1 9 1 9}$ & $\mathbf{1 9 2 0}$ & $\mathbf{1 9 2 1}$ & $\mathbf{1 9 2 2}$ & $\mathbf{1 9 2 3}$ & $\mathbf{1 9 2 4}$ & $\mathbf{1 9 2 7}$ & $\mathbf{1 9 2 9}$ & $\mathbf{1 9 3 1}$ & $\mathbf{1 9 3 3}$ & $\mathbf{1 9 3 5}$ \\
\hline$(1)$ & 28,7 & 29,0 & 26,8 & 29,9 & 29,9 & 30,6 & 29,1 & 29,7 & 29,5 & 24,5 & 31,0 & 23,8 & 37,1 & 42,0 & 40,8 \\
\hline$(2)$ & 25,1 & 28,8 & 25,4 & 26,0 & 23,7 & 27,3 & 27,2 & 27,0 & 27,2 & 25,4 & 27,9 & 29,9 & 18,4 & 20,8 & 17,4 \\
\hline$(3)$ & 13,5 & 13,9 & 11,3 & 13,1 & 11,5 & 12,1 & 11,4 & 9,4 & 9,2 & 8,1 & 7,2 & 10,2 & 6,7 & 5,6 & 5,5 \\
\hline$(4)$ & 8,5 & 8,8 & 8,2 & 8,2 & 7,9 & 8,2 & 10,5 & 12,5 & 12,2 & 13,9 & 14,0 & 18,0 & 14,2 & 12,9 & 14,5 \\
\hline$(5)$ & 4,6 & 6,6 & 5,3 & 5,6 & 4,8 & 4,4 & 6,1 & 6,1 & 4,8 & 5,2 & 6,2 & 7,5 & 4,0 & 6,1 & 3,3 \\
\hline$(6)$ & 4,1 & 4,9 & 4,9 & 5,4 & 4,7 & 4,5 & 5,0 & 4,7 & 6,7 & 3,5 & 3,5 & 1,4 & 2,1 & 3,3 & 2,9 \\
\hline$(7)$ & 3,2 & 4,3 & 5,7 & 7,0 & 6,5 & 7,8 & 5,4 & 5,6 & 5,5 & 3,7 & 4,8 & 4,0 & 3,3 & 3,6 & 2,8 \\
\hline$(8)$ & 1,8 & 1,3 & 2,1 & 1,6 & 1,6 & 2,0 & 2,1 & 1,8 & 2,5 & 1,4 & 1,9 & 2,0 & 3,5 & 3,0 & 2,3 \\
\hline$(9)$ & 1,6 & 1,9 & 1,9 & 2,8 & 2,2 & 2,4 & 2,2 & 2,2 & 1,6 & 1,3 & 1,2 & 0,8 & 1,1 & 1,1 & 1,4 \\
\hline$(10)$ & 6,3 & 0,5 & 5,3 & 0,4 & 4,8 & 0,6 & 0,9 & 0,9 & 0,9 & 9,5 & 2,4 & 2,3 & 9,6 & 1,7 & 9,2 \\
\hline Total & 100 & 100 & 100 & 100 & 100 & 100 & 100 & 100 & 100 & 100 & 100 & 100 & 100 & 100 & 100 \\
\hline \hline
\end{tabular}

Fuente: Elaboración propia en base a las Estadísticas de la Matrícula industrial. COCINC.

Por su parte, en los mercados alimentarios era característico el predominio de los canales tradicionales entre el mayorista y el minorista. Éste era el canal más habitual para la circulación de mercancías dentro del sistema de distribución comercial español, al menos en las principales áreas urbanas (Casares y Briz, 1987: 96). No faltaban en A Coruña tampoco otros establecimientos, como los de carácter cooperativo ${ }^{64}$, o ciertas clases de almacenes cuya finalidad era la atención de las necesidades de determinados

\footnotetext{
64 Tal es el caso de la Cooperativa Militar y Civil, constituida en 1891, empresa cuyo objeto social era proveer el sostenimiento de sus asociados, así como a la tropa de mar y tierra, hospitales militares y otros centros o asilos benéficos. Y la Cooperativa Industrial Coruñesa, S.A., dedicada a la producción y consumo. Anuario de Sociedades Anónimas. Estudio económico-financiero de las existentes en España (Anuario Garci-Ceballos), Madrid, Año I, 1918-1919, ed. de Ilustración Financiera. También existían algunos establecimientos creados por las organizaciones obreras, en especial las católicas.
} 
sectores de la población (economatos), si bien se hallaban en una fase todavía muy embrionaria y tenían escasa importancia cuantitativa y cualitativa.

En Galicia, el comportamiento del sector agrario resulta inseparable de la evolución económica urbana, por actuar tanto como mercado para los productos elaborados en la ciudad o canalizados a través de ella, como por operar como oferente de mercancías para el mercado urbano y para su comercialización hacia el exterior. Con anterioridad a la guerra, los comerciantes del sector alimenticio habían vivido una fase próspera, como consecuencia del auge de las exportaciones hacia el mercado peninsular y hacia el exterior (ganado, pesca y otros diferentes productos).

La guerra brindó una excelente oportunidad al sector pecuario regional, caracterizado por una fuerte orientación hacia el mercado extraregional. El crecimiento fue especialmente destacado en el segmento más importante, el ganado vacuno, como resultado del incremento de la demanda de carne, especialmente en las grandes ciudades españolas, y la consiguiente subida de los precios (Barreiro Gil, 1990: 88-91). Esta expansión siguió en paralelo (en relación de causa-efecto) al crecimiento y transformación de la agricultura gallega (Martínez López, 2000a).

Por otra parte, A Coruña era el centro comercial de su hinterland, con un radio de influencia que se extendía hacia el embrión de la futura área metropolitana. En el caso del comercio cotidiano, la influencia se limitaba al área urbana consolidada y al perímetro suburbano (Carré, 1929). El crecimiento de la demanda asociado al crecimiento del mercado urbano fue indudablemente un factor clave del crecimiento de este tipo de funciones comerciales. Pero dado que este subsector también incluía actividades no cotidianas, el área de influencia seguramente se extendía hacia las comarcas próximas a la ciudad, e incluso para determinadas actividades comerciales de carácter especializado es probable que su influencia abarcase buena parte de la provincia.

Después de la guerra, se aprecian algunos signos de recuperación del subsector. En los casos de las empresas que tributaban por utilidades, se puede observar una mejoría de sus cuentas. Empresas como López y Sánchez, Hijos de Benito Ares, Sastre y Cía., Gran Café Méndez Núñez, S.A., etc. así lo atestiguan ${ }^{65}$.

En primer lugar, el tráfico portuario volvió a desenvolverse con una cierta continuidad y esto repercutió favorablemente en los negocios alimenticios, aunque algo menos en los textiles. Empresas como Pérez Hermanos, dedicada a la compraventa de tejidos desde 1915 tuvieron en 1920 unos beneficios de 19.045,5 pts. sobre un capital de 20.000 pts.; en 1921 los beneficios fueron de 25.575,4 pts., en 1922 de 22.564,9 y en 1923 de 21.936,3 pts., en la línea de lo ocurrido con Baamonde Hermanos ${ }^{66}$. En cambio, sociedades como A. Ansede y Cía. sufrieron pérdidas en los primeros años veinte.

\footnotetext{
$\overline{65}$ Los beneficios de López y Sánchez pasaron de 97.351,3 pts. en 1920 a $61.173,8$ en 1921, 56.318,9 en 1922 y $64.220,0$ en 1923, con una rentabilidad sobre el capital entre el 14,5 y el 25\%. El Gran Café Méndez Núñez, de tener pérdidas en 1918 y 1919 pasó a unos beneficios de 26.092,4 pts. en 1920, 21.109,0 en $1921,25.547,0$ en 1922 y 33.532,79 en 1923. Algo similar le ocurrió a la sociedad La Terraza, S.A. ARG-DHC (Hacienda). Utilidades. Libros 4.541-4.545.

66 Tras una leve caída en 1924, los beneficios de Pérez Hermanos continuaron creciendo hasta 1925-27. En cambio, Baamonde Hermanos mantuvo una tendencia de beneficios decrecientes hasta 1926.
} 
Por otro lado, la situación comenzó a ser de normalidad para la población urbana desde el punto de vista de los mercados. Algunas industrias de alimentación experimentaron incluso un auge exportador tras la guerra, caso de la industria conservera ${ }^{67}$. Es algo sintomático de la naturaleza de la recuperación, porque la mayoría de los negocios de este sector aumentaron en número, si bien destaca por su trascendencia el comportamiento positivo de los mayoristas y comerciantes especializados en el tráfico exterior, incluida la pesca, como actividad prioritaria.

En los textiles concurrían circunstancias muy similares. Una fracción significativa pertenecía a la categoría de sastres, modistas, etc. Es decir, establecimientos regentados por profesionales y artesanos, que combinaban la venta con la elaboración de artículos. Pero existía un numeroso grupo de casas de venta de tejidos al por mayor y al por menor (especialmente estos últimos), que forzosamente debían adquirir sus productos fuera de la ciudad, al no existir en esos años una industria textil consolidada.

Por tanto, se podían distinguir dos grupos de actividades mercantiles. Por un lado, los minoristas y pequeños negocios, cuyo crecimiento estaba relacionado con la propia dinámica interna de la ciudad. Su evolución iba unida a la demanda que generaba la población urbana, y la relación que mantenía con el exterior dependía fundamentalmente del abastecimiento de productos. Un segundo grupo, por el contrario, dependía directamente de la evolución de sus negocios mercantiles con el exterior, y los trastornos que generó la guerra les afectaron profundamente.

\subsubsection{El desigual comportamiento de las restantes actividades comerciales urbanas}

El resto de actividades comerciales tenía una presencia y una trascendencia menores. No obstante, algunas contaban con una cierta tradición en la ciudad. Es el caso de los establecimientos de venta de madera y muebles, productos químicos, productos metalúrgicos, curtidos o combustibles. La mayor parte de ellos obtenía las mercancías a través del tráfico portuario con el extranjero, aunque existían excepciones, como la curtición, de producción autóctona (Fernández Vázquez, 2002).

La importancia del grupo de ferretería, hierros y similares se debe a la inclusión de negocios heterogéneos. Este grupo sufrió los efectos de la guerra, debido a la paralización del tráfico con el exterior y de cabotaje, principal vía de suministro de mercancías para estos establecimientos. Entre sus actividades más destacadas, sobresalía la venta de hierros y otros enseres, artículos de ferretería o instrumentos (óptica, cirugía, velocípedos, etc.). El descenso afectó a todas las actividades más o menos por igual, si bien algo más a las que tenían dificultades para abastecerse fuera de la ciudad. Su caída, no obstante, no fue excesivamente pronunciada, como no lo fue en la mayoría de los sectores que se analizan en este epígrafe, pues el descenso del tráfico de las mercancías que integraban sus catálogos no fue tan pronunciado como en los sectores básicos.

La joyería gozaba de una cierta tradición en nuestra ciudad. La guerra no le favoreció a causa de que los materiales para su trabajo y buena parte de los productos finales se obtenían en el extranjero. Por tanto, el retraimiento comercial le fue claramente perjudicial.

67 En 1919 exportó por valor de 16 millones de pts., una cifra superior a la de los años precedentes (Fernández Santander, 1987: 93). 
El comportamiento del sector de productos químicos resulta llamativo. En conjunto, experimentó un crecimiento durante la guerra, a pesar de las dificultades para el aprovisionamiento externo de combustibles como el carbón mineral. Sin embargo, este período de escasez fue aprovechado para consolidar el proceso de transición de las fuentes de energía en la ciudad. Gracias a la situación de desabastecimiento, en algunos usos industriales y en el transporte marítimo se comenzó a sustituir carbón por petróleo, y la nueva estructura de la demanda dio paso al naciente sector coruñés de la producción de energía eléctrica ${ }^{68}$.

Los curtidos atravesaron una fase de decadencia durante el siglo XX, tanto a nivel industrial como comercial, que será descrita más adelante, debido a que el comienzo del hundimiento del sector corresponde a los años veinte y treinta. Por su parte, el sector de la madera tradicionalmente tuvo una importancia considerable en la economía gallega, y esto dio lugar a efectos de arrastre sobre la economía urbana. En los años iniciales del siglo XX, la industria maderera recibió un importante impulso, lo que repercutió en los establecimientos de venta de estos productos. En conjunto, el sector no se vio excesivamente perjudicado por la guerra, pues los mercados se encontraban principalmente en el área metropolitana.

Finalmente, los establecimientos de librerías, papelerías y similares constituían un sector secundario, de muy escasa importancia a comienzos del período analizado, que resultó muy perjudicado por la coyuntura bélica. El más afectado fue el subsector del libro y del papel, que afrontó graves dificultades mercantiles, ante la imposibilidad de importar papel, tintas, caracteres de imprenta, etc., y ante el aumento del precio de la pasta de papel. Los que tenían que importar esos artículos atravesaron una situación crítica, mientras que los que se abastecían por medio de productores nacionales (guipuzcoanos), mantuvieron mejores perspectivas (IRS, 1914). Una vez finalizada la contienda, los resultados empresariales de estas sociedades mejoraron notablemente ${ }^{69}$.

\subsection{La primacía de las actividades minoristas}

Las empresas dedicadas al comercio al por menor ostentaban una posición preeminente en A Coruña. En 1914 había 144 empresarios minoristas matriculados, es decir, un $44,7 \%$ de los comerciantes. Las diferencias en cuanto a lo que pagaba cada establecimiento eran menores. De hecho, el comercio al por mayor tenía mayor peso, ya que representaba el 43,8\% del comercio, mientras el minorista sólo suponía un 31,1\%. Esto era consecuencia de la diferente escala de negocio de uno y otro tipo de empresa.

Los canales de distribución permitían la existencia de este tipo de estructura, debido a la escasa complejidad que por entonces caracterizaba al aparato comercial: predominio de circuitos de relaciones simples entre productor, mayorista y detallista, aunque existían también canales de venta directa entre productor y consumidor, con la

\footnotetext{
68 Los establecimientos dedicados a las instalaciones eléctricas y a la venta de materiales relacionados con las mismas también experimentaron un crecimiento. Además, en general, mantuvieron una dinámica empresarial positiva, caso de F. Ricoy y Cía., que obtuvo beneficios durante la totalidad del período bélico. ARG-DHC (Hacienda). Utilidades. Libros 4.535-4.541.

69 Es el caso de la S.R.C. Zincke Hermanos, cuyos beneficios se recuperaron tras la guerra, siendo de $8.908,7$ pts. en $1920,9.918,5$ en 1921 y $9.825,6$ en 1922 , con una rentabilidad sobre el capital en torno al 9-10\%. ARG-DHC (Hacienda). Utilidades. Libros 4.541-4.545.
} 
única intermediación del minorista, incluso eliminando completamente los intermediarios, ya que las fábricas y talleres vendían directamente al consumidor.

En cualquier caso, la evolución temporal de ambas formas de comercio fue opuesta. En las épocas de relativo estancamiento, como la guerra mundial, el comercio minorista experimentó una caída, en valores absolutos y relativos, respecto al comercio mayorista y respecto al resto de actividades comerciales. En cambio, el comercio mayorista evolucionó de manera más positiva, gracias a su mayor capacidad de respuesta frente a las dificultades mercantiles, y a las ventajas derivadas de la subida de los precios de los productos. Los comerciantes mayoristas contaban con mayores recursos financieros para hacer frente a necesidades puntuales de capital circulante. Además, tenían la posibilidad de almacenar los productos, en caso de caída de las ventas. Disponían asimismo de un mayor nivel de información, lo que facilitaba la adopción de estrategias acordes a la situación de los mercados. Finalmente, su capacidad de manipulación y tipificación de los productos era mayor que la de los comerciantes minoristas, lo que les permitía influir sobre el comportamiento de la demanda.

Por tanto, el rasgo más sobresaliente del comercio coruñés de las primeras décadas del siglo XX era su acusado minifundismo, una característica, sin embargo, aplicable a otras ciudades españolas (Nielfa, 1989). El número de comerciantes minoristas se multiplicó y expandió por toda la ciudad, con el fin de atender las necesidades de una población en aumento que, además, crecía en varias direcciones (Mirás, 2007).

\section{El SECTOR SERVICIOS}

\subsection{Análisis de las actividades de servicios y factores caracterizadores}

Las actividades de servicios tenían una gran importancia en A Coruña. Durante el primer tercio del siglo este sector se situó por encima de la industria y de las actividades artesanales, individualmente consideradas, excepto en el año 1917, en el que las cuotas fueron similares a las de la industria. Por el contrario, los matriculados dentro de las actividades industriales representaban un porcentaje mayor que los servicios ${ }^{70}$.

Los factores explicativos del predominio del terciario son complejos, aunque algunos de ellos han sido identificados en análisis históricos de otras ciudades. Además de las funciones burocráticas, administrativas, militares, etc., uno de los elementos clave en el progreso del terciario era el movimiento de población, en el que el puerto era un agente esencial. La significación del fenómeno migratorio para la ciudad estaba relacionada con las coyunturas que atravesó la emigración gallega. Por ello, las etapas evolutivas que siguió la emigración han tenido una gran influencia sobre el sector (Gráfico 2.15).

En A Coruña, la burguesía trató de aprovechar el intenso flujo migratorio que experimentó Galicia desde mediados del XIX (Vázquez González, 2000a, b). Por tanto, se trata de un factor de largo recorrido, sobradamente asentado en la economía urbana en los primeros años del siglo XX. Durante el período 1880-1920 cada año partía una media de 30.000 personas desde los puertos de Vigo y de A Coruña con destino a

70 Para un tratamiento en profundidad de la evolución del sector servicios en A Coruña durante el primer tercio del siglo XX, vid. Mirás (2005c). 
América (Losada, 1995: 53). Las compañías de comisión y consignación de buques tuvieron también un auge importante en Vigo, aprovechando la coyuntura de la guerra mundial para obtener elevados beneficios (Souto, 1990: 54).

Gráfico 2.15. Número de pasajeros en tránsito

por el puerto de A Coruña, 1900-36.

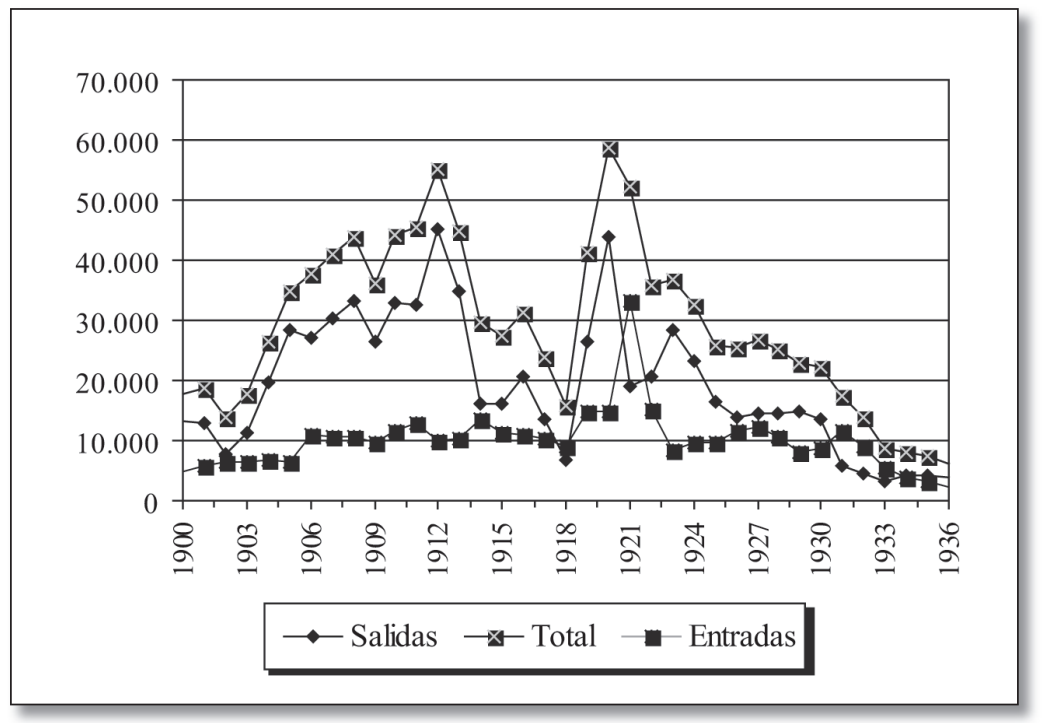

Fuente: Hasta 1909, Brey (1989: 901). Para 1911-15, "El puerto de La Coruña", Comercio, Industria y Navegación. Revista de los Intereses Económicos de La Coruña, año 1, no 1, 1924, p. vi. A partir de 1916, Memorias de la Junta de Obras del Puerto de La Coruña.

Las provincias gallegas proporcionaban los contingentes más importantes de emigrantes del país. Merced a ello, el hinterland migratorio del puerto de A Coruña era probablemente el más extenso dentro de los puertos gallegos, y uno de los más importantes del país (Vázquez González, 2000a: 638) Según una estimación realizada por San Vicente (1954), basándose en un criterio extrapolable a esta época (las distancias kilométricas por carretera), este hinterland abarcaba la totalidad de la provincia de A Coruña, la mayor parte de la de Lugo (con la posible excepción de los partidos de Monforte de Lemos, Chantada y Quiroga), la parte occidental de Asturias y el noroeste de León (Cuadro 2.18).

Durante los primeros años del siglo, los efectos sobre la ciudad fueron especialmente notorios, debido a que a través del puerto embarcó el mayor contingente de población, no sólo de emigración gallega, sino también española. En vísperas de la guerra mundial, el tirón emigratorio estaba siendo aprovechado por un número creciente de compañías navieras, con la intención de penetrar en el tráfico que partía desde Galicia, de modo que poco antes de 1910 la mayoría de las grandes navieras europeas que unían la fachada occidental europea con destinos antillanos y sudamericanos realizaba escalas regulares en los puertos gallegos (Vázquez González, 2000a: 811). El número de consignatarios se había incrementado con el aumento 
de la demanda de pasajes, penetrando la mayoría de ellos de la mano de empresas navieras extranjeras. La década de 1910 fue la época culminante del número de navieras que realizaban escalas en puertos de Galicia. Algunas firmas consignatarias ampliaron su negocio estableciendo sucursales en otros puertos gallegos, e incluso fuera de Galicia.

Cuadro 2.18. Hinterland de los puertos de A Coruña y de Vigo.

\begin{tabular}{|c|c|c|}
\hline Hinterland del puerto de A Coruña & $\begin{array}{l}\text { Superficie } \\
\mathbf{K m}^{2}\end{array}$ & Población* \\
\hline Provincia de A Coruña & 7.903 & 964.095 \\
\hline $\begin{array}{l}\text { Provincia de Lugo (excluidas Chantada, } \\
\text { Monforte de Lemos y Quiroga) }\end{array}$ & 7.486 & 371.599 \\
\hline $\begin{array}{l}\text { Provincia de Oviedo (Castropol, Luarca, Tineo, } \\
\text { Pravia, Avilés, Belmonte y Cangas del Narcea) }\end{array}$ & 5.462 & 278.547 \\
\hline $\begin{array}{l}\text { Provincia de León (Villafranca del Bierzo, Ponferrada, } \\
\text { Astorga, Murias de Paredes, La Bañeza) }\end{array}$ & 8.385 & 290.796 \\
\hline Total & 29.236 & 1.905 .037 \\
\hline \multicolumn{3}{|l|}{ Hinterland del puerto de Vigo } \\
\hline Provincia de Pontevedra & 4.330 & 679.325 \\
\hline Provincia de Ourense & 6.979 & 471.671 \\
\hline Total & 11.309 & 1.150 .996 \\
\hline \multicolumn{3}{|l|}{ Influencia común de ambos puertos } \\
\hline Provincia de Lugo (Chantada, Monforte y Quiroga) & 2.495 & 141.641 \\
\hline
\end{tabular}

Fuente: San Vicente (1954: 12).

Sin embargo, la guerra europea supuso un retroceso para la cifras de emigración exterior gallegas, que incluso arrojaron un superávit en el año 1916, como consecuencia de las dificultades de la navegación marítima provocadas por el desencadenamiento de la guerra submarina por parte de Alemania, y por la delicada situación económica de algunas naciones latinoamericanas, particularmente Argentina y México ${ }^{71}$. Las cifras absolutas de pasajeros embarcados presentan una tendencia de descenso continuado en 1913-18, aunque ésta sea menos pronunciada que en el conjunto de España. Por tanto, se combinaron dos elementos. Por un lado, la persistencia de las dificultades económicas regionales, en especial en el sector agrario. El impacto macroeconómico de la guerra no fue suficiente para dinamizar la economía regional, si lo comparamos

71 Diplomatic and Consular Reports. Spain. Report for the Year 1914 on the Trade and Industries of the Consular District of Corunna (comprising the provinces of the Asturias, Leon and Galicia), London, Foreign Office and the Board of Trade, 1916, Annual Series, nº 5.563 (by Mr. Consul Nightingale), p. 7. 
con lo ocurrido en otras áreas del país. Por otro lado, la ralentización relativa de dicho movimiento supuso un efecto negativo para los puertos migratorios gallegos.

Un segundo componente del desarrollo de los servicios fue el volumen de relaciones mercantiles con el exterior. Hasta la guerra, el tráfico se mantuvo en cotas elevadas. A partir de entonces, una fracción significativa de los consignatarios diversificó sus actividades empresariales, y se reorientó hacia la pesca y su posterior comercialización. Destacan los nombres de Del Río, Molina, Lamigueiro, Pérez Luengo, etc. (Barreiro Fernández, 1986). Este grupo de empresarios fue el que acometió la renovación de la flota pesquera coruñesa (Carmona, Giráldez y Muñoz, 2000: 70; Eiroa, 1997: 125-126). El más renombrado fue Luis Lamigueiro, propietario de la empresa Pescaderías Coruñesas, S.A., constituida en 1924.

\subsection{La crítica evolución de algunas actividades de servicios durante la guerra europea}

Parte de lo dicho para las actividades comerciales resulta aplicable al caso de los servicios. Durante la guerra, los servicios vivieron, en conjunto, un período crítico. Entre 1914 y 1917 se registró un importante descenso en el número de matriculados y una caída muy acusada en sus cuotas de contribución industrial. Esto revela que se trataba de un sector sensible a situaciones procedentes del contexto externo a la economía urbana.

El principal factor responsable del comportamiento regresivo fue nuevamente el descenso del movimiento que se registró en el puerto. Muchos de los empresarios del sector desempeñaban un porcentaje muy importante de sus negocios a través del puerto, a través de las actividades vinculadas al movimiento de personas, el tráfico pesquero o el movimiento de mercancías en general. Otros, sin estar directamente vinculados con aquél, lo estaban indirectamente por la demanda que este flujo comercial creaba en la ciudad.

En primer lugar, se advierte una ralentización de determinados negocios marítimos, sobre todo los relacionados con la pesca. Hacia 1916 se abrió el momento más acusado de crisis del sector, observándose un descenso en el tonelaje de registro bruto matriculado en la ciudad. Las razones ya se apuntaron, y estaban en relación con el aumento del coste de los inputs. La caída del tonelaje registrado, la disminución del ritmo de actividad de la flota pesquera, así como la negativa incidencia que esta crisis tuvo sobre determinadas industrias que controlaban ciertos segmentos empresariales implicados en los negocios marítimos, afectaron negativamente a los principales servicios.

En segundo lugar, la guerra acarreó graves dificultades al transporte de mercancías. Muchas empresas navieras españolas amasaron grandes beneficios, como consecuencia del espectacular alza de los fletes ${ }^{72}$. No obstante, en A Coruña el negocio mayoritario era el de las casas de representación. A principios de los años veinte, la Cámara de Comercio aseguraba que las empresas navieras no tenían otro motivo de atracción más que la emigración, lo que resultaba sintomático de la pobreza de actividades internacionales.

72 Las Cámaras de Comercio. Labor de la de La Coruña hasta fin de 1923, La Coruña, COCINC, 1924, p. 129. 
Durante la guerra, debido a la neutralidad española y a la drástica reducción del número de compañías extranjeras operativas, la proporción de buques de bandera española aumentó sustancialmente. Con todo, el movimiento de buques por los puertos gallegos se redujo fuertemente, contribuyendo a dificultar las exportaciones y los negocios vinculados con estos movimientos (Vázquez González, 2001: 4-7, 21-22; González Laxe et al., 1999: 28). De hecho, gran parte de las compañías de los países beligerantes interrumpieron sus líneas, sobre todo en los años 1917-18.

En tercer lugar, la guerra constituyó una de las épocas de mayor descenso de la emigración gallega. La causa radicó en la disminución de la capacidad de absorción de mano de obra de los países latinoamericanos, debido a que el conflicto ocasionó una notable reducción de la exportación de capitales europeos y del comercio mundial (Vázquez González, 1992: 81). El movimiento de pasajeros con el resto de Europa también registró un retraimiento, aunque éste representase un porcentaje muy bajo de la emigración regional.

Una vez finalizada la guerra, el sector servicios superó la crisis con mayor velocidad que los restantes sectores. Las razones de su recuperación radicaron en el cambio de signo de los factores que motivaron su caída durante la guerra. $\mathrm{Y}$ en ello tuvo una notoria incidencia el crecimiento del movimiento portuario en sus distintas categorías. Por tanto, el sector servicios presenta un rasgo específico, que lo distingue de los demás: la constatación de que en períodos de estancamiento o recesión sufría una paralización más pronunciada. Sin embargo, cuando la coyuntura era favorable para los demás sectores, los servicios se colocaban a la cabeza de la actividad económica local ${ }^{73}$.

Al acabar la guerra, la situación se fue normalizando paulatinamente. Las empresas de consignación y representación recuperaron la tendencia ascendente de sus resultados empresariales ${ }^{74}$. Los años que siguieron a la guerra constituyeron una etapa de comportamiento irregular del tráfico portuario, que hubieron de soportar especialmente aquellas naciones con economías marítimas muy desarrolladas, como Gran Bretaña (Aldcroft, 1961). Tras la guerra, se produjo una crisis marítima, que no afectó inicialmente a España, en donde el tonelaje de la flota creció levemente hasta 1922, mientras en los países europeos ocurría lo contrario, al haberse visto afectados por la guerra submarina. En cambio, éstos se recuperaron rápidamente, mientras España disminuía su tonelaje en 1923. Por su parte, el tráfico mercantil total en A Coruña creció un 32,3\% entre 1918-23, aunque ello esconda importantes fluctuaciones.

Una vez más, se constata que la evolución de la serie de tráfico mercantil portuario dependía de manera creciente de la entrada de mercancías, tanto vía exterior como,

\footnotetext{
73 Existen diversas referencias teóricas que avalan comportamientos similares en las economías occidentales. Vid. Daniels (1991), Britton (1991), Gemmell y Wardley (1990).

74 Rubine e Hijos, Nicandro Fariña o Antonio Vega y Cía. presentan beneficios, aunque la serie es demasiado corta para poder extraer unas conclusiones fiables. En cambio, para Herce y Cía. sí se dispone de más información, y pasaron de 80.400,3 pts. de beneficio en 1920 a 54.689,8 en 1921, 67.746,8 en 1922 y $77.796,1$ en 1923, con una rentabilidad sobre su capital social (de 500.000 pts.) que osciló entre el 10,9 y el 16,1\%. Asimismo, para la sociedad Sobrinos de José Pastor, aunque no ha sido posible diferenciar los resultados de sus actividades de consignación de las restantes actividades económicas (banca, comercio), los beneficios se incrementaron desde las 180.121,6 pts. de 1920, a 690.668,4 en 1921, 771.696,2 en 1922 y $326.717,9$ en 1923, y su rentabilidad sobre capital del 18,0\% al 77,2\%. ARG-DHC (Hacienda). Utilidades. Libros 4.541-4.545.
} 
especialmente, cabotaje, pues el porcentaje de descargas sobre el total del movimiento mercantil pasó del 52,1\% en 1918 al 61,5\% en 1923 (Gráfico 2.16). A partir de ese momento, y hasta la Guerra Civil, esta proporción se mantuvo estable, casi siempre por encima del $65 \%$.

Gráfico 2.16. Porcentaje de descargas respecto al tráfico mercantil total del puerto de A Coruña, 1904-36.

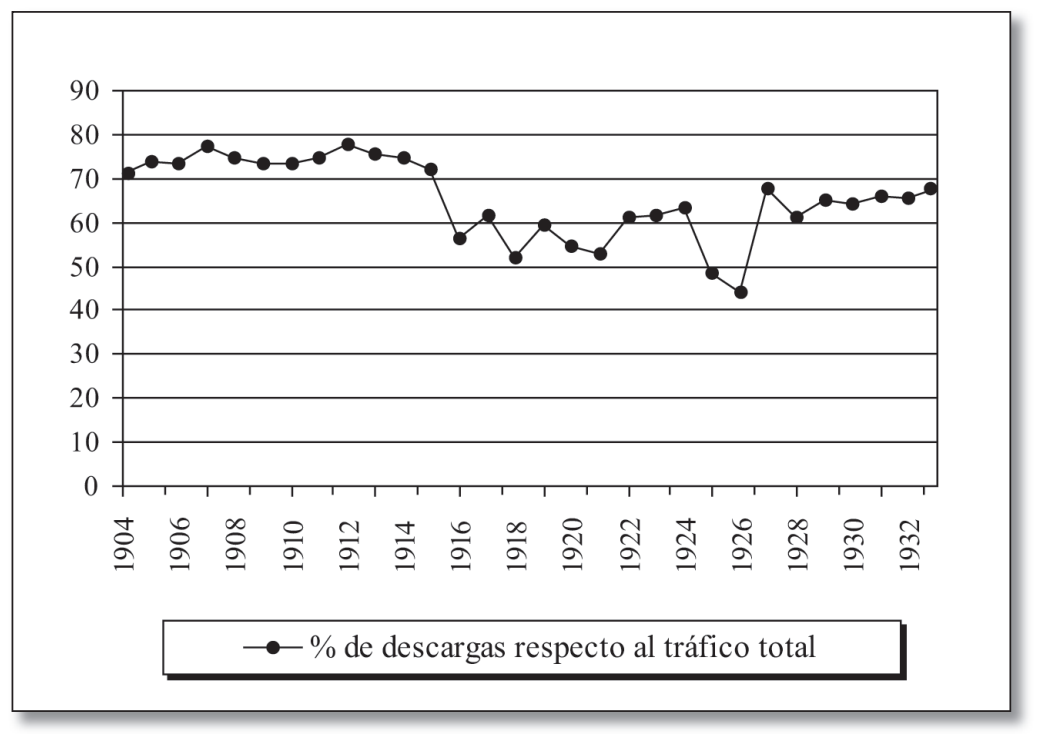

Fuente: Para 1904-15, Valcárcel (1923). Para 1916-39, Memorias de la Junta de Obras del Puerto de La Coruña. No incluye el tráfico pesquero.

Estos datos demuestran que la guerra únicamente significó un paréntesis en el comportamiento histórico del puerto coruñés, pues los porcentajes oscilaban entre el 71-75\% antes de la guerra, mientras que en 1918 llegaron a disminuir hasta el 52,1\%. Por tanto, puede parecer, a simple vista, que el conflicto tuvo efectos positivos sobre las exportaciones locales y regionales. Pero, siendo parcialmente cierto esto último, también lo es que el principal efecto de la contienda fue la reducción de las entradas de mercancías. De hecho, las dificultades del tráfico portuario tardaron un cierto tiempo en desaparecer, pues, incluso una vez rematada la contienda, el puerto mantuvo unos niveles bajos de actividad, en comparación con la situación prebélica.

Tras la guerra, la inclinación del puerto hacia el comercio de cabotaje exhibió un comportamiento alterado. El tráfico exterior (exportaciones e importaciones) representaba en 1916 el 9\% del tráfico total. La guerra originó un fuerte recorte de la importancia cuantitativa de este tipo de partidas. Sin embargo, a partir de 1919, aunque el porcentaje se recuperó parcialmente, apenas se movió en torno a un 3\% hasta 1923 . La lenta reconstrucción europeo-occidental dificultaba la vuelta a los patrones de preguerra. Pero lo más grave fue que el tráfico de cabotaje no consiguió situarse en 
unos niveles suficientemente elevados, si se tiene en cuenta que el cabotaje en España en los años veinte experimentó un fuerte crecimiento ${ }^{75}$.

A Coruña se estaba convirtiendo durante la posguerra en un puerto de tránsito local, un tipo de movimiento, en principio, de escasos efectos inducidos. El tráfico litoral, que en 1916 representaba el $62,1 \%$ de los embarques totales $(54,6 \%$ en 1917 , $36,2 \%$ en 1918 y $55,3 \%$ en 1919), había aumentado su peso, hasta situarse en el $65,1 \%$ en 1920 , el $81,6 \%$ en 1921 y el $82,0 \%$ en 1922 . Durante los años siguientes superó en varias ocasiones el $80 \%$. Por tanto, su especialización se concentró en el área próxima, y concretamente en determinadas partidas de una importancia creciente, como fueron los suministros de agua y carbón, con destino a la flota pesquera coruñesa. En consecuencia, el crecimiento posterior a la guerra mundial del tráfico portuario general no alcanzó a corregir suficientemente la debilidad estructural del puerto.

Por lo que respecta al tráfico de pasajeros, tras una fuerte caída en 1917, con un total de 23.961 pasajeros en tránsito, en 1918 se alcanzó un mínimo de 15.949 personas. Pero la tendencia cambió drásticamente tras la guerra. En 1919 se consignaron 41.217 pasajeros en tránsito, y en 1920 se alcanzó un máximo histórico de $58.577^{76}$. La emigración tuvo, como vimos, otras contrapartidas en forma de remesas de emigrantes, que permitieron consolidar la banca en la ciudad. Frente a la preponderancia del complejo industrial pesquero vigués, en A Coruña destacaba la influencia de la emigración, cuyos rendimientos se canalizaban hacia la inversión en valores de rentabilidad más elevada que hacia el simple ahorro, como el sector de la construcción o la banca como depositaria de valores (Arroyo, 1999: 163).

A pesar de que el grupo de los consignatarios tendió, desde las últimas décadas del siglo XIX, a un mayor grado de especialización en el sector de la consignación y el aprovisionamiento de buques, mantuvo también relaciones muy estrechas con otros sectores económicos no agrarios. En A Coruña gran parte de estos empresarios tuvieron una activa participación en la inversión directa en industrias y servicios públicos y, especialmente, a través de sus fuertes lazos con las principales casas de banca gallegas. Algunos de ellos tenían casas de banca propias o participaron en ellas: Narciso Obanza, Enrique Fraga, Raimundo Molina Couceiro, Martín de Carricarte, Eusebio da Guarda, Herce y Cía., Maristany Hnos., Rubine e Hijos, Pedro Barrié y Pastor (Sobrinos de José Pastor), Dionisio Tejero, etc. (Vázquez González, 2000a: 805). Cuando se constituyan las dos principales iniciativas bancarias en los años veinte, buena parte de esta burguesía marítima estará presente en su formación y en sus Consejos de Administración.

\footnotetext{
75 Valdaliso (1997). Las entradas y salidas de cabotaje cayeron un 47,5\% entre 1919 y 1923 (un 24,5\% de descenso con respecto al año 1917). Esto dio lugar a que el tráfico de cabotaje, que en 1916 representaba el 28,9\% del tráfico total en el puerto de A Coruña (41,1\% en 1917, 62,8\% en 1918 y 41,1\% en 1919, debido al efecto sustitución de los mercados y de los aprovisionamientos), pasase al 31,5\% en 1920 y descendiese al $16,8 \%$ en 1921 y al $14,7 \%$ en 1922 .

76 De nuevo, en 1921-23 la cifra de pasajeros disminuyó. Comparativamente, durante los años veinte, el puerto de A Coruña perdió posiciones, ya que registró un movimiento inferior al de Vigo, que durante esos años se movió entre los treinta y los setenta mil pasajeros totales (embarcados y desembarcados): $1918=9.655 ; 1919=34.847 ; 1920=67.316 ; 1921=51.187 ; 1922=44.705 ; 1923=52.327$. Memoria Comercial de la Cámara Oficial de Comercio, Industria y Navegación, Vigo, 1932. Esto consolidó una situación en la que el puerto vigués mantuvo una ventaja en torno a los veinte mil pasajeros más que el puerto de A Coruña durante la Dictadura de Primo de Rivera.
} 


\subsection{Estructura interna de las actividades de servicios}

El primer rasgo que sobresale dentro de las actividades de servicios era la numerosa presencia de empresarios dedicados a actividades de consignación, corredores de comercio, agentes de diversos tipos, etc. Su número era tan elevado que llegaban a totalizar el 50,7\% del sector, mientras que las cuotas que satisfacían alcanzaban el 67,2\%. Esto revela la extraordinaria importancia de este tipo de actividades y la magnitud de los negocios desempeñados por algunas de las personas matriculadas en la contribución industrial por este tipo de actividades.

Cuando estalló la guerra, el panorama cambió drásticamente para las actividades marítimas coruñesas. De hecho, el único subsector que experimentó una significativa caída fue el vinculado a la consignación y representación, las actividades de gestión, agencias, etc., precisamente los más conectados con el movimiento portuario y los que habían experimentado un mayor crecimiento en los años anteriores. Por tanto, fueron los responsables, casi en exclusiva, del descenso en conjunto del sector ${ }^{77}$.

Las siguientes actividades por su importancia numérica eran las de los transportes. El problema de los transportes terrestres en A Coruña se vio agravado durante la guerra. A la altura de 1915, y con mayor intensidad en 1916 y 1917, existía una grave escasez de material ferroviario, lo que perturbaba penosamente el transporte ferroviario gallego y español ${ }^{78}$. A finales de 1917 la Cámara de Comercio se quejaba ante el Ministerio de Fomento de que existía un peligro serio de que Galicia quedase incomunicada ferroviariamente durante el invierno ${ }^{79}$, problema que el transporte por carretera no podría haber suplido, dadas sus deficiencias ${ }^{80}$. Por este motivo, la Compañía de los Ferrocarriles del Norte recibió continuas quejas por lo inadecuado del material ferroviario, centrándose las reclamaciones en una mejoría de las condiciones en que se desarrollaba el transporte de dos partidas básicas, la pesca y el ganado. Con todo, algunas empresas privadas de transporte mantuvieron una trayectoria positiva ${ }^{81}$. Pero, en su conjunto, la caída del sector guardó relación, entre otros factores, también con la paralización de la actividad pesquera, pues se puede apreciar una disminución de los vapores en las estadísticas.

\footnotetext{
En cambio, las actividades de seguros y salvamentos marítimos experimentaron un crecimiento. Como ejemplo, la sociedad Barbeito, Rodríguez y Cía., que en 1915 sufrió pérdidas, pero durante 1916 y 1917 obtuvo unos beneficios de 98.887,4 pts. y 173.298,6. ARG-DHC (Hacienda). Utilidades. Libros 4.537-4.539. Fruto tal vez de la capitalización derivada de los riesgos de la navegación marítima durante la guerra nació en A Coruña, en 1919, la Asociación de Seguros Mutuos de Buques de Vela, S.A., dedicada al seguro de toda clase de buques veleros mayores de $50 \mathrm{tms}$, o con motor auxiliar, que cubrió los riesgos de un elevado número de buques. Anuario Garciceballos. Información de Sociedades Anónimas. Economía Nacional (1919-1920), Madrid, Año II, ed. de Ilustración Financiera, p. 300.

78 ACTAS Pleno COCINC. Boletín COCINC, $\mathrm{n}^{\mathrm{o}}$ 4, septiembre de 1916, p. 4. Boletín COCINC, $\mathrm{n}^{\circ} 6$, noviembre de 1916, p. 8.

79 ACTAS Pleno COCINC, 19 de noviembre de 1917.

80 Boletín COCINC, $\mathrm{n}^{\circ} 6$, noviembre de 1916, p. 9.

81 Es el caso de la empresa Automóviles Coruñeses, S.A., constituida en 1908, con un capital social de 350.000 pts., dedicada a la explotación de automóviles y al transporte de mercancías y viajeros desde A Coruña a Corcubión y Santiago, que entre 1913 y 1917 presenta una cuenta de resultados saneada, pues sus beneficios fueron de $12.641,4 ; 21.977,6 ; 17.864,6 ; 11.715,9$ y $11.573,5$ pts. (en 1918 tuvo pérdidas), con rentabilidades sobre el capital que oscilaron entre el 3,3\% y el 6,3\%. ARG-DHC (Hacienda). Utilidades. Libros 4.535-4.541.
} 
Cuadro 2.19. Distribución de los servicios, 1914-35 (porcentaje sobre total de contribuyentes).

Ejercicio fiscal*

191419161917191819191920192119221923192419271929193119331935

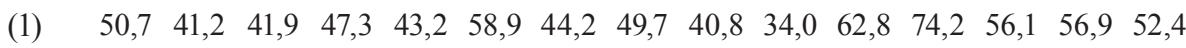

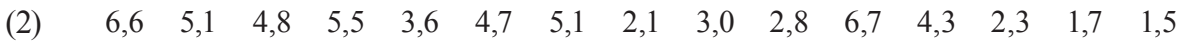

(3) $\quad \begin{array}{lllllllllllllll}5,1 & 3,7 & 4,8 & 4,5 & 5,4 & 5,6 & 3,2 & 3,7 & 1,7 & 1,5 & 3,7 & 2,2 & 1,0 & 1,3 & 1,5\end{array}$

(4) $\quad \begin{array}{lllllllllllllll}23,5 & 37,5 & 33,3 & 29,1 & 28,8 & 22,4 & 35,3 & 30,5 & 45,1 & 50,6 & 16,5 & 10,5 & 6,7 & 13,4 & 11,3\end{array}$

$\begin{array}{llllllllllllllll}\text { (5) } & 6,6 & 5,9 & 8,6 & 8,2 & 8,1 & 0,0 & 5,8 & 4,8 & 4,3 & 3,4 & 0,0 & 3,4 & 19,3 & 19,6 & 20,4\end{array}$

(6) $\quad \begin{array}{lllllllllllllll}7,4 & 6,6 & 6,7 & 5,5 & 10,8 & 8,4 & 6,4 & 9,1 & 5,2 & 7,7 & 10,4 & 5,5 & 14,6 & 7,0 & 13,0\end{array}$

$\begin{array}{llllllllllllllll}\text { Total } & 100 & 100 & 100 & 100 & 100 & 100 & 100 & 100 & 100 & 100 & 100 & 100 & 100 & 100 & 100\end{array}$

* (1) Agentes, consignación, correduría. (2) Actividades de edición. (3) Servicios de enseñanza.

(4) Transportes. (5) Hospedería. (6) Otros.

Fuente: Elaboración propia en base a las Estadísticas de la Matrícula industrial. COCINC.

Cuadro 2.20. Distribución de los servicios, 1914-35 (porcentaje sobre total de cuotas).

\begin{tabular}{cccccccccccccccccc}
$\begin{array}{c}\text { Ejercicio } \\
\text { fiscal }\end{array}$ & $\mathbf{1 9 1 4}$ & $\mathbf{1 9 1 6}$ & $\mathbf{1 9 1 7}$ & $\mathbf{1 9 1 8}$ & $\mathbf{1 9 1 9}$ & $\mathbf{1 9 2 0}$ & $\mathbf{1 9 2 1}$ & $\mathbf{1 9 2 2}$ & $\mathbf{1 9 2 3}$ & $\mathbf{1 9 2 4}$ & $\mathbf{1 9 2 7}$ & $\mathbf{1 9 2 9}$ & $\mathbf{1 9 3 1}$ & $\mathbf{1 9 3 3}$ & $\mathbf{1 9 3 5}$ \\
\hline$(1)$ & 67,2 & 68,5 & 54,6 & 65,0 & 49,8 & 73,3 & 68,3 & 73,6 & 69,1 & 56,4 & 71,3 & 74,8 & 32,6 & 60,5 & 34,3 \\
\hline$(2)$ & 2,7 & 2,2 & 2,3 & 2,0 & 2,2 & 2,1 & 2,2 & 1,4 & 1,6 & 1,8 & 2,2 & 2,3 & 2,0 & 1,3 & 1,3 \\
\hline$(3)$ & 2,0 & 1,6 & 2,4 & 1,5 & 2,0 & 1,7 & 1,0 & 1,0 & 0,8 & 1,1 & 2,2 & 2,1 & 1,6 & 1,3 & 2,5 \\
\hline$(4)$ & 5,0 & 7,5 & 7,3 & 10,5 & 13,9 & 3,5 & 13,8 & 7,2 & 14,9 & 24,5 & 19,0 & 15,2 & 10,6 & 8,7 & 11,0 \\
\hline$(5)$ & 13,1 & 11,2 & 19,2 & 12,6 & 16,5 & 0,0 & 10,2 & 8,9 & 9,4 & 10,5 & 0,0 & 0,0 & 19,4 & 18,2 & 21,3 \\
\hline$(6)$ & 10,0 & 9,1 & 14,2 & 8,4 & 15,6 & 19,4 & 4,5 & 7,9 & 4,2 & 5,6 & 5,3 & 5,6 & 33,8 & 10,0 & 29,5 \\
\hline Total & 100 & 100 & 100 & 100 & 100 & 100 & 100 & 100 & 100 & 100 & 100 & 100 & 100 & 100 & 100 \\
\hline
\end{tabular}

Fuente: Elaboración propia en base a las Estadísticas de la Matrícula industrial. COCINC.

El sector hospedería mantenía una estrecha vinculación con la función de tránsito de la ciudad. El flujo migratorio hacia el exterior había experimentado un descenso, afectando directamente a este tipo de actividades ${ }^{82}$. Sin embargo, la ciudad no supo sacar ventaja de la coyuntura, con independencia del enriquecimiento puntual de

$\overline{82}$ Diplomatic and Consular Reports. Spain. Report for the Year 1914, p. 13. 
algunos empresarios del sector ${ }^{83}$. Como contrapartida, durante la guerra, se dio una excelente oportunidad para desarrollar un turismo todavía en fase embrionaria, ya que el conflicto impidió temporalmente el turismo en otros puntos del extranjero ${ }^{84}$.

En las restantes actividades del sector servicios, observamos que su número no era excesivamente elevado, porque la contribución industrial tampoco recogía la totalidad de establecimientos. En 1914 contabilizamos 9 periódicos inscritos, aunque esta cifra se redujo progresivamente en los años siguientes. Las actividades de enseñanza estaban conformadas por colegios privados, aunque éstos tampoco aparecían recogidos en su totalidad. En 1914, sólo estaban censados 7 colegios. El número de establecimientos se mantuvo estable durante todos estos años, con un pequeño aumento en 1935, como consecuencia del aumento de la población y de la demanda educacional. Los indicios apuntan a que en A Coruña y Pontevedra se estaban alcanzando notables progresos en la calidad pedagógica, gracias a la complementariedad entre la enseñanza pública y la privada, esta última especialmente potenciada por la burguesía urbana.

Los servicios públicos no figuran en la contribución industrial, aunque algunas de las empresas más emblemáticas de la ciudad figurasen en este sector. El crecimiento urbano creó la necesidad de dotar a Coruña de modernos servicios públicos, que permitiesen, además, externalizar costes empresariales, lo que desembocó en la inauguración de los servicios de alumbrado eléctrico (1890), transporte urbano (1903) y abastecimiento de agua (1908) (Martínez López y Piñeiro, 2003: 181).

La génesis del abastecimiento de agua en la ciudad había atravesado un largo periplo (Martínez López, 2001). En 1903 se constituyó la empresa Aguas de La Coruña $S$.A., con un capital social de 2.500 .000 pts. La red de abastecimiento se inauguró en 1908, extendiéndose a buen ritmo hasta la guerra europea. A pesar de ello, la empresa tuvo que luchar contra hábitos adquiridos que impedían que los ciudadanos se abonasen más aceleradamente al servicio, por considerar el agua un bien tradicionalmente gratuito (Martínez López et al., 2004: 80).

La guerra ocasionó una ralentización en el crecimiento del número de abonados. En todo caso, se acometieron importantes obras en las zonas de Zalaeta, Ciudad Vieja, Monte Alto y el puerto. Esto, junto con la inflación propia del ciclo bélico, repercutió en la rentabilidad económica de la empresa, ya que los años de la guerra, junto con la etapa republicana, constituyeron la única etapa hasta la Guerra Civil en la que los beneficios no crecieron de manera significativa. No obstante, las estructuras financiera y patrimonial presentan un estado saludable durante los primeros años de vida de la empresa. Por tanto, ésta se ajustó parcialmente a la dinámica urbana, aunque las expectativas de crecimiento de su mercado impidieron que la guerra tuviese un impacto tan negativo como en otros sectores (Martínez López y Piñeiro, 2003: 185, 204).

Por su parte, el transporte urbano corrió a cargo de la Compañía de Tranvías de La Coruña S.A., constituida en 1901, con un capital de 350.000 pts. (Martínez López y Piñeiro, 2001: 253-256). Desde entonces, sentó las bases de una sólida red tranviaria

83 Consejo Superior de Emigración, La emigración española transoceánica, 1911-1915, Madrid, 1916, p. 256.

84 Estudios Gallegos, nº 3, 5 de marzo de 1915. 
urbana, primero con tracción animal y más tarde con tracción eléctrica, unida a una línea periférica que durante más de tres décadas prestó servicio en el eje metropolitano costero A Coruña-O Burgo-Sada (Mirás, 2005d). La empresa dio inicio a la explotación en 1903, con la apertura del primer tranvía de mulas, Puerta Real-Estación de Ferrocarril de la Compañía del Norte, con ramales a Riazor y a cocheras (situadas en la Explanada del Orzán), uniendo calles que eran arterias principales de la red urbana e importantes núcleos de actividad económica. A partir de entonces, la red se extendió progresivamente, siguiendo las direcciones de la ciudad consolidada y del crecimiento urbano, y agilizando el movimiento intraurbano de pasajeros (Piñeiro, 1996a: 51-52). No obstante, durante los primeros años de vida de la sociedad, las cifras muestran que los resultados económicos no eran los deseados, debido a que el servicio ofrecía todavía una utilidad relativa a los ciudadanos (Piñeiro, 1996b: 187-188). Antes de la guerra, se tendieron dobles vías en algunos ramales. Pero la gestión fue relativamente ineficaz.

En 1913 se inauguró el tendido eléctrico, y en 1921 se había electrificado la totalidad del servicio. Inicialmente, los años de la guerra fueron una etapa de dificultades financieras, con un descenso en los ingresos, un estancamiento en el número de viajeros y un aplazamiento de inversiones proyectadas. Los factores que influyeron en esta coyuntura fueron: la disminución de la capacidad adquisitiva de los usuarios (a causa de la inflación), el aumento de la conflictividad laboral, la disminución de la acomodada población flotante que solía veranear en la ciudad, el retraimiento de los inversores ante la incertidumbre, el incremento de los costes, la dificultad de conseguir repuestos del extranjero y las anomalías en el suministro eléctrico (Martínez López, 2001: 264-265). Ya en los años veinte, los efectos del cambio técnico sobre los resultados empresariales fueron casi inmediatos, pues los ingresos crecieron por encima de los gastos, permitiendo a la compañía disfrutar de casi dos décadas de estabilidad.

Finalmente, resta por analizar uno de los sectores de mayor trascendencia para la economía local, el sector financiero. El primer tercio del siglo XX constituye el período formativo del sistema bancario español (Tortella y Palafox, 1984: 83), gracias a la acumulación de capital animada por la crisis colonial (García Ruiz, 2002: 3), la guerra europea (que generó cuantiosos beneficios especulativos en algunas industrias) y el nuevo marco institucional creado con la Ley de Ordenación Bancaria de 1921 (García Delgado, 1981: 440). Asimismo, éste fue el período de conformación de los rasgos básicos de la banca gallega y coruñesa (Alonso, 1984: 189). La banca regional se mantenía en un ámbito local y/o comarcal, y no abrió en esos años ninguna sucursal fuera de Galicia, lo que le impidió adoptar una posición preponderante (Otero Díaz, 1972: 26). A pesar de ello, se aprecia un crecimiento significativo del sector.

Los indicios apuntan a una vinculación con las principales fuentes de ingreso gallegas del período. El tránsito de las remesas americanas estuvo en la raíz de la creación y consolidación de las más sólidas iniciativas bancarias regionales y coruñesas 
de la época. Una proporción muy importante de esos flujos se canalizaba a través de numerosos comerciantes con casas de banca, dispersos a lo largo de la geografía gallega. Pero los principales bancos gallegos de aquellos años debieron también tener una significativa participación en la conducción de este flujo ${ }^{85}$.

La banca regional nació tardíamente, mostrando signos de debilidad, como su reducido peso relativo en el sistema bancario español, su desconexión del exterior y su excesiva orientación hacia el mercado regional. El bajo nivel de desarrollo económico gallego impedía un impulso más dinámico, de manera que el sector creció de forma fragmentada e inconexa hasta la Guerra Civil (Sequeiros, 1986: 263). Los vínculos banca-industria eran limitados, al contrario de lo que ocurría en España desde la segunda década del siglo (Tortella, 1994: 337), aunque no ocurría lo mismo con los emergentes servicios de la segunda revolución industrial (transportes, agua, electricidad, gas, etc.), en donde sí existía una tupida red de vínculos empresariales (Alonso, 1984: 205-207).

Por otra parte, en el tránsito entre siglos subsistía todavía una típica figura decimonónica, la de los comerciantes banqueros. Estos empresarios experimentaron un considerable crecimiento numérico en España durante el primer tercio del siglo, si bien se concentraron en las ciudades con menos de 20.000 habitantes (García López, 1989). A finales del siglo XIX operaba un elevado número de dichos banqueros en A Coruña, aun cuando muy pocos aparecían registrados en la matrícula industrial. En 1900, había 16 empresarios con la calificación de comerciantes banqueros ${ }^{86}$. En opinión de López Prado, existía un destacado número de personas dedicadas al cambio de moneda, si bien su actividad no se diferenciaba demasiado de la de las entidades que realizaban enteramente actividades propias de la banca moderna ${ }^{87}$. Estas casas de banca se caracterizaban por poseer un carácter familiar y unas dimensiones reducidas. De todos modos, su relevancia en una sociedad como la gallega, cerrada y poco mercantilizada, era notable, gracias a su función de nexo de unión con el pequeño ahorro. Pero, sobre todo, gracias a que actuaron como vehículo canalizador de las remesas de la emigración.

\footnotetext{
85 Para Villares (1984: 31) y Núñez Seixas (1998: 51), la mayoría de las remesas se canalizaron, en un principio, a través de los cónsules y agentes oficiales de inmigración latinoamericanos en Galicia, y también por medio de las casas de armadores, entre otras, la casa José Pastor (más tarde Sobrinos de José Pastor) y la Banca de Narciso Obanza, ambas de A Coruña (Villares, 1992). Posteriormente, a través de los bancos de la colectividad gallega o española en América (Banco Español del Río de la Plata, Banco de Comercio Hispano-Argentino, Banco de Galicia y Buenos Aires, o el Banco Español de la Isla de Cuba). Esta favorable coyuntura vino así a incidir en una ciudad en la que la banca y las actividades financieras en general tuvieron una dilatada tradición histórica (Alonso, 1984).

86 Pedro Barrié y Cía., Narciso Obanza, Viuda e Hijos de Atocha, Martín de Carricarte, Viuda e Hijos de Curbera y Cía., Curbera y Capdesuñer, Eusebio da Guarda, Herce y Cía., Maristany Hnos., Juan Montero Telinge, Ramón Picos, Nicolás María del Río, Rubine e Hijos, Sucesores de Veiga y Veiga, Viuda e hijos de Genaro Zalbidea y Crédito Gallego (López Prado, 1984).

87 López Prado (1966: 48). En 1921 todavía encontramos en A Coruña cuatro casas de cambio de moneda: Manuel Amor, José López, Manuel Malde y Basilio Otero. Anuario General de España (Bailly-BailliéreRiera). Comercio, Industria, Agricultura, Ganadería, Profesiones y Elemento oficial, 1921, $2^{\mathrm{a}}$ Época, Año 10, tomo II, Barcelona.
} 
El conjunto del sector bancario en Galicia fue sensible a las transformaciones derivadas de la guerra mundial, de manera similar a lo ocurrido en España. El banco más destacado de preguerra, el Banco de Vigo aprovechó el florecimiento industrial y del tráfico marítimo ocasionado por la contienda para aumentar su actividad y expandirse por la región. De este modo, entre 1914 y 1919 esta entidad consiguió multiplicar por seis los beneficios, y en los cuatro años siguientes creó sus primeras 15 sucursales, fruto de una política expansiva muy agresiva (Maixé et al., 2003: 108).

Sin embargo, la principal entidad financiera existente en A Coruña durante la guerra no era un banco, sino la Caja de Ahorros y Monte de Piedad, fundada en 1876, y embrión de lo que con el tiempo fue la Caja de Ahorros de Galicia y la posterior Caixa Galicia. La Caja de Ahorros nació con el objetivo de fomentar el ahorro de las clases menos acomodadas, así como facilitar la concesión de préstamos sobre prenda a un interés módico, en sintonía con las demás cajas españolas (Maixé et al., 2003: 45). Desde su creación mantuvo una estrecha vinculación con el Crédito Gallego (institución creada tras la desaparición del Banco de emisión de La Coruña de 1857). De hecho, la caja contó con el apoyo decidido del accionariado del Crédito Gallego. Las relaciones que mantuvo la entidad con otras instituciones de la plaza fueron bastante estrechas, destacando especialmente el Banco Hispano Americano, el Credit Lyonnais y Sobrinos de José Pastor. De hecho, los vínculos con estos últimos se entrelazaron cada vez más desde que la caja se convirtió en una entidad independiente (Maixé et al., 2003: 105).

El cambio de siglo fue un período de cambios trascendentales para la caja coruñesa. El temporal causado por la crisis de 1898 fue relativamente bien capeado por la entidad, reanudando poco tiempo después la tendencia de crecimiento de sus imposiciones. Esta marcha ascendente se vio interrumpida por la desaparición del Crédito Gallego, en 1905, poniendo en riesgo su propia supervivencia. Pero la caja había alcanzado un grado de solidez suficiente como para continuar su andadura en solitario (Maixé et al., 2003: 64-65). Desaparecido el Crédito Gallego, la caja quedó emancipada de toda tutela y libre de actuar en la línea que considerase más conveniente para su desarrollo.

Durante la guerra mundial, la entidad debió hacer frente a una delicada coyuntura, debido al negativo impacto del conflicto sobre el pasivo, las inversiones y los rendimientos de la cartera de valores, consecuencia del pánico financiero que se desató en las ciudades gallegas. Además, una de las principales fuentes de negocio, las remesas americanas, decayeron respecto a los años precedentes. La elevada demanda de efectivo por parte de un público que había perdido la confianza en la institución y en el sistema obligó a adoptar medidas extraordinarias, en la línea de la austeridad y la prevención, que le permitieron sortear con fortuna la coyuntura bélica. Según Maixé et al. (2003: 111), los resultados se situaron lejos de los logrados por los bancos, de modo que su mayor éxito fue robustecer su economía, superar el pánico financiero y mantener la confianza del público. Aunque los beneficios sufrieron un estancamiento, la entidad disfrutó de unas cuentas de resultados saneadas (Maixé et al., 2003: 94-95, 103). 


\section{INDUSTRIA SIN INDUSTRIALIZACIÓN}

\subsection{El impacto de la guerra mundial en la industria de A Coruña ${ }^{88}$}

Las primeras industrias modernas aparecieron en A Coruña en la segunda mitad del siglo XIX, aunque estas iniciativas no condujeron a un crecimiento sostenido del sector, siendo, por tanto, experiencias importantes, pero aisladas en su mayoría. Los sectores instalados se caracterizaban por su escaso nivel de complejidad tecnológica, de modo que el proceso de modernización técnica no se inició en la mayor parte de los sectores hasta las últimas décadas del siglo XIX (Lindoso, 1999).

Al finalizar la guerra mundial, A Coruña contaba con cerca del $30 \%$ de las industrias de la provincia (29,8\%), mientras Santiago, con el 13,3\%, y Ferrol, con el 7,6\% se hallaban más rezagadas ${ }^{89}$. La dotación fabril-manufacturera de la ciudad de A Coruña, ponderada por la población (con datos del censo de 1920), era aparentemente menos sólida que la de Santiago. La ratio de establecimientos industriales por cada 1.000 habitantes era de 7,63 en A Coruña, 3,95 en Ferrol y 8,19 en Santiago. No obstante, en Santiago, los sectores de mayor presencia se concentraban en el artesanado (cordeleros, plateros, curtidores, etc.), con un espectro de actividades menor. En cambio, en A Coruña existía un mayor abanico de actividades productivas, caracterizadas por un efecto de arrastre más potente, mayor volumen de capital, mayor tamaño, etc.

El Cuadro 2.11 muestra el peso de la industria en la ciudad. Su presencia era sustancialmente inferior a los sectores anteriormente analizados, tanto en volumen contributivo como en número de industriales. La evolución del sector no fue independiente de los factores que determinaron el comportamiento de la economía urbana en su conjunto. No obstante, las fases de auge y de contracción industrial aparecen menos acentuados. En ningún momento la industria experimentó un crecimiento que permita conjeturar un verdadero auge industrial, pero tampoco padeció períodos de estancamiento que desembocasen en fuertes depresiones industriales. El período más crítico se vivió durante la guerra y, posteriormente, tras el desencadenamiento de la crisis de los años treinta.

Entre 1914 y 1919 se detecta una caída de las actividades industriales, que se fragua en el segundo año de la guerra. El golpe fue más suave, pero producto de un desarrollo estructural menor. El descenso del número de industriales fue también inferior, lo que guarda relación con el hecho de que desaparecieron industrias marginales. El impacto final de la guerra fue muy distinto al de otras áreas del país, ya que apenas había tenido incidencia en un crecimiento del sector, siguiendo la tendencia de comportamiento provincial (IRS, 1921b: 106).

Con carácter general, descubrimos de nuevo en la actividad portuaria el germen de la crisis. Determinadas actividades industriales mantenían una estrecha vinculación con el puerto, por lo que resultaron muy perjudicadas por el descenso del tráfico mercantil,

\footnotetext{
8 Un tratamiento en profundidad en Mirás (2005e).
}

89 Datos procedentes de la Delegación Provincial de Hacienda. En realidad, estos datos incluyen algunas actividades más propias del sector servicios (consignación, exportación, almacenaje, etc.), que no han sido desglosadas, pues el fin era proceder a una somera comparación en la dotación empresarial de las tres principales ciudades provinciales. Anuario de la Gran Industria de España, Zaragoza, 1918, pp. 266-282. 
más que por las dificultades de exportación de manufacturas hacia el exterior ${ }^{90}$, ya que las industrias coruñesas no tenían potencial para ser exportadoras. A pesar de las excepciones, la característica principal era su limitada capacidad competitiva fuera del mercado urbano, lo que guardaba una íntima concordancia con el minifundismo industrial al que se ha aludido en otro momento. La alternativa del mercado interior se vio entorpecida por los transportes terrestres (IRS, 1919a, 2: 233).

Con la guerra, algunas industrias habían crecido, aunque dominase un panorama caracterizado por las dificultades empresariales. Durante la posguerra muchas de las industrias supervivientes se vieron debilitadas por la escasez y carestía de medios de comunicación terrestres y marítimos, por los conflictos obrero-patronales, la inflación, la caída de la demanda, etc. (IRS, 1921b: 119).

Posteriormente, en 1920-21, A Coruña presentaba una cierta paralización en su desarrollo industrial (IRS, 1923: 125), a pesar de que el puerto recuperase su nivel, siendo como era un indicador claro de la situación industrial, pues desde casi todos los frentes se reconocía que el puerto era la principal fuente de riqueza.

\subsection{Las principales actividades industriales y estructura del sector}

Hasta la Guerra Civil, el sector alimentario era la actividad fabril más extendida en España. En 1914 los sectores pautadores en A Coruña no eran en absoluto novedosos, proyectando experiencias históricas anteriores, que descansaban en buena medida sobre una escasa mecanización y una intensificación del factor trabajo. Por tanto, la tradición mantenía un peso nada desdeñable en los sectores de mayor presencia en la ciudad. Al inicio de la guerra europea, el número de industriales del subsector alimenticio representaba el $35,7 \%$ del total del sector, mientras sus cuotas totalizaban el 38,7\%. Por tanto, su peso en la industria urbana era ciertamente notable.

Dentro de las industrias alimenticias, la más numerosa era la de los molidos, con una concentración total dentro de la moltura de granos. En general, adolecía de algunos defectos estructurales, hipotecada por una demanda local que no justificaba una inversión que modernizase el sector. A pesar de su importancia numérica, lo que más abundaban eran pequeñas fábricas que tenían, en muchos casos, una vida y unos resultados económicos precarios. La producción con frecuencia resultaba insuficiente para atender la demanda urbana, teniendo que recurrir a la importación, vía cabotaje o vía ferrocarril (Rivas Moreno, 1916: vii). Los procedimientos para la obtención de la harina variaban, utilizándose diferentes aparatos para moler los trigos y para clasificar sus harinas ${ }^{91}$. Pero la mayoría de las fábricas estaban movidas por energía hidráulica, y para cuando se empezó a generalizar la utilización de energía eléctrica en la ciudad fueron pocos los establecimientos que adoptaron esta fuente de energía, lo que se tradujo en la producción de una harina de baja calidad (IRS, 1919a: 223).

\footnotetext{
90 IRS (1914: 130). Diplomatic and Consular Reports. Spain. Report for the Year 1914, p. 5.

91 Memorias presentadas por los Ingenieros industriales de la Investigación de la Hacienda Pública, La Gaceta de Madrid, 12 de abril de 1900, p. 220.
} 


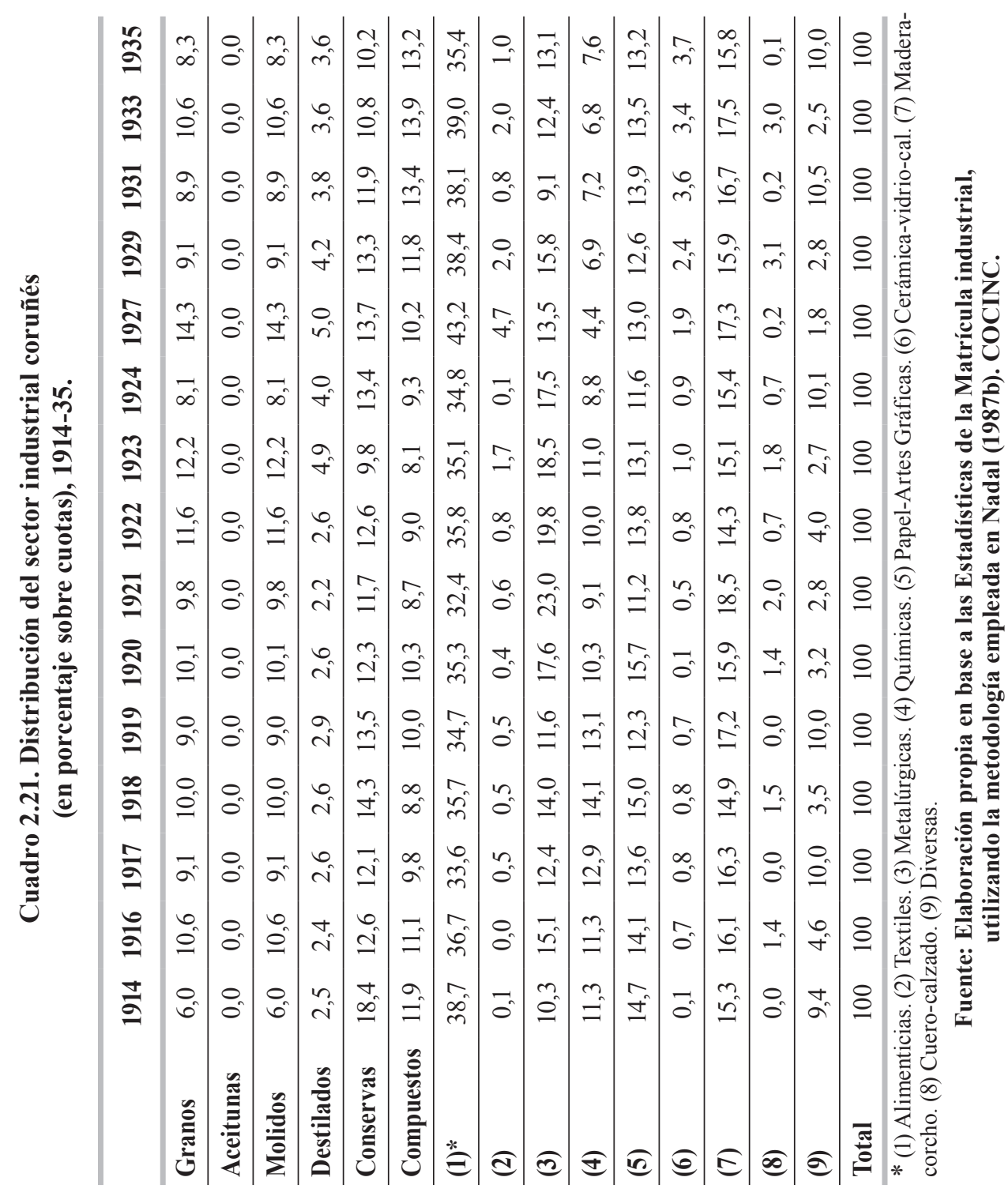

Durante la guerra experimentó un auge, como resultado de que el mercado de su producción se encontraba en el área urbana. De todos modos, este subsector contribuyó a la inflación general de las subsistencias, porque el precio de la harina pasó de 40 pts. en 1914 a 75 en 1917, como consecuencia de tener que importar parcialmente las materias primas, lo que produjo evidentes perjuicios a la fabricación del pan ${ }^{92}$.

92 IRS (1919a, 2: 139-140, 223). El establecimiento más importante era La Cilíndrica Harinera, empresa dedicada a la fabricación y explotación de harinas, que se creó en 1915, con un capital social de 100.000 pts., posteriormente ampliada en los años veinte a 173.000 pts. 


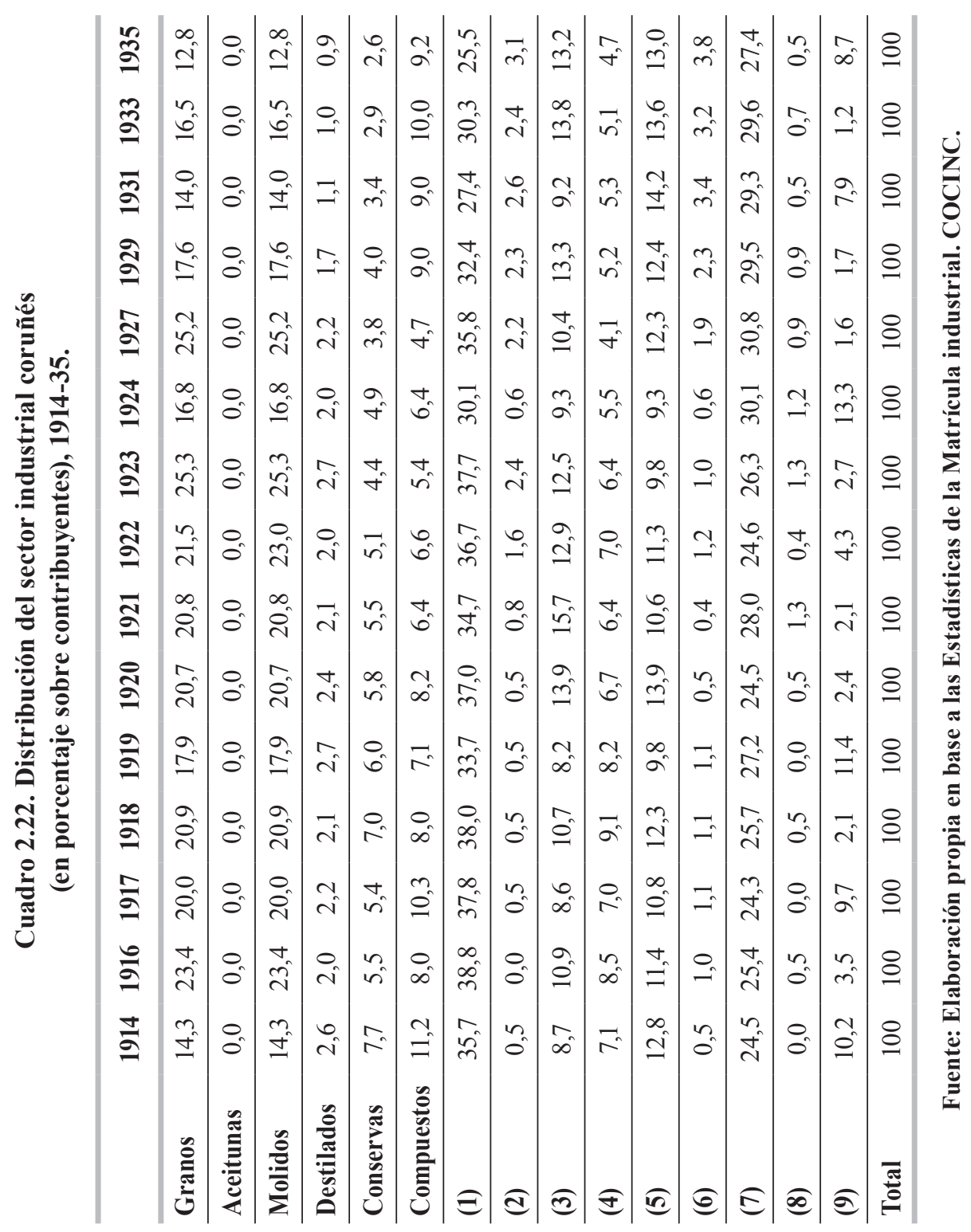

La industria de mayor trascendencia en términos cualitativos era la de conservas de pescado, cuya importancia y tradición tenía una larga historia en la ciudad, tanto en la forma de salazones, como la más moderna industria conservera ${ }^{93}$. El sector conservero formaba parte del complejo marítimo-pesquero que, junto a la comercialización

93 Existía todavía la fabricación tradicional de escabeches, ahumados, secados y salazones de pescado. La moderna industria conservera es heredera de una de esas industrias tradicionales, la salazón de sardina, elaboración que todavía mantenía un fuerte peso a finales del siglo XIX (Carmona, 1994, 127-128). 
de ganado vacuno, fue responsable de la "pequeña revolución industrial" de Galicia (Carmona, 2001a: 23). Su peso en A Coruña era considerablemente inferior al que tenía en el principal centro productor de España (Vigo). No obstante, a la altura de 1907-08, época de despegue del sector (Carmona, 2001a: 23), su número era tan importante que había superado o se había situado a la par de la mayor parte de las zonas productoras del país ${ }^{94}$.

En términos productivos, la contienda tuvo un impacto negativo sobre el conjunto del sector. Su estrecha dependencia del sector pesquero como suministrador de la materia prima principal afectó directamente a la producción. La pesca experimentó una caída, provocando la consiguiente escasez de la materia prima básica (Carmona, 1990b: 37). Además, la pesca de altura, uno de los sectores más intensivos en consumo de energía en la provincia, padeció enormes dificultades para el abastecimiento de carbón extranjero, del que habitualmente se surtía ${ }^{95}$.

En otro frente, el tráfico portuario se resintió como consecuencia del conflicto y esto motivó una disminución de las salidas. Pero el problema fue principalmente de oferta. Las dificultades para la obtención de insumos fuera del mercado urbano se multiplicaron y su precio se encareció notablemente. Los más afectados fueron los tres inputs más complicados de adquirir, el estaño, la hojalata y el aceite, principal cuello de botella para la expansión del sector, en un momento en que el competidor más duro, Portugal, no tuvo los mismos problemas de aprovisionamiento ${ }^{96}$; pero también se vieron afectados los vinagres, las maderas para envase, e incluso la propia pesca, debido a la creciente demanda de pescado en fresco para el interior peninsular ${ }^{97}$.

Por otro lado, una de las características más sobresalientes de esta industria era su manifiesta propensión exportadora (Carmona, 2001a: 24). Esa orientación se vio perjudicada por las dificultades del mercado internacional en los años centrales de la guerra. Pasada esa etapa de adaptación, el sector normalizó la producción, que experimentó un importante aumento del tonelaje manufacturado en 1916-17. Aunque éste disminuyó nuevamente en 1918-19, resultó muy favorecido por el incremento de los precios en los mercados internacional y doméstico (Carmona, 1990b: 36-38).

Sobre el sector también influyeron factores de demanda. Los más importantes fueron el bloqueo de los transportes (que entorpeció el suministro de la producción a los clientes, pertenecientes, en su mayoría a los países beligerantes) ${ }^{98}$, los escollos para cobrar los pedidos, ante las trabas para reintegrar los giros con las naciones en

\footnotetext{
94 Desde esa fecha y hasta 1928, la industria entró en una fase de estabilización (Carmona, 1994: 145), con la excepción de los años 1909-13, en los que la sardina desapareció de las costas gallegas, ocasionando en esos años una disminución del número de traíñas y de tarrafas que operaban en A Coruña, así como una caída de la actividad productiva de las fábricas de conserva, salazón y escabeche (Rubio, 1916: 16).

95 Boletín del Instituto de Reformas Sociales, vol. II, 1915, p. 120. IRS (1916: 105).

96 Carmona (1990b: 37). IRS (1919a, 2: 138; 1916: 105).

97 En 1914-18, el precio de los inputs se duplicó. La subida del precio de la hojalata fue espectacular, ya que pasó de 18 pts. la caja de $40 \mathrm{kgs}$ (112 hojas) a 140,5 pts. El precio del estaño, por su parte, se incrementó de 400 pts./1.000 kgs a 3.000, y el carbón de 45/1.000 kgs a 200 (IRS, 1919a, 2: 138).

98 Tal circunstancia obligó a suspender el envío de pedidos hechos con anterioridad al conflicto, y a conservar almacenada una producción ya envasada y marcada para el destinatario. Inicialmente, esto no constituyó un estorbo insalvable, dada la elevación de los precios del producto (IRS, 1914: 92).
} 
guerra ${ }^{99}$, la crisis de las entidades financieras españolas y extranjeras, la puesta en vigor de la Ley de moratorias en Europa (lo que imposibilitaba el cobro, mermando el capital circulante de los conserveros), las fluctuaciones en los tipos de cambio ${ }^{100}$.

Entre finales de 1914 y 1915 la situación experimentó una mejoría, gracias a que las conservas eran artículo de primera necesidad en tiempo de guerra, lo que consolidó su demanda en Europa ${ }^{101}$. También ayudó el crecimiento de la producción de salazones, cuya demanda era fundamentalmente nacional. Ésta se vio favorecida por el elevado precio del bacalao y por el cese casi total de sus importaciones, aun cuando estas industrias tuviesen un carácter bastante intermitente ${ }^{102}$. Desde 1919, las industrias conserveras coruñesas recuperaron una cierta normalidad exportadora. Sin embargo, en 1922 se firmó un acuerdo comercial con Francia que perjudicaba al sector, ya que este país intentaba recortar sus importaciones de bienes secundarios y de artículos prescindibles ${ }^{103}$.

La otra industria alimenticia de importancia era la de los compuestos. Aquí se incluye una relativa variedad de fábricas (de chocolates, bombones, galletas, etc.), todas ellas con un número y unas cuotas similares. Algunas eran industrias modernas, que incorporaban medios técnicos avanzados, con una calidad de sus productos aceptable, caso de las pastas para sopas. Éstas tenían un mercado acreditado en el extranjero, si bien limitado a las últimas posesiones españolas en Ultramar. Con la pérdida de los restos del Imperio, la demanda cayó en picado, quedando reducida al estricto marco regional. Se puede caracterizar en parecida línea a las fábricas de chocolate, empresas a las que la pérdida de las colonias obligó a limitar su mercado al noroeste peninsular.

La guerra apenas tuvo impacto sobre estas empresas, excepto por un encarecimiento del precio de sus materias primas (IRS, 1919a, 2: 223). Sobresalía la fábrica de chocolate y pastas para sopa de Viuda e Hija de Francisco Leal, establecida en el año 1876. Su producción anual era unos 150.000 paquetes de chocolate y 30.000 arrobas de pasta (Rubio, 1916: 21). Después de la guerra, la empresa más sobresaliente fue Rubine e Hijos, S.R.C., constituida en 1876 (como continuación de Rubine y Salorio, creada en 1871), con un capital social de 1.287 .541 pts.

Lo mismo sucedía con las aguas carbónicas, aunque, en este caso, los establecimientos eran de dimensiones mínimas, con una o dos excepciones. Este subsector padeció las secuelas de la guerra, debido a las dificultades de obtención de las materias primas, pero también como consecuencia de las deficiencias que aquejaban a sus procesos productivos, una situación que se habría de acentuar todavía más una vez terminada la contienda. La empresa más prestigiosa era La Unión Industrial, S.A., constituida en

\footnotetext{
99 Boletín del Instituto de Reformas Sociales, vol. II, 1915, pp. 120-121. IRS (1916: 105).

100 IRS, 1914: 92-94. Informe-resumen leido en la Junta de Señores Accionistas de la sucursal del Banco de España en La Coruña, 7 de febrero de 1915.

101 El "modus vivendi" con Francia y las industrias conserveras (Informe al Ministro de Estado), La Coruña, 1922, en Las Cámaras de Comercio. Labor de la de La Coruña hasta fin de 1923, La Coruña, COCINC, 1924, p. 216.

102 Muñoz Abeledo (2002: 88). Ministerio de Trabajo, Comercio e Industria. Dirección General de Trabajo y Acción Social, Estadística de los salarios y jornadas de trabajo referida al período 1914-1925, Madrid, 1927, p. cl.

103 Las industrias conserveras (ponencia encargada al Sr. Valcárcel, secretario de la Cámara, por el Primer Congreso del Comercio Español en Ultramar), La Coruña, 6 de marzo de 1923.
} 
el año 1917, con un capital social de 160.000 pts., y formada por diferentes fabricantes. Destacó asimismo La Industrial Comercial, fundada también en 1917, con un capital social de 50.000 pts., que tuvo una evolución empresarial ascendente, por cuanto sus beneficios se mantuvieron estables durante los años 1919-23, oscilando entre las $23.489,2$ pts. de 1919 y las $28.479,3$ de 1923, cifras elevadas dado su capital social.

Finalmente, el grupo de los destilados tuvo una importancia aún menor. Se trataba de un reducido número de empresas. Las fábricas estaban constituidas básicamente por sociedades de refinado de azúcar, de pequeñas dimensiones, y por fábricas de cervezas (dos en 1914), especialmente la empresa propiedad de José María Rivera, $L a$ Estrella de Galicia, fundada en 1906, que simultaneaba la fabricación de cerveza y de hielo, y se había constituido en una de las empresas más importantes del ramo de la alimentación en la ciudad (Valiña, 2000: 197).

La industria cervecera había tenido su origen a mediados del siglo XIX, aunque encontró algunas dificultades para su desarrollo, debido a la tradicional demanda que existió siempre de otro tipo de bebidas (vinos). La instalación de J.M. Rivera operaba a un nivel técnico aceptable. Su producción era de 163.616 litros de cerveza en 1917 y de 168.380 en 1918, y exportaba su producción fuera incluso de los límites regionales. La influencia de la guerra fue adversa, aunque de menor gravedad que en otros sectores, ya que la malta era de producción nacional, e incluso el lúpulo (que hasta entonces se importaba de Alemania o Francia) comenzó a producirse en España ${ }^{104}$.

Conviene hacer mención a una última industria alimentaria no recogida en las ECI: la Fábrica de Tabacos de La Palloza ${ }^{105}$. Ésta constituía el principal establecimiento fabril de A Coruña y de Galicia durante la segunda mitad del siglo XIX y gran parte del período aquí analizado, sobre todo por el volumen de población empleada: en torno a 3.000 obreras a principios del siglo XX, 2.405 en 1914 y con cifras en torno a los 2.000 trabajadores durante el primer tercio del siglo. La guerra no tuvo una influencia adversa, debido a que la materia prima, aunque de procedencia estadounidense, se recibió con regularidad. De hecho, la carestía del tabaco, el aumento del precio de los fletes y de los seguros de los navíos estimuló la mecanización y la tecnificación de las fábricas de tabaco (Romero Masiá, 1997: 85). Además, la producción y el consumo alcanzaron cifras próximas a las de preguerra, a pesar de la subida de los precios (IRS, 1919a, 2: 216-217).

En conjunto, este fue un período de notables cambios en la empresa. Durante los primeros años del siglo se acometieron diversas reformas, hasta llegar en 1910 a la configuración final del edificio principal. Además, en 1924 se inició la construcción del edificio destinado a almacén general (Navajas, 1984: 142). Los años veinte presenciaron una nueva modernización, en tres direcciones: introducción de la electricidad como fuerza motriz, instalación de un almacén y de grandes equipos

104 IRS (1919a, 2: 142, 223). Los precios de los inputs experimentaron las siguientes subidas entre 1914 y 1918: la cebada, de 20-22 pts./100 kgs a 50 pts./100 kgs; el lúpulo de 3,50 pts./kg a 6-7 pts./kg; el carbón, de $11 \mathrm{pts} . / \mathrm{tm}$ de menudo lavado a $90-100 \mathrm{pts} . / \mathrm{tm}$. Las demás materias primas auxiliares se incrementaron entre un 80 y un $150 \%$ con relación a los precios de preguerra. El precio de venta del producto pasó de 37,50 pts./hl en 1913 a 47,50 pts./hl en 1918 (IRS, 1919a, 2: 142).

${ }_{105}$ Para un análisis de la fábrica vid. Alonso Álvarez $(2003,1998,1984)$. 
para tratamiento industrial de la hoja (Alonso Álvarez, 2003: 216). Además, la dirección realizó mejoras en las instalaciones que se tradujeron en un incremento de la productividad.

A continuación de las agroalimentarias, el segundo sector industrial en importancia era el de la madera y corcho, aunque en realidad estaba integrado en su práctica totalidad por el primero de ellos. Era una industria bastante desarrollada que, en algunos casos, contaba con excelentes instalaciones, y totalizaba un número bastante elevado de contribuyentes.

La industria maderera contaba con una tradición reciente en la ciudad, remontándose la aparición de los primeros centros fabriles a finales del siglo XIX. La primera fábrica importante data de 1890, cuando Eduardo Cervigón instaló una serrería para la confección de envases. Por esa misma época, se creó también la fábrica de Luis Puig Marcelí, La Progresiva. El puerto se constituyó como uno de los principales puntos de salida de la producción regional (Rico, 2000). El tipo de producto más habitual de la vertiente atlántica gallega eran los tablones de madera, y los destinos de la producción eran Alicante, Valencia, Barcelona, Málaga o Sevilla.

La empresa más importante por entonces era Hijos de Emilio Cervigón, fundada en $1909^{106}$. Su capacidad de producción era de aproximadamente $1.000 \mathrm{~m}^{3}$ anuales en los diferentes trabajos que realizaba, es decir, el aserrado de las maderas para la construcción de edificios y obras de carpintería para los mismos, utilizando materias primas procedentes de Suecia y Estados Unidos, además de las maderas de pino del país. El mercado para su producto era mayoritariamente la propia ciudad y, en todo caso, el resto de la región (Rubio, 1916: 20).

El impacto inicial de la guerra fue negativo sobre determinados tramos de demanda. Los más afectados fueron los talleres de confección de envases y preparación de tablas de maderas del país con destino al exterior, principalmente a la entibación en las minas del Reino Unido. El sector se vio muy influido por el aumento del precio de las importaciones y la disminución de envíos, sobre todo de maquinaria alemana (IRS, 1916: 108), provocada por el conflicto y por los peligros de la navegación; y también por la reducción de la demanda interna, como consecuencia de la paralización de las industrias (vinos) y sectores primarios de exportación (frutas, hortalizas) en el Levante. La crisis de adaptación afectó también a los transportes, y a la construcción, debido a la escasez de numerario y a las dificultades para la importación de cemento y otros artículos (IRS, 1919a, 2: 220). El efecto fue la disminución de las salidas hacia otros puertos del país. En consecuencia, las fábricas de tablas para cajas destinadas al envase en Levante sufrieron una fuerte crisis (IRS, 1914: 29-31).

Con el desarrollo de la guerra, la coyuntura para el sector maderero y forestal provincial cambió, aunque sus efectos fueron de corta duración. El motivo, la falta de madera extranjera (IRS, 1919b: 136), y el aumento de las exportaciones, tanto por vía marítima como terrestre, hacia sectores que habían sufrido la crisis de adaptación inicial: minería del carbón, construcción naval, agricultura de exportación,

$\overline{106}$ Constituida con un capital social de 25.000, ampliado a 300.000 pts. en 1921 y a 501.000 en 1926. 
etc. (IRS, 1919a, 2: 226). Además, la producción se vendía a elevados precios, tanto la madera de primera transformación, como la remitida antes de pasar por los aserradores (IRS, 1919a, 2: 219), aunque sin una transformación sustancial de su estructura industrial (Rico, 2000: 431). Finalmente, la irregular evolución de la industria pesquera y conservera, influyó negativamente sobre un segmento concreto de la producción del sector, la confección de envases y cajones, dando lugar a una disminución relativa de ese tipo de producciones. En cualquier caso, en su conjunto, la guerra resultó beneficiosa para la industria maderera de Galicia y de A Coruña (Rico, 2000: 434-435), al igual que la posguerra, aunque el crecimiento más acelerado del número de empresas se registró en los años veinte, cuando se duplicó el total de efectivos registrados. Empresas como la fábrica de maderas de Hijos de Emilio Cervigón Carreras experimentaron un considerable crecimiento de sus beneficios ${ }^{107}$.

La industria del papel y las artes gráficas se vio perjudicada por la guerra. En primer lugar, la producción de envases de hojalata litografiados, encabezada por La Artística. Esta fábrica se instaló en 1890, con unos procedimientos relativamente primitivos, y su base era la industria escabechera. Posteriormente se modernizó y perfeccionó, al igual que ocurrió con otras empresas de similar naturaleza del sur de Galicia. La producción ya no se limitó a los envases para las conservas, sino que se elaboraban para toda clase de productos, llegando a producir tubos para pastas. Esta empresa llegaba incluso a comercializar su producción en el mercado nacional. La influencia de la guerra no se notó excesivamente en la compañía, dado que el ritmo de trabajo y la producción real continuaron con parecida intensidad. Aunque la facturación se multiplicó por cinco, de 500.000 pts. anuales a 2.500 .000 pts., ésta se cimentó en la elevación de precios del producto (IRS, 1919a, 2: 213-214).

El comportamiento del conjunto del subsector fue titubeante, al depender de la demanda de otras industrias. El factor que más negativamente influyó fue la disminución de las importaciones de productos procedentes de Alemania (IRS, 1916: 106). En cambio, la producción de la prensa periódica en la provincia se incrementó. Lo mismo puede afirmarse de la producción de las empresas tipográficas, cuyo aumento se debió a que muchas casas, que antes de la guerra encargaban sus trabajos en otras regiones e incluso en el extranjero, comenzaron a encargarlos en la ciudad y en la provincia. En contra jugó el fuerte encarecimiento del papel (Román, 1997: 317-321; IRS, 1919a, 2: 223).

La guerra constituyó una excelente oportunidad para la industria metalúrgica española, en especial para los sectores exportadores, al permitir un aumento de la demanda en aquellos países que no podían abastecerse en naciones como Alemania, Bélgica o Francia. Pero la producción nacional carecía de la potencia necesaria para hacer frente a esa demanda con la rapidez y eficacia requeridas ${ }^{108}$.

107 En 1921, 15.306,1 pts., en 1922, 18.668,7 pts. y en 1923, 30.689,9 pts., con una elevada rentabilidad dado lo exiguo de su capital social (25.000 pts.). ARG-DHC (Hacienda). Utilidades. Libro 4.545.

108 IRS (1914). En general, las provincias que más acusaron la influencia de la guerra fueron las que tenían una fuerte industria metalúrgica. Sin embargo, el aumento de precios de las materias primas era una constante que afectó a prácticamente todas las provincias (Vázquez Vaamonde, 1996: 391). 
En Galicia, la industria metalúrgica se encontraba escasamente desarrollada, a pesar de que existía una cierta riqueza mineral, sobre todo de hierro, en la provincia de Lugo (Vázquez Vaamonde, 1996). En todo caso, hasta la guerra se observa un crecimiento considerable en el número de concesiones mineras (del Cueto y de Irimo, 1910: 42-43). Pero este impulso fue insuficiente para apuntalar un sector sidero-metalúrgico sólido. En los casos en los que la explotación se ponía en marcha, el mineral de hierro no era aprovechado en industrias metalúrgicas, sino que se exportaba, por efecto de la excesiva dependencia del capital extranjero, la ausencia de capital gallego dispuesto a invertir y la debilidad de la demanda interna ${ }^{109}$. Además, Galicia resultó perjudicada por las deficientes comunicaciones (del Cueto, 1922: 1415). Por otra parte, la guerra fue, en general, perjudicial para la minería gallega, toda vez que paralizó iniciativas en proyecto y algunas explotaciones, prolongándose la crisis más allá del armisticio ${ }^{110}$.

La industria metalúrgica coruñesa, constituida por pequeñas fundiciones de escasa proyección, demandaba poco mineral, procedente, en este caso, del norte de España. El comportamiento del sector estuvo ligado a factores endógenos. De una parte, la dinámica urbana, por cuanto sus principales demandantes eran clientes locales, en especial la construcción. Este sector sufrió una paralización en las primeras fases de la guerra que determinó la crisis de la metalurgia. De otra, el aumento de los costes empresariales, vía elevación de los precios (a causa del aumento de los fletes de transporte) del carbón español, más caro y de peor calidad que el inglés. Lo mismo ocurrió con otros inputs (IRS, 1916: 100). Por tanto, la industria metalúrgica quedó limitada a las reparaciones antes mencionadas y a la construcción de aquellas obras en las que el hierro constituía un componente básico (IRS, 1919b: 136).

El sector químico nacional prácticamente nació con la guerra mundial y se consolidó durante la posguerra. A pesar de las dificultades para asegurarse el aprovisionamiento de materias primas, este sector fue uno de los más favorecidos por el cese de la competencia extranjera (García Delgado, 1983b: 548). Galicia, en cambio, apenas participó en la industrialización química (Nogueira, 1980b: 216).

El sector químico se hallaba integrado por un grupo bastante heterogéneo de actividades, repartido entre la fabricación de cerámica, la elaboración de productos químicos y la fabricación de colas y jabones ${ }^{111}$. La guerra tuvo un impacto inicial negativo. El problema principal era la dificultad para la adquisición de materias primas y el encarecimiento de su precio (IRS, 1914: 87-88). Conforme avanzaba el conflicto,

\footnotetext{
109 Sequeiros (1986: 14), Rivas Moreno (1916: xii). La carencia de una infraestructura de transporte adecuada también jugó un papel muy importante. Vid. Gómez Martínez (2003).

110 La excepción fueron las explotaciones de ilmenita, estaño, wolframio y antimonio, localizadas en Noia, Lousame, Silleda, Carbia, Verín o Ponte Caldelas, que vivieron una etapa de esplendor, gracias al fuerte incremento de sus exportaciones con destino a los países en guerra (del Cueto, 1922: 12).

111 "Estadística administrativa de la contribución industrial y de comercio", 1914, en Anuario Estadístico de España, 1915. La fábrica más importante era la de carburo de calcio de Cee, de capital francés, un establecimiento que disponía de 7.000 caballos de potencia, que alimentaban varios hornos eléctricos con destino a la obtención de aquel producto (IRS, 1919a, 2: 215).
} 
los problemas se agravaron, padeciendo sus consecuencias la producción de jabón, lejía, cerillas, gas, la refinación de petróleo, etc. (IRS, 1919a, 2: 215).

Varias empresas destacaban dentro del sector. Una de ellas era la refinería de petróleo, propiedad de Mesa, Marchesi y Cía. ${ }^{112}$, en cuya fábrica se desarrollaban dos operaciones principales, la destilación de los petróleos brutos y la refinería propiamente dicha ${ }^{113}$. La empresa no sufrió excesivos reveses como consecuencia del comienzo de la guerra, debido a la relativa normalidad inicial del suministro de petróleo estadounidense (IRS, 1916: 101). Sin embargo, durante los años siguientes, sí atravesó dificultades, ante los inconvenientes para garantizar el aprovisionamiento de materias primas, especialmente del petróleo (IRS, 1919a, 2: 99), para recuperarse durante la posguerra. Sus beneficios en 1919-20 ascendieron a 145.316 y en 1920-21 a 111.935 pts.

Parecidos efectos tuvieron que soportar la fabricación de gas para alumbrado y calefacción (IRS, 1916: 101). Las tres fábricas existentes en la provincia de A Coruña (en Santiago, Ferrol y A Coruña) ${ }^{114}$ atravesaron dificultades en la fabricación de fluido. Las causas fueron la escasez y encarecimiento de los elementos de fabricación (carbón, tuberías de hierro fundido, tuberías de plomo, aparatos de calefacción) ${ }^{115}$.

Por lo que respecta a las industrias eléctricas, el cambio de siglo significó para Galicia el inicio de la etapa propiamente industrial del sector, gracias al surgimiento de varias pequeñas sociedades emplazadas en diversos puntos de la franja costera occidental, aunque el sector se mantuviese todavía en unos niveles muy bajos (Carmona, 1990b: 41). Las empresas más importantes eran la Sociedad General Gallega de Electricidad (SGGE), la Electra Industrial Coruñesa (EIC), la Electra Popular de Vigo y Redondela (EPVR) y la Hidroeléctrica del Pindo (Carmona, 1999: 1378).

La guerra no tuvo especial incidencia, debido a que los costes no sufrieron variaciones significativas. La materia prima más importante, el agua, se mantuvo aproximadamente al mismo precio que antes de la guerra. Además, las empresas todavía no habían entrado en una fase de expansión y concentración, con lo que la escala de operaciones era reducida y los mercados principalmente locales. En consecuencia, las necesidades de importación de maquinaria extranjera no fueron muy pronunciadas y la demanda fue atendida sin excesivas dificultades (IRS, 1919a, 2: 221).

La empresa más importante, la Cooperativa Eléctrica Coruñesa, S.A. (CEC), fundada en el año 1900, dedicada al suministro de alumbrado y fuerza motriz, con un capital de 500.000 pts. (tras sucesivas ampliaciones alcanzó las 635.000 pts. de

\footnotetext{
112 Fundada en 1881, con un capital de 300.000 pts. En 1905 el capital fue ampliado a 600.000 pts.

113 Memorias presentadas por los Ingenieros industriales de la Investigación de la Hacienda Pública, La Gaceta de Madrid, 12 de abril de 1900, p. 221.

114 Esta última, inicialmente de capital francés, fue absorbida en 1917 por las Fábricas Coruñesas de Gas y Electricidad. La coyuntura bélica determinó el cierre de las plantas de Santiago y Ferrol. Apuntes para el momento de la industria española de 1930, op. cit., p. 413.

115 El precio del carbón antes de la guerra era de 25-30 pts./tm, y en 1917 aumentó hasta 140 pts./tm, haciendo "imposible la vida industrial de esta fábrica" (IRS, 1919a, 2: 215).
} 
capital social en 1917), exhibe unos resultados apenas perjudicados por la guerra ${ }^{116}$. Las cifras globales de su balance presentan incluso una tendencia de crecimiento más acelerada que durante la preguerra. En el año 1918 el balance experimentó un incremento especialmente acusado, que coincidió con una ampliación de su capital social a 2.000 .000 pts., paralela a la constitución de las Fábricas Coruñesas de Gas y Electricidad $(F C G E)$, filial de la $C_{E C}{ }^{117}$. Por su parte, la $S G G E$, mostró una tendencia evolutiva muy favorable durante la guerra ${ }^{118}$, con unos beneficios anuales siempre por encima de las 150.000 pts., es decir, en torno al 7-8\% del capital social ${ }^{119}$.

En 1921 se encontraban domiciliadas en A Coruña cinco sociedades de suministro de energía eléctrica: $C E C, E I C, F C G E$, Hidroeléctrica del Pindo y la $S G G E^{120}$. El Cuadro 2.23 muestra que, para las empresas y fechas que existe información disponible en la contribución de utilidades, la posguerra supuso un retorno a la normalidad productiva, dado que sus beneficios mantuvieron, en general, una tendencia creciente. De todos modos, Hidroeléctrica del Pindo (en virtud de la demanda cautiva que representaba su suministro a la fábrica de carburo), la $S G G E$ (que se encontraba a punto de afrontar un salto

\footnotetext{
116 El volumen global de los balances anuales de la sociedad experimentó un progresivo crecimiento desde el inicio de su actividad, a un ritmo en torno al 5\% anual, acelerándose en 1916 y, sobre todo, en 1918, tras la ampliación de capital de ese año. Los beneficios durante la guerra evolucionaron del siguiente modo: $1914=169.504$ pts.; $1915=162.972$ pts.; $1916=165.470$ pts.; $1917=165.689$ pts.; $1918=154.817$ pts.; $1919=$ 182.197. La estabilidad era la norma, dado que en 1911-13 los beneficios fueron muy similares a los de 1915 . La rentabilidad, sin embargo, se vio afectada por la ampliación de capital de 635.000 a 2.000 .000 pts. del año 1918, cayendo del 25-26\% al 5-7\% del último bienio. Anuario Financiero y de Sociedades Anónimas, 1919, p. 599, 1920, p. 438, y ARG-DHC (Hacienda). Utilidades. Libros 4.535-4.541.

117 El motivo de la ampliación del capital social de la CEC fue la ampliación de su cartera de valores industriales, al detentar el control de las FCGE. Esta última sociedad, junto con la EPVR, adquirió en 1918 los activos de la extinguida Sociedad Anónima de Alumbrado, Calefacción y Fuerza Motriz de La Coruña y Vigo (constituida en Lyon, en el año 1906, con un capital de 1.525 .000 pts.), incluida la fábrica que ésta poseía en A Coruña. La creación de la FCGE respondió a la estrategia de lucha contra la competencia extraregional, puesto que pertenecía al mismo grupo empresarial que la SGGE, es decir, el de Sobrinos de José Pastor y Cía. Por tanto, todo el proceso correspondía, en realidad, a dos absorciones con las que la EPVR y el grupo de la SGGE reforzaban sus posiciones en A Coruña y Vigo. Anuario Garciceballos (1919-1920), op. cit.; Carmona (1999: 1382). La S.A. de Alumbrado, Calefacción y Fuerza Motriz antes de su extinción tuvo un comportamiento irregular, pues sus beneficios alcanzaron las 161.079,2 pts. en 1913 y 147.216,9 pts. en 1914. Pero en 1915 y 1917 tuvo pérdidas y sus beneficios en 1916 fueron de sólo $18.428,8$ pts. ARG-DHC (Hacienda). Utilidades. Libros 4.535-4.539.

118 Sociedad constituida inicialmente en Madrid en 1899, con un capital social de 2.000 .000 pts., aunque más tarde fue registrada en A Coruña, en el año 1911. Esta empresa mostró una positiva evolución empresarial durante la guerra, ya que sus beneficios durante la guerra fueron casi idénticos a los de 1911-13: $1914=160.304$ pts.; $1915=154.685$ pts.; $1916=165.509$ pts.; $1917=165.137$ pts.; $1918=162.850$ pts. Anuario Financiero y de Sociedades Anónimas, p. 600.

119 ARG-DHC (Hacienda). Utilidades. Libros 4.535-4.540 y Anuario Financiero y de Sociedades Anónimas, 1920, p. 439. Respecto a la EIC, no se han podido localizar cifras de beneficios, pero entre 1914-16 repartió dividendos del 10-11\%. Anuario Financiero y de Sociedades Anónimas, 1922, p. 521.

120 Anuario General de España (Bailly-Bailliére-Riera), 1921, op. cit. En realidad, en A Coruña la única empresa productora de electricidad era la empresa vinculada al Banco de Vizcaya, EIC, fundada en Bilbao en 1904 (aunque se hallaban presentes intereses del empresariado coruñés), con un capital de 1.700 .000 pts., en tanto la CEC y las FCGE compraban el fluido a aquella sociedad. La EIC era una empresa "extraordinariamente rentable" que poseía el "envidiado" salto de A Capela (Pontedeume), y que formaba parte del grupo del Banco de Vizcaya, competidor potencial del grupo de Sobrinos de José Pastor (Carmona, 1999: 1383). En 1909 esta empresa firmó un acuerdo con la SGGE, para evitar la competencia entre ambas, y en 1912 mancomunaron sus servicios en A Coruña (Sequeiros, 1986: 27). En 1914 y 1915 había repartido unos dividendos del 10\% y en 1916-20 del 11\%. Anuario Financiero y de Sociedades Anónimas, 1921, p. 690.
} 
cuantitativo en su escala empresarial) y, sobre todo, la $C E C$ sostuvieron una posición más firme, por cuanto sus beneficios fueron más elevados en relación con su capital social.

\section{Cuadro 2.23. Beneficios y rentabilidad sobre capital social obtenidos por las empresas de suministro eléctrico domiciliadas en A Coruña, 1919-22.}

\begin{tabular}{lcccccccc}
\hline & \multicolumn{2}{c}{1919} & \multicolumn{2}{c}{1920} & \multicolumn{2}{c}{1921} & \multicolumn{2}{c}{1922} \\
\cline { 2 - 9 } & \multicolumn{1}{c}{$\mathbf{B}^{\text {os }}$} & Rentb & B $^{\text {os }}$ & Rentb & B $^{\text {os }}$ & Rentb & B $^{\text {os }}$ & Rentb \\
\hline CEC, S.A. & 182.197 & $9,1 \%$ & 220.049 & $11,0 \%$ & 276.361 & $13,8 \%$ & 318.153 & $15,9 \%$ \\
\hline FCGE & 32.592 & $1,6 \%$ & 118.010 & $5,9 \%$ & 181.680 & $9,1 \%$ & 238.027 & $11,9 \%$ \\
\hline H. del Pindo, S.A. & 759.333 & $63,3 \%$ & - & - & 439.134 & $36,6 \%$ & 231.700 & $19,3 \%$ \\
\hline SGGE, S.A. & 135.390 & $6,8 \%$ & 136.426 & $6,8 \%$ & 120.393 & $6,0 \%$ & 186.847 & $9,3 \%$ \\
\hline
\end{tabular}

Fuente: ARG-DHC (Hacienda). Utilidades. Libros 4.540-4.544 y Anuarios Financieros y de Sociedades Anónimas.

Las industrias textiles más importantes no figuraban en la ECI, al tributar por utilidades. Son la Primera Coruñesa, S.A. e Hilados y Tejidos Vilasantar, S.A. Estas sociedades modernizaron sus instalaciones, hasta el punto de poseer centrales hidroeléctricas propias para el suministro de energía a sus fábricas ${ }^{121}$. En general, el éxito relativo de estas dos empresas ${ }^{122}$, radicó en que se especializaron en la producción de géneros baratos, que era donde mejor competían con los tejidos catalanes (Carmona, Espido y Lozano, 1995: 73).

La Primera Coruñesa se constituyó con un capital de 1.000 .000 pts. ${ }^{123}$. Inicialmente, la guerra no produjo un impacto inmediato en los resultados empresariales (IRS, 1914: 545). Sin embargo, el desarrollo del conflicto introdujo numerosas distorsiones en las operaciones de la industria, hasta el punto de convertirlo probablemente en el

121 El antecedente inmediato de Hilados y Tejidos de Vilasantar fue la empresa La Arzuana, aparecida en Vilasantar (Arzúa), cuyo propietario, Luciano Soler, la vendió a la familia Miranda, constituyéndose la citada sociedad anónima, dedicada a la fabricación de tejidos, con un capital social de 1.500 .000 pts. y domicilio en A Coruña. En esta segunda fase la fábrica fue ampliada, y funcionó hasta la década de 1950 (Carmona, Espido y Lozano, 1995: 73). Anuario de Sociedades Anónimas (Anuario Garci-Ceballos), Madrid, Año I, 1918-1919, ed. de Ilustración Financiera.

122 El 1873, el comerciante ferrolano Francisco Barcón fundó otra empresa textil en Xubia (Neda, Ferrol), que fue, junto a Hilados y Tejidos de Vilasantar y la Primera Coruñesa "uno de los restos del naufragio del otrora importante sector textil". Posteriormente, sobre los restos de esta empresa, se constituyó otra empresa textil, la Galicia Industrial, S.A., fundada en 1919, con un capital social de 1.000 .000 pts. (ampliados en 1928 a 3.000.000), dedicada a la fabricación de hilados y tejidos (crudos, curados y asargados) que en 1952 fue absorbida por Dionisio Tejero, S.A. Esta última empresa tuvo su origen en la sociedad creada por Dionisio Tejero Pérez el 22 de febrero de 1905, que fue transformada en sociedad anónima en 1952. La presidencia de ambas sociedades correspondió a Dionisio González Tejero. Carmona (1998: 165-166). Anuario Financiero que comprende el historial de valores públicos y de sociedades anónimas de España, Bilbao, 1957-58, Año XLI, p. 648.

123 Esta fábrica fue fundada en 1873 por la sociedad Núñez y Miranda. Fue parcialmente destruida por un incendio en 1889. La reconstrucción de la fábrica se llevó a cabo después del siniestro, iniciándose de nuevo la producción en 1891. En 1905 empleaba a casi 300 obreras y 36 operarios (Brey, 1992: 38). 
sector más afectado (IRS, 1919a, 2: 217, 233). Así lo refleja la cuenta de resultados de la sociedad, que en 1913 arrojaba un beneficio de 9.150,5 pts., incrementándose a $56.469,2$ pts. en 1914 y a $195.292,6$ pts. en 1915, aunque desde 1916 los beneficios descendieron a 98.446,4 pts., y en 1917-19 la sociedad entró en pérdidas. Por su parte, Hilados y Tejidos Vilasantar atravesó una tesitura parecida, ya que sus resultados pasaron de unos beneficios de 41.463,2 pts. en 1913 a pérdidas en 1914-15 y 1917-18 ${ }^{124}$.

Varios factores contribuyeron a la crisis. En primer lugar, la dificultad para la obtención de algodón, de otros inputs y de maquinaria, como resultado de los obstáculos para su transporte desde el exterior ${ }^{125}$. En segundo lugar, el retraimiento de la demanda, como consecuencia de la subida de precio de los productos. Finalmente, los problemas de liquidez, fruto de la conjunción de varios factores: el hecho de que las condiciones de pago eran a noventa días desde la fecha de conocimiento de embarque, el establecimiento de un seguro especial de guerra para responder a la inseguridad del transporte y la imposición del pago al contado en Londres o Liverpool contra entrega de documentos de embarque en América (IRS, 1916: 103; 1914: 46-47, 545). Así, hacia el final de la guerra, las cuatro fábricas de hilados y tejidos de la provincia se habían visto obligadas a una labor intermitente (IRS, 1919a, 2: 133, 217).

Al término de la guerra, el sector experimentó una aguda crisis en España (García Delgado, 1983b: 548). Sin embargo, en A Coruña se recuperó con celeridad. Frente a las utilidades negativas obtenidas por la Primera Coruñesa en 1918-19, los beneficios se elevaron a $258.974,4$ pts. en $1920,400.054,9$ en $1921,386.788,5$ pts. en 1922 y $212.514,3$ pts. en 1923 , con una rentabilidad muy elevada, entre el 21,3 y el $40 \%$. Por su parte, Hilados y Tejidos también vio crecer sus beneficios de 39.413,9 pts. en 1919 , a $44.559,8$ pts. en $1920,400.872,6$ pts. en 1922 y $159.058,9$ pts. en 1923 , con rentabilidades entre el 2,6 y el $26,7 \%{ }^{126}$.

La industria de la cerámica, vidrio y cal tenía una escasa presencia en la ciudad. La fábrica de mayor relieve era Hijos de B. Escudero y Cía., dedicada a la confección de mosaicos, losetas, pulimentos de granito, etc., cuyo destino principal era la utilización en pavimentos de los edificios de la ciudad (Rubio, 1916: 20). La guerra afectó a la industria por la vía de la subida de los fletes, así como por la dificultad de comunicaciones con Italia, país del que se importaban considerables cantidades de mármoles y productos similares (IRS, 1919a, 2: 228). Destacaba asimismo la fábrica de biselar, grabar y decorar cristal, propiedad de Narciso L. Pereira, a la que la guerra perjudicó por la mayor dificultad de adquirir vidrios y cristales en las fábricas nacionales y en el extranjero (IRS, 1919a, 2: 153, 229).

La industria de cuero y calzado sufrió dos grandes descensos en Galicia: durante los años ochenta del siglo XIX, y en la Primera Guerra Mundial, que coincidieron con la difusión de los cambios técnicos a nivel mundial (Carmona, 1990b: 29-30). A la altura de la guerra, la especialización productiva de las fábricas de la provincia se

\footnotetext{
124 La fuente consultada no ha permitido determinar la cuantía exacta de las pérdidas sufridas por ambas empresas en ese período. ARG-DHC (Hacienda). Utilidades. Libros 4.535-4.541.

125 "Un problema de gran interés". Boletín COCINC, n 21, febrero de 1918, p. 2.

126 ARG-DHC (Hacienda). Utilidades. Libros 4.541-4.545.
} 
concentraba en productos de escasa complejidad técnica, baja calidad y reducido valor añadido. Durante los primeros meses del conflicto, la curtición alcanzó momentos prósperos, manteniéndose la favorable coyuntura incluso durante los primeros seis meses de 1915, gracias a la fuerte demanda procedente de Francia. Pero el negocio sufrió pronto un freno repentino (IRS, 1916: 107, 111).

La crisis que había venido sufriendo el sector se agudizó. Desde mediados de 1915 las fábricas forzaron la producción en perjuicio de la calidad del producto. Además, la industria se vio muy afectada por efecto de la dificultad de recepción y por el encarecimiento de los precios de las pieles (de procedencia americana), motivada por la extraordinaria elevación de los fletes, lo que repercutía en el precio final del producto ${ }^{127}$. La recesión tuvo su origen también en un problema de demanda, pues muchas fábricas tuvieron que cerrar por exceso de producción, debido a que ésta era muy superior a las necesidades del país ${ }^{128}$. La producción se limitaba a suministrar curtidos para suelas corrientes y aunque suministraba a un mercado nacional, los mayores consumidores eran regionales. La guerra terminó amortiguando su impacto inicial, pero la escasa modernización del sector condicionó definitivamente su futuro.

Respecto a las fábricas de calzado, la más sobresaliente era la de Angel Senra Fernández. La empresa había sido creada en 1879, siendo ampliada en 1913, e instalada en un edificio de nueva planta, con más de $2.000 \mathrm{~m}^{2}$ de superficie. Sus materias primas consistían en suelas de procedencia gallega y pieles de fuera de la región y abastecía a todo el mercado nacional, con una pequeña exportación, gracias a que su especialidad era el calzado fino (Rubio, 1916: 20-21). El sector resultó perjudicado, debido a la imposibilidad de importar pieles finas de Alemania, teniendo que recurrir a las pieles autóctonas (insuficientes), con lo que los beneficios, aunque elevados, fueron menores (IRS, 1919a, 2: 147). Su principal vía de crecimiento fue la demanda militar europea, especialmente del ejército francés.

27 IRS (1914: 124), Boletín del Instituto de Reformas Sociales, vol. II, 1915, p. 304.

128 Estudios gallegos, 20 de febrero de 1915, $\mathrm{n}^{\circ} 2$. 



\section{2}

La "paz social" de la

Dictadura de Primo de Rivera

y las transformaciones

del ciclo económico, 1923-1930 



\section{La economía de A Coruña se adentra por una Senda inestable de CRECIMIENTO SOSTENIDO}

A nivel internacional, los años veinte fueron testigo de los esfuerzos por retornar a las condiciones de normalidad de preguerra. Para ello, las políticas económicas aplicadas se afanaron en restaurar los principales símbolos de la estabilidad anterior. Sin embargo, tras la guerra surgieron nuevos equilibrios y nuevas condiciones que imposibilitaban en la práctica el logro de aquel ideal. Dentro de este período, ordinariamente se ha establecido una bisagra hacia mediados de los años veinte. Si la primera mitad de la década presenció todavía algunos desajustes, a partir de 1925 aparentemente se logró una relativa normalidad económica. Pero continuaban existiendo profundos desequilibrios en las relaciones económicas internacionales que la crisis de finales de la década puso crudamente de manifiesto.

En España, el escenario político estaba experimentando una transformación. El directorio militar constituido en 1923 coincidió con una nueva coyuntura económica de prosperidad. El rápido crecimiento económico perduró, no sin discontinuidades, hasta 1929 (García Delgado, 1986: 120), favorecido por la favorable coyuntura internacional (Harrison, 1988: 141) y por la confluencia de un conjunto de innovaciones tecnológicas y económicas disponibles desde hacía una década (Carreras, 1990: 160). Así lo atestigua el crecimiento del PIB per cápita, que aumentó un 2,5\% anual, resultado del impulso generado por la demanda de inversión y, sectorialmente, por el crecimiento de la industria y la construcción (Comín, 2002: 291). Las industrias de bienes de consumo se desarrollaron, pero el crecimiento más notable correspondió a la industria pesada, en persecución del ritmo de una demanda espoleada por la intensificación de los procesos migratorios campo-ciudad y la consiguiente aceleración de la urbanización.

Los elementos clave que distinguen esta etapa fueron el marcado nacionalismo económico y el fuerte intervencionismo estatal (Comín, 1993), aunque ambos no fuesen sino una culminación de tendencias iniciadas varias décadas antes, fortalecidas durante la guerra mundial (García Delgado, 1991: 181). Pero, en general, el modelo de crecimiento fue desequilibrado. El crecimiento industrial fue básicamente extensivo, con ganancias en la productividad del trabajo muy débiles e incluso negativas, con una pérdida del poder adquisitivo de los salarios que contribuyó a estrangular aún más los niveles de consumo, con un excesivo énfasis en las obras públicas (que permitía absorber el paro, aunque a costa del crecimiento del gasto público), con un creciente desequilibrio de la Hacienda, y con importantes inyecciones de beneficios, pero gracias a que el monopolio de facto existente en algunos sectores permitía trabajar con costes de producción no competitivos (Aracil y Segura, 1995: 396).

Las investigaciones desarrolladas en los últimos años señalan que Galicia había retomado en los años veinte el camino hacia la modernización que se había iniciado con el arranque del siglo (Villares, 1991: 148), a través del cambio que se advierte en el sector agrario (Fernández Prieto, 1992) y en el complejo marítimo-pesquero. El crecimiento probablemente guarda relación con el dinamismo tecnológico vinculado a las actividades marítimas industriales (Ortiz-Villajos, 1999). 
La Dictadura de Primo de Rivera, sin embargo, no parece haber constituido el período más dinámico en términos de constitución de nuevas sociedades, ni en Galicia ni en A Coruña. Superada la excepcional coyuntura bélica, el año de máxima actividad fue 1921. El ritmo de creación de sociedades y el capital invertido fueron similares en Galicia y en España, y la evolución de las dos provincias más importantes, A Coruña y Pontevedra, muy semejante entre sí. El auge que había traído la guerra se cortó a mediados de los años veinte, siguiendo una breve etapa de acentuada caída del número de sociedades creadas en 1928-30, en el que el declive fue más intenso en las provincias de A Coruña y Pontevedra que en el resto de España (Abreu, 1992: 254-256). Como factores principales, cabe apuntar la culminación de la fase de conflictividad asociada al ciclo bélico, que continuó manifestándose con dureza en los años de la inmediata posguerra y el final del impulso generado por la demanda exterior sobre ciertos sectores económicos regionales. Una vez estabilizada la economía, se produjo un retorno a la normalidad en el ritmo de creación de empresas aproximadamente hacia 1925-28.

De todos modos, la serie presenta pronunciadas oscilaciones en A Coruña y Pontevedra. En el sur se registró un mayor dinamismo, como consecuencia de la consolidación del impulso industrial acaecido durante la guerra. La idea de la estabilidad resulta reforzada al analizar la serie de capitales en la provincia de A Coruña. En cambio, la serie de Pontevedra experimentó considerables movimientos, con una fuerte caída, coincidente con la crisis de 1929. Es probable que la distinta estructura económica de las dos principales ciudades - A Coruña y Vigo - originase el distinto comportamiento. Según Abreu (1992), el entramado construido en las Rías Bajas en torno a la transformación de los productos del mar vivió en los años veinte una etapa difícil. En cambio, la consolidación de las actividades terciarias orientadas hacia el mercado urbano, junto con el afianzamiento del sector financiero y el de la producción y distribución de energía eléctrica, permitieron una mayor estabilidad en A Coruña.

Por otra parte, el factor responsable de la divergencia entre las series de sociedades y capitales residía en la presencia todavía dominante de las sociedades colectivas, que experimentaron un descenso en 1922-29. En cambio, las sociedades anónimas, mucho menos dinámicas en número, contribuyeron a la estabilidad de la serie de capitales, mientras que las sociedades limitadas desempeñaron un papel fundamental, por cuanto su número y su capital crecieron de manera significativa durante la primera mitad de los años veinte y hacia el final del período dictatorial ${ }^{1}$. Por tanto, se consolidó la modernización en las formas jurídicas que se inició en Galicia durante esa década².

\footnotetext{
En el Anuario Financiero y de Sociedades Anónimas de España de 1923 figuraban inscritas en la provincia un total de 29 sociedades anónimas, con un capital nominal total de 83.383 .000 pts., de un total de 68 empresas en Galicia, con un capital de 118.385 .500 pts. La distancia con respecto a la media española era considerable, ya que estos datos arrojan un total de 0,04 sociedades anónimas por cada 1.000 habitantes en A Coruña frente a la media española de 0,23. El diferencial respecto al capital era aún mayor (123,2 pts./habitante en A Coruña frente a 767,5 en España). Hacia el final de los años veinte, en 1929, la situación apenas había mudado. El total de sociedades anónimas coruñesas era ahora de 29, pero las ratios relativas permanecían prácticamente inalteradas.

2 Abreu (1992). Algunas de las empresas más importantes creadas en los años veinte no se constituyeron bajo la forma de sociedad anónima, lo que avala la hipótesis de Carmona (1998: 153) de que en Galicia es imposible realizar una identificación entre las empresas de mayor tamaño y las sociedades anónimas.
} 
Hacia 1922 se detectan síntomas de un cambio de tendencia en la economía de A Coruña. Se aprecia un desarrollo del comercio, aunque el sector que más creció fue el de los servicios. A pesar de todo, la Dictadura no constituye un bloque homogéneo, ya que a lo largo de la segunda mitad de los años veinte se asiste a una desaceleración del ritmo de crecimiento económico, coincidente con la tendencia de la economía española. Las causas de la recuperación fueron similares a las de anteriores períodos de crecimiento.

En primer lugar, el restablecimiento del negocio de la emigración. En segundo lugar, A Coruña se hallaba emplazada en un entorno predominantemente agrario, lo que la hacía muy dependiente de la prosperidad de este sector a nivel regional. La aludida transformación de las estructuras agrarias gallegas permitió a los comerciantes de A Coruña incrementar su volumen de negocio. En tercer lugar, la demanda asociada a las funciones propias de las capitales provinciales, que se desarrolló especialmente durante el período dictatorial. En cuarto lugar, aunque el sector pesquero experimentó una aparente irregularidad, fue una fuente de innovaciones. Lo sustantivo reside en que los empresarios se vieron sometidos a unas presiones que estimularon la adopción de respuestas creativas. Una de las apuestas más arriesgadas fue la emigración de la flota, lo que condiciona la información que proporcionan las estadísticas pesqueras, transmitiendo una imagen pesimista que no se correspondía plenamente con la realidad.

\section{Cuadro 3.1. Número y tonelaje de las embarcaciones dedicadas a la pesca en los principales puertos peninsulares en 1927.}

\begin{tabular}{lcclcclllc}
\hline \multicolumn{1}{c}{ Vapores $>\mathbf{5 0}$ tms } & \multicolumn{3}{c}{ Vapores $<\mathbf{5 0}$ tms } & \multicolumn{3}{c}{ Total } \\
\hline & $\mathbf{N}^{\mathbf{0}}$ & tonelaje & & $\mathbf{N}^{\mathbf{0}}$ & tonelaje & & $\mathbf{N}^{\mathbf{0}}$ & tonelaje \\
\hline Vigo & 180 & 11.413 & Vigo & 260 & 9.640 & Vigo & 440 & 21.053 \\
\hline San Sebastián & 65 & 7.083 & Gijón & 65 & 1.811 & San Sebastián & 120 & 8.671 \\
\hline Huelva & 62 & 4.327 & San Sebastián & 55 & 1.588 & Huelva & 85 & 5.106 \\
\hline Málaga & 41 & 3.568 & A Coruña & 33 & 1.031 & Málaga & 62 & 4.242 \\
\hline Gijón & 28 & 1.740 & Huelva & 23 & 779 & Gijón & 93 & 3.551 \\
\hline A Coruña & 17 & 1.743 & Málaga & 21 & 674 & A Coruña & 50 & 2.774 \\
\hline Cádiz & 6 & 839 & Cádiz & 15 & 513 & Cádiz & 21 & 1.352 \\
\hline
\end{tabular}

Fuente: Los puertos nacionales de pesca en España. Aportación de Vigo al estudio del problema, Vigo, Ediciones de la Unión de Entidades Viguesas, 1928, pp. 17-18, tomado de la Lista oficial de Buques de Guerra y Mercantes, 1927.

Se observa una recuperación coyuntural del volumen de capturas pesqueras hacia 1924, aunque hasta 1927 se estancó a unos niveles próximos a los de $1923^{3}$. Los precios

3 Archivo COCINC, Legajo, A.D./5. 
tampoco se recuperaron, sino que experimentaron una caída en términos reales hasta la Guerra Civil, lo que forzó la orientación hacia otras especies pelágicas (espadín, jurel o bocarte). Esta situación forzó a la flota a acceder desde 1927-28 a los caladeros del Mar Céltico y suroeste de Irlanda (Giráldez, 1997a: 26). En ese momento coincidió una subida de los costes de producción, vinculada al alejamiento de los caladeros de las costas españolas, con un estancamiento de la demanda (vinculado a la inflación de posguerra $)^{4}$. Por fin, a finales de los años veinte, el panorama mostraba mejores perspectivas, ya que en 1928 se recuperaron los volúmenes de capturas ${ }^{5}$. Si tomamos como referente la flota pesquera matriculada, A Coruña se había consolidado como uno de los principales puertos pesqueros nacionales, aunque a cierta distancia de Vigo, cuyo dominio era incuestionable (Cuadro 3.1).

Sin embargo, el crecimiento fue breve porque, coincidiendo con la crisis de los años treinta, la pesca coruñesa atravesó una nueva recesión (González Laxe, 1984: 99). La producción pesquera continuó aumentando durante algunos años, pero los beneficios de los productores disminuyeron, ya que el sector se hallaba en un período de transformación tecnológica. Las industrias derivadas (conservas) también se resintieron, debido al elevado precio de la pesca y de los inputs, la depresión de los mercados exteriores debida a la revalorización de la peseta y a la crisis económica internacional ${ }^{6}$. De todos modos, las fluctuaciones de la actividad pesquera, inherentes por otra parte a las propias características del recurso, no impidieron que A Coruña se consolidase como uno de los más importantes puertos de pesca de altura del norte y noroeste peninsular, y uno de los principales exportadores de pescado fresco ${ }^{7}$.

Las deficiencias organizativas del sector fueron soslayadas por algunos empresarios especialmente dinámicos, quienes optaron por la estrategia de la formación de empresas financiera y productivamente más sólidas. La primera fue La Pesquera del Norte de España, S.A., constituida en 1923, compañía que complementaba la pesca de altura con la fabricación de hielo, reparación naval y explotación de cámaras y vagones frigoríficos ${ }^{8}$. Pero la empresa más destacada fue Pescaderías Coruñesas, $S$.A., constituida en 1924 , con un capital de 10.000 .000 pts $^{9}$. Su objeto era la industria

\footnotetext{
$4 \quad$ ACTAS Pleno COCINC, 1927.

5 Por otra parte, aunque la información es fragmentaria, los beneficios de los armadores, al menos de los más sólidos, parecen haberse recuperado. Es el caso de Armadores de Buques Pesqueros, S.L., empresa dedicada también a la explotación de carbones minerales, a la administración de un Depósito comercial, al suministro de agua a buques, y que poseía la concesión del Depósito Franco de Carbones. Su rentabilidad sobre el capital social (100.000 pts.) se situó en un elevado 45,1\% en 1928 frente al 18,9\% de 1927. En 1929 (32,6\%), 1930 (33\%) y 1931 (40,9\%) también obtuvo resultados muy positivos.

$6 \quad$ Argüelles (1931). Los precios del pescado descargado experimentaron un considerable aumento durante los últimos años de la Dictadura y durante la República, pero la subida fue claramente menor que la sufrida por el promedio español. Orientación Económica y Financiera, I, 2, julio-agosto, 1943, p. 14.

7 La mayor parte de la producción se destinaba a consumo en fresco. La Coruña puerto pesquero nacional, La Coruña, 1927.

8 "La Pesquera del Norte de España, S.A. Algunas consideraciones sobre esta importantes industria", en Libro de Oro de Galicia, Madrid, Rivadeneyra, 1932, [s.a.], p. 77.

9 Pescaderías Coruñesas, S.A. figura inscrita en el Registro Mercantil desde 1917, con un capital de 200.000 pts., aunque ya estaba en funcionamiento con anterioridad. En 1918 amplió su capital hasta 1.800 .000 pts. y al año siguiente hasta 3.800 .000 pts. (Giráldez, 1996: 277, 302), para reconstituirse con un capital de 10.000 .000 pts. en 1924. En diciembre de 1925 adquirió de la S.A. de Pesca y Navegación su flota pesquera por valor de 1.600.000 pts. Anuario Financiero y de Sociedades Anónimas, 1926, p. 211.
} 
pesquera en todas sus manifestaciones, derivaciones y aplicaciones. Agrupaba la fase de producción, el transporte y la comercialización de la pesca. En 1911 inauguró su primer establecimiento de venta de pescado al por menor en Madrid, incrementando considerablemente su presencia en los años siguientes, al tiempo que asentaba su domicilio social en la capital del país, e iba abriendo sucesivamente sucursales en los principales puertos. Su importancia y su influencia sobre el mercado fueron notorias, ya que fijaba los precios y actuó como pionera en la transformación del comercio minorista de Madrid en una línea netamente capitalista (Giráldez, 1997a: 19).

\section{LA CULMINACIÓN DE LA MODERNIZACIÓN DEMOGRÁFICA}

La evolución económica de la ciudad en la tercera década del siglo XX tuvo repercusiones inmediatas en su estructura demográfica. Su progresión fue la tercera más rápida de las ciudades gallegas, con una tasa de crecimiento del 19,5\% en 1920-30, siendo superada por Ourense y por Vigo (Cuadro 2.2). Pasados los efectos distorsionadores de la guerra, se observa ahora un cierto retroceso a los patrones de preguerra. El crecimiento poblacional de la ciudad se alimentó del crecimiento vegetativo, más que de la inmigración rural, y la principal razón de este desequilibrio reside en la recuperación de la corriente migratoria gallega con destino a América.

Comparativamente, el crecimiento de la ciudad durante los años veinte ocupó un nivel intermedio en el conjunto español, ya que la posición en el ranking de capitales que había alcanzado en $1920\left(18^{\mathrm{a}}\right)$ se mantuvo en 1930. La corriente migratoria con destino a las ciudades españolas, que se había iniciado durante la guerra, se consolidó e incluso se aceleró en las ciudades de mayor tamaño (principalmente las ciudades industriales) (Cuadro 3.2), que aprovecharon este período para dar un salto cuantitativo y cualitativo importante (García Barbancho, 1967).

Si tomamos como referencia el espacio conformado por los partidos judiciales, como una aproximación del área de influencia inmediata de la ciudad, se observa que A Coruña fue capaz de atraer un volumen considerable de la emigración provincial, aun cuando el resto de los partidos judiciales tuviesen saldos negativos elevados (Cuadro 3.3) ${ }^{10}$. Sin embargo, esto no impidió que después de la guerra, la emigración exterior gallega se recuperase y aumentase hasta 1929, cuando se frenó bruscamente (de Juana y Fernández, 1990: 56). En consecuencia, continuaba existiendo una lamentable falta de articulación entre A Coruña (también el resto de ciudades gallegas, que presentaron la menor capacidad de atracción del país) y el resto de la provincia y de la región, consecuencia de un modelo de crecimiento económico subordinado y desarticulado. Por tanto, A Coruña se separó parcialmente del patrón de las ciudades pequeñas y medias españolas, en las que la expansión demográfica se cimentó casi exclusivamente en la inmigración. Pero sí compartió con otras muchas ciudades la circunstancia de ser incapaces de captar a elevados contingentes de emigración provincial (Delgado, 1995: 77-80).

\footnotetext{
10 En esas mismas fechas, el otro gran espacio aglutinador de población fue la ciudad de Vigo, que en 1901-10 recibió un saldo inmigratorio positivo de 8.094 habitantes, en 1911-20 de 11.966 y en 1921-30 de 8.748 , mostrando todo el potencial que estaba desarrollando como centro industrial. También Pontevedra tuvo un saldo positivo entre 1921 y 1930 de 3.819 habitantes (García Barbancho, 1967: tabla A. 1). Las ciudades españolas de mayor tamaño presentan saldos positivos más elevados que A Coruña. Por tanto, la capacidad de atracción de estas últimas era considerablemente mayor.
} 


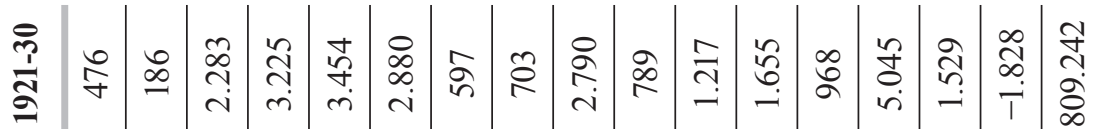

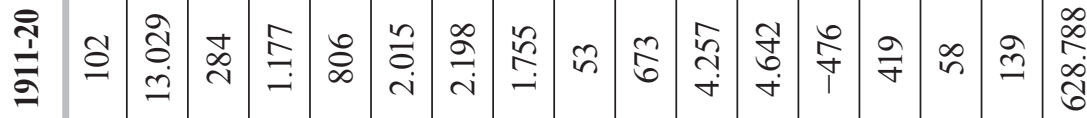

คें

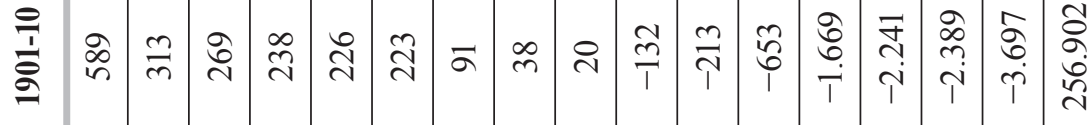

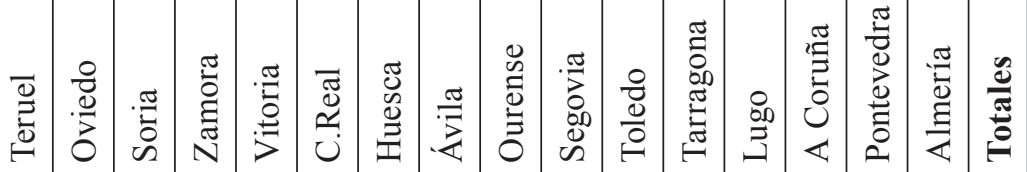

:

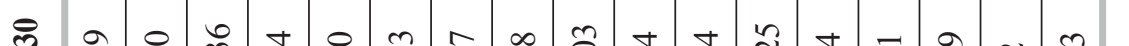

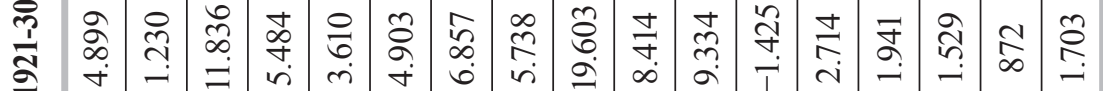

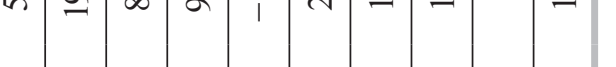

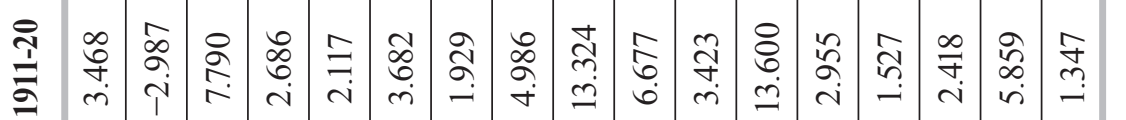

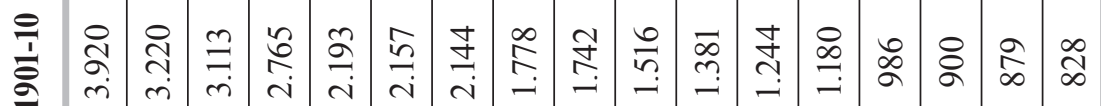

$\stackrel{2}{\frac{2}{2}}$

ֻ

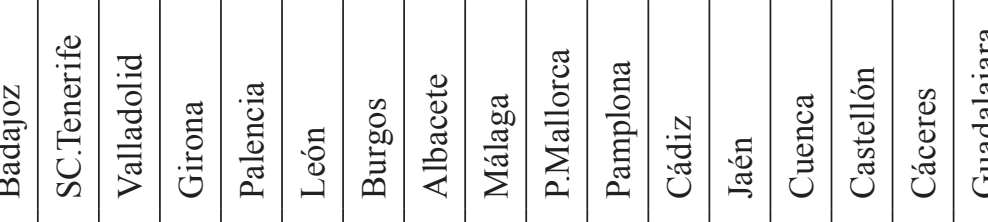

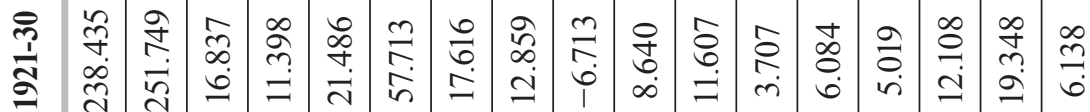

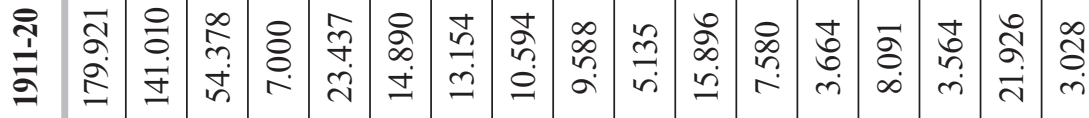

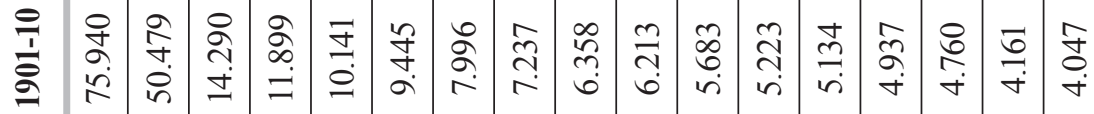

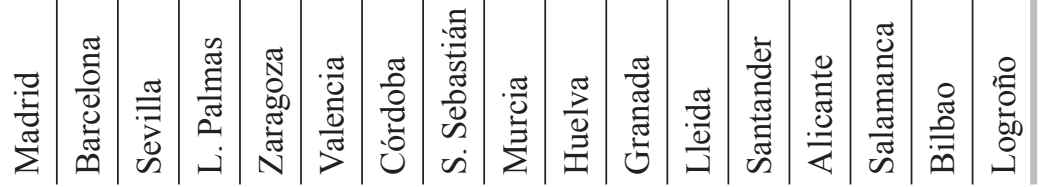


Desde el punto de vista del comportamiento endógeno de la población, en el entorno occidental el primer tercio del siglo supuso una consolidación de la transición demográfica, con la consiguiente aceleración de la caída de la natalidad y la fecundidad. En las ciudades españolas se registró asimismo un descenso de la fertilidad, especialmente pronunciado en 1920-30, lo que indica que la transición demográfica ya se había iniciado. Estos niveles se muestran aun más bajos en las ciudades de mayor tamaño, revelando una relación negativa entre el tamaño de la ciudad y los niveles de fertilidad (Reher, 1989: 211-214).

Sin embargo, en A Coruña los años veinte representan una fase de transición entre el comportamiento de los primeros años del siglo y el definitivo asentamiento de un régimen demográfico moderno. Tras la recuperación coyuntural de la natalidad en la posguerra, a partir de 1923 este indicador atravesó una fase de indecisión, con sucesivos aumentos y caídas, hasta que a partir de 1931 se inició una decidida y definitiva caída de esta variable en la ciudad. En conjunto, el período 1923-30 muestra un suave incremento de la tasa de natalidad del $2,3 \%$.

\section{Cuadro 3.3. Saldos migratorios, por partidos judiciales, en la provincia de A Coruña, 1901-40.}

1901-10 1911-20 1921-30 1931-40

1901-10 1911-20 1921-30 1931-40

\begin{tabular}{lcccclcccc}
\hline Arzúa & -6.097 & -2.755 & -2.447 & 377 & Negreira & -3.121 & -2.311 & -2.920 & -38 \\
\hline Betanzos & -6.144 & -4.856 & -4.141 & -2.161 & Noia & -2.740 & -1.027 & -4.435 & -2.479 \\
\hline Carballo & -4.391 & -2.682 & -1.717 & 1.467 & Ordes & -2.488 & -1.943 & -854 & 335 \\
\hline Corcubión & -3.450 & -1.478 & -3.705 & -2.424 & Ortigueira & 520 & -2.030 & -1.763 & -7.014 \\
\hline A Coruña & -6.711 & -2.251 & 4.796 & 14.139 & Padrón & -3.800 & -2.092 & -2.601 & -1.136 \\
\hline Ferrol & -10.669 & 4.587 & 1.131 & 11.822 & Pontedeume & -3.092 & -4.101 & -2.185 & -298 \\
\hline Muros & -2.071 & -1.305 & -3.197 & -1.640 & Santiago & -5.284 & -2.694 & 186 & 6.732 \\
\hline Provincia & & & & & & -59.538 & -26.938 & -23.852 & 17.682 \\
\hline
\end{tabular}

Fuente: García Barbancho (1967: tabla A. 1).

Por su parte, la mortalidad en España continuó con el descenso iniciado antes de la guerra, interrumpido circunstancialmente con la gripe de 1918 (Pérez Moreda, 1985), a un ritmo más acelerado que la caída de la natalidad (Rodríguez Osuna, 1985: 27). En A Coruña, la mortalidad consolidó la tendencia iniciada con el final del conflicto, lo que demuestra el asentamiento definitivo de la transición de esta variable hacia pautas modernas. Se asiste a una normalización del número de fallecimientos, durante los años veinte, cuya responsabilidad habría que atribuir a las condiciones de estabilidad socioeconómica que vivió la ciudad, y que se proyectaron incluso a los primeros años treinta, etapa en la que se agregaron las reformas sociales republicanas. En definitiva, 
durante la Dictadura las tasas de crecimiento vegetativo permitieron un crecimiento demográfico más sólido, no basado casi exclusivamente en la inmigración neta, como había ocurrido en buena medida durante las décadas anteriores.

El proceso de urbanización español presenta un notorio retraso cronológico en relación con los países desarrollados, cuya causa principal radica en el tardío proceso de industrialización, que difirió la urbanización de la sociedad española hasta el primer tercio del siglo XX e incluso más tarde ${ }^{11}$. Sin embargo, recientemente se ha señalado que desde los años veinte las ciudades españolas experimentaron un considerable cambio (Bonet, 1992: xii). Se presentó una nueva oportunidad de desarrollo, en especial para las urbes pequeñas y medianas, a partir de la consolidación del sector servicios. A partir de esta década, se reforzó la especialización terciaria de esas poblaciones; pero, paralelamente, se inició en varias ciudades una incipiente industrialización de su base económica (Delgado, 1995: 213).

\section{Cuadro 3.4. Principales actividades socioprofesionales en A Coruña, 1930 (hombres, en porcentaje).}

\begin{tabular}{lccccccccccc}
\hline & \multicolumn{10}{c}{ Hombres } \\
\hline Grupos de edad & $<15$ & $16-20$ & $21-25$ & $26-30$ & $31-35$ & $36-40$ & $41-50$ & $46-50$ & $51-60$ & $>60$ & Total \\
\hline Tabaco & & & 0,08 & 0,13 & 0,34 & 0,14 & 0,11 & 0,12 & 0,22 & 0,17 & 0,09 \\
\hline Industrias diversas & 1,42 & 26,88 & 26,60 & 39,21 & 37,16 & 35,27 & 32,8 & 34,79 & 33,87 & 30,99 & 21,44 \\
\hline Navegación & 0,07 & 2,46 & 4,91 & 7,35 & 7,82 & 7,97 & 9,87 & 6,69 & 4,63 & 2,82 & 3,76 \\
\hline Comercios diversos & 0,65 & 6,62 & 5,27 & 7,35 & 8,71 & 8,49 & 8,55 & 8,21 & 6,77 & 4,23 & 4,73 \\
\hline Servicio doméstico & 0,08 & 0,86 & 0,49 & 0,59 & 0,3 & 0,42 & 0,40 & 0,61 & 0,52 & 0,79 & 0,39 \\
\hline Ejército & 0,10 & 10,41 & 31,33 & 4,65 & 4,83 & 5,96 & 6,08 & 3,65 & 3,97 & 0,73 & 6,48 \\
\hline Administración Pública & & 0,36 & 0,95 & 2,01 & 2,90 & 2,35 & 3,16 & 3,47 & 4,93 & 3,83 & 1,51 \\
\hline $\begin{array}{l}\text { Otras profesiones } \\
\text { liberales }\end{array}$ & 2,55 & 3,24 & 4,51 & 4,61 & 3,89 & 3,44 & 2,55 & 3,40 & 2,31 & 2,21 \\
\hline Alumnos 1 ${ }^{\text {a enseñanza }}$ & 48,89 & 3,06 & & & & & & & & & 17,68 \\
\hline Estudiantes & 4,86 & 14,48 & 4,65 & 1,68 & 0,13 & 0,05 & & & & & 3,83 \\
\hline Niños sin profesión & 39,00 & & & & & & & & & & 13,87 \\
\hline Total* & 95,07 & 67,68 & 77,52 & 67,48 & 66,8 & 64,54 & 64,41 & 60,09 & 58,31 & 45,87 & 75,99 \\
\hline * Sólo se han incluido aquellas actividades con una cierta presencia, dado que el número total de catego- \\
rías en el censo de 1920 era de 129.
\end{tabular}

Fuente: I.N.E. Censos de la población de España.

\footnotetext{
11 Reher (1989). La transición urbana española atravesó varias etapas desde el primer tercio del siglo XIX, época en la que García Merino sitúa la fase de despegue de la urbanización en nuestro país. Entre 1875 y 1940 tuvo lugar la segunda etapa del proceso, sobresaliendo los años veinte, momento en el que se produjo un notorio impulso de algunas ciudades medias (García Merino, 1995: 14-15).
} 
La distribución sectorial de la población activa española refleja el proceso de éxodo rural, con un importante crecimiento en los sectores de la construcción, el comercio, los transportes u otros servicios, aun cuando dentro del sector servicios se operase una inflación de efectivos causada por la hiper-burocratización puesta en marcha bajo la Dictadura de Primo de Rivera (Martínez Cuadrado, 1974: 113).

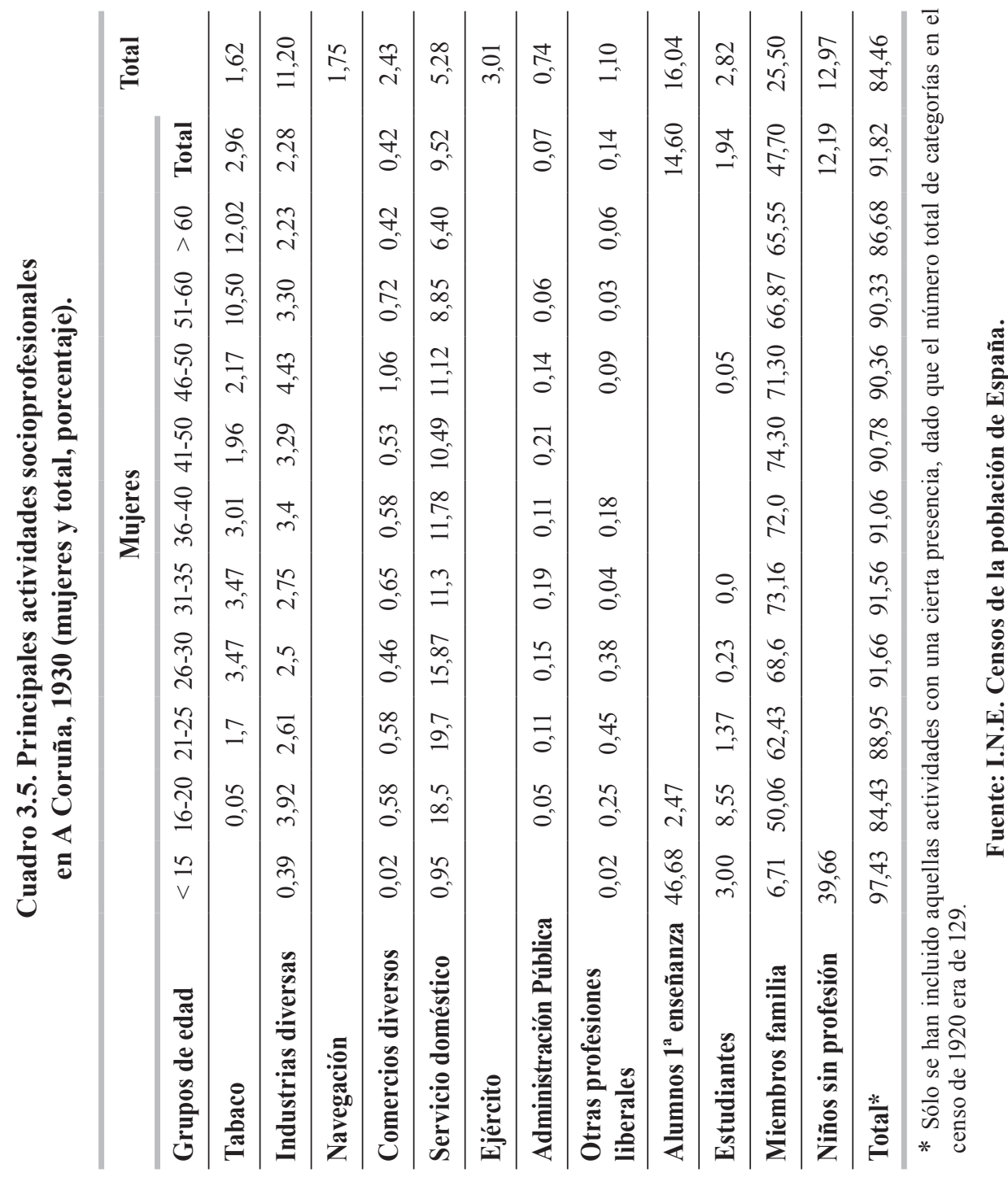

Uno de los indicadores que confirma las transformaciones socioeconómicas experimentadas por A Coruña es el crecimiento de la población activa, en términos absolutos y relativos (Cuadro 2.4). La progresión es visible tanto entre hombres como entre mujeres, si bien el incremento fue mucho mayor en términos relativos entre estas 
últimas, gracias a su acelerada incorporación a la inmigración rural-urbana en los años posteriores a la guerra, con destino a actividades del sector secundario y, sobre todo, hacia actividades tradicionales del terciario, como el servicio doméstico o el comercio. A pesar de ello, la población inactiva siguió siendo dominante. Las actividades que mayor presencia tenían en A Coruña en 1930 continuaban siendo los individuos ocupados en tareas domésticas. La principal modificación corresponde al segundo tipo de categoría censal dominante, que ahora pasó a ser la correspondiente a los alumnos de primera enseñanza y, en tercer lugar, los niños sin profesión.

Se observa una recuperación especialmente interesante dentro de las actividades ligadas a los servicios, coincidiendo con una etapa de fuerte crecimiento del número de trabajadores terciarios en España. El sector terciario vio crecer la participación de sus efectivos, recuperándose de la caída coyuntural en términos relativos que se había producido en 1920, debido al crecimiento industrial acaecido durante la guerra. A ello se añadieron otras mejoras, principalmente en los servicios públicos e infraestructuras urbanas, tales como la ampliación de las redes de abastecimiento de agua y electricidad, las reformas portuarias, viarias, y en los transportes urbanos y con el exterior.

Se dieron, además, dos fenómenos complementarios, observados en otras ciudades españolas. Por un lado, un crecimiento de los empleos en tareas burocráticas, relacionadas con el mayor grado de intervención gubernamental en la economía. Por otro, el aumento de los empleos en oficinas y, especialmente, de las profesiones liberales, que experimentaron un considerable desarrollo. El servicio doméstico continuaba acaparando una gran proporción de la mano de obra inmigrante femenina (Mirás, 2005b). Perdieron peso de forma considerable las actividades agrarias y también disminuyeron en términos relativos algunas actividades tradicionales, como el comercio, los transportes, la pesca y derivados, la manufactura del tabaco, etc. Sin embargo, se aprecia un correlativo crecimiento de un amplio abanico de industrias, aunque ninguna de ellas llegó a tener un peso individual determinante en la estructura económica local.

Por lo que respecta al sector secundario, la población activa empleada mantuvo la tendencia de crecimiento iniciada con el fin de la guerra (Cuadro 2.5). 1930 marca el punto álgido de la industrialización de la ciudad, ya que a partir de entonces la crisis industrial que se cernió sobre el país, combinada con la Guerra Civil y la ulterior posguerra bloquearon la continuación del proceso iniciado durante el primer tercio del siglo. El crecimiento industrial avivado en algunos sectores durante la guerra, y continuado durante la posguerra en los sectores mejor blindados, se consolidó durante la Dictadura. Pasada la primera posguerra, cuando sucumbieron las empresas más débiles, en los años veinte continuaron su proceso expansivo las actividades más sólidas. Este fenómeno evidencia que se estaba produciendo una diversificación del tejido industrial y, en general, de la base económica de A Coruña, paralelo al que se desarrollaba en el territorio nacional. No obstante, en su conjunto, el sector secundario siguió estando caracterizado por numerosas debilidades estructurales. 


\section{El heterogéneo CRECIMIENTO de LA FUNCIÓN COMERCIAL}

\subsection{El avance del comercio sin modificaciones significativas en su organización}

El nuevo marco legislativo, la estabilidad laboral y la reactivación económica que acompañaron a la Dictadura permitieron el paso de las formas personalistas a fórmulas empresariales más desarrolladas, gracias a la creación de sociedades mercantiles, sobre todo de responsabilidad limitada. Esto facilitó la acumulación de capital y la constitución de empresas más sólidas y solventes. El resultado fue la aparición de los primeros comercios modernos (Toboso, 2002: 25).

La aparición de nuevas formas de comercio afectó a los pequeños comerciantes. La principal novedad fue la apertura de grandes almacenes, lo que representó un paso más en la transformación del sector, pues estuvo acompañado de una revolución en las técnicas comerciales. Sin embargo, en España su instalación fue más tardía que en el mundo occidental, quedando limitada inicialmente a algunas grandes ciudades ${ }^{12}$. Además, la modalidad más empleada estuvo más cerca del almacén popular que del gran almacén (Toboso, 2002: 26). En España, los pequeños establecimientos familiares, con uno o dos dependientes, continuaban representado una fracción muy alta del total del comercio ${ }^{13}$. Sin embargo, la situación estaba comenzando a cambiar en las grandes ciudades (Fernández de Castro, 1973: 49), debido a la aparición de nuevas empresas comerciales de carácter capitalista (Nielfa, 1984: 141). En A Coruña, sin embargo, la presencia de esos establecimientos era prácticamente nula, debiendo aguardar a los años cincuenta para que comenzasen a producirse verdaderas modificaciones, gracias a la puesta en práctica y generalización de modernos métodos y modelos organizativos ${ }^{14}$.

Las actividades comerciales reflejan las líneas generales descritas para el conjunto de la economía urbana, pues presentan claros signos de reactivación durante los años veinte ${ }^{15}$. A pesar de ello, éste no fue el sector que experimentó un desarrollo más acelerado en términos relativos (Cuadro 2.10 y Cuadro 2.11). Por tanto, el número de comercios y de actividades de servicios se vio acrecentado en estos años, con un importante número de tiendas de textiles, confección, víveres, panaderías, carnicerías, efectos navales, suministradores de barcos, etc., repartidos por toda la ciudad.

El sector comercial continuaba adoleciendo de deficiencias estructurales. Durante la guerra no se había modernizado, y en los casos en los que se generaron beneficios empresariales, éstos no se utilizaron para reinvertir en nuevas formas comerciales ${ }^{16}$.

\footnotetext{
12 En Barcelona, en 1916, y en Madrid, en 1933. Pero el primer gran almacén que puede considerarse como tal fue Galerías Preciados, en el año 1943. En 1940 abrió su primer establecimiento de textiles, que más adelante se convirtió en el primero de esta cadena. El fenómeno, con todo, fue lento, pues en los años cuarenta y cincuenta apenas se registraron nuevas aperturas (Rebollo, 1987: 219).

13 Informe del Ministerio de Economía y Comercio, La estructura del comercio interior en España, s.f.

14 Casares y Rebollo (1991). Será a partir de entonces cuando el pequeño comercio sufra su competencia de forma directa, obligándole a renovar sus estrategias. Pero no por ello desapareció, sino que coexistió a lo largo de esa etapa con los nuevos tipos de establecimientos comerciales (Rodríguez Regueiro, 1973).

15 Breve estudio de la economía mercantil e industrial coruñesa, op. cit., pp. 338-339.

16 Ibid., op. cit., p. 340.
} 
La elevación de los costes acaecida durante la guerra, había apremiado al comerciante a una mayor necesidad de capital, sobre todo circulante. Tras la vuelta a la normalidad, se contrajo el volumen de capital circulante, lo que dio lugar a pérdidas de consideración en numerosos comerciantes ${ }^{17}$. De hecho desde el final del ciclo bélico, y especialmente en 1920-22, se produjo una importante disminución en el descuento de efectos de comercio, producida como consecuencia de la contracción de los precios ${ }^{18}$. Resultado de ello fue el incremento de los saldos de las cuentas corrientes bancarias, debido al dinero que estaba a la espera de colocación, por ser sobrante de los negocios. Hacia finales de los años veinte se comienzan a apreciar síntomas de dificultades en todos los negocios, especialmente en los comerciales, que anticiparán el cambio de signo de la actividad económica urbana que se producirá a principios de los años treinta ${ }^{19}$.

Según el Anuario del Comercio, Industria y Profesiones de España del año 1927, las actividades que mostraban una mayor presencia en las tres principales ciudades de la provincia eran las comerciales y de servicios. No obstante, las diferencias se manifestaban en una estructura terciaria más sofisticada y más acorde con los tiempos en la capital, mientras Ferrol y Santiago seguían ancladas en actividades tradicionales. Lo que diferenciaba a Coruña de las otras dos ciudades era el elevado peso de las actividades de transporte, de los consignatarios, comisionistas, agentes, corredores, etc. y las funciones de hospedería ${ }^{20}$.

\subsection{La dicotomía de las actividades comerciales}

\subsubsection{Las actividades comerciales básicas (alimentación y textil)}

En los años veinte tuvo lugar una de las coyunturas más prósperas para los dos subsectores más importantes del comercio de A Coruña, la alimentación y los textiles. El número de contribuyentes y sus cuotas experimentaron un continuo crecimiento, mayor en el segundo caso, debido a la rectificación de las tarifas decretada en 1922. La prosperidad arrastró a los negocios que tenían su mercado en la plaza - empujados por el incremento de la demanda urbana - y a los que compraban y vendían en el exterior.

Los establecimientos orientados al mercado local, al atender el crecimiento demográfico urbano, aumentaron en número. La ciudad, además, consolidó su rol como núcleo comercial, de atracción e influencia sobre su hinterland. De ahí la proliferación de comercios destinados a satisfacer las necesidades básicas. Los negocios que tenían sus intereses con puertos situados fuera de los límites de A Coruña gozaron también de buenas perspectivas. El volumen de mercancías descargadas en el puerto superaba con claridad a los embarques, lo que indica una vocación importadora de la economía metropolitana. A Coruña actuaba como vehículo de comercialización a gran escala de productos del hinterland. Además de la salida de mercancías procedentes del entorno

17 Ibid., p. 338.

18 Durante los años veinte se presentaron con frecuencia situaciones de escasez de numerario en la plaza, según se infiere de la información procedente de las ACTAS Pleno COCINC.

19 Cooperativa Militar y Civil (S.M.). Memoria del año 1930 presentada a la Junta General de 1931. Año $X X X X 15^{\circ}$ del $2^{\circ}$ período social, La Coruña, p. 8.

20 Anuario del Comercio, Industria y Profesiones de España, 1927, op. cit. 
rural, primaron las entradas de productos, que posteriormente eran redistribuidos por los numerosos comerciantes importadores. De la abundancia de productos también dependía el pequeño comercio, pues existía una estrecha conexión entre el comercio aprovisionador (mayorista) y el vendedor directo (minorista).

El movimiento mercantil portuario siguió una marcha ascendente. A pesar de que los fuertes controles establecidos durante la Dictadura sobre el comercio exterior desincentivaban este tipo de tráfico, parece haber primado el empuje derivado de la mejora de la situación económica en Europa (Ben-Ami, 1983: 34). Aunque el ranking del tráfico mercantil no sufrió un cambio significativo, aparecieron nuevos productos, que revelan una mayor diversificación comercial en la ciudad. Las mercancías que habían protagonizado el tráfico portuario durante la preguerra recuperaron la normalidad, por ejemplo, el carbón mineral, de procedencia mayoritariamente británica, aunque complementado con las entradas vía cabotaje de carbón nacional, a pesar de que el sector carbonífero atravesó una fuerte depresión estructural durante los años veinte.

La evolución del sector alimenticio local se vio influida directamente por el comportamiento del sector agrario regional. En primer lugar, porque la ciudad constituía un importante mercado para sus productos. En segundo lugar, debido a la creciente evidencia de que el campo constituía un mercado potencial de cierta envergadura, consumidor de materias primas, bienes de consumo y de equipo.

El sector agrario gallego ejerció un papel positivo. Las transformaciones que se vislumbraban en el complejo agropecuario se consolidaron durante los años veinte (Villares, 2000: 71). Las mejoras técnicas y los cambios en el régimen de propiedad territorial condujeron a una mercantilización efectiva de la agricultura gallega (Villares, 1991: 155), que tuvo su corolario en el aumento de la comercialización de productos agropecuarios, tanto hacia el interior peninsular como hacia la capital.

Por otro lado, durante esos años se registró el período de mayor salida de contingentes de población gallega hacia Latinoamérica. La contrapartida la constituyeron las remesas de emigrantes que en este período se intensificaron de forma destacada y que tuvieron como destino principal la agricultura.

Se dieron así dos fenómenos distintos pero que generaron un mismo efecto final. Por un lado, el incremento de la productividad del trabajo agrario provocado por el éxodo migratorio, que dio lugar a una mayor capacidad de acumulación ${ }^{21}$. Por otro, las remesas del exterior (García Lombardero, 1984: 322). Esto permitió que se intensificase el proceso de paulatino acceso a la propiedad plena de la tierra y la aceleración de la modernización de la agricultura, con un mayor grado de inserción en el mercado español (Barreiro Gil, 1990). Por tanto, una modificación de la estructura productiva gallega en general, y en particular del sector agro-ganadero que tuvo sus consecuencias en la forma de reconversión del sistema de cultivos, introducción de maquinaria y abonos minerales y el incremento de la productividad ganadera (Villares, 1996c: 400).

\footnotetext{
21 En consonancia con la hipótesis de Bairoch (1988), según la cual el desarrollo agrícola provoca un trasvase poblacional, como consecuencia de la baja elasticidad del consumo de alimentos.
} 


\subsubsection{El resto de los sectores}

La estructura comercial se hallaba relativamente diversificada. No obstante, su evolución interna fue dispar. El sector de la madera continuó desempeñando una función de primer orden, ya que durante los años veinte mantuvo una línea ascendente. Era un sector muy conectado con el correspondiente sector industrial. El crecimiento se produjo en paralelo a la expansión de la industria maderera en Galicia, como consecuencia de los procesos de apropiación de los montes y la posterior política de repoblaciones forestales, cuya labor se inició hacia 1929 (Rico, 2000: 414). En los años veinte, el empuje que había recibido la industria anteriormente se consolidó, siendo uno de los sectores que experimentó un mayor impulso, gracias a la expansión de distintas actividades industriales y comerciales que demandaban los productos del sector, sobre la base de materias primas de procedencia regional. Sin duda, uno de los más importantes fue el sector de la construcción, a consecuencia del crecimiento que experimentaron las principales ciudades españolas y, en menor medida, las propias ciudades gallegas (Sequeiros, 1986: 80). Este dinamismo repercutió en su comercialización. Aunque su número no representaba una fracción elevada dentro del conjunto, mantuvieron una situación relativamente firme, gracias a la estabilidad de su demanda.

Una parte importante de la madera era comercializada en el mercado urbano, aunque no faltaban remisiones de madera sin elaborar hacia el resto de la región y hacia España. Otra fracción considerable se importaba del norte de Europa. El puerto servía como centro distributivo de algunos de esos productos hacia el resto de España, especialmente a raíz del fuerte impulso que, desde finales del siglo XIX, recibieron las exportaciones de puntales de pinos hacia el exterior y hacia el norte y Levante ${ }^{22}$.

Dentro del sector predominaba el segmento de venta de maderas de primera transformación (IRS, 1919a, 2: 227). Sus efectos de arrastre sobre la segunda transformación - la que generaba un mayor valor añadido - eran escasos, ya que ésta se localizaba en otros puntos del territorio nacional (Nadal et al., 2003: 166). Por ello, en conjunto, no se había visto excesivamente perjudicado por la guerra mundial, pues los mercados se encontraban principalmente en el área metropolitana. Aunque el mercado nacional absorbiese parte de los productos de primera elaboración, los comerciantes dedicados a la venta de maderas y/o derivados (muebles, fundamentalmente) ubicaban en la ciudad o en la provincia el destino principal de sus productos. La empresa Hijos de Emilio Cervigón, la única para la que se ha hallado información contable, aunque incompleta, permite extrapolar parcialmente sus resultados al resto del sector, con unos beneficios que presentan una tendencia ascendente durante el primer lustro dictatorial ${ }^{23}$.

El número de empresas del subsector ferretería, hierros y maquinaria se duplicó entre 1919 y 1924, pero el incremento de las cuotas fue espectacular, fruto del alza contributiva y también de una mayor diversificación de los negocios y de la aparición de

2 Apuntes para el momento de la industria española de 1930, op. cit., p. 400.

$231923=30.689,9$ pts.; $1924=42.094,1 ; 1925=49.812,7 ; 1926=67.884,2 ; 1927=63.526,3$. ARG-DHC (Hacienda). Utilidades. Libros 4.545-4.547, 4.564-4.565. Sin embargo, sus resultados están probablemente distorsionados, porque esta sociedad simultaneaba producción y venta, siendo imposible diferenciar a qué actividad correspondían los beneficios. 
algunos nuevos, con una tributación individual elevada. Se han incluido actividades de escasa presencia anterior en la ciudad, como los concesionarios y establecimientos de venta de automóviles y accesorios. Se instalaron sociedades nuevas, al cobijo de la nueva demanda de transportes urbanos y extraurbanos que trajeron el incremento del número de unidades en circulación, el aumento de las empresas de transporte de viajeros y la mejoría de las infraestructuras de transporte regionales.

Por otro lado, los establecimientos de suministro de equipamiento de ferretería, maquinaria agrícola e industrial y accesorios de distintos tipos también experimentaron un crecimiento. Los factores impulsores de la demanda de esos artículos residieron en el crecimiento urbano — con el aumento de las necesidades de bienes de trabajo manualen el crecimiento y modernización del sector agropecuario regional — que precisaba cada vez de más utillaje - y en la demanda de los demás sectores industriales urbanos.

El establecimiento más emblemático era Torres y Sáez ${ }^{24}$. Los beneficios de la sociedad, desde su constitución, presentan un considerable vigor, con una rentabilidad elevada para su capital social ${ }^{25}$. Otra empresa relevante era la de Agustín Fernández Moretón. Al contrario que la anterior, en los años veinte los beneficios siguieron un perfil descendente, a pesar de haber expandido su escala de negocio ${ }^{26}$.

Tras la guerra, los productos químicos mantuvieron su peso, pero posteriormente se estancaron, al tiempo que aumentaba el sector de los carbones. Este último continuó expandiéndose, debido a que aún se utilizaba como combustible, sobre todo en el movimiento portuario y ferroviario ${ }^{27}$. Sin embargo, los combustibles minerales no experimentaron la misma dinámica. El crecimiento del resto del sector encontró su demanda en la ampliación del consumo industrial de algunos inputs.

En el extremo opuesto se encontraba el sector de los curtidos. Los curtidos entraron en decadencia durante los años veinte, aunque los antecedentes de su declive se encuentran en el siglo XIX y en el tránsito al siglo XX (Fernández Vázquez, 2002: 299-300). Los curtidos gallegos fueron progresiva e ininterrumpidamente superados por los del área mediterránea, aunque el proceso se consolidó en los años veinte. El motivo de esa pérdida relativa fue el mejor aprovechamiento de las favorables condiciones creadas por la guerra mundial, que limitó las posibilidades de expansión de la

\footnotetext{
24 Nacida en 1897 con un capital de 80.000 pts., bajo la razón social Fernández y Torres, e integrada por los socios Manuel Torres García y Manuel Fernández López, su objeto social era la venta de hierros, aceros y ferretería. En 1916 se incorporaron a la empresa Ángel Torres García (hermano de Manuel Torres) y Manuel Sáez Torres (sobrino de los anteriores), pasando a denominarse Torres y Sáez y Cía. En 1926, con un capital social de 500.000 pts., nació Torres y Sáez, S.R.C., tras la liquidación de la sociedad anterior (Pérez de los Heros, 2000: 266).

$25 \quad 1926=52.798,0$ pts.; $1927=25.456,5 ; 1928=34.627,1 ; 1929=86.141,3 ; 1930=92.844,5 ; 1931=76.161,4$. ARG-DHC (Hacienda). Utilidades. Libro 5.233. La rentabilidad sobre el capital fue la siguiente: 1926 = 10,6\%; $1927=5,1 \% ; 1928=6,9 \% ; 1929=17,2 \% ; 1930=18,6 \% ; 1931=15,2 \%$.

26 Constituida inicialmente como Agustín Fernández y Cía., en 1898, con un capital de 240.000 pts. La sociedad tenía su casa central en Vigo, y una sucursal en Santander. Los beneficios fueron de $48.605,9$ pts. en $1923 ; 1924=53.664,9 ; 1925=22.938,4 ; 1926=16.048,6 ; 1927=19.686,0 ; 1928=5.640,0$; $1929=7.297,3 ; 1930=4.159,7 ; 1931=10.618,7$. La rentabilidad sobre su capital (725.000) alcanzó valores bajos, pasando del 7,4\% en 1924 al 0,6\% en 1930. ARG-DHC (Hacienda). Utilidades. Libro 5.233.

27 El transporte del carbón de la cuenca leonesa a La Coruña, La Coruña, 1922, en Las Cámaras de Comercio. Labor de la de La Coruña hasta fin de 1923, La Coruña, COCINC, 1924, p. 243.
} 
oferta de los países beligerantes. El conflicto proporcionó importantes beneficios a las empresas de curtidos españolas y también gallegas, aunque al finalizar la contienda no se modificó la situación que venía perfilándose antes de la guerra (Fernández Vázquez, 2002: 304).

La decadencia del sector se debió a factores de oferta y de demanda. Por un lado, la escasa adopción de innovaciones tecnológicas (curtición química, mecanización del curtido, etc.) en comparación con las regiones mediterráneas. También tuvo influencia el excesivo peso en la producción final de bienes de menor valor añadido, como las suelas. El otro factor fue la reducida demanda interior, debida al bajo nivel de renta, a un mercado regional escasamente articulado, a las dificultades de acceso a los mercados peninsulares, etc. El sector no aprovechó las ventajas que proporcionó la guerra para modernizarse adecuadamente. En consecuencia, la crisis de superproducción de posguerra agravó la situación anterior (Martínez López, 1997: 100-104). Las fábricas existentes en la ciudad eran muy escasas. La producción final era fundamentalmente de suelas y, en consecuencia, la obtención de cueros de calidad quedaba reservada a otras regiones. Esto tuvo su reflejo en la comercialización de los productos y, por ello, el número de establecimientos de venta experimentó un continuo descenso.

La otra sección del sector era la venta de calzado, cuya principal protagonista en A Coruña era la fábrica de Ángel Senra, que poseía establecimientos de venta en el centro de la ciudad ${ }^{28}$. La expansión comercial de esta sociedad la llevó a abrir otras sucursales de venta en Ferrol y Vigo durante esta década, gracias a una expansión de la demanda paralela a la de otros bienes de primera necesidad como los textiles o los productos alimenticios derivados de carácter más novedoso. Otras empresas, en cambio, no se beneficiaron en igual medida de esa prosperidad. Feijoo y Paz, dedicada también a la venta de calzado, tuvo una evolución empresarial irregular durante la segunda mitad de la década, generando en varias ocasiones pérdidas ${ }^{29}$.

El sector de las librerías y papelerías experimentó un progresivo aumento en su número y en sus cuotas, al calor del crecimiento de la demanda urbana, que estaría relacionada con la reducción del analfabetismo y el crecimiento demográfico. La S.R.C. Zincke Hermanos es representativa de las características del sector. Una pequeña empresa constituida en el año 1910, con un capital social de 10.000, dedicada a la compra y venta de papel y artículos del ramo de la librería, al por mayor y al por menor. Los beneficios de esta sociedad mantuvieron una tendencia muy estable, alcanzando una rentabilidad elevada ${ }^{30}$.

\footnotetext{
28 El capital invertido era de 2.250 .000 pts., con un total de 256 obreros a finales de los años veinte. Su capacidad de producción era de unos 1.000 pares diarios. Las materias primas eran de procedencia nacional. Por un lado, las suelas procedían del resto de Galicia, y las pieles para los cortes en su mayor parte de fuera de la región. El mercado de los productos se localizaba por todo el país, exportándose una pequeña proporción al extranjero. La Coruña, capital de Galicia. Guía del turista, 1924, La Coruña. Anuario Guía de La Coruña, 1930, La Coruña, Nós.

$291926=6.126,3$ pts.; $1927=-9.604,0 ; 1928=1.266,9 ; 1929=-7.323,0 ; 1930=1.992,6 ; 1931=4.168,3$. ARG-DHC (Hacienda). Utilidades. Libro 5233.

$30 \quad 1923=12.995,7$ pts. $; 1924=13.766,0 ; 1925=14.309,0 ; 1926=13.825,4 ; 1927=11.536,9 ; 1928=13.494,7$; $1930=12.500,3$. ARG-DHC (Hacienda). Utilidades. Libros 4.545-4.547 y 4.564-4.566.
} 


\section{LOS SERVICIOS EXPANDEN DE MANERA CRECIENTE SU PROTAGONISMO}

\subsection{Factores diferenciales del desarrollo de la función terciaria urbana}

Durante los años veinte el sector servicios experimentó un notable crecimiento, debido a la confluencia de varios factores. En primer lugar, A Coruña desempeñaba funciones burocráticas, administrativas y militares, al igual que la práctica totalidad de las capitales españolas. La consolidación de estas actividades tenía repercusiones inmediatas sobre un amplio abanico de profesiones, fundamentalmente las liberales ${ }^{31}$. Paralelamente, su crecimiento facilitó la generación de una amplia demanda de servicios de muy diverso espectro. De este modo, la economía urbana aprovechó sus inercias de desarrollo interno, con una considerable preeminencia de las actividades comerciales y de $\operatorname{servicios}^{32}$. En segundo lugar, A Coruña era la ciudad gallega con mayor volumen de población. En estos casos, la literatura coincide en señalar que, salvo los núcleos con un perfil decididamente industrial, lo habitual es que genere una potencial demanda de servicios. En tercer lugar, el desarrollo de una función rectora de los municipios colindantes, lo que culminó en la conformación de una de las principales áreas metropolitanas regionales a lo largo del siglo XX (Precedo, 1990a: 68-70; Santos Ledo, 1984: 410-412). En cuarto lugar, la tradicional tendencia migratoria de la población gallega.

Sin embargo, respecto a este último factor, se aprecia desde el primer momento de impulso de la emigración una cierta debilidad del empresariado local dedicado a estos negocios, por cuanto no fue capaz de consolidar su posición dentro de este tipo de tráfico marítimo. Muy pronto, las casas dedicadas a esta actividad fueron absorbidas por compañías extranjeras, fundamentalmente inglesas (Barreiro Fernández, 1986), aunque para defender sus intereses comunes creasen una Asociación de Navieros Consignatarios de Buques Trasatlánticos y una Asociación de Navieros del Noroeste. La dependencia del exterior a la hora de gestionar el movimiento de pasajeros revela la incapacidad del empresariado para multiplicar en favor propio y de A Coruña los efectos de una corriente migratoria que transitaba por la ciudad, condicionando el futuro del sector, por cuanto lo hicieron tremendamente dependiente de decisiones y de coyunturas externas a la ciudad. Al contrario de lo que ocurrió en otros puertos con otros tipos de movimientos, en A Coruña la burguesía marítima no fue capaz de consolidar un sector naviero que canalizase con recursos y con medios propios el flujo migratorio.

Durante estos años del siglo XX, la emigración gallega experimentó una de sus fases alcistas más pronunciadas (Beiras y López, 1999: 185). En términos relativos, el esfuerzo migratorio fue muy intenso, por cuanto las tasas de emigración gallegas

\footnotetext{
31 Las profesiones liberales con mayor presencia en la ciudad en los años veinte eran los médicos: en 1924, 64 profesionales, en 1926, 73, en 1928, 81 y en 1930, 86. En segundo lugar, los abogados (48, 51, 49 y 62 en esas mismas fechas). También se localizaban otros profesionales, aunque en número mucho más reducido, como procuradores y otros servicios vinculados con la justicia y el derecho (16 en 1930), odontólogos (14), practicantes (6), veterinarios (4), arquitectos (5), ingenieros (2), etc. ARG-DHC (Hacienda). Administración de Rentas Públicas. Registro de liquidaciones de profesionales por utilidades. Tarifa $1^{\text {a }}$. Capital y pueblos. 1924-1939. Libros 5.237 y 5.238 .

32 Archivo Municipal de A Coruña. Ayuntamiento de A Coruña, Memoria de la Gestión Administrativa del Excmo. Ayuntamiento de La Coruña en el año 1919.
} 
triplicaban la media nacional (Eiras, 1993). Estos individuos embarcaban en su práctica totalidad por puertos gallegos, pues normalmente la salida se efectuaba a través de los puertos más cercanos al lugar de origen del emigrante (Vázquez González, 1988: 83), alternándose Vigo y A Coruña la primacía nacional. Sin embargo, después de la guerra europea no recuperaron la intensidad del movimiento de anteguerra, a pesar de que A Coruña avanzó más deprisa, gracias a la intensificación del pasaje hacia Cuba, pues éste era el puerto principalmente utilizado por la emigración hacia ese país ${ }^{33}$.

Tradicionalmente, las teorías explicativas de la emigración se han agrupado en dos grandes categorías. En primer lugar, las que ponen el acento en los factores de expulsión, es decir, las que se centran en las categorías socio-estructurales, como la necesidad, miseria o los desequilibrios socioeconómicos, políticos, etc. En segundo lugar, las que conceden preponderancia a los factores de atracción. En Galicia, los primeros han tenido históricamente una mayor incidencia (Villares y Fernández, 1996: 84-85). Sin embargo, con independencia de la situación económica regional, que actuaba expulsando mano de obra excedentaria, desde el mercado mundial varias condiciones impulsaron este movimiento durante los años veinte.

En primer lugar, la favorable coyuntura económica internacional, que tuvo su incidencia en las economías latinoamericanas de exportación. La mayor parte de los países de destino de los gallegos atravesaron una fase alcista en sus exportaciones de productos primarios, y en algunos casos, se sentaron los cimientos de sus primeros procesos de industrialización, lo que incentivó una fuerte demanda de fuerza de trabajo para los procesos productivos. En segundo lugar, la liberalización de las legislaciones migratorias en España, principalmente la Ley de emigración de 1907. En tercer lugar, la mejora de las condiciones técnicas del transporte, gracias a la generalización de la navegación a vapor en buques modernos (Vázquez González, 1990). Finalmente, entre otros, también actuó a favor de este movimiento la existencia de una compleja red de captación de los emigrantes potenciales.

\subsection{El crecimiento de las funciones tradicionales y la expansión de los servicios modernos}

Durante los años veinte las actividades de consignación, gestión, etc. continuaban desempeñando un papel de primer orden. La recuperación de la corriente migratoria durante los años veinte impulsó el asentamiento de las grandes navieras europeas, que fueron las que acapararon el movimiento de pasajeros. Los empresarios coruñesas que anteriormente habían actuado como casas consignatarias de esas navieras continuaron desempeñando un papel decisivo en un transporte que mostraba un creciente grado de

\footnotetext{
33 Losada (1995: 53) sostiene que el puerto de Vigo ostentó con claridad la primacía en volumen de pasajeros durante el período 1911-64. Vázquez González (2000a: 772) matiza que el puerto de A Coruña tuvo una posición preeminente, tanto en salidas como en entradas de pasajeros hasta 1890. A partir de entonces, los puertos de las Rías Bajas (con Vigo a la cabeza) retuvieron un monto próximo o similar al coruñés en las salidas hasta 1904. De 1905 a 1907 A Coruña recuperó su primacía hasta que en 1908 pasaron a predominar los puertos de las Rías Bajas, y tras un breve paréntesis (1915-20), ligado al final de la guerra mundial y la inmediata posguerra, en el que A Coruña superó a los puertos sureños, definitivamente estos últimos concentraron una mayor proporción de embarques.
} 


\section{Cuadro 3.6. Consignatarios y agentes existentes en A Coruña durante el primer tercio del siglo $\mathrm{XX}$.}

\begin{tabular}{|c|c|c|c|}
\hline Consignatarios y agentes & & Consignatarios y agentes & \\
\hline Aranda Granell y Cía. (CUBAN) & 1900 & $\begin{array}{l}\text { Vda. de H.Hervada (ANGLO } \\
\text { ARGENTINE SHIPPING CO.) }\end{array}$ & $1907-1909$ \\
\hline $\begin{array}{l}\text { Tejero, Pérez y Gil } \\
\text { (SERRA) }\end{array}$ & 1904 & $\begin{array}{l}\text { Nicandro Fariña } \\
\text { (NELSON) }\end{array}$ & $\begin{array}{r}1907-1912 \\
1921-1922 \\
\end{array}$ \\
\hline $\begin{array}{l}\text { Tejero, Pérez y Gil } \\
\text { (MALA REAL DINAMARQUESA) }\end{array}$ & 1905 & Daniel Álvarez (LAMPORT) & $\begin{array}{l}1907-1912, \\
1922-1923 \\
\end{array}$ \\
\hline Eduardo del Río (HAL) & 1908 & Raimundo Molina Couceiro (LLRH) & 1907-1934 \\
\hline $\begin{array}{l}\text { Oya Gilard y Cía. } \\
\text { (SUD-ATLANTIQUE) }\end{array}$ & 1919 & $\begin{array}{l}\text { E.Baña y Vázquez } \\
\text { (R.P.HOUSTON) }\end{array}$ & $1908-1912$ \\
\hline Daniel Álvarez (WORD LINE) & 1920 & Antonio Sánchez de Movellán (CTE) & $1911-1912$ \\
\hline Eladio Pérez (SKOGLAND LINE) & 1922 & $\begin{array}{l}\text { Daniel Álvarez } \\
\text { (THE ATLANTIC \& EASTERN) }\end{array}$ & 1911-1912 \\
\hline $\begin{array}{l}\text { Rubine e Hijos } \\
\text { (LINE SOUTHAMPTON) }\end{array}$ & 1922 & $\begin{array}{l}\text { López y Sánchez } \\
\text { (HOULDER LINE) }\end{array}$ & 1911-1912 \\
\hline Narciso Obanza (PINILLOS) & 1923 & $\begin{array}{l}\text { Eduardo del Río y Cía. } \\
\text { (CIAS. HAMBURGUESAS) }\end{array}$ & $1911-1913$ \\
\hline $\begin{array}{l}\text { Sobrinos de José Pastor } \\
\text { (AMERICAN LINE) }\end{array}$ & 1923 & $\begin{array}{l}\text { Antonio Conde y Hno./Antonio Conde, } \\
\text { Hijos (CHARGEURS) }\end{array}$ & $\begin{array}{r}\text { 1911-1916, } \\
1919 \\
\end{array}$ \\
\hline Gabriel López Companioni (HAL) & 1930 & $\begin{array}{l}\text { Sobrinos de José Pastor } \\
\text { (WHITE STAR LINE) }\end{array}$ & $\begin{array}{r}1919,1922, \\
1932 \\
\end{array}$ \\
\hline $\begin{array}{l}\text { Vda. de Daniel Álvarez } \\
\text { (UNITED STATES LINES) }\end{array}$ & 1930 & $\begin{array}{l}\text { Sobrinos de José Pastor } \\
\text { (RED STAR LINE) }\end{array}$ & 1920-1923 \\
\hline Eusebio da Guarda (CTE) & $1897-1901$ & $\begin{array}{l}\text { Antonio Conde, Hijos } \\
\text { (CHARGEURS/SUD-ATLANTIQUE) }\end{array}$ & $1920-1925$ \\
\hline Herce y Cía. (MENSAJERIAS) & $1890-1904$ & Narciso Obanza (CTE) & $1920-1926$ \\
\hline Rubine e Hijos (RMSPC) & 1896-1934 & Sobrinos de José Pastor Ltd.(PSNC) & 1920-1937 \\
\hline Hijos de Marchesi Dalmau (HAPAG) & 1901-1909 & López y Sánchez (HAL) & 1921-1927 \\
\hline $\begin{array}{l}\text { Nicandro Fariña } \\
\text { (CGTF) }\end{array}$ & $\begin{array}{r}1903-1911, \\
1923-1932 \\
\end{array}$ & $\begin{array}{l}\text { Rogelio Fernández Conde (HUGO } \\
\text { STINNES) }\end{array}$ & $1922-1926$ \\
\hline $\begin{array}{l}\text { Daniel Álvarez } \\
\text { (ARROTEGUI) }\end{array}$ & $1903-1912$ & $\begin{array}{l}\text { Enrique Fraga } \\
\text { (COMPAÑÍAS HAMBURGUESAS) }\end{array}$ & $1922-1934$ \\
\hline Pablo Meyer (NLLB) & 1903-1912 & Enrique Fraga (HAPAG) & 1922-1934 \\
\hline Sobrinos de José Pastor (PSNC) & $1903-1912$ & Felipe Rodríguez Rey (NLLB) & 1923-1934 \\
\hline $\begin{array}{l}\text { Sobrinos de José Pastor } \\
\text { (PINILLOS) }\end{array}$ & $\begin{array}{r}1904,1911- \\
1912\end{array}$ & $\begin{array}{l}\text { Eduardo Fariña Dalmau } \\
\text { (CGTF) }\end{array}$ & $1930-1934$ \\
\hline Eduardo del Río (HAPAG) & 1904-1913 & Luis Alfeirán Conde (CTE) & 1931-1934 \\
\hline Eduardo del Río (NLLB) & $1907-1909$ & & \\
\hline
\end{tabular}

Fuente: Vázquez González (2000a: 801-803). 
internacionalización en los operadores internacionales ${ }^{34}$. Vázquez González (2000a) recoge un listado de los consignatarios y agentes que operaron en A Coruña desde mediados del siglo XIX, de los que entresacamos los que actuaron en la ciudad durante el primer tercio del siglo XX (Cuadro 3.6).

El negocio de la emigración proporcionaba una de las fuentes de liquidez más sólidas y duraderas a estos empresarios, que solían compaginar dichas actividades con otras de carácter comercial e industrial. La influencia de los empresarios ligados a los negocios portuarios se aprecia en la presencia de muchos de ellos en las más importantes iniciativas industriales y de servicios de A Coruña antes de la Guerra Civil. Su papel en la política y en las instituciones locales fue asimismo destacado, constituyendo un poderoso lobby (Vázquez González, 2001: 11).

Los beneficios empresariales derivados de la consignación redundaron en una notable fuente de capitalización que, además, se concentró en unas pocas familias. El contacto con el exterior les permitía disponer de numerosas ventajas: la posibilidad de contar de forma casi permanente con una oferta de transporte de mercancías con Europa occidental y España, dado que las navieras compaginaban el transporte de pasajeros con el de mercancías; la disponibilidad de divisas y de letras de cambio, fundamental para compensar los pagos internacionales que apenas podían cubrir las limitadas exportaciones gallegas; un amplio margen de maniobra para operar y acrecentar la escala de su actividad sin grandes necesidades de infraestructuras portuarias, etc. (Vázquez González, 2001: 11, 21).

Cuadro 3.7. Beneficios de algunas de las principales casas consignatarias de A Coruña, 1923-31.

\begin{tabular}{|c|c|c|c|c|c|c|c|c|c|}
\hline & 1923 & 1924 & 1925 & 1926 & 1927 & 1928 & 1929 & 1930 & 1931 \\
\hline Rubine e Hijos & & & 72.216 & & 79.747 & 82.996 & & 91.012 & \\
\hline $\begin{array}{l}\text { Jesús de Labra } \\
\text { y Hno. }\end{array}$ & & & 13.087 & & 17.019 & 13.069 & 5.189 & 10.978 & 5.435 \\
\hline $\begin{array}{l}\text { Sobrinos de José } \\
\text { Pastor }\end{array}$ & 326.717 & 396.252 & 23.487 & 18.785 & 22.460 & 21.745 & 23.998 & -17.100 & -50.95 \\
\hline Herce y Cía. & 77.796 & 81.884 & 86.455 & 364.582 & 45.444 & 55.954 & 52.870 & 60.815 & 61.151 \\
\hline Nicandro Fariña & 45.201 & 28.432 & 18.152 & & 26.812 & & & & \\
\hline
\end{tabular}

Fuente: ARG-DHC (Hacienda). Utilidades. Libros 4.545-4.547, 4.564-4.566.

\footnotetext{
34 Vázquez González (2001: 1 y 8). Los consignatarios matriculados en la contribución industrial del año 1924 eran: Rubine e Hijos, Sobrinos de José Pastor, Antonio Conde e Hijos, López y Sánchez, Mayor, Sánchez y Cía., Nicandro Fariña, Enrique Fraga, Raimundo Molina, Narciso Obanza, Viuda de Daniel Álvarez y Cía., Rogelio Fernández Conde, Felipe Rodríguez Rey, Eduardo Baña, Eladio Pérez, Dionisio Tejero, Melitón Fernández, Ramiro González Lorenzo y Jesús Labra y Hermano.
} 
Las series de beneficios presentan un perfil saneado. A pesar de que resulta muy difícil elucidar cuál era la procedencia exacta de los resultados finales, Rubine e Hijos, Jesús de Labra y Hermano, Sobrinos de José Pastor, Herce y Cía. o Nicandro Fariña arrojan saldos muy positivos, con rentabilidades sobre sus respectivos capitales sociales que demuestran que las líneas de negocio que desarrollaban durante los años veinte se encontraban en una etapa ascendente (Cuadro 3.7). Parece existir coincidencia en que los años centrales de la década fueron los de mayor esplendor, mientras que conforme nos acercamos a la crisis de los años treinta, los resultados comienzan a resentirse.

Los transportes experimentaron un importante crecimiento, coincidiendo con la constitución de las principales empresas cuyo objeto era el transporte de mercancías y de pasajeros (Sequeiros, 1986: 268), así como con el desarrollo de servicios vinculados a la automoción (gasolineras, garajes, reparación de automóviles, etc.). El principal factor que influyó en el crecimiento del sector fue el incremento del volumen de intercambios comerciales, en donde la batalla por la competencia entre el ferrocarril y la carretera estaba decantándose del lado de esta última (Martínez Cuadrado, 1974: 169).

Desde principios de siglo, se estaba intentando lograr la mejora de las infraestructuras de distribución terrestre, con el fin de garantizar que la ciudad se convirtiera en el eje canalizador de los productos del área metropolitana hacia el resto de la región y del país ${ }^{35}$. Pero todas las iniciativas puestas en marcha sufrieron penosas dilaciones. A pesar de estas carencias, el tráfico ferroviario en la estación de A Coruña refleja el dinamismo comercial de la ciudad y de su hinterland. Desde el final del ciclo bélico, el movimiento de salida de mercancías experimentó un primer crecimiento, tanto del transporte de gran velocidad como de pequeña velocidad que, tras una breve desaceleración en 1920, se prolonga hasta 1927 (Gráfico 2.7). Al crecimiento del tráfico mercantil portuario se unía el crecimiento del transporte hacia el interior.

El incremento en la construcción de carreteras acometido durante la Dictadura fue espectacular para los estándares de la época, dentro de un intento modernizador, a menudo subestimado por muchos estudiosos (Carr, 1969: 557). Se decretó a mediados de la década una mejora de la red viaria nacional, incluyendo caminos vecinales, carreteras y un plan de construcción de autopistas. Sin embargo, la industria española del automóvil fue incapaz de satisfacer la creciente demanda (García Ruiz, 2003). Además, tanto la ampliación del kilometraje como las operaciones de adaptación de la red no alcanzaron los objetivos previstos.

Las siguientes actividades del sector servicios tenían todas ellas un peso numéricamente inferior. El subsector más destacado, por el importe individual de sus cuotas, era la hostelería. Su importancia fue creciendo de forma constante. El impulso principal de estos negocios guardaba en parte relación con el movimiento portuario de pasajeros. Al tiempo, en A Coruña se consolidó una cierta función turística, que se intensificó

35 Cámara Oficial de Comercio, Industria e Navegación, Comunicaciones ferroviarias de Galicia, La Coruña, 1921. Las Cámaras de Comercio. Labor de la de La Coruña hasta fin de 1923, La Coruña, COCINC, 1924, pp. 143-144. André, E.L. (1926), El sistema ferroviario de Galicia y León: Los Planes del Consejo Ferroviario y del Ministerio de Fomento y el Ferrocarril del Príncipe de Asturias (Zamora-Orense) y Complementarios Vigo-Xinzo de Limia y Ferrol-Coruña-Santiago, Madrid, Rivadeneyra, 1926. 
desde los años veinte ${ }^{36}$. Además de los hoteles existían otro tipo de establecimientos destinados a proporcionar alojamiento a la población de paso en la ciudad ${ }^{37}$. Por las propias características de los emigrantes, éstos debían alojarse en la ciudad en locales modestos, quedando reservados los hoteles de mayor alcurnia para un turismo de mayor poder adquisitivo (Vázquez González, 1990: 126).

He aquí los dos elementos de los que se nutría fundamentalmente el sector en la ciudad. El emigrante que terminaba en uno de los puertos gallegos constituía el punto final en su patria de un amplio engranaje comercial creado por los puertos gallegos y que dio lugar a una diversificada red de enganches. Esta red se encargaba de lo necesario para facilitarle al candidato a emigrante su viaje. Los propios fondistas portuarios, así, también participaban en el negocio ${ }^{38}$.

Por lo que respecta a la prensa, los años veinte presenciaron una notable modernización técnica en España, debido a factores de oferta (aplicación de las linotipias y las rotativas) y de demanda (crecimiento demográfico y urbano, aumento del grado de alfabetización, mejora del nivel de vida, progresiva participación de los ciudadanos en la vida política y sindical, etc.). Desde entonces, fue posible imprimir grandes tiradas, lo que permitió reducir los precios de venta y llegar a un mayor número de lectores. Las mejoras en los medios de transporte y en las comunicaciones permitieron ampliar el abanico de noticias y la velocidad de transmisión de la información y del producto final. En cambio, la creciente complejidad del sector requería importantes inversiones económicas, lo que redujo el número de títulos publicados. Esto explica el carácter predominantemente urbano de la prensa gallega (Pérez Pais, 1997: 14-15).

En A Coruña, el número de publicaciones periódicas se redujo a lo largo del primer tercio del siglo, debido a la desaparición de algunas de ellas ${ }^{39}$. Se constata, además, una diferenciación entre los periódicos de tirada importante y salida diaria y los de menor volumen de publicación y salida más irregular ${ }^{40}$, destacando entre los primeros La Voz de Galicia y El Noroeste (éste ya no figura en 1919), a los que hay que unir en 1917 Tierra Gallega y El Eco de Galicia y en 1919 El Orzán y El Ideal Gallego.

La variable educativa aparece bastante limitada en la contribución industrial. Lo que se recogía básicamente eran los colegios. Pero existía otro tipo de instituciones de

\footnotetext{
36 Carré (1935). Alvajar, C. (1924), "Bosquejos coruñeses", Comercio, Industria y Navegación. Revista de los Intereses Económicos de La Coruña, 1 (1), pp. 25-27. "La Coruña, centro de turismo de Galicia", en Libro de oro de Galicia, Madrid, Rivadeneyra, 1932, [s.a.], pp. 43-47. La Coruña ciudad de turismo, La Coruña, Ayuntamiento, 1933.

37 De todos modos, A Coruña no pudo sostener una posición comparativamente ventajosa frente a otras ciudades más avanzadas en su transición a centros turísticos. Dejando de lado el turismo vinculado a las modernas pautas de mediados del siglo XX (del que en nuestro país se beneficiaron las regiones del sur y Levante, junto con Canarias y Baleares), existían en el norte de España dos centros turísticos consolidados: Santander y, sobre todo, San Sebastián (Walton, 2002: 7; Pozueta et al., 1985).

38 Vázquez González (1988: 90), tomado de un informe elaborado por el Consejo Superior de Emigración, La emigración transoceánica (1911-1918), Madrid, 1916, pp. 490 y ss.

39 Santos Gayoso (1990: 873 y ss.). El motivo principal del cierre de algunos periódicos fue que el precio de las materias primas (sobre todo, el papel), aunque había descendido respecto a los años del ciclo bélico, continuaba siendo elevado, incrementando los costes empresariales (Román, 1997: 328).

40 Los periódicos de mayor tirada eran La Voz de Galicia (de 12.285 ejemplares en 1913 a 15.000 en 1927), El Ideal Gallego (de 6.000 en 1920 a 10.000 en 1927) y El Noroeste (en torno a los 6.000-7.000 ejemplares).
} 
enseñanza que no aparecían registradas y que tenían una considerable importancia en la ciudad. En todo caso, la instrucción pública era insuficiente, con la particularidad de que muchas de estas escuelas no contaban con locales propios, sino que utilizaban instalaciones municipales. De ahí la necesidad de complementar la educación con escuelas populares gratuitas (la del Patronato, la de Ciegos, las dominicales, las nocturnas para obreros, etc.) y de ahí también la explicación del mercado que existía para los establecimientos privados ${ }^{41}$.

En general, las condiciones de escolarización en A Coruña y en Galicia a principios de siglo no parecen haber sido las idóneas (Porto, 1986: 365) y en los años veinte la situación no había mejorado sustancialmente (Bello, 1973). De ahí el impulso dinamizador que se llevó a cabo desde entonces (Méndez Romeu, 1987: 135-140), al calor de las nuevas ideas acerca de la educación desde la Restauración (Costa Rico, 1986). Particularmente influyente fue la incidencia que tuvo la emigración. Las remesas y los capitales repatriados procedentes de América tuvieron como uno de sus destinos más sobresalientes la creación de escuelas. Pero esto tuvo incidencia fundamentalmente en la Galicia rural y en las zonas costeras (Peña Saavedra, 1991). En las ciudades, los principales potenciadores de la enseñanza fueron los estamentos burgueses, además de la influencia que pudieron tener otras instituciones de tipo religioso o laico, e incluso el propio movimiento obrero (Costa Rico, 1986: 147).

Las empresas de servicios públicos urbanos tuvieron una evolución algo distinta. Los años veinte permitieron a Aguas de La Coruña, S.A. acometer una fuerte expansión de su red de abastecimiento, cimentada en el crecimiento físico de la ciudad, con el consecuente aumento del número total de abonados (Martínez López et al., 2004: 94). A lo largo de la década se completó la red principal desarrollada en los años anteriores para reforzar el servicio en el núcleo central de la ciudad y extender la oferta de abastecimiento hacia la periferia (Martínez López et al., 2004: 92).

La expansión experimentada por el negocio se puede calificar de espectacular, ya que la empresa disfrutó de un rápido crecimiento del margen de explotación, propiciado por el aumento del número de abonados y una eficaz política de control de gasto (Martínez López et al., 2004: 97). La mejoría de los resultados empresariales estuvo acompañada de un incremento de los costes financieros, debido a la estrategia de practicar una política de financiación basada en la captación de recursos ajenos mediante la emisión de renta fija. Desde el final de la guerra, la explotación entró en una fase de madurez, en la que el crecimiento del número de abonados permitió aumentar el ingreso y el margen de explotación en términos constantes, tanto en términos absolutos como por abonado, a pesar de que los gastos de explotación también sufrieron un considerable aumento, pero más moderado (Martínez López y Piñeiro, 2003: 202-204).

La Dictadura de Primo de Rivera coincidió con el máximo esplendor de la red tranviaria. En 1922 se completó la construcción del tranvía a la villa de Sada, cuya

\footnotetext{
41 Carré (1929: 494-495). La Coruña en la mano. Guía Anunciadora Comercial e Industrial, año II, agosto 1918, La Coruña, La Voz de Galicia. La Coruña. Guía-Almanaque para 1923. Año I, La Coruña, Ayuntamiento de La Coruña. El avance de la provincia de La Coruña en un quinquenio, 1923-1929, 1929, La Coruña, Imprenta de la Casa de la Misericordia.
} 
importancia como elemento vertebrador del área metropolitana se percibió pronto, al facilitar el intercambio comercial con parte del área de influencia y, sobre todo, posibilitar un más eficiente movimiento de la mano de obra ${ }^{42}$. Durante los años veinte la explotación de esta línea impulsó notablemente los ingresos, pero la crisis económica, la magnitud de la inversión comprometida y el peso del endeudamiento contraído para financiarla, así como la competencia de los transportes por carretera provocaron desde mediados de los años treinta considerables problemas que pusieron en serio riesgo la supervivencia de la empresa ${ }^{43}$.

Por su parte, los tranvías urbanos continuaron ampliando sus servicios, con la apertura de tramos que conectaban áreas en expansión. En ese momento, coincidiendo con el final de la electrificación de la red, ésta alcanzó su máxima extensión. Sin embargo, desde el punto de vista financiero, el resultado del crecimiento no fue satisfactorio. Aunque el tranvía urbano continuaba operando a buen ritmo, la cuenta de resultados tendió al estancamiento, y la sociedad atravesó frecuentes dificultades de liquidez, aunque éstas nunca supusieron un riesgo real de quiebra. A lo largo de los años veinte, se combinaron un fuerte crecimiento de los gastos de explotación con problemas de equilibrio financiero derivados de una errónea política de financiación. Como resultado, los márgenes de explotación se estancaron (Piñeiro, 1996b: 188-192).

El sector financiero de A Coruña en los años veinte estaba integrado por cinco tipos de instituciones: los comerciantes banqueros, las sociedades anónimas bancarias locales, la Caja de Ahorros y Monte de Piedad de La Coruña, la banca extranjera asentada en la ciudad, y la sucursal del Banco de España.

La actividad de los comerciantes banqueros resulta complicada de rastrear, por cuanto sus negocios habitualmente constituían una sección de una actividad más diversificada. Lo más frecuente era que se tratase de firmas sociales dedicadas al comercio, la industria y/o a otras actividades, en las que la sección de banca era una más de sus ocupaciones. En A Coruña, en 1919 y en 1923 sólo permanecían como banqueros privados Narciso Obanza y Sobrinos de José Pastor ${ }^{44}$. Esta última era, indudablemente, la casa más sobresaliente, ya que se hallaba presente en las cuatro provincias gallegas, y poseía sucursales en Lugo, Ourense y Vigo ${ }^{45}$.

\footnotetext{
42 Piñeiro (1996a). Los ejes A Coruña-Sada y A Coruña-Betanzos formaban el esqueleto principal del área periurbana, con el que la ciudad mantenía estrechas relaciones (Precedo, 1990a).

43 Piñeiro (1996b: 187-188). La línea a Sada entró en crisis en la segunda mitad de los años veinte, agravándose más tarde, como consecuencia de la competencia ilegal de un servicio de autobuses no regulado que recorría un itinerario idéntico al del tranvía (Martínez López y Piñeiro, 1998: 20).

44 Alonso (1984: 195). Anuario Financiero y de Sociedades Anónimas, 1919, p. 424.

45 Una vez transformada en el Banco Pastor, quedaron a la cabeza de los comerciantes banqueros la Banca Hijos de Olimpio Pérez, de Santiago, y la Banca Hijos de Simeón García, de Ourense. En 1922 los recursos de Hijos de Olimpio Pérez ascendían aproximadamente a 21,82 millones de pts., aumentando progresivamente hasta los 33,75 millones en 1930 y 31,66 millones en 1934, año en el que ocupaba el 54 lugar dentro del sistema bancario español. Hijos de Simeón García poseía unos recursos de 9,1 millones de pts. en 1922, incrementados a 12,79 millones en 1930 y 10,18 millones en 1934, ocupando el $80^{\circ}$ lugar del ranking. A continuación, figuraban la Banca de Viuda e Hijos de Carlos Casas (Ribadeo), Narciso Obanza e Hijos de A. Núñez (Betanzos), en las posiciones 84, 112 y 121. Las 13 casas de banca que todavía operaban en el mercado gallego en 1935 manejaban casi el 0,7\% de los recursos totales del sector (Arroyo, 2003: 114, 130).
} 


\section{Cuadro 3.8. Recursos totales de la Banca}

Narciso Obanza (miles pts. corrientes).

\begin{tabular}{ccccccccccc}
\hline Año & CN* & CD & FR & RP & AUT & PC & PA & GPC & GPA & RT \\
\hline 1922 & 800 & 800 & 0 & 800 & 0,00 & 1.337 & 1.337 & 59,84 & 59,84 & 2.137 \\
\hline 1923 & 617 & 617 & 0 & 617 & 0,00 & 1.628 & 1.628 & 37,90 & 37,90 & 2.245 \\
\hline 1924 & 617 & 617 & 0 & 617 & 0,00 & 1.903 & 1.903 & 32,42 & 32,42 & 2.520 \\
\hline 1925 & 617 & 617 & 17 & 634 & 2,76 & 1.664 & 1.664 & 38,10 & 38,10 & 2.298 \\
\hline 1926 & 617 & 617 & 42 & 659 & 6,81 & 1.658 & 1.658 & 39,75 & 39,75 & 2.317 \\
\hline 1927 & 617 & 617 & 10 & 627 & 1,62 & 2.656 & 2.656 & 23,61 & 23,61 & 3.283 \\
\hline 1928 & 617 & 617 & 34 & 651 & 5,51 & 1 & 3.940 & $65.100,00$ & 16,52 & 4.591 \\
\hline 1929 & 617 & 617 & 34 & 651 & 5,51 & 36 & 4.199 & $1.808,33$ & 15,50 & 4.850 \\
\hline 1930 & 617 & 617 & 34 & 651 & 5,51 & 518 & 4.804 & 125,68 & 13,55 & 5.455 \\
\hline 1931 & 617 & 617 & 34 & 651 & 5,51 & 3.340 & 3.340 & 19,49 & 19,49 & 3.991 \\
\hline 1932 & 617 & 617 & 34 & 651 & 5,51 & 622 & 3.390 & 104,66 & 19,20 & 4.041 \\
\hline 1933 & 617 & 617 & 34 & 651 & 5,51 & 671 & 3.615 & 97,02 & 18,01 & 4.266 \\
\hline 1934 & 617 & 617 & 34 & 651 & 5,51 & 680 & 3.693 & 95,74 & 17,63 & 4.344 \\
\hline * CN = Capital nominal; CD = Capital desembolsado; FR=Fondos de reserva; RP = Recursos propios; \\
$\begin{array}{l}\text { AUT = Autofinanciación; PC = Pasivo clientes; PA = Pasivo acreedor; GPC = Garantín sobre pasivo } \\
\text { clientes; GPA = Garantía sobre pasivo acreedor; RT = Recursos totales. }\end{array}$ \\
\hline
\end{tabular}

\section{Fuente: Arroyo (1999: 198).}

Sin embargo, esta figura perdió progresivamente presencia, como consecuencia de que los bancos comenzaron a asumir las funciones hasta entonces realizadas por aquéllos. La mayor complejidad de las operaciones bancarias y el creciente volumen de recursos requeridos para atenderlas estaba relacionado con el incremento de la actividad económica y con la mayor dimensión de las empresas. Aunque participaron de la favorable coyuntura de la guerra mundial, también sufrieron el embate de la crisis de los primeros años veinte. Finalmente, la creciente competencia en sus plazas de origen obligó a algunas de estas casas a traspasar sus negocios o a integrarse en el organigrama de otros bancos regionales o nacionales en expansión (Arroyo, 2003: 114-116, 233). A la altura de 1930 en A Coruña sólo pervivía la Banca de Obanza (López Prado, 1966). Esta casa, finalmente, se integró en el Banco Español de Crédito en el año 1942, una vez que los herederos de la firma decidieron vender el nombre comercial y una parte del activo y pasivo en la cantidad de 500.000 pts., aunque el proceso final de liquidación del negocio se prolongó todavía hasta 1946 (Alonso Álvarez, 2000: 23). 
La única casa de banca para la que se ha encontrado información es la de Narciso Obanza, C.B. ${ }^{46}$. Esta entidad atravesó una etapa de estancamiento de sus recursos totales durante la primera mitad de los años veinte (Cuadro 3.8). Pasado ese período, en el que se combinaron la crisis de readaptación posbélica y la crisis financiera española, la firma vivió un último período de crecimiento de sus recursos, al amparo de la favorable coyuntura dictatorial, especialmente entre 1926-28. En este caso, la variable se nutrió de la captación de recursos ajenos, ya que los recursos propios y el capital se mantuvieron estables, e incluso descendieron en 1923 y en 1927.

Su comportamiento inversor estuvo estrechamente vinculado con sus recursos, ya que la tendencia de la inversión total fue casi idéntica a la de los recursos totales, es decir, caída en 1923-26, con una notable recuperación hasta 1931 (Cuadro 3.9). Ahora bien, la estrategia inversora experimentó modificaciones, al menos si nos atenemos al período 1922-34. La variable que marcó la tendencia fue la inversión en fondos públicos, que mantuvo un comportamiento mimético al de la serie global, aunque más pronunciado. Por el contrario, el principal protagonista de la inversión en la posguerra mundial, los valores industriales, perdió posiciones durante los años siguientes, a pesar de que en valores absolutos todavía experimentase un crecimiento en la segunda mitad de los años veinte. Parece detectarse una estrategia de minimización de riesgos, a la búsqueda de valores, en principio, más seguros.

Pero el segmento más destacado lo formaban las sociedades anónimas bancarias. Los dos principales bancos de este período fueron el Banco de La Coruña, constituido en 1918, y el Banco Pastor, creado en 1925, ambos favorecidos por la mayor competencia establecida en el sector bancario español de las dos primeras décadas del siglo (Martín Aceña y Pons, 1995: 14). La primera sociedad constituye un ejemplo de la tradición bancaria de la ciudad, que arranca de la creación el 1 de julio de 1858 del primitivo Banco de La Coruña (desaparecido en 1875, para dar paso a la sociedad Crédito Gallego).

El Banco de La Coruña se constituyó el 8 de diciembre de 1917, con un capital de 5.000.000 de pesetas ${ }^{47}$. Su creación se enmarca en la coyuntura bancaria expansiva del período 1916-20, en la que se abrieron numerosos bancos en España (Martín Aceña y Pons, 1995: 3-4), se modernizó el sistema bancario y se conformó el núcleo que capitaneó la formación de la gran banca en el país (Arroyo, 2001: 13). Los años veinte

\footnotetext{
46 El fundador original del negocio fue Narciso Obanza y Díaz, fallecido en 1901. A partir de su fallecimiento los negocios giraron bajo la forma de comunidad de bienes, entre sus herederos, viuda e hijos. Según García López (2003: 158-159), desde que los dos principales herederos, Narciso y Fernando Obanza Alonso, se hicieron cargo del negocio, comenzó el declive económico de la familia. De hecho, su representación como consignataria de la naviera Pinillos les servía para complementar "los escasos ingresos del negocio bancario".

47 Banco de La Coruña S.A.: proyecto de estatutos, 1917. La escritura fundacional se inscribió ante el Notario José Pérez Porto, y el capital social estaba integrado por 10.000 acciones de 500 pts., siendo suscrito del siguiente modo: Dionisio Tejero, 2.000 acciones; Julio González Valerio, 300; Raimundo Molina, 300; Miguel Sánchez Barros, 200; Gabriel López Companioni, 120; Julio López Bailly, 100; Ricardo Pernas, 100. El resto de la suscripción se cubrió rápidamente. El Banco de La Coruña, Bodas de Oro, 1918-1968, La Coruña, 1968.
} 
fueron asimismo una etapa favorable para la banca gallega, ya que, además del Banco de La Coruña, se incorporaron el Banco Viñas Aranda de Vigo (en 1918), el Banco Pastor (1925) y el Banco Perfecto Castro Canosa de Cee (1927), todos ellos formados por personas o grupos financieros de las respectivas plazas (García López, 2003).

\section{Cuadro 3.9. Saldos totales y estructura inversora de la Banca Narciso Obanza (miles pts. corrientes y porcentaje).}

\begin{tabular}{|c|c|c|c|c|c|c|c|c|c|c|c|c|c|}
\hline \multirow[b]{2}{*}{ Año } & \multirow[b]{2}{*}{ EC* } & \multirow[b]{2}{*}{$\mathrm{CR}$} & \multirow[b]{2}{*}{ IC } & \multirow[b]{2}{*}{ FP } & \multirow[b]{2}{*}{ VI } & \multirow[b]{2}{*}{ CT } & \multirow[b]{2}{*}{ IT } & \multicolumn{6}{|c|}{ Estructura de la inversión (en \%) } \\
\hline & & & & & & & & EC & CR & IC & FP & VI & CT \\
\hline 1922 & 164 & 180 & 344 & 285 & 350 & 635 & 979 & 16,75 & 18,39 & 35,14 & 29,11 & 35,75 & 64,86 \\
\hline 1923 & 82 & 121 & 203 & 503 & 393 & 896 & 1.099 & 7,46 & 11,01 & 18,47 & 45,77 & 35,76 & 81,53 \\
\hline 1924 & 143 & 142 & 285 & 383 & 363 & 746 & 1.031 & 13,87 & 13,77 & 27,64 & 37,15 & 35,21 & 72,36 \\
\hline 1925 & 83 & 241 & 324 & 117 & 281 & 398 & 722 & 11,50 & 33,38 & 44,88 & 16,20 & 38,92 & 55,12 \\
\hline 1926 & 168 & 167 & 335 & 42 & 375 & 417 & 752 & 22,34 & 22,21 & 44,55 & 5,59 & 49,87 & 55,45 \\
\hline 1927 & 148 & 203 & 351 & 432 & 567 & 999 & 1.350 & 10,96 & 15,04 & 26,00 & 32,00 & 42,00 & 74,00 \\
\hline 1928 & 239 & 205 & 444 & 1.142 & 586 & 1.728 & 2.172 & 11,00 & 9,44 & 20,44 & 52,58 & 26,98 & 79,56 \\
\hline 1929 & 266 & 418 & 684 & 1.096 & 547 & 1.643 & 2.327 & 11,43 & 17,96 & 29,39 & 47,10 & 23,51 & 70,61 \\
\hline 1930 & 270 & 598 & 868 & 1.121 & 266 & 1.387 & 2.255 & 11,97 & 26,52 & 38,49 & 49,71 & 11,80 & 61,51 \\
\hline 1931 & 249 & 631 & 880 & 1.122 & 337 & 1.459 & 2.339 & 10,65 & 26,98 & 37,62 & 47,97 & 14,41 & 62,38 \\
\hline 1932 & 201 & 528 & 729 & 1.226 & 336 & 1.562 & 2.291 & 8,77 & 23,05 & 31,82 & 53,51 & 14,67 & 68,18 \\
\hline 1933 & 176 & 537 & 713 & 1.134 & 336 & 1.470 & 2.183 & 8,06 & 24,60 & 32,66 & 51,95 & 15,39 & 67,34 \\
\hline 1934 & 292 & 472 & 764 & 1.134 & 332 & 1.466 & 2.230 & 13,09 & 21,17 & 34,26 & 50,85 & 14,89 & 65,74 \\
\hline
\end{tabular}

Fuente: Arroyo (1999: 199).

El banco dio inicio a sus operaciones el 1 de febrero de 1918, como una institución crediticia de ámbito local, aunque pronto se convirtió en un banco regional. Fue el fruto de la iniciativa de los principales elementos representativos de la clase empresarial dominante, manteniendo los mismos vínculos que el banco decimonónico con los comerciantes locales y el entorno portuario ${ }^{48}$. La presidencia del banco recayó en Dionisio Tejero Pérez (hasta su fallecimiento, en abril de 1941), destacado empresario

\footnotetext{
48 Alonso Álvarez (2000: 21). El Consejo de Administración quedó integrado por: presidente, Dionisio Tejero Pérez; vicepresidente, Raimundo Molina y Couceiro; secretario, Gabriel López Companioni; vocales, Julio González Valerio, Miguel Sánchez Barros, Julio López Bailly, Ricardo Pernas Varela, Demetrio Salorio Rubine, Ramón del Cueto Noval, Mariano Fernández Morales y Canuto Berea Rodrigo.
} 
coruñés, que desplegó un amplio abanico de actividades empresariales: consignatario, armador de buques, almacenista de carbones y sal, industrial textil, importador-exportador, presidente del Colegio Oficial de Aduanas de La Coruña, etc. ${ }^{49}$.

Cuadro 3.10. Recursos totales del Banco de La Coruña (miles de pts. corrientes).

\begin{tabular}{|c|c|c|c|c|c|c|c|c|c|c|}
\hline Año & $\mathrm{CN}^{*}$ & CD & FR & RP & AUT & PC & PA & GPC & GPA & RT \\
\hline 1918 & 5.000 & 2.000 & 0 & 2.000 & 0 & 13.050 & 13.361 & 15 & 15 & 15.361 \\
\hline 1919 & 5.000 & 3.000 & 75 & 3.075 & 3 & 19.000 & 19.000 & 16 & 16 & 22.075 \\
\hline 1920 & 5.000 & 4.997 & 149 & 5.146 & 3 & 19.909 & 19.909 & 26 & 26 & 25.055 \\
\hline 1921 & 10.000 & 5.000 & 242 & 5.242 & 5 & 22.809 & 22.809 & 23 & 23 & 28.051 \\
\hline 1922 & 10.000 & 5.000 & 636 & 5.636 & 13 & 27.981 & 27.981 & 20 & 20 & 33.617 \\
\hline 1923 & 10.000 & 5.000 & 759 & 5.759 & 15 & 26.587 & 26.587 & 22 & 22 & 32.346 \\
\hline 1924 & 10.000 & 5.000 & 882 & 5.882 & 18 & 31.170 & 31.555 & 19 & 19 & 37.437 \\
\hline 1925 & 10.000 & 5.000 & 1.005 & 6.005 & 20 & 18.167 & 57.853 & 33 & 10 & 63.858 \\
\hline 1926 & 10.000 & 5.000 & 1.128 & 6.128 & 23 & 20.954 & 56.040 & 29 & 11 & 62.168 \\
\hline 1927 & 10.000 & 5.000 & 1.251 & 6.251 & 25 & 23.722 & 36.455 & 26 & 17 & 42.706 \\
\hline 1928 & 10.000 & 5.000 & 1.383 & 6.383 & 28 & 25.840 & 44.111 & 25 & 14 & 50.494 \\
\hline 1929 & 10.000 & 5.000 & 1.533 & 6.533 & 31 & 29.990 & 49.168 & 22 & 13 & 55.701 \\
\hline 1930 & 10.000 & 6.250 & 1.683 & 7.933 & 27 & 32.478 & 53.784 & 24 & 15 & 61.717 \\
\hline 1931 & 10.000 & 6.250 & 2.056 & 8.306 & 33 & 32.745 & 51.503 & 25 & 16 & 59.809 \\
\hline 1932 & 10.000 & 6.250 & 2.055 & 8.305 & 33 & 33.033 & 51.152 & 25 & 16 & 59.457 \\
\hline 1933 & 10.000 & 6.250 & 2.199 & 8.449 & 35 & 31.404 & 48.184 & 27 & 18 & 56.633 \\
\hline 1934 & 10.000 & 6.250 & 2.195 & 8.445 & 35 & 31.313 & 42.167 & 27 & 20 & 50.612 \\
\hline 1935 & 10.000 & 6.250 & 2.338 & 8.588 & 37 & 35.062 & 43.707 & 24 & 20 & 52.295 \\
\hline
\end{tabular}

Fuente: Arroyo (2001: 45).

\footnotetext{
49 Su perfil se asemejaba al de otros empresarios promotores de la banca local y regional, comprometidos en su mayoría en actividades marítimas (de consignación, principalmente) y comerciales, y desempeñando asimismo un activo papel en las promociones industriales y de servicios modernos del primer tercio del siglo. Con frecuencia, la implicación de estos empresarios en la vida política local era muy acentuada.
} 
La sociedad se caracterizó por una activa participación en iniciativas de la banca privada de su época, manteniendo una estrecha relación con otras entidades y mercados $^{50}$. En parte como secuela de los negocios de los integrantes del accionariado, el banco mantuvo contactos con el mercado americano desde el final de la guerra (Arroyo, 2003: 76-79; 2001: 19-23). Sin embargo, el escenario en el que comenzó sus operaciones, la posguerra, sufrió un drástico cambio de signo que condicionó sus primeros pasos. Entre finales de 1920 y finales de 1921 se abrió una coyuntura de crisis, cuyo origen se encontraba en el acusado reajuste posbélico de mercados. Ante el impacto de la crisis, internacional primero y nacional después, la política del banco se dirigió hacia la venta de valores de la cartera para hacer frente a posibles contingencias. La vocación del banco era comercial, vía crédito y descuento a clientes, una filosofía que le reportó progresos en sus inicios. Pero el cambio de coyuntura de los años veinte se reflejó en una contracción crediticia, con saldos en retroceso entre 1921 y 1925. De hecho, en el bienio 1924-26 seis entidades bancarias de importancia se liquidaron y otras muchas estuvieron a punto de suspender pagos (Martín Aceña, 1984: 81-84). La reacción del sector ante la crisis se encaminó en la dirección de una mayor concentración, en tanto el gobierno trataba de encauzar el marco institucional por la vía de una mayor vigilancia y control sobre la banca privada.

Cuadro 3.11. Red operativa del Banco de La Coruña, 1918-35.

\begin{tabular}{cllcll}
\hline Apertura & \multicolumn{1}{c}{ Plaza } & Provincia & Apertura & Plaza & Provincia \\
\hline $1 / 2 / 1918$ & A Coruña (sede) & A Coruña & $19 / 12 / 1927$ & Mondoñedo & Lugo \\
\hline $20 / 8 / 1918$ & Ferrol & A Coruña & $20 / 3 / 1928$ & Ortigueira & A Coruña \\
\hline $22 / 3 / 1920$ & Lugo & Lugo & $29 / 4 / 1928$ & Padrón & A Coruña \\
\hline $15 / 11 / 1921$ & Santiago & A Coruña & $1 / 6 / 1928$ & Ourense & Ourense \\
\hline $13 / 1 / 1923$ & Vilagarcía & Pontevedra & $16 / 7 / 1928$ & Verín & Lugo \\
\hline $15 / 2 / 1923$ & Betanzos & A Coruña & $3 / 9 / 1928$ & Riveira & A Coruña \\
\hline $9 / 8 / 1926$ & Carballo & A Coruña & $10 / 9 / 1928$ & Rúa de Petín & Ourense \\
\hline $1 / 10 / 1926$ & Cee & A Coruña & $10 / 11 / 1928$ & Lalín & Pontevedra \\
\hline $20 / 11 / 1926$ & Noia & A Coruña & $1 / 12 / 1928$ & Monforte & Lugo \\
\hline $16 / 4 / 1927$ & A Estrada & Pontevedra & $18 / 1 / 1929$ & Barco de Valdeorras & Ourense \\
\hline $12 / 7 / 1927$ & Melide & A Coruña & $7 / 10 / 1929$ & Sarria & Lugo \\
\hline $17 / 8 / 1927$ & Pontedeume & A Coruña & $11 / 6 / 1930$ & Cedeira & A Coruña \\
\hline $3 / 10 / 1927$ & Vigo & Pontevedra & $18 / 3 / 1931$ & Ordes & A Coruña \\
\hline $27 / 10 / 1927$ & Vilalba & Lugo & $1928-1933$ & Ribadavia & Ourense \\
\hline
\end{tabular}

Fuente: Arroyo (2001: 60). La sucursal de Ribadavia se inauguró en 1928, posiblemente a la par que la de la Rúa de Petín, el 10 de septiembre, clausurándose en 1933.

\footnotetext{
50 En la fase de concentración bancaria que se abrió a nivel nacional en la segunda mitad de los años veinte (Pueyo, 2003), la entidad entabló negociaciones hasta con cuatro representantes de la gran banca, que desembocaron en la entrada del Banco de Bilbao en 1942 en su capital social.
} 
Por el contrario, el Banco de La Coruña salió reforzado de la crisis, ya que mantuvo una estrategia inversora mixta — similar a la del Banco de Vigoagresiva en inversiones directas (Alonso, 1984: 199), y eso le permitió remontar mejor la crisis que se produjo después de la guerra europea. Los recursos totales atravesaron una etapa de crecimiento en 1920-22, viéndose afectados por la delicada coyuntura del bienio 1922-24 (Cuadro 3.10). La crisis se reflejó en los saldos ajenos, en dos momentos, 1923 y 1925, aunque, posteriormente, los recursos experimentaron un fuerte tirón en 1925, para decaer en los dos siguientes ejercicios, hecho que coincidió con la merma de las remesas de ahorros de América, pero también con la apuesta por potenciar una red operativa extensa en Galicia (Cuadro 3.11). Posteriormente, la recuperación continuó hasta 1930. En 1934 era el 41 ${ }^{\circ}$ banco nacional (Arroyo, 2001: 33, 48, 57, 158).

Cuadro 3.12. Sucursales bancarias en Galicia, a principios de los años veinte.

\begin{tabular}{|c|c|c|}
\hline A Coruña & Pontevedra & Lugo \\
\hline Banco de España & Banco de España & Banco de España \\
\hline Banco de La Coruña & Banco de Vigo & Banco de La Coruña \\
\hline Banco H. Americano & Banco H. Americano & Banco Herrero \\
\hline Banco E. del Río de la Plata & Banco E. del Río de la Plata & Banca S. de José Pastor \\
\hline Banca Narciso Obanza & Banca M. Alonso & \\
\hline Banca S. de José Pastor & Banca Riestra y Cía. & \\
\hline Santiago & Ourense & Vilagarcía \\
\hline Banco de España & Banco de España & Banco de Vigo \\
\hline Banco de La Coruña & Banco de Vigo & Banco de La Coruña \\
\hline Banco de Vigo & Banco H. Americano & Banca H. de Simeón \\
\hline Banco H. Americano & Banca H. de Simeón & Banca H. de Olimpio Pérez \\
\hline Banco E. del Río de la Plata & Banca S. de José Pastor & \\
\hline \multicolumn{3}{|l|}{ Banca H. de Olimpio Pérez } \\
\hline \multicolumn{3}{|l|}{ Banca H. de Simeón } \\
\hline \multicolumn{3}{|l|}{ Vigo } \\
\hline \multicolumn{3}{|l|}{ Banco de España } \\
\hline \multicolumn{3}{|l|}{ Banco H. Americano } \\
\hline \multicolumn{3}{|l|}{ Banco E. del Río de la Plata } \\
\hline Anglo South American Bank & & \\
\hline
\end{tabular}

Fuente: Alonso (1984); Arroyo (1999: 47). 
Desde el principio, el banco diseñó una estrategia de expansión dentro del mercado gallego, en unos tiempos en los que éste carecía todavía de redes operativas amplias, si se exceptúa la pujanza de las capitales de provincia, Santiago o Vigo (Cuadro 3.12). Pero la incierta coyuntura del inicio de los años veinte obligó a replantear la estrategia inicial. Para evitar posibles eventualidades, se dotó de una mayor potencialidad, al aumentar su capital a 10.000 .000 pts. en 1921, aunque en la práctica no liberó cantidad alguna hasta 1930 (Arroyo, 2001: 39). Con todo, hasta 1925 la red se extendió hacia las provincias de A Coruña y Lugo (Arroyo, 1999: 37-42), en dos coyunturas diferenciadas: en 1918-23, cuando se inauguraron 5 oficinas (Ferrol, Santiago, Lugo, Vilagarcía y Betanzos) y en 1926-30, en que se instalaron 21 nuevas sucursales (Cuadro 3.11).

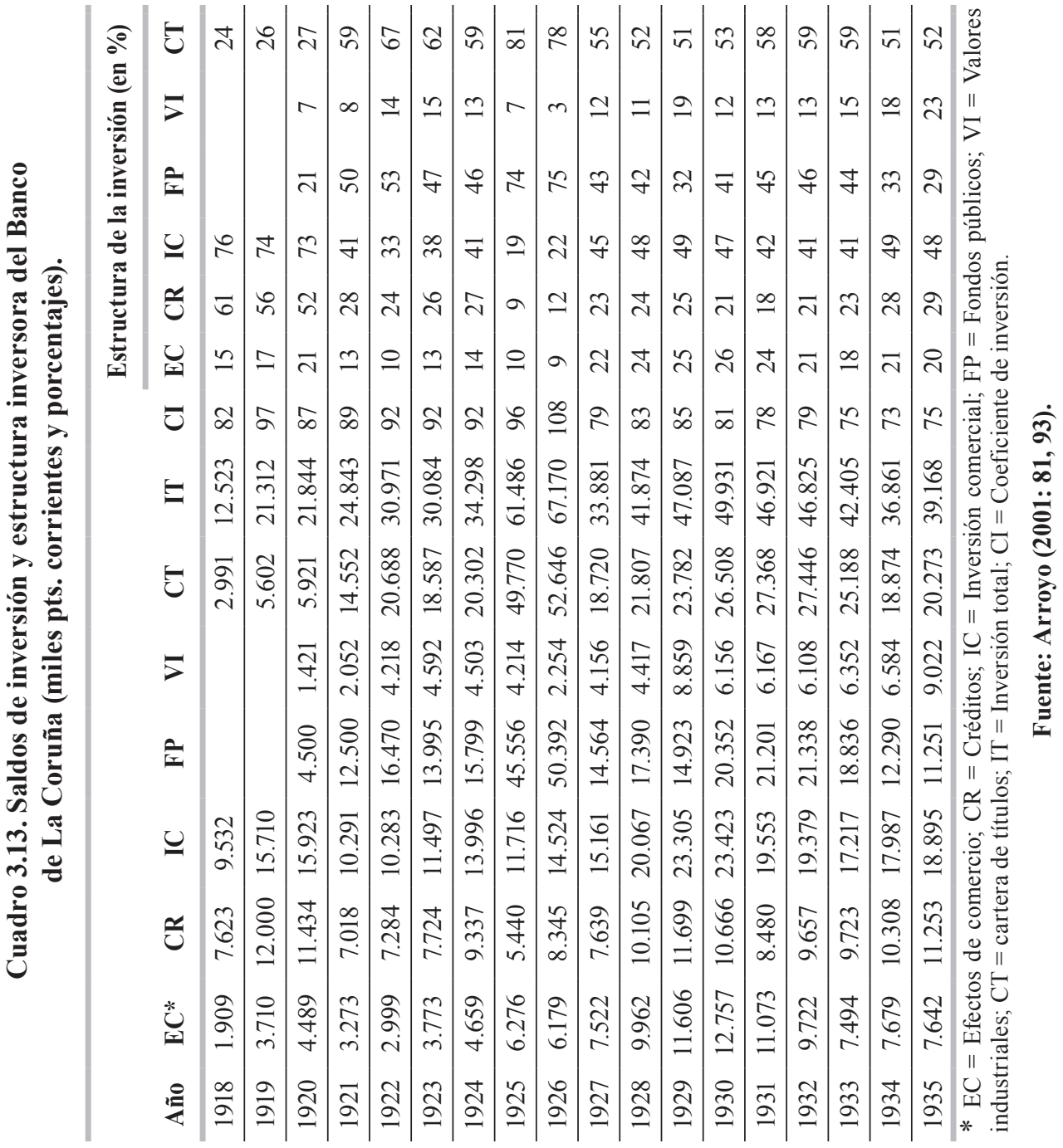


Por lo que respecta a la inversión, la sociedad participó como accionista en diversas industrias y servicios gallegos ${ }^{51}$. La inversión en su conjunto tuvo un comportamiento similar al de los recursos totales: rápido crecimiento desde su fundación, ralentización en 1923-24, recuperación en 1925 y, posteriormente, fuerte crecimiento, coincidiendo con el inicio del segundo esfuerzo expansivo (Cuadro 3.13).

Como resultado final de la operativa del banco, los beneficios líquidos progresaron de forma nítida desde su constitución hasta 1920, para estabilizarse hasta 1935, lo que permitió el reparto regular de dividendos a los accionistas (Cuadro 3.14). A pesar de ello, resulta significativo el estancamiento real de la rentabilidad durante el período 1920-35, ya que la ratio de rentabilidad del dividendo sobre los recursos propios de la entidad se estabilizó en torno al 6\% anual entre 1921-30 (Arroyo, 2001: 101-103).

Por su parte, el Banco Pastor nació el 1 de enero de 1925, por conversión jurídica de la casa Sobrinos de José Pastor, existente desde $1776^{52}$. A lo largo del siglo XIX y principios del XX, esta razón social, sin dejar de operar en actividades bancarias, se dedicó de un modo especial a la consignación de buques en los principales puertos gallegos (González, 2000: 97). En 1921 se disgregaron las actividades bancarias de las marítimas (consignaciones) (Rojo, 1980: 267). Antes de transformarse en sociedad anónima, contaba ya con ocho sucursales en Galicia (Alonso, 1984).

El presidente del banco fue Ricardo Rodríguez Pastor ${ }^{53}$, y su vicepresidente vitalicio, Pedro Barrié de la Maza, sobrino del anterior ${ }^{54}$. Ricardo Rodríguez fallecía en 1941, quedando entonces como presidente y socio mayoritario de la entidad, con un 93\% del capital, Pedro Barrié de la Maza (Rojo, 1980: 267), quien se convirtió posteriormente en el financiero más sobresaliente de Galicia ${ }^{55}$. Entre 1917 y 1963 fue

\footnotetext{
E1 En el período 1918-20 predominó la inversión comercial, mientras que en el período 1921-35 dominó la cartera de títulos (Arroyo, 2001: 96).

52 Se fundó bajo la razón social Banca Jaime Dalmau y Pastor, cambiando posteriormente su denominación social por Pedro Barrié y Cía., y posteriormente Sobrinos de José Pastor, en 1890, hasta su definitiva transformación en el Banco Pastor (López Prado, 1984: 305). El objeto social de Sobrinos de José Pastor era la realización de operaciones comerciales e industriales de todo tipo, aunque extendió sus intereses hacia las actividades de representación de empresas navieras (Pacific Steam Navigation Company, A. Folch y Cía. y Pinillos, Izquierdo y Cía), comisiones y banca (Lindoso, 1999: 98).

53 Ricardo Rodríguez Pastor presenta un perfil semejante al de algunos de los principales empresarios de A Coruña (Mirás, 2003c). El principal destino de sus inversiones era el sector financiero, aunque sus intereses se dirigían también hacia otros negocios (Lindoso, 1999: 125; González Catoyra, 1990: 576).

54 El Consejo de Administración del Banco Pastor estuvo constituido inicialmente por: presidente vitalicio y director, Ricardo Rodríguez Pastor. Vicepresidente vitalicio y director, Pedro Barrié de la Maza. Consejeros y subdirectores, Ernesto de Llano Lamas, Agustín Tenreiro Rodríguez, Eduardo Vergne Núñez y Abelardo Zas y Simó, como secretario general. En torno a este grupo de empresarios, la mayoría destacados consignatarios e industriales, se constituyó el grupo Pastor, presente en las más destacadas iniciativas empresariales de A Coruña y de Galicia de los años veinte y treinta y, muy especialmente, de la posguerra civil. De ahí que los negocios de la banca coruñesa estuviesen unidos al tráfico portuario, al comercio marítimo, comercio al por mayor, pesca y derivados y servicios públicos (Alonso, 1984).

55 Pedro Barrié de la Maza era hijo de Pedro Barrié y Pastor, que fue socio-gerente de José Pastor y Cía. En 1911 dio los primeros pasos de su actividad empresarial en Sobrinos de José Pastor, de la que sería nombrado socio-gerente en 1912. Al fallecimiento de José Pastor fue nombrado presidente y director general de Sobrinos de José Pastor. Cuando en 1925 ésta se transformó en Banco Pastor, pasó a desempeñar el cargo de vicepresidente y director general (Rojo, 1980: 267).
} 
presidente de la Compañia de Tranvías. De hecho, esta sociedad y el Banco Pastor compartieron numerosos consejeros durante su vida empresarial, siendo una prueba de la presencia del banco en los servicios públicos urbanos de A Coruña. Pero su éxito empresarial habría de llegar en la posguerra, cuando participó activamente en la creación de numerosas empresas a lo largo de la región ${ }^{56}$.

Cuadro 3.14. Beneficios, coeficientes de explotación, dividendos activos y rentabilidad del Banco de La Coruña (miles de pts. corrientes y porcentaje).

\begin{tabular}{|c|c|c|c|c|c|c|c|c|c|c|c|}
\hline Año & Productos & Gastos & Intereses & $B^{0}$ Neto & $\mathrm{BL}^{*}$ & DA & $\mathbf{R P}$ & CD & RRP & DACD & DARP \\
\hline 1918 & & & & 235 & 235 & 70 & 2.000 & 2.000 & 11,75 & 3,50 & 3,50 \\
\hline 1919 & & & & 339 & 339 & 140 & 3.075 & 3.000 & 11,02 & 4,67 & 4,55 \\
\hline 1920 & 1.241 & 217 & 472 & 552 & 552 & 150 & 5.146 & 4.997 & 10,73 & 3,00 & 2,91 \\
\hline 1921 & 1.727 & 289 & 835 & 603 & 603 & 300 & 5.242 & 5.000 & 11,50 & 6,00 & 5,72 \\
\hline 1922 & 1.671 & 381 & 716 & 574 & 574 & 300 & 5.636 & 5.000 & 10,18 & 6,00 & 5,32 \\
\hline 1923 & 1.928 & 485 & 866 & 577 & 577 & 300 & 5.759 & 5.000 & 10,02 & 6,00 & 5,21 \\
\hline 1924 & 2.010 & 493 & 954 & 563 & 563 & 300 & 5.882 & 5.000 & 9,57 & 6,00 & 5,10 \\
\hline 1925 & 2.101 & 510 & 1.022 & 569 & 569 & 300 & 6.005 & 5.000 & 9,48 & 6,00 & 5,00 \\
\hline 1926 & 3.280 & 531 & 2.173 & 576 & 576 & 300 & 6.128 & 5.000 & 9,40 & 6,00 & 4,90 \\
\hline 1927 & 2.823 & 776 & 1.454 & 593 & 593 & 300 & 6.251 & 5.000 & 9,49 & 6,00 & 4,80 \\
\hline 1928 & 2.861 & 1.050 & 1.208 & 603 & 603 & 300 & 6.383 & 5.000 & 9,45 & 6,00 & 4,70 \\
\hline 1929 & 3.119 & 1.200 & 1.306 & 613 & 613 & 300 & 6.533 & 5.000 & 9,38 & 6,00 & 4,59 \\
\hline 1930 & 3.134 & 1.131 & 1.342 & 661 & 661 & 375 & 7.933 & 6.250 & 8,33 & 6,00 & 4,73 \\
\hline 1931 & 3.293 & 1.262 & 1.379 & 652 & 652 & 225 & 8.306 & 6.250 & 7,85 & 3,60 & 2,71 \\
\hline 1932 & 3.337 & 1.346 & 1.471 & 520 & 520 & 225 & 8.305 & 6.250 & 6,26 & 3,60 & 2,71 \\
\hline 1933 & 3.333 & 1.581 & 1.286 & 466 & 466 & 250 & 8.449 & 6.250 & 5,52 & 4,00 & 2,96 \\
\hline 1934 & 3.109 & 1.610 & 1.076 & 423 & 423 & 250 & 8.445 & 6.250 & 5,01 & 4,00 & 2,96 \\
\hline 1935 & 3.143 & 1.708 & 970 & 465 & 465 & 281 & 8.588 & 6.250 & 5,41 & 4,50 & 3,27 \\
\hline
\end{tabular}

Fuente: Arroyo (2001: 101, 104).

\footnotetext{
$\overline{56}$ Sobresalió por encima de todas la sociedad Fuerzas Eléctricas del Noroeste, S.A. (FENOSA). Para un análisis detallado de la actividad empresarial de Pedro Barrié de la Maza vid. Mirás (2003c: 52-53).
} 
En España, se estaba consolidando el protagonismo de la banca mixta, en dos direcciones, ya que desempeñó un rol vital en la financiación industrial del período de entreguerras y porque se benefició del crecimiento económico de la etapa dictatorial, reforzándose los lazos entre banca e industria (Tortella y Palafox, 1984: 85, 90, 110). El Pastor tuvo precisamente vocación de banca mixta, orientada en buena medida hacia la financiación de las industrias familiares, con un predominio equilibrado entre sus inversiones en cartera y sus inversiones directas, aunque en términos absolutos su inversión industrial fue abultada (Alonso Álvarez, 2000: 22). El crecimiento del negocio en los años veinte discurrió parejo a una fuerte expansión de la red (Cuadro 3.15). La estrategia de desarrollo pasó por la adquisición de los negocios de banqueros que tenía como corresponsales en distintas plazas, por la apertura de nuevas sucursales y por la instalación sobre negocios de sus propios corresponsales (González, 2000: 98-99). El Pastor se convirtió así en el banco de mayor crecimiento, estableciendo numerosas sucursales, de modo que en los años treinta se situaba en 34 localidades gallegas. El Banco de La Coruña también aprovechó la situación, pero sus fondos propios eran prácticamente la mitad de los del Banco Pastor en 1933 (Maixé et al., 2003: 133).

\section{Gráfico 3.1. Beneficios obtenidos por los principales bancos gallegos, 1900-35 (pts. corrientes).}

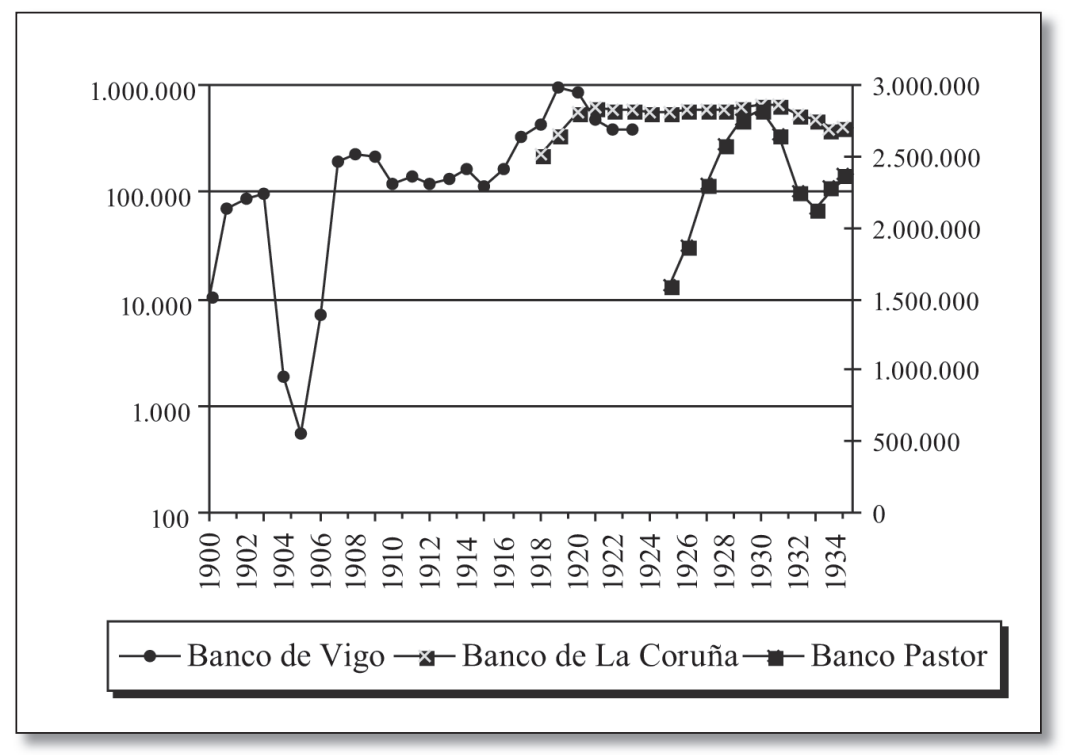

Fuente: Alonso (1984: 198) y Anuario Financiero y de Sociedades Anónimas.

El Pastor experimentó la evolución más acelerada dentro de la banca regional. Por un lado, su capital (tanto nominal como disponible) prácticamente duplicaba el del Banco de La Coruña. Desde la transformación de Sobrinos de José Pastor al Banco Pastor, los recursos propios experimentaron un continuo crecimiento, con una leve desaceleración en 1929-30. El ritmo de incremento más intenso se produjo en 1927-28, 
coincidiendo con la expansión de la red operativa, una vez superada la fase dubitativa que supuso la coyuntura posterior a la desaparición del Banco de Vigo.

Cuadro 3.15. Red operativa del Banco Pastor, 1920-35.

\begin{tabular}{ll}
\hline Sede social: & A Coruña \\
\hline 1920-1922: & Lugo, Ourense y Vigo \\
\hline 1923-1925: & Viveiro, Ferrol, Sarria y Monforte \\
\hline 1925:1927: & A Estrada, Tuy \\
\hline 1928:1930: & $\begin{array}{l}\text { Melide, Muxía, Carballo, Mondoñedo, Pontedeume, Vilalba, Ribadeo, } \\
\text { Ortigueira, Carballiño, Padrón, Póboa do Caramiñal, Ribadavia, Noia, } \\
\\
\text { Barco de Valdeorras, Verín, Rúa de Petín, Vimianzo, Ponteareas }\end{array}$ \\
\hline 1931-1935: & $\begin{array}{l}\text { Ordes, Fonsagrada, Cangas, Cedeira, Celanova, Chantada, A Guarda, } \\
\text { Pontevedra, Marín, Caldas de Reis }\end{array}$ \\
\hline
\end{tabular}

Fuente: Arroyo (1999: 56).

\section{Cuadro 3.16. Recursos totales del Banco Pastor, 1920-35 (miles pts. corrientes).}

\begin{tabular}{ccccccccccc}
\hline Año & CN* & CD & FR & RP & AUT & PC & PA & GPC & GPA & RT \\
\hline 1922 & 4.661 & 4.661 & 0 & 4.661 & 0 & 53.544 & 53.544 & 8,70 & 8,70 & 58.205 \\
\hline 1923 & 5.330 & 5.330 & 0 & 5.330 & 0 & 71.592 & 74.198 & 7,44 & 7,17 & 79.628 \\
\hline 1924 & 5.330 & 5.330 & 0 & 5.330 & 0 & 59.137 & 101.406 & 9,00 & 5,26 & 106.736 \\
\hline 1925 & 17.000 & 8.500 & 0 & 8.500 & 0 & 55.896 & 92.637 & 15,21 & 9,18 & 101.137 \\
\hline 1926 & 17.000 & 8.500 & 700 & 9.200 & 8,24 & 63.416 & 96.842 & 14,51 & 9,50 & 106.042 \\
\hline 1927 & 17.000 & 8.500 & 2.500 & 11.000 & 29,41 & 76.049 & 102.755 & 14,46 & 10,71 & 113.755 \\
\hline 1928 & 17.000 & 11.000 & 3.500 & 14.500 & 31,82 & 89.104 & 133.313 & 16,25 & 10,88 & 147.813 \\
\hline 1929 & 17.000 & 11.000 & 4.500 & 15.500 & 40,91 & 113.210 & 158.382 & 13,69 & 9,79 & 173.882 \\
\hline 1930 & 17.000 & 11.000 & 6.000 & 17.000 & 54,55 & 138.191 & 171.167 & 12,30 & 9,93 & 188.167 \\
\hline 1931 & 17.000 & 11.000 & 12.497 & 23.497 & 113,61 & 141.274 & 167105 & 16,63 & 14,05 & 190.702 \\
\hline 1932 & 17.000 & 11.000 & 14.074 & 25.074 & 127,95 & 158.564 & 190.525 & 15,81 & 13,16 & 215.599 \\
\hline 1933 & 17.000 & 11.000 & 15.407 & 26.407 & 140,06 & 152.219 & 190.633 & 17,35 & 13,85 & 217.040 \\
\hline 1934 & 17.000 & 11.000 & 7.000 & 18.000 & 63,64 & 147.895 & 184.176 & 12,17 & 9,77 & 202.176 \\
\hline 1935 & 17.000 & 11.000 & 8.000 & 19.000 & 72,73 & 156.082 & 189.141 & 12,17 & 10,05 & 208.141 \\
\hline * CN = Capital nominal (capital social); CD = Capital desembolsado (Capital desembolsado en circula- \\
ción); FR = Fondos de reservas; RP = Recursos propios; AUT=Autofinanciación; PC = Pasivo clientes; \\
PA = Pasivo acreedor; GPC = Garantías s/PC; GPA= Garantías s/PA; RT = Recursos totales.
\end{tabular}

Fuente: Arroyo (1999: 186). 
El fuerte crecimiento del banco durante el período de entreguerras lo convirtió en el primero por volumen de recursos dentro del grupo de la banca regional española, habiendo multiplicado sus cifras por 3,5 entre 1922 y 1934. Según la estimación de Arroyo (2003: 101), en 1922 el Banco Pastor era el octavo banco dentro de la banca de categoría regional. En 1930 había ascendido al segundo lugar, y en 1934 era ya el primero, por encima del Mercantil y el Guipuzcoano, duplicando sus recursos respecto a 1925. En vísperas de la Guerra Civil, el Pastor ocupaba el octavo lugar dentro del ranking global del sistema bancario nacional (Arroyo, 2003: 157).

El perfil de los recursos totales era muy similar al de los recursos propios, aunque con un crecimiento más lento al inicio de la actividad de la sociedad anónima, que se transformó en un rápido incremento (mayor que el de los recursos propios) a partir de 1927. Al contrario de lo ocurrido con el Banco de La Coruña, el pasivo-clientes y el pasivo acreedor experimentaron una fuerte elevación hasta la crisis de los años treinta $^{57}$, lo que apunta a una mayor eficacia del banco en relación con sus competidores regionales a la hora de captar el ahorro regional y el americano (Cuadro 3.16).

Su papel como inversor en la economía de A Coruña y en Galicia fue fundamental. Las conexiones que mantuvo con diversas industrias y servicios regionales fueron todavía más estrechas que las del Banco de La Coruña (Mirás, 2003c). La inversión total presenta tres etapas diferenciadas. La primera (1925-27) muestra un descenso, como resultado de la prudencia que presidió la política inversora tras la crisis financiera que se acababa de salvar. Superada esa etapa de indecisión, las inversiones crecieron con fuerza hasta 1930, para resultar, finalmente, perjudicadas por la crisis de los años treinta, con caídas muy marcadas en 1931 y 1934.

La política crediticia fue asimismo muy activa, aunque comparativamente menos acentuada que la del Banco de La Coruña, superando generalmente el 20\% de la inversión total, aunque desde los años treinta creció hasta situarse en torno al 30\%, como resultado del abandono parcial de otras estrategias de utilización del capital.

Aunque el destino más importante de la inversión fueron los fondos públicos, conforme el banco crecía y consolidaba su posición, la participación de los valores industriales creció de manera muy significativa. Este cambio permite vislumbrar la intensa política industrial que desarrollará el banco durante los años del franquismo.

Los beneficios líquidos crecieron a un ritmo bastante más rápido que los del Banco de La Coruña (Gráfico 3.1). Además, la rentabilidad real durante el período 1920-35 experimentó un respetable aumento, toda vez que la ratio de beneficios sobre los recursos propios de la entidad se situó en torno el 10-12\% antes de su conversión a sociedad anónima, y en torno al 4-6\% en la segunda mitad de los años veinte.

57 El Banco Pastor manejaba el 36,2\% de los recursos totales de la banca gallega en 1922, aumentando al $42,6 \%$ en 1923 y superando ya el $50 \%$ en 1924. A partir de aquí prosiguió su proceso concentrador, de manera que en 1934 el banco totalizaba ya el 64\% de los recursos de la banca en Galicia (el 67\% si se consideran los saldos de inversión). Por el contrario, el peso específico del Banco de La Coruña se resintió desde 1922, a medida que se fueron instalando nuevos bancos (Arroyo, 2003: 235-236). 


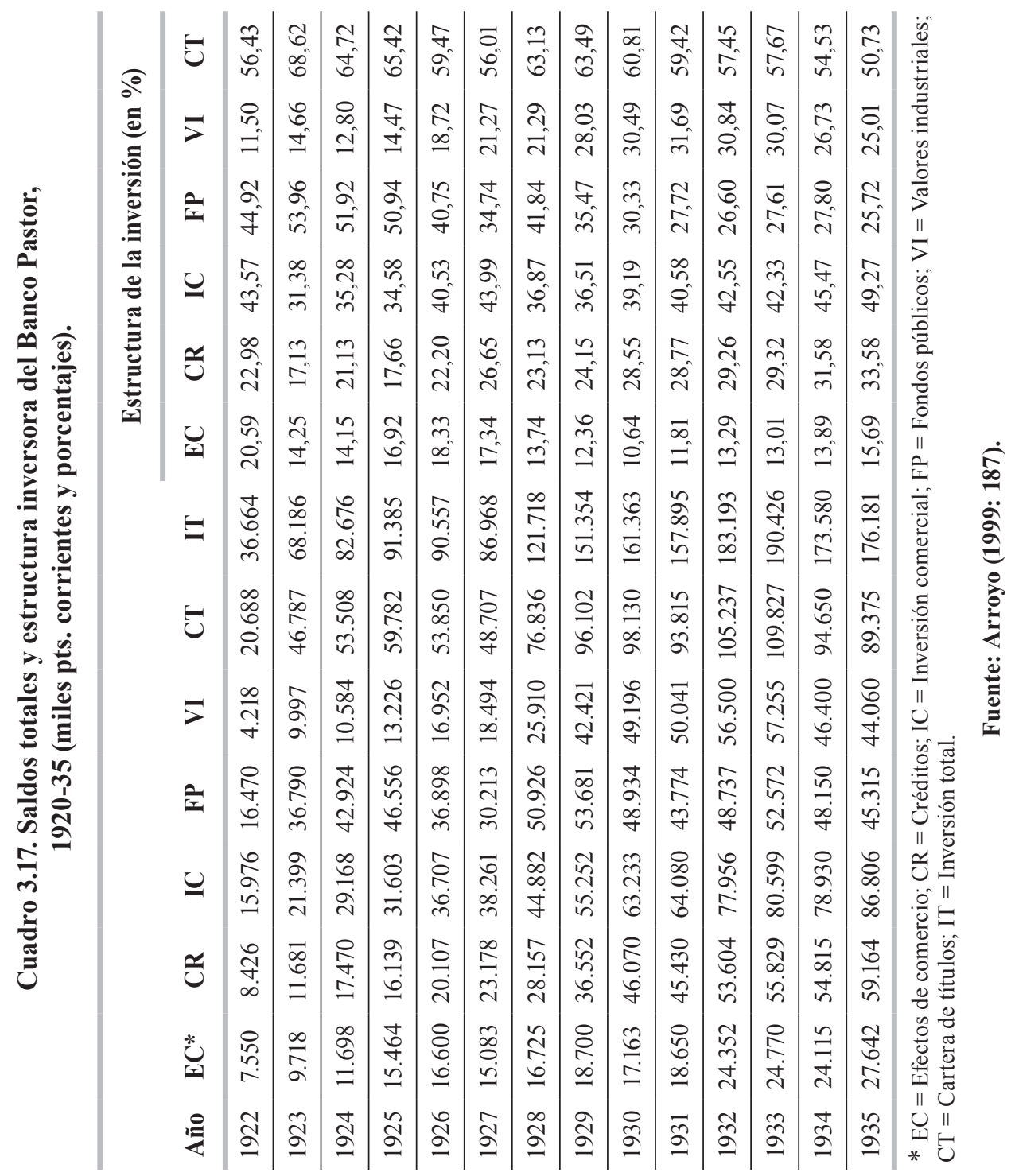

Superada la fase de afianzamiento inicial, la posguerra proporcionó una excelente oportunidad para incrementar la presencia de la Caja de Ahorros de La Coruña, a nivel local y regional, en consonancia con lo ocurrido a nivel español, cuando las cajas comenzaron a abandonar su carácter exclusivamente benéfico para convertirse, progresivamente, en verdaderas instituciones financieras (Maixé et al., 2003: 89).

Durante los años veinte, las cajas de ahorro y las sociedades cooperativas de ahorro adquirieron un creciente protagonismo (Martín Aceña, 1985: 128). A partir de ese decenio, la caja coruñesa se orientó a la realización de préstamos hipotecarios, ampliando 
este campo a los préstamos personales y pignoraticios desde 1930 (Arroyo, 1999: 74). Gracias a su carácter de institución benéfica, desempeñó una destacada labor social, a través de la construcción de casas baratas, donativos, etc. (Sagredo, 1976), de manera similar a otras instituciones análogas. Además, cosechó excelentes resultados con la política difusora del ahorro y la previsión. La captación de nuevos clientes provocó que triplicara sus saldos impositores hasta la Guerra Civil (Maixé et al., 2003: 140). De ese modo, en 1935 la caja ocupaba el décimoséptimo lugar en el ranking de cajas españolas, por saldo de captación de pasivo clientes (Arroyo, 2003: 70-73).

Gráfico 3.2. Activo patrimonial y recursos propios de la Caja de Ahorros y Monte de Piedad de La Coruña, 1900-36 (pts. corrientes).

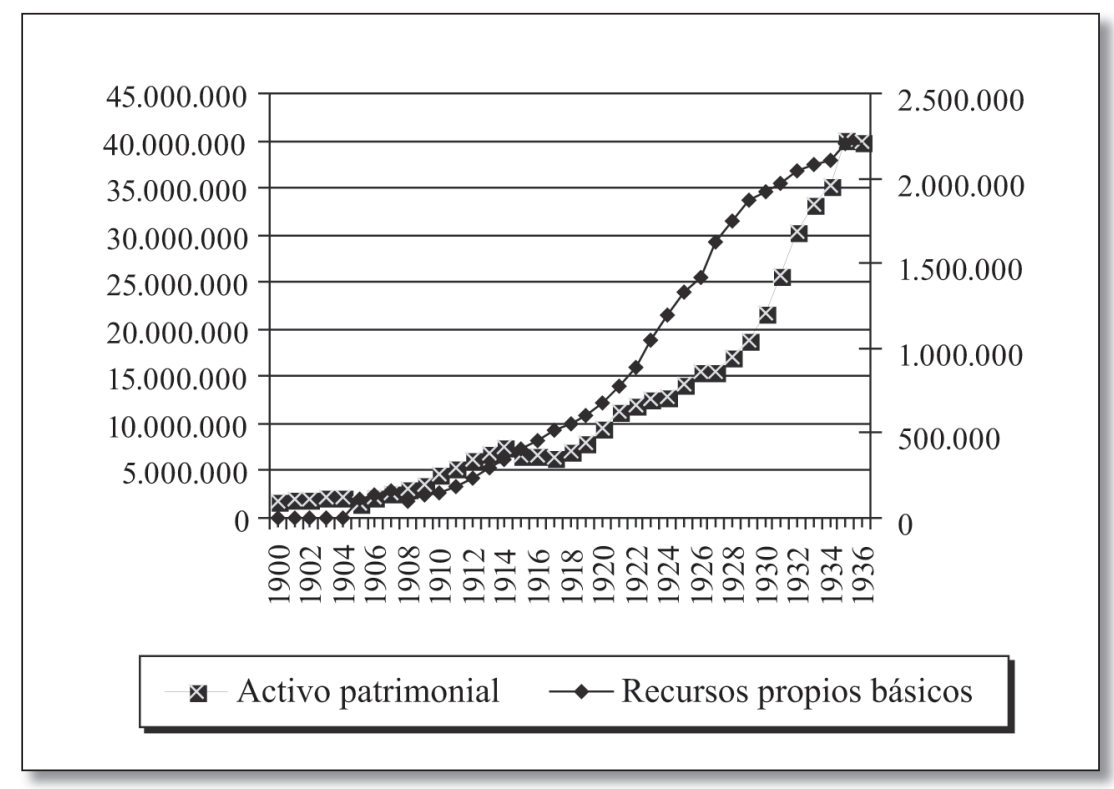

Fuente: Maixé et al. (2003: 349, 353).

Los recursos propios básicos experimentaron un continuo crecimiento durante el primer tercio del siglo, especialmente acusado durante los años previos a la guerra europea (Gráfico 3.2). En cualquier caso, la tendencia se hallaba sobradamente consolidada durante los años veinte, rompiéndose durante la crisis de los treinta. Por su parte, el activo patrimonial total también presenta una tendencia de crecimiento casi continua, con la excepción de los años 1905 (tras su emancipación del Crédito Gallego), 1915-17 (en plena crisis de confianza provocada por la guerra), 1927 y 1936. Los años posteriores a 1905 y los de la posguerra mundial revelan una clara consolidación de la empresa, aun cuando el ritmo de crecimiento de los activos patrimoniales se ralentizase.

Por otra parte, existía una importante nómina de bancos españoles y extranjeros en la ciudad. Hacia 1919, los bancos extraregionales que habían instalado sucursales en 
la ciudad eran el Banco Hispano Americano y el Banco Español del Río de la Plata. Durante los años veinte se amplió la presencia de estas entidades: Credit Lyonnais, Banco de Comercio Exterior, Banco de Seguros de Crédito a la Exportación, etc., como primer paso de su posicionamiento en la región. Desde 1926 los supervivientes del reajuste bancario previo tomaron parte del proceso bancario expansivo que se vivía en España, y que se mantuvo hasta la crisis de 1929. Coincidiendo con el final de la década, la banca española comenzó a abrir tímidamente sus primeras sucursales en Galicia.

Gráfico 3.3. Cartera de valores e inversiones crediticias de la Caja de Ahorros y Monte de Piedad de La Coruña, 1900-36 (pts. corrientes).

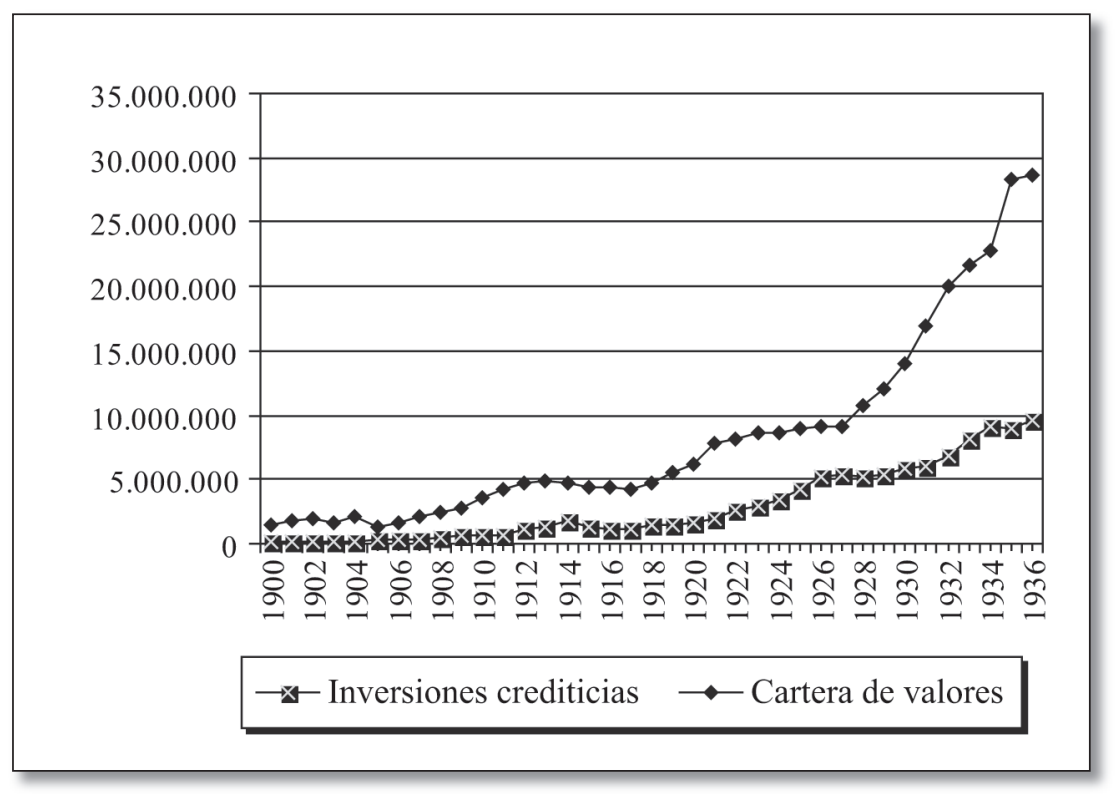

Algo similar ocurría con uno de los sectores que contaban con una presencia más dilatada en la ciudad, el de los seguros. Este conjunto de actividades consolidó sus posiciones durante los años veinte, como resultado del afianzamiento de los negocios marítimos, y de las crecientes necesidades derivadas del crecimiento urbano y regional. Pero, además, el grueso del sector estaba integrado por empresas de procedencia extranjera o española, para las que actuaban en calidad de agentes diversos empresarios ligados a actividades financieras, de consignación, representación, comisión, correduría, etc ${ }^{58}$. La de mayor tradición era la Sociedad de Seguros Mutuos contra Incendios de Casas de La Coruña, fundada en 1835, en la que figuraban algunos notables miembros de la burguesía local (Vilela, 1997).

\footnotetext{
58 El Anuario General de España (Bailly-Bailliére-Riera), 1921, op. cit., proporciona un listado de las diversas sociedades de seguros existentes en la ciudad, que se aproximaba a las setenta.
} 


\section{UN CRECIMIENTO INDUSTRIAL CON DESACELERACIÓN DEL IMPULSO INICIAL}

Durante el primer tercio del siglo la industria coruñesa experimentó cambios cuantitativos, ya que ésta fue una de las épocas de mayor crecimiento del número de empresas. Los progresos también fueron cualitativos, ya que algunas instalaciones se electrificaron, se incrementó la escala productiva y el capital de las sociedades, aunque ese dinamismo modernizador se vería frenado por la crisis industrial de los años treinta y por las propias deficiencias que todavía caracterizaban al sector.

De todos modos, la industria en A Coruña en los años veinte continuaba desempeñando un rol secundario en la economía local ${ }^{59}$, al igual que ocurría en el conjunto de la provincia ${ }^{60}$. El sector presentaba una estructura dual, producto de la existencia de sectores e industrias de naturaleza y tamaño muy diferentes, con estructuras organizativas, tecnológicas y comerciales heterogéneas. El sector industrial mayoritario estaba formado por empresas de pequeñas dimensiones, escasamente capitalizadas y con plantillas reducidas. Este tipo de empresa era dominante en gremios de rancia tradición artesanal (madera, pequeña metalurgia, alimentación, calzado y curtido, etc.). Por otro lado, existía un sector industrial más moderno, tanto en su organización empresarial como en la tecnología empleada en sus procesos productivos. De todos modos, individualmente consideradas, las dimensiones de las empresas industriales coruñesas eran, en general, inferiores a las del sector terciario.

En A Coruña, la estructura industrial era comparativamente más diversificada que la de las otras dos ciudades principales de la provincia, aunque más próxima a la de Ferrol que a la de Santiago. Las actividades dominantes se hallaban vinculadas a los sectores maderero, alimenticio y metalúrgico, con un carácter más decididamente fabril que en la capital compostelana. Aunque abundaban los establecimientos de carácter artesanal en el sector de la madera, existían numerosas fábricas, si bien concentradas en la primera transformación. En el sector de la alimentación también proliferaban los obradores, pero destacaban las fábricas de conservas, salazones, chocolates, hielo, cerveza, etc. Finalmente, el sector metalúrgico agrupaba un elevado número de herrerías, pero también algunas fundiciones de diversos metales, fábricas de envases de hojalata y de telas metálicas, talleres de maquinaria, de reparación de motores, etc ${ }^{61}$.

Los factores del crecimiento industrial de los años veinte fueron diversos. La industria coruñesa se benefició de la excelente coyuntura general tanto en la ciudad como en el conjunto de la economía gallega y española. El sector creció incluso por encima de los otros sectores económicos urbanos, dado que triplicó su cuota y prácticamente duplicó el número de empresas.

La bonanza económica internacional también alcanzó a la economía española, a pesar de soportar un período de fuerte autarquía económica (García Delgado, 1984). Se estaba llevando a cabo un proceso de sustitución de los mercados exteriores por el mercado nacional, es decir, un proceso de progresivo proteccionismo, del que se beneficiaron más las industrias de otras regiones. En el caso coruñés, esto tuvo también

\footnotetext{
59 Breve estudio de la economía mercantil e industrial coruñesa, op. cit., p. 338.

60 Estadística de los salarios y jornadas de trabajo, op. cit., p. cl.

61 Anuario del Comercio, Industria y Profesiones de España, 1927, op. cit.
} 
influencia, si bien en gran medida las industrias locales se limitaban al marco local, provincial o como mucho regional. El período de la Dictadura parece, por tanto, haber sido favorable a la evolución de la industria coruñesa.

En contra del desarrollo del sector actuaron numerosos factores, en su mayor parte de carácter estructural. Más que establecimientos fabriles propiamente dichos, en A Coruña existía un elevado número de talleres, en la mayor parte de los casos de carácter familiar, plenamente equiparables a los talleres artesanales.

Las remesas de la emigración tampoco incidieron suficientemente en la financiación del conjunto del sector. Las entradas de capital canalizadas por las entidades financieras gallegas no se tradujeron en proyectos industriales sólidos (Alonso, 1984: 230). No obstante, la participación de la banca en la financiación de proyectos industriales, especialmente en Vigo (Souto, 1990) ha sido destacada en otros estudios ${ }^{62}$.

Por tanto, al igual que ocurría en numerosas ciudades españolas durante este período, la estructura industrial coruñesa estaba anclada en un extendido minifundismo industrial, con un tipo preponderante basado en industrias ligeras, productoras de bienes de consumo (alimentación, bebidas, tabaco, etc.). Frente al avance en el proceso de diversificación del sector en España entre 1913 y 1929, caracterizado por una reducción del peso de las industrias de bienes de consumo en favor de las de bienes de inversión (Carreras, 1991: 297-299), A Coruña mantenía una estructura industrial similar a la de años anteriores. De ahí sobreviene la imagen de un cierto estancamiento industrial, que no resulta del todo real, ya que algunos subsectores sí experimentaron una progresión.

No es conveniente infravalorar el peso de la industria en su conjunto, ya que durante esos años mantuvo una distancia relativamente reducida con respecto a su inmediato predecesor. Si no consiguió desarrollarse en mayor grado, se debió a problemas estructurales, circunstancias del mercado, etc. Así pues, no se puede negar una cierta expansión industrial durante el primer tercio del siglo, especialmente hasta la tercera década, cuando se había desplegado una base industrial no despreciable.

En A Coruña existía una estructura industrial asentada desde el siglo XIX. Pero todo parece indicar que el sector se hallaba lejos de haberse consolidado. A Coruña no era por entonces un núcleo industrial comparativamente importante a nivel español. Incluso la aparición de actividades industriales fue un tanto tardía (Lindoso, 1999). La industrialización fue, en buena medida, un fenómeno de la década de los sesenta, gracias a la política estatal de promoción industrial, concretada en los Polos de Desarrollo. Por el contrario, la política de apoyo a la producción industrial nacional, simbolizada en el Real Decreto de 30 de abril de 1924 y en las posteriores medidas dictatoriales, que establecían un nuevo régimen de auxilios para favorecer la creación y desarrollo de empresas industriales, tuvieron escaso eco en A Coruña.

El proceso de crecimiento industrial corrió en paralelo al que se estaba desarrollando en otros puntos de la geografía regional —Vigo y Ferrol-. En esos años se

\footnotetext{
62 Particularmente, algunos servicios públicos. En el caso de la electricidad, donde existía una fuerte vinculación entre la banca y las empresas eléctricas, vid. Carmona y Pena (1989).
} 
consolidó un proceso iniciado en el siglo XIX de incorporación progresiva de la economía gallega al sistema capitalista, a pesar de que se ha sostenido que esta integración significó la especialización de nuestra economía en la exportación de materias primas y en el rol de reserva de mano de obra en el proceso de expansión del capitalismo (Nogueira, Soto y López Facal, 1980). De ahí el desarrollo de algunos sectores industriales, fundamentalmente ligados en esa etapa con el sector pesquero y sus efectos de arrastre, fenómeno que se llevó a cabo con mucha mayor intensidad, sin embargo, en el núcleo industrial vigués (Nogueira, 1980a: 13 y ss.).

La pesca fue un factor preponderante, igual que lo era en los demás sectores económicos. Los efectos de arrastre de la actividad pesquera repercutieron sobre un amplio abanico de industrias derivadas - salazones, conservas, harinas de pescado, hielo, pertrechos, etc.- , si bien su peso no se podía comparar con el de las Rías Bajas. Sus efectos directos se extendieron también a la producción de bienes de equipo, aunque con menor intensidad que sobre la industria manufacturera - talleres mecánicos y de vapores, centros de reparación de motores y maquinaria, etc- - Este impulso pudo significar una excelente oportunidad para consolidar el sector metalúrgico, una actividad de larga tradición en la ciudad, si bien con un peso relativamente reducido y claras deficiencias estructurales. Por tanto, el puerto también aquí se constituyó como uno de los principales factores de desarrollo económico urbano.

Por otra parte, existen signos que confirman la existencia de un proletariado industrial activo. A Coruña era desde finales del siglo XIX una ciudad con una extendida organización sindical, sobre todo de inspiración anarcosindicalista, lo que desembocó en una conflictividad laboral bastante acentuada. Ejemplo de ello fueron las frecuentes (y en algunos casos prolongadas) huelgas de los primeros años del siglo XX (Pereira, 1992a).

\subsection{Las principales actividades industriales y su significación en la economía urbana}

La estructura industrial coruñesa no experimentó un cambio sustancial con la llegada de la Dictadura. A nivel provincial, A Coruña ocupaba a mediados de los años veinte un lugar destacado por tributación en la tarifa $3^{\text {a }}$ de la contribución industrial, por encima de Pontevedra (Cuadro 3.18).

Los sectores dominantes en la capital seguían detentando una participación similar a la inmediata posguerra. El sector alimenticio continuaba manifestando una significativa presencia. Dada la inexistencia en la provincia de grandes explotaciones industriales, los establecimientos más característicos eran los vinculados a la pesca, especialmente la industria conservera, en sus distintas vertientes ${ }^{63}$. La importancia que poseía este sector se aprecia en la valoración de sus productos, ya que según estimaciones del Ministerio de Trabajo, ésta ascendía a más de 100 millones de pts. anuales, si se considera

63 Las fábricas de conservas existentes en 1921 eran once: José María Cervera, Genaro Fernández, Viuda de Carlos Albo, Manuel Arredondo, Augusto Bendamio, Pedro Campo Ugidos, José Chas Morlán, Genaro Fernández, Ángel Herrero y hermanos, José Pérez Insua e Hijos de Salvadores. 
conjuntamente la pesca en fresco, en salazón y en conserva ${ }^{64}$. A nivel provincial, A Coruña había consolidado su predominio dentro del sector, al contar con algunas de las más importantes fábricas de conservas y salazones de su entorno ${ }^{65}$.

\section{Cuadro 3.18. Total de la tarifa $3^{\text {a }}$ de la contribución industrial en las provincias gallegas y en España, 1928.}

\begin{tabular}{lcccc}
\hline & $\mathbf{N}^{\mathbf{0}}$ contribuyentes & Base por beneficios & Base por capital & Importe contribución \\
\hline A Coruña & $123\left(10^{\mathrm{a}}\right.$ provincia) & $8.037 .321\left(11^{\mathrm{a}}\right)$ & $23.483 .107\left(15^{\mathrm{a}}\right)$ & $1.393 .206\left(10^{\mathrm{a}}\right)$ \\
\hline Lugo & 25 & 454.231 & - & 262.082 \\
\hline Ourense & 31 & 994.093 & - & 115.028 \\
\hline Pontevedra & 21 & 3.190 .879 & 6.588 .962 & 335.149 \\
\hline Vigo & 91 & 3.441 .460 & 17.432 .442 & 476.815 \\
\hline España & 8.150 & 893.133 .461 & 4.065 .265 .399 & 124.462 .007 \\
\hline
\end{tabular}

Fuente: Dirección General de Contribuciones, Impuestos y Rentas, Estadística de la contribución sobre las utilidades de la riqueza mobiliaria. Año económico de 1928, Madrid, 1932.

Sin embargo, sus efectos de arrastre no alcanzaban las proporciones del poderoso complejo pesquero-conservero que se estaba consolidando en Vigo desde principios de siglo. Como resultado, el sector conservero coruñés no había dado lugar a una industria abastecedora de inputs, de manera que necesitaba obtenerlos del exterior ${ }^{66}$. De ahí que, al finalizar la guerra, se recuperase lentamente. Incluso su vocación exportadora se hallaba menos consolidada que en el sur, resultando afectada, asimismo, por la creciente competencia de la producción de otros países en los mercados internacionales (Carmona, 2001a: 26).

Las industrias de bienes de consumo popular se desarrollaron a buen ritmo durante la Dictadura. La producción de compuestos creció considerablemente, gracias a los establecimientos de chocolates y similares y a la elaboración de bebidas carbónicas ${ }^{67}$.

\footnotetext{
64 Estadística de los salarios y jornadas de trabajo, op. cit., p. cl.

65 Anuario del Comercio, Industria y Profesiones de España, 1927, op. cit., p. 1.276.

66 En A Coruña el sector pesquero no había generado grandes empresas vinculadas. Pero esta carencia también se detecta en Galicia, como resultado de la confluencia de varios factores. El principal, el hecho de que la expansión de la pesca gallega de altura desde los años veinte se realizó mayoritariamente por medio de empresas de tamaño medio, dominando la figura del armador independiente, propietario de un número reducido de embarcaciones (Carmona, 1998: 160).

67 La fabricación de chocolate de la sociedad más importante, la Cooperativa Militar y Civil, obtuvo unos beneficios elevados, incluso dentro del conjunto del sector industrial, gracias en parte a la diversificación de su producción, con una rentabilidad que se situó siempre por encima del 11\% de su capital social (de 500.500 pts.). Los beneficios fueron de 104.203,9 pts. en 1923; $1924=90.180,4 ; 1925=74.811,1$; $1926=66.337,4 ; 1927=78.776,6 ; 1928=87.974,7 ; 1929=55.897,6 ; 1930=70.465,5$. La rentabilidad fue de la siguiente: $1923=20,8 \% ; 1924=18,0 \% ; 1925=14,9 \% ; 1926=13,3 \% ; 1927=15,8 \% ; 1928=17,6 \%$; $1929=11,2 \% ; 1930=14,1 \%$. Cooperativa Militar y Civil (S.M.). Memoria del año 1930 presentada a la Junta General de 1931. Año XXXX $15^{\circ}$ del $2^{\circ}$ periodo social, La Coruña y ARG-DHC (Hacienda). Utilidades. Libros 4.545, 4.565-4.566 y 5.233.
} 
La empresa industrial más destacada en este último ramo, La Unión Industrial, S.A., experimentó un considerable crecimiento, tanto en el plano productivo como en sus resultados ${ }^{68}$, de manera similar a lo ocurrido con la Cooperativa Industrial Coruñesa, S.A., constituida en el año 1927, aunque en este caso su rentabilidad fue más modesta ${ }^{69}$.

El sector maderero se hallaba en una fase de consolidación de su crecimiento, a pesar de que la política gubernamental no favoreció sus intereses (Rico, 2000: 434-435). De hecho, tras la guerra europea, la producción atravesó dificultades, derivadas de una política proclive a la importación de materias primas (entre ellas, la madera), sin una modernización de las pequeñas fábricas diseminadas por Galicia (Máiz, 1988: 12). La relación con el monte gallego era evidente. Este tipo de explotación era uno de los más importantes de la región, junto con la ganadería, y la pesca y sus derivados. En Galicia el sector se hallaba muy repartido y subdividido por todo el país. Existía un minifundismo empresarial muy acentuado, con empresas a menudo de carácter familiar, escaso nivel de capitalización, reducido nivel productivo, predominando el tratamiento de la especie regional más abundante, el pino gallego (pinus pinaster) ${ }^{70}$.

Desde los primeros años del siglo XX había tenido lugar un proceso de repoblación forestal en Galicia a gran escala, que tuvo una importante incidencia en la expansión de la industria maderera. Además, las condiciones edafológicas y climáticas de la región favorecían este tipo de explotación. La coyuntura económica de la primera década del siglo había impulsado especialmente este tipo de iniciativas, pues existía un fuerte consumo internacional de madera y en algunas zonas la construcción naval ejercía un importante efecto de atracción, como demandante de maderas de escaso tratamiento. Por otra parte, el desarrollo de las comunicaciones terrestres y marítimas tuvo un impacto muy positivo sobre la comercialización de los bienes finales.

En A Coruña, de manera análoga al resto de la provincia, esta industria había alcanzado un notorio desarrollo, contando con instalaciones muy apropiadas para el trabajo de la madera ${ }^{71}$. Abundaban los talleres dedicados al suministro de los entablados que precisaba la industria de la construcción residencial. Y también existían negocios especializados en la fabricación de otros elementos precisos en la construcción, como parquets y persianas (IRS, 1914: 28). La ciudad estaba creciendo a un ritmo considerable ${ }^{72}$, y los más beneficiados por el crecimiento de la demanda fueron los talleres

\footnotetext{
68 Los resultados durante los años veinte fueron muy homogéneos. Los beneficios fueron de 27.444,7 pts. en $1923 ; 1924=35.780,8 ; 1925=38.241,2 ; 1926=40.876,6 ; 1927=36.586,8 ; 1928=42.325,9.39 .328,3$ pts., es decir, una rentabilidad entre el 3,9\% y el 6\% sobre el capital social (700.000 pts.). ARG-DHC (Hacienda). Utilidades. Libros 4.546-4.547, 4.564-4.566. Memoria que presenta el Consejo de Administración de la Sociedad Anónima La Unión Industrial, a la Junta General que se celebrará el día 23 de Febrero de 1931 y ARG-DHC (Hacienda). Utilidades. Libros 4.545-4.546 y 5.233.

69 Los beneficios fueron: $1923=8.913,7$ pts.; $1924=11.154,2 ; 1927=-4.418,0 ; 1928=15.511,6$; $1929=23.091,3 ; 1930=8.582,6$, y la rentabilidad del 3,0\% en 1923 (sobre un capital de 300.000 pts.); $1924=3,7 \% ; 1927=-1,5 \% ; 1928=5,2 \% ; 1929=7,7 \% ; 1930=2,9 \%$. Cooperativa Industrial Coruñesa, Sociedad Anónima. Memoria y Balance del Cuarto Ejercicio Social para dar cuenta a la Junta General de Accionistas que ha de Celebrarse el día 22 de Febrero de 1931, La Coruña.

70 Estadistica de los salarios y jornadas de trabajo, op. cit., pp. cl-cli.

71 Apuntes para el momento de la industria española de 1930, op. cit., p. 399

72 Entre 1900 y 1919 se habían solicitado poco más de setecientas cincuenta licencias de obra nueva, mientras entre 1920 y 1930 se gestionaron alrededor de mil doscientos expedientes (Garrido, 2003: 17).
} 
de carpintería, ebanistería, aserraderos, etc. Por ello, la diferenciación entre sector industrial y artesanal resulta complicada en este sector.

También existía un número elevado de talleres dedicados a la confección, mediante la utilización de sierrras de cinta, de envases y preparación de tablas con destino al exterior $^{73}$. No obstante, éste era uno de los problemas que presentaba esta industria en la ciudad: se limitaba a la realización de trabajos de primera transformación y no existía una industria que realizase otras producciones más sofisticadas, de mayor valor añadido. De hecho, aunque el mercado no estaba circunscrito sólo a la provincia, la demanda extraprovincial estaba básicamente conformada por madera en tablas y tablones, y por tablillas que se enviaban al Levante, y en menor cuantía a Andalucía, para ser transformada allí en los envases de la fruta que se exportaba al extranjero.

Otra de las fuentes específicas de demanda provino del principal establecimiento manufacturero de la ciudad, la Fábrica de Tabacos. Ricardo Molezún o Antonio Wais (ambos socios) le suministraban importantes partidas del total de la producción de sus respectivas industrias. Pero, en general, buena parte de las fábricas de aserrado, cajas, etc., encontraban en esta fábrica una destacada demanda para sus productos ${ }^{74}$. El propio Antonio Wais, por ejemplo, había constituido a principios de siglo una sociedad con industriales catalanes y madrileños para suministrar en exclusiva cajones de madera para envasar el tabaco en las doce fábricas estatales existentes en el país ${ }^{75}$. Finalmente, un cliente fundamental para el sector era asimismo, la industria conservera, sobre todo sobre un segmento productivo concreto, la confección de envases y cajones.

Con un peso similar en términos de cuotas contributivas, pero con un número más reducido se situaba la industria del papel y las artes gráficas. En su práctica totalidad estaba constituida por industrias de artes gráficas que, en gran medida, estaban asociadas a empresas periodísticas. El conjunto del sector evolucionó con gran lentitud, debido a la ausencia de un proceso acelerado de urbanización en la región, lo que le impedía consolidar una demanda más extensa. Al contrario, la producción se movió principalmente como auxiliar de la industria conservera (Sequeiros, 1986: 118).

La prensa escrita tenía gran importancia en la ciudad desde principios del siglo XIX ${ }^{76}$. Existía una amplia gama de publicaciones de distinta periodicidad, aunque el volumen de tirada era reducido en la gran mayoría de los casos - excepto los diarios-, debido al escaso número de lectores. A pesar de los esfuerzos desplegados durante la República, los reducidos niveles de alfabetización de Galicia hacían que necesariamente los lugares a donde la prensa podía llegar no fuesen lejanos (Fernández y López, 2000: 43). Además, el carácter rural y disperso del poblamiento gallego dificultaban la distribución. Generalmente, estas publicaciones limitaban su radio de acción a A Coruña o a otros

\footnotetext{
73 Apuntes para el momento de la industria española de 1930, op. cit., p. 399. Existía todavía, igual que en años anteriores, una considerable demanda de madera de pino para las entibaciones mineras de las cuencas carboníferas, principalmente con destino a las minas de País de Gales, pero también a las cuencas españolas. La madera para construcción de buques y otras aplicaciones también encontraban salida dentro y fuera de la región. Estadística de los salarios y jornadas de trabajo, op. cit., p. cli.

74 Apuntes para el momento de la industria española de 1930, op. cit., p. 399.

75 Anuario de la Renta del Tabaco, 1905.

76 De ahí el número de imprentas que existía en A Coruña en el siglo XIX (Odriozola y Barreiro, 1992).
} 
núcleos urbanos importantes. Las imprentas en la mayoría de los casos pertenecían, por tanto, a sociedades periodísticas, alguna de las cuales contaba con instalaciones de calidad. Una de las principales era la Casa Roel que realizaba trabajos de litografías y grabados de gran perfección. También realizaba trabajos de litografiado sencillo otra empresa que se citará más adelante, propiedad de Germán Suárez Pumariega.

Durante los años veinte, el número de empresas matriculadas se incrementó, como resultado de la recuperación de la actividad económica y del crecimiento de los sectores económicos vinculados. En realidad, la mayoría eran establecimientos ya existentes, pero concentrados en un número reducido de industriales que tributaban por varias máquinas. Pero en los años treinta se estancó en su evolución, como consecuencia de la crisis de la industria local, que tuvo su influencia también en esta rama productiva.

Los años veinte fueron testigo de un notorio crecimiento de la producción metalúrgica nacional, que ya se había iniciado con el final de la guerra mundial (IRS, 1919a, 2: 115). Éste fue uno de los sectores más favorecidos por las medidas de protección industrial decretadas por el gobierno. Sin embargo, su falta de competitividad, tanto vía precio como vía calidad, impidió un aprovechamiento más eficiente de las ventajas derivadas de la neutralidad primero y de la protección después.

El fracaso en la adaptación del sector metalúrgico gallego a la demanda bélica impidió que en los años siguientes iniciase el despegue que reclamaba el potencial minero existente en la región ${ }^{77}$. Como resultado, la minería prácticamente se paralizó y las únicas minas en funcionamiento permanecían operativas merced al capital extranjero.

En A Coruña las industrias metalúrgicas tenían una antigua tradición. Durante el siglo XIX existieron tempranas iniciativas en la capital, la primera de ellas de 1850 . Pero no llegó a tener peso específico en el conjunto de la industria. A principios de siglo existían dos únicas fundiciones: una situada en Monelos, propiedad de Hijos de Solórzano, y otra propiedad de Miguel Ortiz, en el Camino Nuevo ${ }^{78}$. En 1914, al lado de estas fundiciones encontramos la de Julio Wonemburger, en la calle Hospital. En los años veinte se incorporó la sociedad Explotación General de Trapos y Metales de Galicia, S.A. ${ }^{79}$. Pero lo que más predominaba eran los talleres de herrería mecánica,

\footnotetext{
77 Vázquez Vaamode (1996: 390). Según la Estadística de los salarios y jornadas de trabajo, op. cit., p. cli, en la provincia no existía industria metalúrgica propiamente dicha.

La historia de la fundición más importante, Hijos de Solórzano, se remonta a 1845, cuando Joaquín Galiacho instaló su fábrica en la ciudad. A finales de los años cincuenta y hasta 1895 pasó a ser propiedad de Manuel Solórzano, transformándose entonces y hasta mediados de los años veinte en Viuda e Hijos de Solórzano. Hasta mediados de los años cuarenta se denominó Hijos de Solórzano, convirtiéndose, finalmente, en Talleres Solórzano hasta los años ochenta. La fundición de Miguel Ortiz tuvo su origen en los años setenta, transformándose en 1911 en Hijos de M. Ortiz, bajo cuya denominación se mantuvo operativa hasta 1934. La fundición propiedad de Julio Wonemburger también arrancaba del siglo XIX, adoptando tal denominación en 1908 y hasta 1943, año en que se transformó en Wonemburger, S.L. Finalmente, entre 1962 y 1988 funcionó bajo la razón social Wonemburger, S.A. (Vázquez Vaamonde, 1996: 390).

79 Su constitución se cimentó en los cambios tecnológicos que posibilitaron el reciclaje de la chatarra. Se creó en 1921, con un capital de 500.500 pts. (elevados en 1925 a 1.000 .000 pts.), dedicándose a la utilización de chatarra en producción de hierro de segunda fusión. Permaneció en funcionamiento durante veinticinco años, llegando a establecer sucursales en varios puntos de la geografía española (Vázquez Vaamonde, 1996 : 387). La empresa dio inicio a sus actividades obteniendo unos beneficios reducidos durante su primer año de vida. Sin embargo, durante los años veinte incrementó de manera notable su rentabilidad: $1922=33.122,2$ pts.; $1923=38.414,4 ; 1924=57.466,5 ; 1925=527.969,6 ; 1926=1.020 .909,0 ; 1927=0,0 ; 1928=51.836,4$, con una rentabilidad que pasó del $6,6 \%$ en 1922 al $102,1 \%$ en 1926 , aunque disminuyese de nuevo hacia el final de la década. ARG-DHC (Hacienda). Utilidades. Libros 4.544-4.547 y 4.564-4.566.
} 
así como algún taller de construcción de máquinas. La causa de la existencia de estos establecimientos era el movimiento portuario, al atender la demanda de reparación de buques, dado que la construcción naval estaba menos desarrollada ${ }^{80}$.

También existían empresas dedicadas a la fabricación de envases de hojalata litografiados. Tal era el caso de la sociedad La Artística, fundada en 1890 por Germán Suárez Pumariega, que contó con el apoyo financiero del emigrante retornado Manuel Salgado, bajo la razón social de Germán Suárez y Salgado ${ }^{81}$. Con un capital de 806.724,88 pts. en 1923, esta sociedad experimentó un crecimiento de sus beneficios en los años veinte, gracias a la demanda de las industrias conserveras y de la prensa ${ }^{82}$.

Las fábricas de fundición atendían también otras demandas. El sector mantuvo una estrecha relación con el crecimiento urbano. Las nuevas demandas que se exigían a las fundiciones se orientaban hacia la construcción de infraestructuras urbanas, en una época en la que éstas se hallaban en sus fases de consolidación (agua, iluminación, alcantarillado, etc.). El acondicionamiento de las calles, la construcción de viviendas, las obras públicas, generaron asimismo una demanda que sólo se podía satisfacer mediante las fundiciones.

Finalmente, las industrias locales constituían también un componente esencial de la demanda. Éstas necesitaban piezas para sus máquinas. Por este motivo, al lado de los cubilotes y fraguas que podía haber en las fábricas de fundición, solía existir un taller mecánico anexo cuya finalidad era la composición y mecanización de las piezas allí fundidas, así como la cobertura de las necesidades de reparación de máquinas de otras industrias. Además, no se trataba sólo de reparaciones, sino incluso, en algunos casos, de la construcción de maquinaria (Vázquez Vaamonde, 1996: 382).

El crecimiento experimentado por la industria metalúrgica en esta década fue debido a la proliferación de talleres de soldadura autógena, relacionados con el impulso que mantuvo la actividad portuaria pero, sobre todo, con el aumento de los talleres de cerrajería. Eran industrias caracterizadas por una cierta inelasticidad en su demanda y que limitaban su radio de acción a las necesidades urbanas. Pero se observa también un crecimiento de las empresas de mayor tamaño, que fueron capaces de mantener una rentabilidad elevada durante este período ${ }^{83}$.

\footnotetext{
$80 \quad$ IRS (1919a, 2: 149-151). Los buques propiedad de los armadores de A Coruña eran adquiridos casi siempre en otros puntos de la geografía española. Un buen número procedía de los talleres existentes en Vigo. Sin embargo, en A Coruña nunca existió un potente empresariado ligado a las conservas que sintiese la necesidad de consolidar un sector paralelo de construcción naval privada.

81 Fernández Santander (1987: 14 y 83). Esta sociedad, originalmente dedicada a la "estampación de hojalata, papel y construcción de envases metálicos para toda clase de industrias", estableció en Vigo, en 1906, La Artística. Manufacturera de Hojalata, que nacía como sucursal de aquélla. El crecimiento de la industria conservera y los beneficios extraordinarios obtenidos durante la guerra mundial resultaron decisivos para la expansión de la sociedad, que en 1921 fundó Talleres Mecánicos Alonarti, S.A., dedicados a la fabricación de maquinaria para la industria conservera (Giráldez, 2000: 212). En 1930 se transformó en La Artística Suárez Pumariega, S.A., con un capital social de 1.250 .000 pts. Anuario Financiero y de Sociedades Anónimas de España, 1935, p. 858.

82 Los beneficios fueron en 1924 de 51.265,0 pts.; $1925=49.674,8 ; 1926=77.094,1 ; 1927=86.383,6$; $1928=121.194,7 ; 1929=145.193,3 ; 1930=200.137,8 ; 1931=137.323,6$. La rentabilidad: $1924=6,4 \%$; $1925=6,2 \% ; 1926=9,6 \% ; 1927=10,7 \% ; 1928=15,0 \% ; 1929=18,0 \% ; 1930=24,8 \% ; 1931=11,0 \%$. ARGDHC (Hacienda). Utilidades. Libro 5.233. Desde 1931, opera como La Artística Suárez Pumariega, S.A.

83 Hijos de Solórzano presentó unos beneficios de $21.981,2$ pts. en 1923; $2.341,5$ en $1924 ; 24.564,1$ en $1925 ; 21.157,1$ en $1926 ; 15.676,1$ en $1927 ; 7.131,2$ en 1930 , con una rentabilidad sobre el capital social del $9,6 \%, 1,0 \%, 10,7 \%, 9,2 \%, 6,8 \%$ y 3,1\%, respectivamente. Igualmente la rentabilidad de Hijos de Miguel M. Ortiz fue elevada, en torno $26-30 \%$, con unos beneficios estables, que se situaron entre las $19.562,7$ y las 22.627,2 pts. entre 1923 y 1928. ARG-DHC (Hacienda). Utilidades. Libros 4.546-4.547 y 4.564-4.565.
} 
Las últimas industrias con un cierto peso en A Coruña eran las químicas. Aquí se han incluido diversos tipos de empresas: laboratorios, fábricas de jabón, lejía, sebo, cera, etc. Eran industrias de cierta importancia, pero que apenas experimentaron sustanciales modificaciones en estos veinte años, lo que motivó que su peso fuese reduciéndose. Consideradas individualmente, no tenían excesiva trascendencia en el conjunto industrial de la ciudad. Abundaban los laboratorios y las fábricas de productos como lejías o jabones. Algunas de estas industrias tuvieron su origen en el siglo XIX. Una de las más destacadas fue la fábrica de refinación de petróleo de Mesa, Marchesi y Cía. Esta sociedad experimentó una evolución muy positiva, con unos elevados beneficios durante este período, al rebufo de la demanda generada por la utilización de derivados de petróleo en los procesos productivos $\mathrm{y}$, especialmente, en los transportes ${ }^{84}$.

Otro de los subsectores que experimentó una evolución más positiva fue el de la producción y comercialización de abonos químicos. El consumo de abonos aumentó en la agricultura gallega durante esos años, al ritmo marcado por la modernización del sector primario. En este aumento de la demanda se fundamentó la instalación de la firma Cros, S.A., en 1930, especializada en la fabricación de superfosfatos, que se convertiría en una de las empresas químicas de mayor importancia en A Coruña. Esta sociedad contaba ya con una instalación en la ciudad, pero la nueva unidad productiva se ubicó en El Burgo, en el municipio limítrofe de Culleredo ${ }^{85}$.

La industria textil había tenido su origen en la provincia en 1845, con la instalación de una fábrica en O Seixo (Mugardos), desaparecida en 1896. Posteriormente se crearon otras, la más notable, la fábrica propiedad de Núñez y Miranda, fundada en 1872, que posteriormente se convertiría en la Primera Coruñesa, S.A. ${ }^{86}$. Sin embargo, el estado de esta industria era insatisfactorio, lo que ha de atribuirse a una falta de mercado para una producción continuada (incluso con frecuentes intervalos de paralización). En general, el textil coruñés disponía de muy pocas fábricas, que se mantenían en condiciones precarias; incluso las mayores tenían importantes problemas de dimensión. Empresas como la Galicia Industrial, S.A., padecieron una contracción de sus resultados, sometidas incluso a frecuentes períodos de intermitencia productiva. El mercado nacional, principal destino de la producción, sufría un estancamiento del consumo, más acentuado durante los años finales de la década de $1920^{87}$.

Hilados y Tejidos de Vilasantar presenta unas cuentas con beneficios decrecientes durante los años veinte, que se transformaron en pérdidas en 1926 y 1930, síntoma de

\footnotetext{
$1924=313.298,1$ pts.; $1925=292.437,7 ; 1926=312.000,0 ; 1927=450.159,2 ; 1928=91.075,5$. ARG-DHC (Hacienda). Utilidades. Libros 4.546-4.547 y 4.564-4.566.

85 La sociedad Cros era la empresa más destacada del sector en España en 1935, al poseer 9 fábricas. La planta de A Coruña era una de las que alcanzaba una cifra de producción más baja, con un total de unas 33.500 toneladas (Nadal et al., 2003: 197).

86 El Consejo de Administración de la Primera Coruñesa durante los años veinte estaba constituido por miembros muy activos del empresariado coruñés: Presidente: José Fernández España y Vigil; secretariocontador: Manuel Molezún y Núñez; vocales: Ricardo Molezún y Lauga, Gerardo Blanco de la Viña, Enrique Molezún y Núñez y Dionisio Tejero Pérez; director-gerente: Ricardo Molezún y Lauga.

87 Galicia Industrial, S.A. Memoria presentada a los señores accionistas en la Junta General celebrada el día 31 de Marzo de 1931, correspondiente al tercer ejercicio social.
} 
la crisis que atravesaba la industria textil española en la segunda mitad de la década. La competencia por el mercado interior se endurecía, especialmente desde la región más poderosa (Cataluña), pero también entre los productores gallegos, incrementando los stocks no vendidos. Además, hacia el final del decenio, los costes de producción se incrementaron como resultado de la depreciación de la peseta, en tanto los precios de venta no sufrían alteraciones visibles ${ }^{88}$. En consecuencia, la rentabilidad de la sociedad cayó del $26,7 \%$ de 1922 a niveles próximos a cero durante el resto de la década ${ }^{89}$. La situación de la Primera Coruñesa era algo más deshogada durante la primera mitad de los años veinte, pero posteriormente se deterioró con rapidez ${ }^{90}$.

La industria de la cerámica, vidrio y cal experimentó un fuerte crecimiento en España durante el primer tercio del siglo, gracias al proceso de urbanización y a la mecanización del sector. En cambio, apenas mantenía presencia en A Coruña, limitándose prácticamente a la fabricación de loza ordinaria. Sólo destacó la fábrica de cristales La Coruñesa, que desaparecería durante la crisis industrial. Los únicos talleres que existían eran los de losetas hidráulicas y de biselado de cristales, que fueron los responsables del leve incremento que se observa en los años treinta. Asimismo sobresalía la empresa Hijos de B. Escudero y Cía. y la fábrica de biselar, grabar y decorar cristal, propiedad de Narciso L. Pereira. La comercialización de artículos del sector experimentó asimismo un crecimiento, como lo demuestran los resultados de varias empresas para las que se conserva información documental ${ }^{91}$.

Por último, la industria de cuero y calzado tenía una presencia testimonial. Ya se ha hecho referencia a la visible decadencia de los curtidos en Galicia a lo largo del siglo XX (Martínez López, 1997), aunque esta industria aún contase con un peso relativamente importante en el conjunto estatal a comienzos del período estudiado. Esta industria comenzó a sufrir una aguda recesión a principios del siglo XX, debido a su falta de modernización. Durante los años veinte se encontraba inmersa en una fuerte crisis $^{92}$.

El sector eléctrico gallego, en su conjunto, había experimentado desde sus orígenes, a finales del siglo XIX, una larga fase de crecimiento, aunque tuvo un escaso protagonismo a nivel nacional hasta finales de los años cuarenta. Destacan dos momentos de relativa aceleración: la puesta en marcha de los primeros saltos hidroeléctricos (1903-07), y los años 1928-32, que coincidieron con la fusión de la CEC, la EIC y las

\footnotetext{
88 Hilados y Tejidos Vilasantar, S.A. Memoria. Año de 1930.

89 Los beneficios de la sociedad evolucionaron del siguiente modo: $1922=400.872,6$ pts.; $1923=159.058,9 ; 1924=25.782,2 ; 1925=3.041,6 ; 1926=$ pérdidas $; 1927=144.510,5 ; 1928=75.875,5 ;$ $1930=-19.549,6$. Por su parte, la rentabilidad fue muy pobre: $1922=26,7 \% ; 1923=10,6 \% ; 1924=1,7 \%$; $1925=0,2 \% ; 1927=9,63 \% ; 1928=5,1 \% ; 1930=-1,30 \%$. ARG-DHC (Hacienda). Utilidades. Libros 4.545-4.547, 4.564-4.566 y ARG-DHC (Hacienda). Utilidades. Legajo 782.

90 Los beneficios fueron los siguientes: $1923=212.514,3$ pts.; $1924=127.088,7 ; 1925=117.863,7 ; 1926=23.662,3$; $1927=143.819,3 ; 1928=-133.410,0 ; 1929=-55.736,8 ; 1930=12.734,1 ; 1931=54.710,5$. La rentabilidad: $1923=21,3 \% ; 1924=12,7 \% ; 1925=11,8 \% ; 1926=2,4 \% ; 1927=14,4 \% ; 1928=-13,3 \% ; 1929=-5,6 \%$; $1930=1,3 \% ; 1931=5,5 \%$. ARG-DHC (Hacienda). Utilidades. Libros 4545-4547 y 5233.

91 El Espejo (Díaz, Lage y Cía.), Insua y Vizoso, Hijos de B. Escudero y Cía. ARG-DHC (Hacienda). Utilidades.

92 Estadística de los salarios y jornadas de trabajo, op. cit., p. cli.
} 
FCGE (en 1928) ${ }^{93}$, y la entrada en funcionamiento del principal salto de preguerra, el del Tambre, en 1925 (Carmona, 1999: 1378).

A partir de 1917 dio inicio el proceso de concentración del sector en Galicia, ante la previsión de entrada de los más importantes grupos eléctricos españoles en la región (Carmona, 1999: 1382). Desde entonces se acentuó uno de sus rasgos definitorios, la fuerte propensión de las sociedades suministradores a alcanzar acuerdos sobre precios y/o mercados, que junto con el acusado predominio de la generación hidráulica, son dos de las principales características durante la preguerra civil (Carmona y Pena, 1989: 40). Sin embargo, en los años veinte su dimensión era reducida. El principal problema era el escaso desarrollo industrial, lo que derivaba en una baja demanda de fuerza y tracción. En consecuencia, la productividad (medida a través del coeficiente de utilización), era desigual entre las empresas. La SGGE mostraba coeficientes elevados, pero la mayor parte de las compañías, situadas en zonas donde el único consumo era el alumbrado, tenían un coeficiente de utilización muy bajo, lo que obligaba a mantener unos elevados precios y limitaba la capacidad de acometer nuevas inversiones (Carmona, 1990b: 42).

La acentuada compenetración entre banca y empresas eléctricas, con una fuerte participación en sus Consejos de Administración, condicionó el devenir del sector en los siguientes años. El posicionamiento en Galicia de grupos de capital español en la posguerra europea obligó a la SGGE a acelerar sus planes de concentración empresarial. En 1921 se aprobó un acuerdo con la EPVR y con la Sociedad de Gas y Electricidad de Santiago (SGES). La fusión se produjo en 1923, bajo la razón social de la antigua SGGE, con un capital nominal de 20.000.000 pts., y con el apoyo bancario de Sobrinos de José Pastor, Hijos de Olimpio Pérez (Santiago) y la Banca Marsans de Barcelona ${ }^{94}$. En 1926, la SGGE adquirió los bienes de la Cooperativa Santiaguesa, y en 1932 la Eléctrica Sarriana, de Sarria (Lugo). En 1929 adquirió las sociedades Hulla Blanca y Eléctrica de Pontevedra-Marín, y en 1930 la sociedad Eléctrica de Orense. En 1936 absorbió estas tres empresas filiales, controlando su red de distribución ${ }^{95}$.

\footnotetext{
$93 \quad$ Estatutos de la S.A. Fábricas Coruñesas de Gas y Electricidad. Aprobados por Junta General de 27 de Marzo de 1928, La Coruña, Tip. El Ideal Gallego.

94 Carmona (1999: 1383). En apariencia, las fusiones dentro del sector eléctrico gallego confluyeron sobre dos empresas, las FCGE y la SGGE. Sin embargo, ambas pertenecían a un mismo grupo empresarial, el del Banco Pastor, ya que el presidente del banco se sentaba simultáneamente en la presidencia de sus respectivos Consejos de Administración (Carmona y Pena, 1989: 45). En 1930 se firmó un convenio entre ambas sociedades, mediante una participación recíproca de cada empresa en el capital social y funcionamiento de la otra. Fábricas Coruñesas de Gas y Electricidad, S.A., año de 1930. Memoria redactada por el presidente de esta sociedad que presenta el Consejo de Gobierno a la Junta General de Accionistas que habrá de celebrarse el día 30 de marzo de 1931, La Coruña.

95 Sociedad General Gallega de Electricidad, S.A. Memoria presentada por el Consejo de Administración a la Junta General de Accionistas convocada para el 26 de abril de 1936. Ejercicio de 1935. La Coruña, p. 3. Después de una ampliación de capital a 40 millones de pts. en 1930, en 1941 se elevó a 125 millones, como resultado de la adquisición de las Fábricas Coruñesas de Gas y Electricidad en 1946 en 15 millones de pts. En marzo de 1949 adquirió la Electra Popular Coruñesa, pasando el capital social a ser de 250 millones de pts. Anuarios Financieros y de Sociedades Anónimas.
} 
Cuadro 3.19. Beneficios y rentabilidad sobre el capital social obtenidos por las empresas de suministro eléctrico domiciliadas en A Coruña, 1923-30.

\begin{tabular}{|c|c|c|c|c|c|}
\hline & & CEC & FCGE & H. Pindo & SGGE \\
\hline \multirow{2}{*}{1923} & $\mathrm{~B}^{\mathbf{0} *}$ & 207.463 & 339.023 & - & 500.165 \\
\hline & $\mathbf{R}$ & 10,4 & 16,9 & - & 2,5 \\
\hline \multirow{2}{*}{1924} & $\mathbf{B}^{0}$ & 236.864 & 327.020 & 260.103 & 893.020 \\
\hline & $\mathbf{R}$ & 11,8 & 16,3 & 21,7 & 4,5 \\
\hline \multirow{2}{*}{1925} & $\mathbf{B}^{0}$ & 253.016 & 400.671 & 177.171 & 999.629 \\
\hline & $\mathbf{R}$ & 12,7 & 20 & 14,8 & 5 \\
\hline \multirow{2}{*}{1926} & $\mathbf{B}^{0}$ & 291.014 & 472.521 & 507.415 & 349.371 \\
\hline & $\mathbf{R}$ & 14,6 & 23,6 & 42,3 & 1,7 \\
\hline \multirow{2}{*}{1927} & $\mathbf{B}^{\mathbf{0}}$ & 257.970 & 553.758 & 311.944 & 661.484 \\
\hline & $\mathbf{R}$ & 12,9 & 27,7 & 26 & 3,3 \\
\hline \multirow{2}{*}{1928} & $\mathbf{B}^{\mathbf{0}}$ & 124.542 & 1.375 .807 & 121.887 & 715.341 \\
\hline & $\mathbf{R}$ & 6,2 & 15,3 & 10,2 & 3,6 \\
\hline \multirow{2}{*}{1930} & $\mathbf{B}^{0}$ & - & 1.105 .752 & 357.038 & 1.648 .169 \\
\hline & $\mathbf{R}$ & - & 12,3 & 29,8 & 18,3 \\
\hline
\end{tabular}

$* \mathrm{~B}^{\mathrm{o}}=$ beneficios; $\mathrm{R}=$ rentabilidad (en porcentaje).

Fuente: ARG-DHC (Hacienda). Utilidades. Libros 4.545-4.547, 4.564-4.566 y Anuarios Financieros y de Sociedades Anónimas.

La CEC incrementó notablemente su actividad a lo largo de los años veinte. Además, los beneficios y la rentabilidad crecieron ininterrumpidamente respecto al período anterior, hasta 1928, cuando los beneficios disminuyeron por primera vez desde el final de la guerra. En el caso de FCGE se mantuvieron a un nivel constante hasta esa misma fecha, en que el balance arrojó un fuerte crecimiento, lo que apunta a la incidencia de los procesos de fusión que se estaban llevando a cabo en el sector. La SGGE siguió una tendencia similar. Por tanto, la conclusión es clara: los años veinte suponen la consolidación del sector eléctrico en A Coruña, con una notable expansión de la rentabilidad de las empresas domiciliadas en la ciudad (Cuadro 3.19). 

El impacto de la crisis internacional en la Segunda República española. Su incidencia en A Coruña, 1931-1936 



\section{LA EVOLUCIÓN ECONÓMICA GLOBAL INTERNACIONAL Y NACIONAL}

Como suele acaecer con los grandes acontecimientos, no existe una única interpretación de las causas que provocaron el cambio de ciclo que se inició a finales de los años veinte y se aceleró a partir de 1930. De ahí que tienda a ser contemplado desde una óptica más globalizadora. Existe un acuerdo creciente a la hora de admitir que la combinación de un amplio abanico de trastornos a nivel internacional durante los años veinte en numerosos países condujo, junto con factores coyunturales, a una gran depresión sin precedentes en la historia de la economía mundial.

En primer lugar, los desequilibrios generados por el desigual desarrollo económico internacional. En segundo lugar, los importantes desajustes económicos internos de Estados Unidos. En tercer lugar, la crisis de los sectores industriales tradicionales y los excesos de capacidad en las nuevas ramas, fenómeno extensible también al sector primario a nivel mundial. Finalmente, la inadecuación de la teoría económica para hacer frente a los nuevos problemas económicos. Cualquier indicador que se emplee para caracterizar la crisis arroja un balance muy adverso: fuerte reducción del comercio internacional, crisis industrial, caída del producto, deflación de precios, ruptura del sistema de pagos internacional, aumento del desempleo, etc.

Frente a esta situación, las recetas económicas aplicadas fueron completamente ineficaces y contraproducentes, conduciendo a un agravamiento de la crisis. Los gobiernos ensayaron políticas anticíclicas de desigual éxito. Algunos continuaron con fórmulas ortodoxas (Gran Bretaña), mientras otros aplicaron nuevos planteamientos, basados en las nuevas políticas económicas disponibles en el mercado (escuela sueca, doctrina keynesiana, etc.). En cualquier caso, la recuperación, excepto el heterodoxo modelo alemán, fue muy desigual, y los países menos desarrollados no extrajeron excesivo provecho, debido a que el escenario económico ultra-proteccionista obstaculizaba su crecimiento. En el mejor de los casos, las sociedades debieron convivir con altas tasas de desempleo. En el peor, admitir soluciones con un alto coste social o político, como el fascismo, el nazismo o el estalinismo. La preparación para una futura contienda militar fue prácticamente la última posibilidad para engancharse al tren de la recuperación económica, a pesar del terrible coste que ello supuso.

Tras la guerra, España había logrado converger a un ritmo acelerado con respecto a los países más desarrollados, disfrutando de varios años de una inusual prosperidad comparada. Sin embargo, a finales de los años veinte, la española todavía seguía siendo una economía atrasada y aislada respecto a Europa occidental, con un gobierno centrado en el logro de la creación de un mercado interior, pero no en la mejora de la tradicionalmente baja competitividad en el exterior (Prados, 2003). En estas condiciones, inició su andadura un nuevo régimen político, la Segunda República. Pero el sistema sufrió de lleno los efectos de la depresión, y más tarde llegaría a su fin bajo la influencia de los desequilibrios estructurales de la sociedad española, agravados por las consecuencias de la crisis internacional (Hernández Andreu, 1980: 107).

La crisis se sintió en España algo más tarde que en el resto del mundo desarrollado (Harrison, 1983: 304). Su impacto, además, fue menor que en la mayoría de los países europeos, tanto por lo que se refiere a la caída de la renta como por lo que respecta a 
la reducción global del comercio. De ahí que se haya insistido en el comportamiento atípico de la economía española durante los primeros años de la depresión. A diferencia de lo que sucedía en otros países, los precios se sostuvieron relativamente y la producción industrial no empezó a caer hasta 1931, lo que permitió a la economía española capear el temporal económico mucho mejor que gran parte de los países europeos (Martín Aceña, 1987: 122).

Hay varias explicaciones a esta aparente paradoja. La tesis defendida por Comín y Martín Aceña ha puesto el acento sobre la incidencia de la crisis económica internacional y sus efectos sobre las expectativas. En primer lugar, la elevada protección arancelaria española, que forma parte de una tendencia a largo plazo, y que se inscribe dentro del denominado nacionalismo económico. Frente a ella, se ha argüido que la Segunda República practicó una política comercial diferente de la de la Dictadura. Sin embargo, ésta no sería más que una continuación de las tendencias previas. Aunque más liberal y reformista, sólo logró, en parte, desprenderse de su carácter dirigista. Por otro lado, hoy tiende a considerarse que en los años veinte y treinta la economía española no se encontró tan aislada del comercio mundial como se había sostenido. En todo caso, la depreciación de la moneda en los años finales de la Dictadura sí contribuyó, probablemente, a aislar la economía de la deflación internacional, aunque el proceso inflacionario que teóricamente debería haber desencadenado a nivel interno no fue suficiente para reactivar la demanda (Tortella y Palafox, 1984: 89; Martín Aceña, 1983: 611). En segundo lugar, el reducido peso relativo de las inversiones extranjeras también habría minimizado el impacto de la reducción del crédito internacional.

Por tanto, por lo que se refiere a los resortes exteriores de la crisis, ésta se manifestó en España principalmente a través de una reducción del comercio exterior de bienes y servicios (especialmente el de exportación), debido a la caída de la demanda exterior, sobre todo de las naciones más industrializadas (Harrison, 1983: 301). En consecuencia, la caída del sector exterior afectó a los sectores exportadores tradicionales, es decir, la agricultura y la minería, aunque el sector exterior sólo representase una fracción reducida de la renta nacional (Palafox, 1980). En términos productivos, la incidencia fue desigual por sectores. Su impacto sobre el sector agrario, en su conjunto, no fue especialmente perceptible. Pero sí lo fue sobre el sector industrial, en donde se desató una crisis que afectó especialmente a las industrias básicas.

Pero la crisis también se vio agravada por factores internos específicos de la economía española. Según Palafox, parte de la responsabilidad habría que adjudicársela al cambio en los mecanismos de acumulación, provocado por la sustitución de la política económica de la Dictadura por la republicana. La manifestación más importante de este giro se había concretado en una reducción del gasto público. El objetivo era tratar de lograr el equilibrio presupuestario, única política viable, dado el desorden financiero existente por entonces. Pero el resultado fue la depresión de aquellos sectores que dependían del gasto público. Asimismo, la República permitió un aumento de salarios y una reducción de las horas de trabajo, medidas que buscaban mejorar las condiciones de vida y laborales de la población española. Esto explica la desigual evolución de los sectores industriales. Mientras la industria siderúrgica reducía a la mitad su producción 
entre marzo de 1930 y septiembre de 1931 (Harrison, 1983), las industrias de bienes de consumo evolucionaron más positivamente durante el mismo período.

La crisis tocó fondo en 1933, el año de mayor intensificación de la recesión económica, nacional e internacionalmente. Aunque el paro alcanzó un nivel inferior al de otros países más avanzados y a pesar de que conservaba una fuerte componente estructural, propia de una economía atrasada (Comín, 1991: 132), éste alcanzó su punto máximo, duplicándose en 1931-35 (Martín Aceña, 1987: 124). Pero conviene tener presente que el freno a la emigración exterior repercutió negativamente sobre este indicador, a la vez que reducía las entradas de divisas de los emigrantes. Según Carreras, la producción industrial muestra signos de recuperación a partir del año 1934, y en 1935 se había superado ya el bache, recuperando prácticamente el nivel de 1931, aunque los índices sectoriales presentan tendencias opuestas: evolución desfavorable de las industrias de bienes de producción y de las industrias exportadoras frente a la tendencia inversa de las industrias de bienes de consumo, químicas y electricidad ${ }^{1}$.

Por su parte, la República fue un período de singular trascendencia para Galicia, en el que estaba alcanzando su punto culminante el proceso de modernización de las estructuras socioeconómicas que había venido desarrollándose durante los decenios precedentes (Velasco, 2002: 227). A la altura de la República, se habían formado o se hallaban en proceso de constitución algunos importantes grupos industriales-capitalistas. Además, existían algunos focos de proletariado industrial en Vigo, Ferrol o A Coruña, cuya organización fue algo más lenta que en otras áreas de España, pero que experimentaron una expansión sin precedentes (Pereira, 2002: 135). Como resultado, se produjo un fuerte aumento de la conflictividad laboral durante el período republicano (Alonso, 1991: 238-239).

Junto a estos grupos socialmente dominantes, existían otras categorías profesionales de distinto tipo, como pequeños comerciantes, dependientes de comercio y obreros de gran diversidad laboral, que completaban la composición de una sociedad que en el primer tercio del siglo vivió importantes transformaciones internas (Villares, 1998: 108-109).

La reducción de determinadas importaciones del extranjero, la apertura de nuevos mercados para las conservas, etc. proporcionaron a Galicia una situación de equilibrio económico en términos comparativos quizá más favorable que la que vivía la España latifundista o las zonas industriales, aquejadas de unas elevadas cifras de desempleo y una situación social explosiva (Máiz, 1988: 13). Pero los años treinta fueron de estancamiento económico, con la excepción principal de la creciente especialización pesquera y conservera. La región continuaba ocupando una posición marginal dentro del conjunto del país. La creación de nuevas sociedades y el capital invertido en Galicia atravesaron una importante crisis en el tránsito de la Dictadura a la República (192830 ), situándose en los niveles más bajos del primer tercio del siglo. Las cifras de capital experimentaron una notoria depresión incluso desde 1926 (Abreu, 1992: 262).

\footnotetext{
Según el indicador del Gasto Nacional Bruto en 1931-35 no se podría hablar con propiedad de Gran Depresión en España, sino de estancamiento o somera depresión (Carreras, 1985a).
} 
El indicador de constitución de sociedades refleja con claridad la cronología de la crisis en la economía regional. En una primera fase, la tendencia es ascendente, continuadora de una breve coyuntura alcista que se inició en el ocaso de la Dictadura, y que se prolonga hasta 1931 en la provincia de A Coruña y hasta 1932 en la de Pontevedra (Gráfico 2.1). Por tanto, las dos provincias costeras marcaron la pauta de la coyuntura regional (Abreu, 1992: 256), que todavía se sostuvo hasta 1933. Si se considera el volumen de capital agregado de las nuevas sociedades, A Coruña alcanza su máximo en 1932, mientras Pontevedra presenta un crecimiento hasta 1933, e incluso en 1934 la caída no fue demasiado pronunciada (Gráfico 2.2 y Gráfico 2.3). A partir de 1933 se aprecia con claridad el impacto de la crisis sobre las economías coruñesa y pontevedresa, alcanzando el punto más bajo del ciclo en 1935, a un nivel incluso más bajo que el de 1936 (al menos en A Coruña).

La base industrial gallega atravesó un punto de inflexión durante la depresión. Inicialmente, no se produjo una contracción de las exportaciones ni de la producción, sino que éstos se mantuvieron a niveles altos, gracias al efecto favorable de la depreciación de la peseta. Pero las elevaciones arancelarias, los contingentes, y los problemas de impagos de los países latinoamericanos (sus principales clientes) acabaron con la trayectoria ascendente de las exportaciones conserveras (Carmona, 2001a: 26).

Sin embargo, la historiografía regional ha insistido durante los últimos años en la existencia de algunos sectores más dinámicos. La economía gallega dio pasos importantes en la búsqueda de una mayor inserción en el mercado interior español. El ejemplo más sobresaliente fue el de la industria conservera, que reorientó con eficacia sus mercados, desde el exterior hacia un mercado nacional hasta entonces desatendido, lo que permitió a los conserveros mantener la tendencia ascendente de la producción. Las razones que explican esa rápida reorientación fueron, esencialmente, dos: la mejora en la distribución de la renta y la tendencia positiva del consumo durante la República, y el descenso del coste de algunas materias primas, en especial el pescado, gracias a la extraordinaria abundancia de la pesca a lo largo de la República (Carmona, 2001a: 26).

Durante esos años no se interrumpió la modernización de la agricultura gallega (Fernández Prieto, 2000), aunque sí se desaceleró, por efecto de un estancamiento de la demanda interna y de los precios, y del deterioro de la relación de intercambio (Martínez López, 2000b). Con todo, se advierte una continuación de las tendencias que definen el conjunto del primer tercio del siglo: reconversión del sistema de cultivos, intensificación de la producción, aumento de la utilización del factor capital, incorporación de maquinaria y fertilizantes químicos ${ }^{2}$, incremento de la productividad y crecimiento cuantitativo y cualitativo de la cabaña ganadera (Villares, 1991: 153-154).

\footnotetext{
2 A pesar de todo, en los años treinta Galicia mostraba un nivel de mecanización de su agricultura bastante bajo, incluso en comparación con una España también escasamente mecanizada (Martínez López, 1995: 120-121). La mecanización, en realidad, arrancó a principios del siglo XX, con un fuerte incremento entre 1907 y 1914, una paralización durante la guerra europea, y un nuevo relanzamiento del proceso a partir de principios de los años veinte (Fernández Prieto, 1992: 330-335). La depresión de los años treinta hizo descender sensiblemente las compras de maquinaria agrícola y el proceso de renovación tecnológica de la agricultura por parte de un campesinado afectado por la depreciación de sus productos. Los fertilizantes siguieron un comportamiento muy similar (Fernández Prieto, 1998: 32).
} 
Con todo, la tarea era ardua, debido a la permanencia de algunos elementos retardatarios: foros, caciquismo, predominio de un marcado ruralismo, atraso en las infraestructuras de comunicación, etc. Elementos, todos ellos, que dificultaban una adecuada articulación dentro del modelo industrial español (Villares, 1982).

Por su parte, una de las actividades de mayor repercusión, los negocios relacionados con la emigración y el transporte marítimo, sufrieron también el impacto de la depresión (Hernández Borge, 1980: 50), debido a las dificultades económicas y a las nuevas políticas migratorias de los países latinoamericanos (Palazón, 1991). Esto se tradujo en un freno de la corriente migratoria (Villares, 1996a: 138), lo que tuvo varias consecuencias. Por un lado, la supresión de varias de las principales líneas de vapores y una fuerte caída en la actividad portuaria. Dada la gran vinculación de las ciudades portuarias gallegas con América a través de la emigración, el aislamiento internacional las convertía en núcleos muy vulnerables a la coyuntura económica y política de los países receptores (Losada, 1995: 63). Por otro lado, se produjo una importante disminución de las remesas de la emigración (Carmona, 2001a: 26). Pero, además, la emigración había sido tradicionalmente una salida al paro encubierto en Galicia, y esta vía se cortó de raíz a partir de 1930. En consecuencia, los índices de paro se incrementaron, aunque a un nivel levemente más bajo que en las zonas industrializadas del país, debido a las condiciones sectoriales específicas gallegas ${ }^{3}$. En esta situación, el minifundio en propiedad, que había sido en Galicia una alternativa de (sub)empleo ante las crisis económicas externas, ejerció ese rol durante la crisis de los años treinta (Sequeiros, 1981: 54). En definitiva, hacia 1936, advierte Carmona (2001a: 26), Galicia se encontraba en la fase baja del ciclo.

\section{La coyuntura económica en la ciudad de A Coruña}

La crisis económica, aparentemente, no tuvo fuertes repercusiones sobre la economía de A Coruña. El aislamiento de la economía española y la política distributiva republicana probablemente contribuyeron a moderar los efectos de la crisis, al menos durante sus primeras manifestaciones, al frenar la caída del consumo, evitando un descenso brusco de la actividad mercantil, aunque al final del período se aprecia una fuerte contracción del mismo.

Por otra parte, el freno a la emigración exterior permitió a la ciudad canalizar parte del flujo, al igual que las demás ciudades regionales (Sequeiros, 1985: 285). Esto permitió una sustancial expansión física, de manera que los años treinta fueron testigo de una notable actividad constructiva, ya que prácticamente se colmató el Ensanche de principios de siglo, y la ciudad se extendió por el norte, en las barriadas de Atocha y Monte Alto, y por el sur, en Santa Margarita y Os Mallos, en donde se concentraban los mayores contingentes de población obrera (Martínez Suárez y Casabella, 1989: 25, 225).

\footnotetext{
3 Máiz (1988: 19-20). El paro era más reducido, en parte porque el número de obreros industriales en las ciudades era menor que en otras regiones. Sin embargo, en el campo la situación era angustiosa. "La situación especial de Galicia ante la solución del problema del paro", Vida Gallega, 20 de junio de 1935.
} 
No obstante, cuando la crisis dejó sentir sus efectos, la economía de la ciudad padeció las consecuencias, a través, principalmente, de la coyuntura que atravesó el puerto ${ }^{4}$. Los puertos gallegos se encontraban sometidos a las influencias de los cambios políticos y económicos, tanto a escala regional o nacional como internacional (González Laxe et al., 1999: 27). De este modo, la depresión reforzó las actitudes proteccionistas de muchos países dañando, de ese modo, el comercio exterior.

Gráfico 4.1. Número total de buques en tránsito y tonelaje bruto registrado en el puerto, 1922-36.

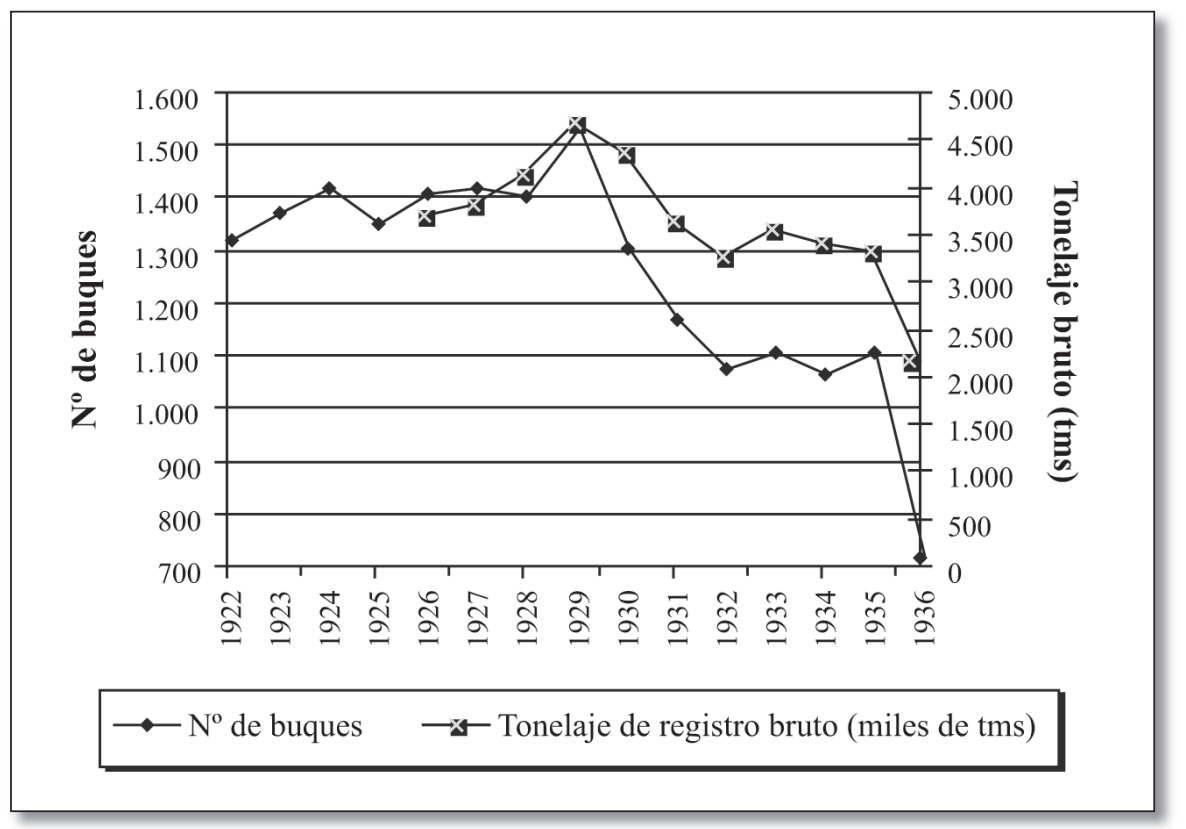

Fuente: Memorias de la Junta de Obras del Puerto de La Coruña.

A pesar de que en el Cuadro 4.1 no se aprecia la totalidad del período republicano (por ausencia de información), hasta 1932 el tráfico mercantil no presenta una tendencia excesivamente preocupante, si se compara con otros puertos españoles más conectados con el mercado internacional, y si se considera como barómetro exclusivamente el movimiento total de mercancías ${ }^{5}$. Si consideramos el número de buques, se observa que la crisis ya se inició con el comienzo de la década (Gráfico 4.1). En torno a 1934 el puerto atravesaba un momento crítico, que se agravó en los dos años siguientes ${ }^{6}$.

$4 \quad$ Estudio realizado, op. cit., p. 21.

5 Mirás (2004c). Dentro del sistema portuario español, los puertos que más sufrieron la crisis fueron los que concentraban su volumen de tráfico en la importación y exportación (Aracil, 1989).

6 "La Coruña y su puerto", Galicia industrial y comercial, marzo de 1934, pp. 9-10. 


\section{Cuadro 4.1. Movimiento total de mercancías y buques en los principales} puertos españoles, 1929-39 (índice 1929 = 100).
(1)*
(2) (1)
(2) (1)
(2) (1)
(2)
(1)
(2) (1)
(2) (1)
(2) (1) (2)

\begin{tabular}{lcccccccccccccccc} 
& \multicolumn{1}{c}{$\mathbf{1 9 2 9}$} & \multicolumn{1}{c}{$\mathbf{1 9 3 0}$} & \multicolumn{1}{c}{$\mathbf{1 9 3 1}$} & $\mathbf{1 9 3 2}$ & $\mathbf{1 9 3 3}$ & $\mathbf{1 9 3 7}$ & $\mathbf{1 9 3 8}$ & $\mathbf{1 9 3 9}$ \\
\hline Algeciras & 100 & 100 & 69 & 89 & 49 & 113 & 43 & 114 & 40 & 105 & 62 & 59 & 61 & 65 & $\mathbf{7 4}$ & 60 \\
\hline Alicante & 100 & 100 & 103 & 88 & 98 & 82 & 101 & 87 & 93 & 82 & & & & 37 & 16 \\
\hline Almería & 100 & 100 & 71 & 101 & 53 & 91 & 46 & 98 & 40 & 97 & & & & 10 & 31 \\
\hline Avilés & 100 & 100 & 114 & 134 & 110 & 123 & 91 & 100 & 84 & 96 & 5 & 10 & 66 & 49 & 94 & 62 \\
\hline Barcelona & 100 & 100 & 101 & 102 & 85 & 96 & 96 & 100 & 82 & 93 & & & & 36 & 42 \\
\hline Bilbao & 100 & 100 & 80 & 44 & 59 & 39 & 56 & 38 & 58 & 37 & 18 & 8 & 49 & 32 & 51 & 34 \\
\hline Cádiz & 100 & 100 & 51 & 60 & 37 & 46 & 57 & 41 & 29 & 41 & 43 & 29 & 33 & 30 & 25 & 34 \\
\hline Cartagena & 100 & 100 & 94 & 110 & 71 & 77 & 63 & 84 & 64 & 93 & & & & 23 & 33 \\
\hline Castellón & 100 & 100 & 124 & 66 & 108 & 59 & 108 & 63 & 99 & 61 & & 35 & 6 & 93 & 60 \\
\hline Ceuta & 100 & 100 & & & & & & & & & & & & \\
\hline A Coruña & 100 & 100 & 114 & 88 & 112 & 79 & 117 & 75 & 100 & 73 & 79 & 31 & 84 & 40 & 100 & 48 \\
\hline Ferrol & 100 & 100 & 32 & 145 & 21 & 70 & 38 & 98 & 33 & 138 & 15 & 63 & 25 & 68 & 45 & 71 \\
\hline Gijón & 100 & 100 & 111 & 80 & 96 & 73 & 97 & 80 & 86 & 90 & & 67 & 67 & 78 & 84 \\
\hline Huelva & 100 & 100 & 97 & 25 & 65 & 18 & 58 & 15 & 65 & 15 & 72 & 14 & 70 & 15 & 52 & 12 \\
\hline Málaga & 100 & 100 & 92 & 99 & 84 & 90 & 82 & 86 & 71 & 84 & 33 & 25 & 62 & 37 & 62 & 42 \\
\hline Melilla & 100 & 100 & & & & & & & & & & & & \\
\hline Palma & 100 & 100 & 86 & 103 & 95 & 95 & 71 & 95 & 65 & 120 & 35 & 24 & 54 & 26 & 54 & 51 \\
\hline Las Palmas & 100 & 100 & & & & & & & & & & & & \\
\hline Pasajes & 100 & 100 & 118 & 93 & 109 & 91 & 106 & 85 & 103 & 80 & 57 & 26 & 88 & 62 & 117 & 84 \\
\hline S.Esteban P & 100 & 100 & & & & & & & & & & & & \\
\hline
\end{tabular}

S.Esteban P. $100 \quad 100$

\begin{tabular}{lcccccccccccccccc}
\hline Santa Cruz & 100 & 100 & 100 & 10 & 10 & 10 & 70 & 49 & 36 & 58 & 42 \\
\hline Santander & 100 & 100 & 88 & 80 & 73 & 62 & 60 & 57 & 60 & 55 & 12 & 7 & \\
\hline Sevilla & 100 & 100 & 86 & 97 & 56 & 75 & 57 & 79 & 51 & 47 & 65 & 60 & 84 & 66 & 72 & 55 \\
\hline Tarragona & 100 & 100 & 98 & 102 & 108 & 102 & 106 & 97 & 92 & 92 & & & & & 34 & 33 \\
\hline Valencia & 100 & 100 & 100 & 112 & 82 & 95 & 87 & 90 & 70 & 88 & & & & & 32 & 32 \\
\hline Vigo & 100 & 100 & 120 & 55 & 103 & 62 & 93 & 65 & 109 & 68 & 128 & 46 & 119 & 52 & 116 & 27 \\
\hline Vilagarcía & 100 & 100 & 90 & 50 & 72 & 41 & 64 & 43 & 53 & 40 & 32 & 24 & 62 & 39 & 80 & 40 \\
\hline Media & 100 & 100 & 76 & 71 & 65 & 62 & 63 & 63 & 57 & 63 & 24 & 16 & 37 & 26 & 50 & 37
\end{tabular}

* (1) Tráfico total de mercancías. (2) No de buques totales en tránsito.

Fuente: Anuarios Estadísticos de España. 
Cuadro 4.2. Movimiento mercantil exterior y de cabotaje en los principales puertos españoles, 1930-39 (índice 1930 = 100).
(1)
(2)
(1)
(2)
(1)
(2)
(1)
(2) (1)
(2) (1)
(2) (1)
(2)

$\begin{array}{lllllll}1930 & 1931 & 1932 & 1933 & 1937 & 1938 & 1939\end{array}$

\begin{tabular}{|c|c|c|c|c|c|c|c|c|c|c|c|c|c|c|}
\hline Algeciras & 100 & 100 & 75 & 71 & 74 & 60 & 61 & 58 & 146 & 34 & 32 & 102 & 45 & 132 \\
\hline Alicante & 100 & 100 & 86 & 96 & 107 & 96 & 86 & 98 & & & & & 21 & 48 \\
\hline Almería & 100 & 100 & 58 & 94 & 60 & 126 & 26 & 100 & & & & & 8 & 64 \\
\hline Avilés & 100 & 100 & & 96 & & 80 & & 63 & & 3 & & 55 & & 77 \\
\hline Barcelona & 100 & 100 & 85 & 86 & 90 & 102 & 74 & 100 & & & & & 16 & 63 \\
\hline Bilbao & 100 & 100 & 72 & 83 & 71 & 76 & 58 & 86 & 25 & 7 & 23 & 65 & 29 & 89 \\
\hline Cádiz & 100 & 100 & 101 & 73 & 182 & 57 & 82 & 35 & 143 & 56 & 18 & 60 & 14 & 57 \\
\hline Cartagena & 100 & 100 & 94 & 72 & 100 & 82 & 79 & 84 & & & & & 23 & 44 \\
\hline Castellón & 100 & 100 & 111 & 95 & 144 & 83 & 67 & 73 & & & & 116 & 71 & 168 \\
\hline Ceuta & 100 & 100 & & & & & & & & & & & & \\
\hline A Coruña & 100 & 100 & 82 & 107 & 98 & 106 & 90 & 87 & 81 & 58 & 16 & 103 & 22 & 124 \\
\hline Ferrol & 100 & 100 & 38 & 87 & 104 & 131 & 22 & 162 & 15 & 67 & 16 & 120 & & 235 \\
\hline Gijón & 100 & 100 & 73 & 87 & 88 & 87 & 44 & 78 & & & 17 & 60 & 29 & 71 \\
\hline Huelva & 100 & 100 & 70 & 72 & 44 & 87 & 67 & 76 & 60 & 19 & 9 & 70 & 21 & 91 \\
\hline Málaga & 100 & 100 & 80 & 88 & 103 & 81 & 73 & 79 & 31 & 45 & 20 & 103 & 41 & 112 \\
\hline Melilla & 100 & 100 & & & & & & & & & & & & \\
\hline Palma & 100 & 100 & 109 & 110 & 46 & 89 & 37 & 88 & 131 & 4 & 166 & 11 & 47 & 61 \\
\hline Las Palmas & 100 & 100 & 118 & 107 & 136 & 145 & 138 & 115 & 79 & 127 & 60 & 214 & 73 & 256 \\
\hline Pasajes & 100 & 100 & 98 & 92 & 95 & 91 & 131 & 71 & 66 & 31 & 39 & 87 & 42 & 132 \\
\hline S.Esteban P. & 100 & 100 & & & & & & & & & & & & \\
\hline Santa Cruz & 100 & 100 & 134 & 326 & 147 & 232 & 159 & 170 & 117 & 425 & 111 & 1.849 & 167 & 950 \\
\hline Santander & 100 & 100 & 97 & 77 & 106 & 60 & 97 & 50 & 10 & 14 & 26 & 75 & 40 & 83 \\
\hline Sevilla & 100 & 100 & 80 & 81 & 68 & 67 & 64 & 72 & 51 & 88 & 32 & 141 & 25 & 131 \\
\hline Tarragona & 100 & 100 & 103 & 123 & 121 & 127 & 81 & 126 & & & & & 16 & 75 \\
\hline Valencia & 100 & 100 & 94 & 89 & 95 & 101 & 74 & 82 & & & & & 30 & 55 \\
\hline Vigo & 100 & 100 & 44 & 121 & 56 & 123 & 83 & 133 & 83 & 155 & 25 & 209 & 42 & 190 \\
\hline Vilagarcía & 100 & 100 & 63 & 76 & 21 & 65 & 28 & 58 & & 38 & & 70 & & 89 \\
\hline Media & 100 & 100 & 73 & 89 & 80 & 87 & 64 & 79 & 39 & 43 & 23 & 130 & 30 & 126 \\
\hline
\end{tabular}

*(1) Tráfico de mercancías con el exterior. (2) Tráfico de mercancías de cabotaje.

Fuente: Anuarios Estadísticos de España. 
Si aislamos el tráfico exterior del de cabotaje, es evidente que el primero sufrió más las secuelas de la depresión, debido a las consecuencias que ésta tuvo sobre el mercado internacional, en forma de caída de la actividad comercial a nivel mundial ${ }^{7}$. Pero en A Coruña el impacto fue menor que en los puertos más grandes y más orientados hacia el exterior. Incluso se observa que el tráfico de cabotaje compensó parcialmente la caída del tráfico exterior, al igual que ocurrió en otros puertos (fundamentalmente, los insulares, más Vigo y Tarragona, es decir, puertos con una posición periférica extrema), aunque no sirvió para menguar el impacto sobre el conjunto de la economía urbana (Cuadro 4.2).

\section{Cuadro 4.3. Coste de las operaciones comparadas de los puertos de A Coruña y norte de España.}

\begin{tabular}{|c|c|c|c|c|c|c|}
\hline Coste por tonelada en pts. & A Coruña & Vigo & Musel & Santander & Pasajes & Bilbao \\
\hline \multicolumn{7}{|l|}{ Mercancías } \\
\hline Primer grupo & 6,35 & 3,90 & 3,50 & 4,00 & & \\
\hline Segundo grupo & 7,25 & $\mathrm{a}$ & $\mathrm{a}$ & $\mathrm{a}$ & 2,25 & 3,50 \\
\hline Tercer grupo & 8,15 & 4,65 & 4,75 & 5,00 & & \\
\hline \multicolumn{7}{|l|}{ Jornales } \\
\hline Jornada ordinaria & 15,00 & 13,00 & 15,00 & 14,00 & 11,50 a 13,50 & 12,00 a 13,50 \\
\hline $\begin{array}{l}\text { Jornada festiva } \\
\text { (cabotaje) }\end{array}$ & 30,00 & & & & & \\
\hline $\begin{array}{l}\text { Jornada festiva } \\
\text { (altura) }\end{array}$ & 25,00 & 19,00 & 26,25 & 28,00 & & 27,00 \\
\hline Medios jornales & había & no había & no había & había & había & había \\
\hline Recargo por seguros & $25 \%$ & 16 a $22 \%$ & $33 \%$ & $40 \%$ & 20 a $22 \%$ & $19 \%$ y $0,10 \mathrm{tm}$ \\
\hline
\end{tabular}

Fuente: Estudio realizado para conocer las causas del decrecimiento mercantil de La Coruña, La Coruña, COCINC, 1935, p. 8.

La responsabilidad en la contracción del tráfico portuario no sería atribuible totalmente al contexto internacional. El descenso del tráfico se justificaba en que el puerto era antieconómico y, por tanto, su posición comparativa en términos de costes, desventajosa (Cuadro 4.3). A pesar de sus favorables condiciones, era el puerto más caro del norte de España y el trabajo era escasamente eficiente. Además, los derechos consulares que se abonaban eran elevados y el relativamente reducido volumen de carga transportado no podía soportar tales $\operatorname{costes}^{8}$. Además, en este período se acentuó la

\footnotetext{
7 En España, la navegación de cabotaje resultó beneficiada por la guerra de fletes que se desató a partir de 1929 entre la más poderosa compañía naviera española, la Compañía Naviera Sota y Aznar, y las empresas firmantes del Convenio de Mancomunidad (Transmediterránea, Ybarra y la Compañía Ramón A. Ramos, en 1922). Este conflicto finalizó en 1930, con la firma de un convenio que daría lugar al consorcio de más efectividad y duración en la historia del cabotaje regular en España (Valdaliso, 1997).

8 Estudio realizado, op. cit., pp. 8 y 15.
} 
competencia de otros puertos y otros sistemas de transporte, gracias a que durante la década anterior había aumentado el número de puertos habilitados para operaciones aduaneras y a que el desarrollo del transporte por carretera posterior a la guerra europea trajo consigo un decrecimiento del papel de la ciudad como distribuidora del mercado interior y del litoral $^{9}$. A ello se añadía el problema de dotación de infraestructuras portuarias. Algunas operaciones resultaban difíciles y se realizaban ineficientemente, en particular el carboneo. La conflictividad obrera o la organización de las operaciones de carga y descarga por parte de la patronal es probable que incidiesen también en la disminución del número de buques que realizaban aprovisionamiento, pues tales deficiencias desincentivaban las escalas ${ }^{10}$.

Para la pesca, los años treinta se abrieron manteniendo la tendencia iniciada a finales del decenio anterior. Estos años fueron testigo de la consolidación de las principales empresas pesqueras de A Coruña, del asentamiento definitivo de los trawlers y del perfeccionamiento de las técnicas de pesca de comienzos de siglo, aunque a un ritmo algo más lento que en el sur de Galicia ${ }^{11}$. El crecimiento de la flota pesquera coruñesa se realizó precisamente durante la primera mitad de esta década, lo que se tradujo en un incremento del volumen de capturas y la erección de A Coruña como un puerto pesquero de primer orden, anticipo del esplendor posterior a la Segunda Guerra Mundial (Freire, 1984). La flota de fresco inició una expansión que se mantendría hasta comienzos de los setenta (González Laxe, 1984: 99). De hecho, todavía en 1930 se aprecia un notorio aumento de las capturas, lo que aparentemente constituye un signo del afianzamiento del sector pesquero en la ciudad ${ }^{12}$.

Sin embargo, durante el período republicano se manifestaron algunos síntomas de estancamiento $^{13}$, algo parecido a lo que ocurría en Vigo (Souto, 1990: 26; Colectivo Xerminal, 1990: 149). Los años 1931-37 se caracterizaron por un marcado descenso en las capturas. La disminución del valor económico de la pesca fue especialmente significativa en A Coruña (Gráfico 2.13), quizá a causa de que la industria pesquera

$9 \quad$ Ibid., pp. 5-6, 25, 73.

10 A Coruña era de los pocos puertos donde tales operaciones eran organizadas por la patronal. Esto tenía consecuencias en la elevación de los precios. Estudio realizado, op. cit., pp. 16-18.

11 Según el Consejo de Industria, op. cit., p. 396, en A Coruña existían 22 vapores de altura (trawlers), con un desplazamiento total de 6.000 tms y un valor aproximado de 6.000 .000 pts., a los que se añadían 60 vapores (tipo pareja), para pesca de arrastre, con un registro de 5.500 tms y un valor de 6.000 .000 pts., y 100 tarrafas (lanchas de motor, tiradas por motor de gasolina), con un peso de 250.000 tms y un valor de 350.000 pts.

12 La industria frigorífica, muy vinculada al desarrollo de la pesca de altura, vivió un considerable crecimiento a finales de los años veinte, hecho relacionado con la expansión de la pesca gallega a Grande Sole (Carmona, 1998: 159). La venta de hielo de la empresa más importante, la Compañía Frigorífica, S.A., ascendió en 1930 a unas 6.555 tms, cantidad hasta entonces no alcanzada. El incremento se gestó en la mejora de las instalaciones acometidas a finales de la década anterior y en la creciente demanda de su producción, dando como fruto un incremento de los beneficios y de la rentabilidad de la empresa (31.900 pts. en 1925, 53.500 en 1926, 66.500 en 1930 y 108.424,6 en 1931). Compañía Frigorífica (S.A.). Memoria correspondiente al Undécimo Ejercicio. Año de 1930, La Coruña, pp. 6-7. Desde el comienzo de los años treinta, la producción de hielo continuó incrementándose a buen ritmo, pero no ocurrió lo mismo con los beneficios, debido a la subida de los costes. Compañía Frigorífica, S.A., Memorias, 1930-36. ARG-DHC (Hacienda). Utilidades.

13 "La Coruña y su puerto", op. cit., pp. 9-10. 
se hallaba por entonces en un período de transformación, que necesitaba consumir grandes capitales en la adquisición de nuevos elementos y utillajes ${ }^{14}$.

En el sector de exportación de pescado en fresco, la norma fue el exceso de oferta, debido a la apertura de nuevas áreas de pesca altamente productivas, que no encontraban salida en el mercado, por rigideces de demanda. La crisis se agravó por efecto de la confluencia de otros factores. En primer lugar, el aumento de los costes de producción, dado que la mayoría de los inputs procedía de fuera de A Coruña. Ello dio lugar a un fuerte descenso de los beneficios empresariales (Cuadro 4.4), porque a las empresas pesqueras les resultaba muy difícil repercutir los costes sobre el precio final (Giráldez, 1996: 334). En segundo lugar, la desfavorable política estatal, que cerró los flujos crediticios para la renovación de la flota, cuando la lejanía de los caladeros requería unidades más eficientes (Sinde, Fernández y Diéguez, 2002). Probablemente, la inquietud social ante la depresión presionó a las autoridades a desviar recursos hacia otros destinos (Pereira, 2001: 362). En tercer lugar, la crisis mundial forzó el amarre de los buques. Finalmente, la competencia de otros alimentos sustitutivos del pescado probablemente repercutió en un descenso de su demanda ${ }^{15}$.

\section{Cuadro 4.4. Beneficios obtenidos por varios armadores y navieros, 1930-36.}

\begin{tabular}{lccccccc}
\hline & $\mathbf{1 9 3 0}$ & $\mathbf{1 9 3 1}$ & $\mathbf{1 9 3 2}$ & $\mathbf{1 9 3 3}$ & $\mathbf{1 9 3 4}$ & $\mathbf{1 9 3 5}$ & $\mathbf{1 9 3 6}$ \\
\hline $\begin{array}{l}\text { Armadores de Buques } \\
\text { Pesqueros, S.L. }\end{array}$ & 32.963 & 40.918 & 38.671 & 33.937 & 30.114 & 4.137 & 19.267 \\
\hline $\begin{array}{l}\text { Pérez, Alejo y Cía, S.L. } \\
11.833\end{array}$ & 49.299 & 13.733 & 3.327 & 8.837 & 44.854 & -24.707 \\
\hline Rodríguez Rincón & - & - & - & 3.197 & 3.260 & 5.089 & -15.980 \\
\hline Martínez y Neira & - & - & - & -5.827 & 22.691 & 4.596 & -10.131 \\
\hline
\end{tabular}

Fuente: ARG-DHC (Hacienda). Utilidades.

La base industrial asociada a la pesca también se resintió con la crisis. La industria conservera gallega, basada aún en la sardina fue desplazada de su principal destino, los mercados internacionales. Éstos venían atravesando una acentuada crisis, lo que acarreó un enorme descenso de las exportaciones conserveras coruñesas, obligando al sector a reorientarse hacia el mercado interior ${ }^{16}$. El cambio se realizó de forma rápida, gracias al descenso en los costes de algunas materias primas (en especial, el pescado), debido a que la extraordinaria abundancia de algunas especies deprimió su precio en lonja (Carmona, 1990b: 39). No obstante, fue muy frecuente que las empresas, para

\footnotetext{
14 Lo que llevó a Peña Novo (1929a: 104) a afirmar que la crisis era "más aparente que real", y que la imagen de crisis, en realidad, procedía de las continuas lamentaciones de los interesados (Peña Novo, 1928). De hecho, la situación de la flota se calificaba desde los estamentos pesqueros de "verdaderamente angustiosa". Archivo COCINC. Legajo A.D./153, carpeta "Pesca-Crisis de la flota".

${ }_{15}$ A pesar de que la crisis provocó un estancamiento de la tendencia ascendente del consumo global de carne, tanto en A Coruña como en las demás capitales de provincia españolas (Martínez López, 2002).

16 "El transporte de pescado en La Coruña", Ferrocarriles y Tranvías, (50), 1935.
} 
conquistar el mercado interior, forzasen una disminución de sus precios, con la consiguiente disminución de los beneficios ${ }^{17}$. También tuvo algo que ver la mejora en la distribución de la renta y del consumo durante los años de la República (Massó, 1967).

El resultado de estos procesos fue el estancamiento global de la economía urbana, y, sobre todo, el hecho de que, en vísperas de la Guerra Civil, varios sectores industriales y especialmente el sector terciario atravesaron claramente una situación crítica, que se había venido gestando durante el quinquenio anterior ${ }^{18}$.

Sólo se mostraron relativamente ausentes de la crisis algunos segmentos del comercio local ${ }^{19}$. En un período de crisis económica generalizada, las actividades comerciales parecieron mantener un comportamiento mucho más positivo que los demás sectores. El factor que explica este comportamiento sería el carácter fundamentalmente minorista del comercio coruñés, más acentuado si cabe en el subsector alimentación, aunque concurrieron otras circunstancias menos favorables que bloquearon un desarrollo más eficaz de la función comercial.

Una posible hipótesis de este anormal comportamiento sería su carácter de sector refugio frente a la crisis $^{20}$. Ante las dificultades de la población para acceder a un empleo en otros sectores, se recurría a la ocupación en pequeños comercios, aunque mantuviesen una existencia precaria ${ }^{21}$. Además, se trataba de actividades en buena medida vinculadas al mercado urbano, que no dependían de la coyuntura exterior, circunstancia que afectó a otros servicios. Pero estos establecimientos frecuentemente tenían una corta esperanza de vida, a causa de las deficiencias estructurales que aquejaban al comercio de A Coruña, más perceptibles en este tipo de tiendas.

\section{UNA POBLACIÓN AFECTADA POR LOS EFECTOS DE LA CRISIS}

Durante los años treinta la población de A Coruña experimentó su etapa de mayor avance (Cuadro 2.1), con una tasa de crecimiento del 4,05\% anual, muy por encima del crecimiento del conjunto de las capitales de provincia españolas $(2,41 \%)^{22}$. A pesar de ello, no fue la ciudad gallega que experimentó una mayor progresión, sino Ferrol, que creció un 6,8\% anual, exhibiendo uno de los mayores ritmos de crecimiento a nivel nacional durante esa década. El "anormal" comportamiento ferrolano se debió a la anexión del municipio de Serantes, en 1940, y a que la Guerra Civil le otorgó un gran

\footnotetext{
“La Pesquera del Norte de España, S.A.”, Memorias, años 1930-36. ARG-DHC (Hacienda). Utilidades.

"Ante las fiestas coruñesas", Galicia industrial y comercial, no 112, julio 1935, p. 1.

19 Esto no significa que el comercio no se viese afectado por la crisis. La Mercantil Cívico Militar. Memoria del año 1933 presentada a la Junta General de 1934. Año XLIII. $18^{\circ}$ del $2^{\circ}$ período social, La Coruña, 1934, p. 8.

20 Un fenómeno que se ha detectado en diversas ocasiones dentro del sector terciario (Lanvin, 1991).

21 El comercio era un sector intensivo en trabajo. En consecuencia, una de las mayores demandas de empleo urbano se daban en este sector, lo que estimulaba el flujo inmigratorio que alimentó a la mayoría de las ciudades españolas durante este período, más que la producción fabril (Germán, 1996).

22 En términos comparativos, el crecimiento de A Coruña fue notable dentro del contexto nacional. En 1930 la ciudad ocupaba el $18^{\circ}$ lugar en la jerarquía urbana española. En 1940 había ascendido al $14^{\circ}$ puesto. El crecimiento anual duplicaba la media de las capitales provinciales, y era el $15^{\circ}$ más elevado dentro del conjunto (Mirás, 2005a).
} 
protagonismo en la industria de la construcción naval, gracias a la revitalización de los suministros a la Armada ${ }^{23}$.

En realidad, la explicación de este crecimiento, en A Coruña y en el conjunto del sistema urbano gallego, radica en el cierre de la emigración exterior ${ }^{24}$. Pero, además, porque tras el comienzo de la Guerra Civil, Galicia ocupó una situación de neutralidad. Desde los primeros días del conflicto, formó parte estable de la zona sublevada, sirviendo de vivero del bando franquista ${ }^{25}$.

Durante los años treinta, la dinámica poblacional fue similar a la de las dos décadas anteriores, en la medida en que el crecimiento demográfico tuvo en la inmigración su principal punto de apoyo. Sin embargo, se evidencia un leve descenso relativo del crecimiento vegetativo, mientras que el saldo migratorio se disparó, multiplicándose casi por cinco, debido al bloqueo de la emigración latinoamericana. Por tanto, la ciudad absorbió una proporción elevada del excedente demográfico regional.

Si nos ceñimos a los partidos judiciales, se observa que los años treinta revirtieron la tendencia emigratoria de la provincia de A Coruña, de manera similar al conjunto de España (Harrison, 1988: 183). A Coruña sobresale como el núcleo más atractivo. Pero, en realidad, esto no significa que la articulación rural-urbano hubiese mejorado, sino que las condiciones del mercado mundial modificaron el curso del flujo migratorio regional y provincial.

Durante los años treinta se aceleró la corriente migratoria hacia las ciudades del país. Mientras en el período 1900-30 el mayor crecimiento correspondió a las capitales de industrialización temprana, que rebasaron ampliamente sus respectivos crecimientos vegetativos, durante el período 1930-50 disminuyó considerablemente el crecimiento de esas capitales, mientras que el máximo aumento correspondió a las capitales provinciales agrícolas (Rodríguez Osuna, 1985: 93, 106, 153).

La República fue testigo de una aceleración de las tendencias observadas en el comportamiento de las variables vitales durante los años anteriores. Aunque la crisis de los años treinta golpeó más tardíamente a España, lo que explica el retraso en la respuesta demográfica, la caída fue espectacular. La natalidad y la mortalidad fortalecieron la línea de descenso anterior, siguiendo la dirección de la población española (Gráfico 2.4). La difícil situación socioeconómica, con un aumento del paro en la ciudad, perjudicó a los estratos más modestos de la población, principalmente los obreros industriales, lo que pudo tener un efecto sobre la natalidad urbana ${ }^{26}$. Por tanto, el ciclo económico estaba influyendo negativamente sobre la conducta reproductiva de los habitantes de A Coruña más que en los períodos de crisis anteriormente descritos, unido a los cambios

\footnotetext{
23 Precedo (1995: 219). En los años cuarenta, se pusieron en marcha numerosas empresas vinculadas a distintas industrias ligeras y, sobre todo, se crearon ASTANO (1941) y BAZÁN (1947).

24 Durante los años de bloqueo de la emigración exterior gallega, hubo un flujo, primero desde el campo hacia el exterior, que posteriormente retornó hacia las ciudades gallegas, generando un efecto de sustitución que incrementaba el éxodo rural/urbano (Fernández Leiceaga, 1998: 133).

25 Grandío (2000: 63). La otra cara de la moneda era la estabilidad sociopolítica.

26 Por otra parte, al inicio del período republicano, la remuneración del trabajo parece haberse deteriorado considerablemente en la ciudad. Ministerio de Trabajo y Previsión Social, Estadística de salarios y jornadas de trabajo referida al período 1914-1930, Madrid, 1931, pp. xl-lii.
} 
más generales que presenciaba la sociedad española en su conjunto. Como resultado, la distancia entre la natalidad y la mortalidad se redujo, dando como consecuencia un descenso de las tasas de crecimiento vegetativo a valores que oscilaron entre el 12,7\%o de 1931 y el 10,01\%o de 1935 (Gráfico 2.4).

\section{Cuadro 4.5. Distribución de las capitales de provincia españolas en 1900, por su posición en el ranking de los sectores primario, secundario y terciario (en porcentaje).}

\begin{tabular}{|c|c|c|c|c|c|c|}
\hline & Primario & & Secundario & & Terciario & \\
\hline Lugo & 82,4 Palencia & 35,1 Cádiz & 38,4 S.C.Tenerif. & 22,4 Ávila & 58,8 Sevilla & 41,1 \\
\hline Murcia & 78,6 Sevilla & 34,3 S.Sebast. & 36,7 Córdoba & 22,3 Guadalaj. & 56,6 Zaragoza & 40,9 \\
\hline Pontevedra & 70,2 León & 33,3 Barcelona & 36,0 Logroño & 21,8 Segovia & 56,2 Girona & 40,2 \\
\hline Cáceres & 60,9 Oviedo & 33,0 Castellón & 32,6 Soria & 21,6 Madrid & 55,9 Oviedo & 40,0 \\
\hline Almería & 58,3 Burgos & 32,7 Girona & 32,2 C.Real & 21,4 Soria & 53,8 Santander & 38,9 \\
\hline Jaén & 58,0 Teruel & 32,5 A Coruña & 30,8 Huesca & 20,8 Salamanca & 53,8 & 36,8 \\
\hline Málaga & 57,5 Zaragoza & 32,4 Vitoria & 30,3 Cuenca & 19,7 León & $52,4 \mathrm{Ba}$ & 36,4 \\
\hline Albacete & 56,3 Logroño & 30,6 Salamanca & 30,0 Badajoz & 19,3 Pamplona & 51,9 Ourense & 36,2 \\
\hline Lleida & 51,4 Huesca & 29,9 Granada & 28,8 Segovia & 19,3 A Coruña & 51,0 Lleida & 35,9 \\
\hline Badajoz & 48,1 Tarragona & 28,2 Bilbao & 28,1 Jaén & 18,8 Huesca & 49,4 Granada & 34,3 \\
\hline Palma & 48,0 Guadalaj. & 27,8 Alicante & 28,0 Palencia & 18,5 Burgos & 49,2 Valencia & 33,4 \\
\hline Córdoba & 45,2 Barcelona & 27,6 Oviedo & 27,0 Burgos & 18,1 Cádiz & 47,8 Badajoz & 32,6 \\
\hline Valencia & 43,8 Girona & 27,6 Tarragona & 26,9 Albacete & 17,3 Logroño & 47,6 Córdoba & 32,4 \\
\hline Alicante & 42,7 Bilbao & 27,2 Zaragoza & 26,6 Valladolid & 17,1 Palencia & 46,4 Castellón & 30,0 \\
\hline S.C.Tenerif. & f. 40,8 Soria & 24,6 Pamplona & 26,0 Toledo & 16,9 Vitoria & 45,3 Alicante & 29,2 \\
\hline Ourense & 39,6 Segovia & 24,5 Ávila & 25,8 Guadalaj. & 15,6 S.Sebast. & 44,9 Palma & 29,2 \\
\hline Toledo & 39,5 Vitoria & 24,4 Sevilla & 24,5 Almería & 15,1 Tarragona & 44,8 Cáceres & 29,0 \\
\hline Valladolid & 38,9 Pamplona & 22,1 Ourense & 24,2 Málaga & 14,6 Bilbao & 44,7 Málaga & 27,8 \\
\hline Santander & 38,5 Madrid & 19,9 Madrid & 24,2 Pontevedra & 14,5 Valladolid & 44,0 Almería & 26,6 \\
\hline Cuenca & 38,4 S.Sebast. & 18,3 Teruel & 23,9 León & 14,3 Toledo & 43,6 Albacete & 26,4 \\
\hline Castellón & 37,5 A Coruña & 18,3 Valencia & 22,8 Lleida & 12,7 Teruel & 43,6 Jaén & 23,2 \\
\hline Granada & 36,9 Salamanca & 16,2 Palma & 22,8 Cáceres & 10,0 Zamora & 41,9 Pontevedra & 15,4 \\
\hline C.Real & 36,9 Ávila & 15,4 Santander & 22,6 Murcia & 7,2 Cuenca & 41,9 Murcia & 14,2 \\
\hline Zamora & 35,6 Cádiz & 13,8 Zamora & 22,4 Lugo & 3,5 C.Real & 41,7 Lugo & 14,1 \\
\hline
\end{tabular}

Fuente: I.N.E. Censos de la población de España. 
Tras el final de la etapa republicana y de la guerra, en A Coruña la evolución de los indicadores demo-económicos sufrió una alteración respecto a la tendencia del primer tercio del siglo. La población inactiva, mayoritaria en la ciudad, que había experimentado un descenso en los años diez y veinte, cambió de tendencia, aumentando ligeramente (Cuadro 2.4) ${ }^{27}$. La principal distorsión provino del incremento de la ocupación no económica tradicionalmente más importante, los miembros de la familia, es decir, los individuos dedicados a trabajos domésticos, que representaban en 1940 un $28,2 \%$ de la población total, en su totalidad mujeres. Esto revela la existencia de una fuerte corriente inmigratoria femenina hacia la ciudad, tanto de mujeres retornadas de las primeras oleadas de emigración hacia América como, sobre todo, del medio rural.

La otra gran fuerte de distorsión provino del aumento de la población inactiva, por la vía de la extensión de la escolarización (Costa Rico, 1980: 31). Además, la población incluida en los primeros tramos de la educación creció más entre las mujeres que entre los varones, lo que ayuda a explicar el fuerte aumento de los inactivos entre las primeras. Los estudiantes de enseñanza secundaria y superior también crecieron, pero en ambos casos con una mayor participación masculina.

Por lo que respecta a la población activa, sobresale una consecuencia del desencadenamiento de la Guerra Civil y de la instauración del franquismo: el formidable crecimiento de las fuerzas de seguridad, en especial del ejército, como consecuencia de la movilización de reclutas durante y después del conflicto.

Por otra parte, el sector más beneficiado de la evolución urbana durante los años treinta fue el de la construcción, circunstancia que se halla en estrecha relación con el crecimiento del parque de viviendas construidas que muestra el Nomenclátor, de manera que los oficios y profesiones vinculados crecieron de manera muy considerable. Estas subidas sirvieron para compensar la brutal caída del empleo industrial.

En 1930, el sector económico que había experimentado un mayor crecimiento era el terciario (Cuadro 2.5). En vísperas de la guerra el sector ascendió posiciones a un ritmo vertiginoso, pues pasó de representar el 46,20\% en 1920 a un 55,2\% en 1940. Este aumento se hizo en detrimento, en términos relativos, del sector industrial, todavía en crecimiento hasta 1930, pero en plena crisis tras el cambio del ciclo de los años treinta.

A nivel nacional, numerosas ciudades habían dado síntomas de atravesar una situación de crisis con anterioridad a 1929, incluso desde bastantes años antes. La depresión y la Guerra Civil, en realidad, complicaron el escenario, incrementando las diferencias de crecimiento entre los tres grupos en que usualmente se han dividido las ciudades que integraban la jerarquía urbana.

\footnotetext{
27 La principal responsabilidad de esta regresión correspondió a la población femenina cuyos inactivos se incrementaron notablemente, lo que en buena medida se explica por el retroceso femenino en el acceso al mercado laboral provocado por el franquismo y la influencia clerical en la "nueva" sociedad.
} 


\section{Cuadro 4.6. Distribución de las capitales de provincia españolas en 1930, por su posición en el ranking de los sectores primario, secundario y terciario (en porcentaje).}

\begin{tabular}{|c|c|c|c|c|c|c|}
\hline & Primario & & Secundario & & Terciario & \\
\hline Murcia & 38,7 Teruel & 8,7 Barcelona & 72,4 Vitoria & 39,4 Ceuta & 73,2 Las Palmas & 47,0 \\
\hline Castellón & 31,8 Oviedo & 8,4 Sevilla & 60,5 S.Sebastián & n 37,8 Melilla & 66,9 Pontevedra & 45,5 \\
\hline Jaén & 30,7 S.Sebastián & 6,5 Zamora & 54,1 Lleida & 37,7 Salamanca & 64,1 Valencia & 45,4 \\
\hline Córdoba & 29,5 Huelva & 6,2 S.C.Tenerif. & 53,1 Palencia & 37,3 León & 61,9 Huelva & 45,4 \\
\hline Pontevedra & 24,1 Soria & 6,0 Palma & 50,6 León & 36,9 Cádiz & 61,8 Lleida & 44,3 \\
\hline Ourense & 22,7 Burgos & 5,7 Teruel & 49,7 Badajoz & 36,8 Huesca & 60,8 Granada & 43,5 \\
\hline Badajoz & 22,1 Zamora & 5,2 Las Palmas & s 49,1 Segovia & 36,8 Segovia & 60,4 Oviedo & 43,4 \\
\hline Lugo & 21,6 Melilla & 5,1 Lugo & 48,9 Logroño & 36,7 Soria & 58,6 Teruel & 41,5 \\
\hline Albacete & 18,0 Pamplona & 4,6 Huelva & 48,5 Zaragoza & 36,4 Burgos & 58,0 Badajoz & 41,2 \\
\hline Lleida & 18,0 Las Palmas & 3,8 Oviedo & 48,2 Burgos & 36,3 Girona & 57,2 Málaga & 41,1 \\
\hline Málaga & 16,8 Santander & 3,8 Albacete & 48,1 Cádiz & 35,7 Pamplona & 55,8 Zamora & 40,7 \\
\hline Granada & 16,3 Valladolid & 3,1 A Coruña & 47,2 Soria & 35,3 S.Sebastián & 55,6 Palma & 39,9 \\
\hline Cáceres & 16,0 Segovia & 2,9 Cáceres & 46,3 Murcia & 35,3 Ávila & 54,3 Córdoba & 38,8 \\
\hline Zaragoza & 15,3 A Coruña & 2,7 Valencia & 45,7 Alicante & 34,1 Alicante & 54,0 Sevilla & 38,0 \\
\hline Huesca & 13,0 Cádiz & 2,4 Santander & 45,2 Salamanca & a 33,5 Ourense & 53,6 Cáceres & 37,6 \\
\hline Vitoria & 12,7 Salamanca & 2,4 Valladolid & 45,0 Córdoba & 31,7 Logroño & 53,2 Castellón & 37,2 \\
\hline Alicante & 11,9 Girona & 2,3 Ávila & 44,0 Castellón & 31,0 Palencia & 51,9 S.C.Tenerif. & 36,9 \\
\hline Palencia & 10,8 Ceuta & 1,8 Málaga & 42,1 Pontevedra & a 30,3 Valladolid & 51,8 Albacete & 33,9 \\
\hline Logroño & 10,2 Ávila & 1,7 Jaén & 41,0 Melilla & 28,0 Santander & 51,0 Lugo & 29,5 \\
\hline S.C.Tenerif. & 9,9 Sevilla & 1,6 Girona & 40,5 Huesca & 26,2 A Coruña & 50,0 Jaén & 28,3 \\
\hline Palma & 9,5 León & 1,2 Granada & 40,2 Ceuta & 24,9 Zaragoza & 48,3 Barcelona & 26,9 \\
\hline Valencia & 8,9 Barcelona & 0,7 Pamplona & 39,6 Ourense & 23,7 Vitoria & 48,0 Murcia & 26,0 \\
\hline
\end{tabular}

Fuente: I.N.E. Censos de la población de España.

Por un lado, las ciudades industriales no sólo habían conseguido efectuar su despegue, sino que continuaron creciendo, al menos hasta el inicio de la depresión. Pero las capitales medias que habían intentado despegar en las coyunturas favorables (etapa dictatorial), simplemente desarrollaron y consolidaron su aparato terciario, ya notable antes del siglo XX, aunque éste se hallase excesivamente sesgado hacia servicios tradicionales o administrativos, en vez de hacia sectores más modernos (Cuadro $4.5 \mathrm{y}$ 
Cuadro 4.6) $)^{28}$. En estas ciudades, los intentos de industrialización cristalizaron en el establecimiento de talleres y espacios industriales apenas esbozados. Eran ciudades cuya área de mercado se ceñía al estricto marco local o, a lo sumo, regional, con una muy escasa competitividad exterior. Así, muchas pequeñas capitales de provincia quedaron definitivamente atrás, enraizadas en el provincialismo (García Merino, 1987: 9).

\section{Cuadro 4.7. Principales actividades socioeconómicas en A Coruña, 1940 (hombres, porcentajes).}

\begin{tabular}{|c|c|c|c|c|c|c|c|c|}
\hline \multirow[b]{2}{*}{$\begin{array}{l}\text { Profesiones/grupos } \\
\text { de edad }\end{array}$} & \multicolumn{8}{|c|}{ Hombres } \\
\hline & $<15$ & $15-19$ & $20-29$ & $30-39$ & $40-49$ & $50-59$ & $60+$ & Total \\
\hline Pesca & 0,01 & 2,15 & 2,26 & 4,86 & 4,51 & 4,92 & 3,44 & 2,48 \\
\hline Carpintería & 0,02 & 3,20 & 1,98 & 4,13 & 4,53 & 5,50 & 4,72 & 2,50 \\
\hline Trabajo de los metales & 0,03 & 4,80 & 2,35 & 3,68 & 2,46 & 2,12 & 1,35 & 2,08 \\
\hline Albañilería & 0,04 & 5,35 & 3,77 & 7,50 & 6,03 & 5,85 & 4,43 & 3,84 \\
\hline Industrias diversas & 0,29 & 12,96 & 3,46 & 5,17 & 7,99 & 8,00 & 6,84 & 4,66 \\
\hline Comercios diversos & 0,02 & 1,73 & 1,61 & 3,50 & 3,40 & 3,86 & 1,79 & 1,80 \\
\hline Servicio doméstico & 0,01 & 0,19 & 0,08 & 0,09 & 0,08 & 0,13 & 0,33 & 0,09 \\
\hline Ejército & 0,04 & 11,00 & 49,66 & 4,30 & 3,08 & 3,18 & 1,65 & 14,95 \\
\hline Administración Pública & & 0,15 & 1,18 & 3,21 & 4,04 & 4,18 & 3,95 & 1,69 \\
\hline Alumnos $1^{\mathrm{a}}$ enseñanza & 62,34 & & & & & & & 17,44 \\
\hline Estudiantes & 3,65 & 26,48 & 3,79 & 0,38 & & & & 4,52 \\
\hline \multicolumn{9}{|l|}{ Miembros de la familia } \\
\hline Alumnos & 30,52 & & & & & & & 8,54 \\
\hline Total & 96,97 & 68,01 & 70,14 & 36,82 & 36,12 & 37,74 & 28,50 & 64,59 \\
\hline
\end{tabular}

Fuente: I.N.E. Censos de la población de España.

A Coruña no encaja en el patrón de las capitales marginadas del crecimiento urbano, pero sí soportó un cierto fracaso en su industrialización, pues una parte de su tejido industrial quedó liquidado en los años treinta, mientras las ciudades con un sector secundario más sólido, aunque afectadas por la crisis, resistieron, hasta que la política económica franquista de posguerra acudió en su auxilio. Esto explica que en 1930 A Coruña, a pesar del crecimiento del número de efectivos industriales que tuvo lugar durante las dos primeras décadas del siglo, perdiese posiciones a nivel nacional dentro del sector secundario. El retroceso del sector terciario con respecto al resto 
de capitales de provincia españolas se explica por la excesiva atrofia del empleo que experimentaron las ciudades pequeñas hacia funciones burocráticas asociadas a la capitalidad. La ciudad debió, así, esperar varios años (casi tres décadas) hasta que las políticas estatales de promoción industrial, local y regional, favorecieron un nuevo despegue del sector.

\section{Cuadro 4.8. Principales actividades socioeconómicas en A Coruña, 1940 (mujeres y total, porcentajes).}

\begin{tabular}{|c|c|c|c|c|c|c|c|c|c|}
\hline \multirow[b]{2}{*}{$\begin{array}{l}\text { Profesiones/grupos } \\
\text { de edad }\end{array}$} & \multicolumn{8}{|c|}{ Mujeres } & \multirow[t]{2}{*}{ Total } \\
\hline & $<15$ & $15-19$ & $20-29$ & $30-39$ & $40-49$ & $50-59$ & $60+$ & Total & \\
\hline Pesca & & 0,06 & 0,18 & 0,30 & 0,59 & 0,67 & 0,32 & 0,23 & 1,31 \\
\hline Carpintería & & & & & & & & & 1,20 \\
\hline Trabajo de los metales & & & & & & & & & 1,00 \\
\hline Albañilería & & & & & & & & & 1,85 \\
\hline Industrias diversas & 0,16 & 3,50 & 2,05 & 2,36 & 1,74 & 1,58 & 2,48 & 1,70 & 3,12 \\
\hline Comercios diversos & & 0,26 & 0,24 & 0,18 & 0,34 & 0,22 & 0,20 & 0,17 & 0,95 \\
\hline Servicio doméstico & 0,18 & 10,38 & 14,68 & 8,15 & 7,17 & 7,30 & 4,19 & 6,97 & 3,66 \\
\hline Ejército & & & & & & & & & 7,18 \\
\hline Administración Pública & & 0,60 & 0,67 & 0,44 & 0,22 & 0,37 & 0,12 & 0,33 & 0,98 \\
\hline Alumnos $1^{\mathrm{a}}$ enseñanza & 61,74 & & & & & & & 16,84 & 17,13 \\
\hline Estudiantes & 2,40 & 16,36 & 1,88 & 0,05 & & & & 2,65 & 3,55 \\
\hline Miembros de la familia & 2,66 & 61,77 & 71,31 & 77,91 & 78,09 & 77,95 & 76,05 & 54,33 & 28,22 \\
\hline Alumnos & 31,74 & & & & & & & 8,66 & 8,60 \\
\hline Total & 98,88 & 92,93 & 91,01 & 89,39 & 88,15 & 88,09 & 83,36 & 91,88 & 78,75 \\
\hline
\end{tabular}

Fuente: I.N.E. Censos de la población de España.

Tras el inicio de la crisis, la economía de A Coruña experimentó un proceso involutivo, de retraimiento hacia actividades orientadas al mercado urbano y regional, perdiendo competitividad y mercados fuera del marco metropolitano y provincial. La alternativa fue el crecimiento del mercado local, que experimentó un considerable aumento, gracias al incremento de la población comentado. En cambio, los negocios que mantenían relaciones con otros puertos regionales, nacionales o extranjeros, sufrieron las consecuencias de la caída del tráfico mercantil e industrial.

En el contexto de la crisis, las tentativas locales de desarrollo estaban en alto grado abocadas al fracaso, si la base de partida era insuficiente. El sistema económico estaba 
más integrado que en el siglo XIX. Por tanto, la ciudad se hallaba sometida a múltiples factores exógenos y a decisiones tomadas en otros lugares. Las ciudades dotadas de pequeños sectores industriales carecieron de efectos multiplicadores. De ahí que todavía a la altura de los años treinta, el desarrollo de una actividad industrial no básica se viese constreñido por las fluctuaciones de la oferta y la demanda campesinas y, por tanto, por las condiciones de la actividad agraria (Delgado, 1995: 59).

\section{EL SECTOR COMERCIAL Y SU CRECIMIENTO COMPARATIVO}

\subsection{Estructura de las actividades comerciales}

Con la llegada del cuarto decenio, el comercio experimentó un crecimiento realmente notable, pasando a representar aproximadamente tres cuartas partes del total recaudado (Cuadro 2.11) y cerca de dos tercios del total de contribuyentes (Cuadro 2.10). Paradójicamente, en un período de crisis económica, estas actividades parecieron mantener un comportamiento mucho más positivo que los demás sectores. Esto avala la hipótesis de que la ciudad se estaba orientando aún con más fuerza hacia una función comercial y de servicios, a pesar de que este último conjunto de actividades pareció experimentar una cierta ralentización en los años previos a la Guerra Civil. La contienda, sin embargo, interrumpió este proceso y la economía urbana tuvo aún que esperar algunos años para continuar con su dinámica de crecimiento (Mirás, 2004d).

De acuerdo a los datos proporcionados por los censos, el comercio seguía constituyendo una de las principales actividades económicas desplegadas en A Coruña a principios de los años treinta, manteniendo un peso semejante al que detentaba a principios de siglo (Cuadro 4.9). Sin embargo, el comportamiento del sector fue bastante heterogéneo. La crisis económica afectó a algunas actividades comerciales; pero los segmentos menos especializados del sector, las actividades de alimentación y textiles, se mantuvieron en buena medida a salvo y continuaron creciendo.

El sector alimenticio creció de forma espectacular, con mucha más intensidad que los textiles. No fue, con todo, el aumento más pronunciado. Otros sectores lo hicieron en mayor medida fruto también de unos niveles de partida más bajos. La crisis no pareció afectarles de forma notoria, pero esta evolución esconde comportamientos muy heterogéneos en su seno. Los que resultaron más afectados fueron los principales empresarios, debido a la paralización del movimiento mercantil. Lo prueba el hecho de que, habiendo aumentado el número de contribuyentes, no lo hicieron en igual medida las cuotas, pese al fuerte incremento tributario derivado de las nuevas tarifas ${ }^{29}$. Esto revela una vez más el carácter fundamentalmente minorista del comercio coruñés, muy acentuado en el sector de la alimentación.

$29 \quad$ Las últimas aprobadas fueron las de 1926 (Decreto Ley de 11 de mayo de 1926). Posteriormente se efectuaron algunas adiciones y modificaciones en el impuesto, así como algunos recargos (un 20\% por Ley de 11 de marzo de 1932, para remediar el paro obrero y otra décima por Orden de 31 de octubre de 1931, con el mismo fin). 


\section{Cuadro 4.9. Distribución de las actividades económicas en A Coruña en 1930 (\% de población activa).}

\begin{tabular}{ll}
\hline Industrias varias & $28,84 \%$ \\
\hline Servicio doméstico & $13,47 \%$ \\
\hline Comercio & $11,21 \%$ \\
\hline Fuerza pública & $9,10 \%$ \\
\hline Transportes & $6,31 \%$ \\
\hline Profesiones liberales & $5,58 \%$ \\
\hline Industrias textiles & $4,86 \%$ \\
\hline Industrias químicas & $4,64 \%$ \\
\hline Agricultura, ganadería, pesca, silvicultura & $2,68 \%$ \\
\hline Total & $86,70 \%$ \\
\hline
\end{tabular}

Fuente: I.N.E. Censo de la Población de España, 1930.

Cuadro 4.10. Resultados de algunas empresas del ramo de la alimentación, 1931-35.

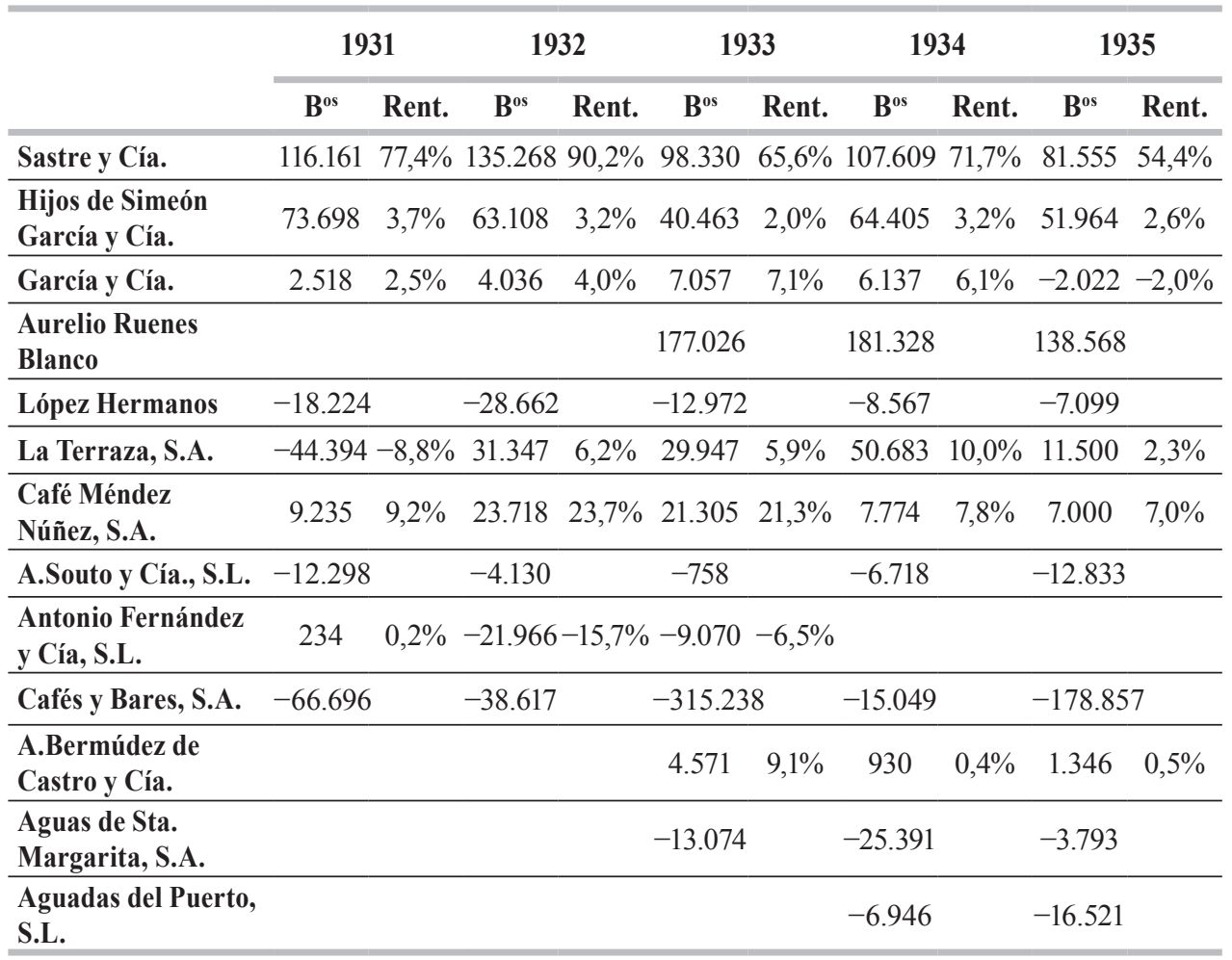


Los negocios de alimentación atravesaron una situación delicada, con caídas de los beneficios e incluso importantes quebrantos empresariales, de los que salieron más perjudicados los negocios de mayor tamaño, especialmente aquéllos que tenían en los mercados español y gallego su campo de acción ${ }^{30}$. Las continuas oscilaciones de los precios en los centros productores y en los artículos de importación (agravada por las incertidumbres derivadas de las fluctuaciones monetarias) y el incremento de la presión fiscal sobre numerosas ramas productivas y comerciales no contribuyó a movilizar la demanda agregada, causando un efecto rebote que se transmitía de sector en sector. Además, los gastos generales aumentaron considerablemente, por efecto del incremento de los gastos salariales, aunque esto fuese común al conjunto de la economía urbana.

Sin embargo, en términos comparativos, los resultados eran mejores que en otros sectores económicos urbanos. Aunque los beneficios no fueron elevados, dado que se lograron a menudo con una reducción de los ingresos brutos por venta - provocados por la caída de los precios-, el declive de la demanda perjudicó con mayor crudeza a los sectores comercializadores de mayor elasticidad-renta.

En el sector textil los incrementos numéricos y cuantitativos fueron similares (incluso en 1931 aumentaron más sus cuotas). La estructura del sector era también básicamente minorista y no se modificó sustancialmente durante el período de entreguerras. Su crecimiento se vio un tanto ralentizado, aunque conservando una línea de evolución que se mantuvo prácticamente constante durante estos veinte años.

Cuadro 4.11. Resultados de algunas empresas del ramo textil, 1931-35.

\begin{tabular}{|c|c|c|c|c|c|c|c|c|c|c|}
\hline & \multicolumn{2}{|c|}{1931} & \multicolumn{2}{|c|}{1932} & \multicolumn{2}{|c|}{1933} & \multicolumn{2}{|c|}{1934} & \multicolumn{2}{|c|}{1935} \\
\hline & $\mathbf{B}^{o s}$ & Rent. & $\mathbf{B}^{\text {os }}$ & Rent. & $\mathbf{B}^{\text {os }}$ & Rent. & $\mathbf{B}^{\text {os }}$ & Rent. & $\mathbf{B}^{o s}$ & Rent. \\
\hline $\begin{array}{l}\text { Antonio Pernas } \\
\text { y Hnos. }\end{array}$ & & & & & -41.089 & $-103 \%$ & & & & \\
\hline Pernas y Piñón & & & 910 & $4,5 \%$ & 410 & $2,1 \%$ & & & & \\
\hline $\begin{array}{l}\text { Dionisio Manovel y } \\
\text { Cía, S.L. }\end{array}$ & 723 & $0,8 \%$ & 635 & $0,7 \%$ & -4.788 & $-5,3 \%$ & -6.446 & $-7,2 \%$ & -1.789 & $-2,0 \%$ \\
\hline $\begin{array}{l}\text { Escudero y } \\
\text { Rodríguez }\end{array}$ & -399 & $-0,2 \%$ & 1.198 & $0,5 \%$ & -4.102 & $-1,6 \%$ & -8.559 & $-3,4 \%$ & -16.112 & $-6,4 \%$ \\
\hline $\begin{array}{l}\text { Hijos de Olmedo } \\
\text { y Cía. }\end{array}$ & 7.473 & $3,6 \%$ & 3.764 & $1,8 \%$ & 6.162 & $2,9 \%$ & 1.077 & $0,5 \%$ & 785 & $0,4 \%$ \\
\hline A. Ansede y Cía. & 14.020 & $4,7 \%$ & 1.089 & $0,4 \%$ & 489 & $0,2 \%$ & 647 & $0,2 \%$ & 846 & $0,3 \%$ \\
\hline Francesch y Cía., S.L. & & & 3.600 & $4,5 \%$ & 2.631 & $3,3 \%$ & 3.600 & $4,5 \%$ & 434 & $0,5 \%$ \\
\hline $\begin{array}{l}\text { Soto, Otero } \\
\text { y Fernández }\end{array}$ & & & & & -23.375 & $-9,3 \%$ & 651 & $0,3 \%$ & 1.266 & $0,5 \%$ \\
\hline
\end{tabular}

Fuente: ARG-DHC (Hacienda). Utilidades.

30 De "honda crisis económica" calificaba La Mercantil Cívico Militar la situación en su memoria del año 1931, p. 8. 
El comportamiento de la comercialización de productos textiles estuvo estrechamente vinculado a la evolución del sector industrial en España y en Galicia. Los mercados regional y urbano se hallaban en fase de contracción, por efecto de la caída de la demanda. Sin embargo, el endurecimiento de la competencia entre productores regionales y catalanes dio origen a una guerra de precios. De hecho, tanto las empresas productoras como las comercializadoras incrementaron sus volúmenes de venta. Por tanto, el sector comercial coruñés resistió el embate de la crisis, gracias a la disminución de los precios, permitiendo el sostenimiento del volumen de ventas. Ahora bien, los márgenes se redujeron, siendo más agudo el problema en las empresas de mayor tamaño, debido a la mayor componente de gastos generales, mientras que los negocios más pequeños sobrellevaban, aunque de manera precaria, la crisis económica.

Así pues, llegados a los años treinta se reforzaron algunos de los rasgos que ya descubrimos durante los años anteriores en la evolución del comercio coruñés: minifundismo empresarial, aumento del número de contribuyentes, principalmente de los más pequeños, freno de algunas actividades relacionadas con el exterior, etc.

El sector de los combustibles minerales, muy sensible a las variaciones de la demanda de los transportes, la pesca y las actividades industriales, recibió directamente el impacto de la crisis. Lo habitual en estos negocios era el entrecruzamiento con otros tipos de actividades, ya que los empresarios pesqueros (armadores) se dedicaban al suministro de combustibles, o se agrupaban para crear sociedades más potentes que obtuviesen concesiones de depósitos de carbón y/o otros combustibles minerales. Otra circunstancia que se repetía con frecuencia era su vinculación con los negocios de transporte e incluso con las actividades de venta de automóviles y accesorios. Por ello, resulta complicado discernir la procedencia exacta de los resultados de sus negocios, al carecer de memorias individualizadas, y contar, en el mejor de los casos, con balances muy simplificados.

En cualquier caso, la norma era la dificultad para acceder a suministros regulares, y en condiciones ventajosas de calidad y precio, de carbón mineral y petróleo. La minería española del carbón experimentó una fuerte contracción durante los años treinta, aunque los canales de importación también se habían visto sometidos a fluctuaciones derivadas de las crisis productivas y de precios de los suministradores tradicionales. Los transportes se hallaban afectados por una dura recesión, nacida de la caída de los intercambios comerciales. Tanto el transporte por vía marítima como por ferrocarril y carretera disminuyeron considerablemente, trasladando sus efectos inducidos a las empresas de transporte. Al mismo tiempo, la actividad pesquera atravesaba unos años difíciles. En consecuencia, el sector de los combustibles padeció los efectos por la vía tanto de la oferta como de la demanda ${ }^{31}$.

\footnotetext{
31 En el Cuadro 4.4 se han detallado los beneficios de algunos armadores coruñeses. De ellos, Armadores de Buques Pesqueros, S.L. y Pérez, Alejo y Cía., S.L. desarrollaban actividades de suministro de combustibles. Sus resultados no se vieron excesivamente perjudicados por la crisis, gracias a la diversificación de sus negocios. Sin embargo, empresas como Sucesores de Manuel Fernández Abella. S.R.C. vieron decaer su rentabilidad al $1-3 \%$ de su capital social (de 240.000 pts.) y oscilar sus beneficios: $1932=7.016,8$ pts.; $1933=-12.654,3 ; 1934=2.962,9 ; 1935=2.528,5$. En este caso, las pérdidas tuvieron su origen en una caída de las ventas y en un crecimiento de las deudas con los proveedores. Por su parte, la sociedad concesionaria Depósito Flotante de Carbones de La Coruña, S.L. también tuvo pérdidas durante algunos años, a pesar de que el depósito coruñés era uno de los de mayor movimiento del país, con un tráfico de importación de carbón cercano a las 40.000 tms anuales, sólo superado por Vigo y Pasajes. ARG-DHC (Hacienda). Utilidades. Anuario Estadístico de España, 1931, p. 243.
} 
Otros sectores, como las joyerías, se comenzaron a recuperar, y de forma importante, en los años treinta, si bien el decaimiento comercial de la ciudad volvió a perjudicarles conforme nos acercamos a la Guerra Civil. Como sector dirigido a la demanda de lujo, la rúbrica correspondiente a joyerías propiamente dichas sufrió una considerable caída, que reflejan los balances de las empresas. Por el contrario, proliferaron los establecimientos de venta de quincalla y bisutería ordinaria, más ajustados a las necesidades de la demanda en tiempo de crisis.

El sector de los curtidos experimentó un notable y llamativo repunte durante los años treinta, multiplicando por cinco el número de establecimientos de venta. La causa está en el mayor número de tiendas de otras clases que se incluyeron en el sector en esos dos últimos censos, por ejemplo, establecimientos de guantes y calzados, que en los anteriores censos no existían, y no únicamente en un incremento de los establecimientos de venta de curtidos en sentido estricto.

La supervivencia comercial durante los años treinta pasó en buena medida por la diversificación de los negocios y por la multiplicidad de las demandas. Es el caso de las empresas del sector de la ferretería y similares, que se beneficiaron del crecimiento y pluralización del mercado que tuvo lugar durante el primer tercio del siglo. Las empresas contaban con un variado abanico de posibilidades de venta, desde bienes de consumo ordinario a otros más especializados y de lujo. Como resultado de ello, las cuentas de resultados consolidadas reflejaban la mayor complejidad de sus stocks, distinguiendo a menudo las ventas y los beneficios que se obtenían por categorías de productos. Algunas de las empresas del sector, además, operaban en otras plazas regionales y contaban con una clientela importante en el medio rural, lo que les permitía una mayor flexibilidad comercial que los negocios orientados exclusivamente hacia el mercado urbano. Incluso dentro de la ciudad, algunas de ellas contaban con varios establecimientos de venta, en los que se solían disociar los diferentes segmentos de mercado a los que se dirigían.

\section{Cuadro 4.12. Resultados de algunas empresas del ramo de la ferretería y la automoción, 1931-35.}

\begin{tabular}{|c|c|c|c|c|c|c|c|c|c|c|}
\hline & \multicolumn{2}{|c|}{1931} & \multicolumn{2}{|c|}{1932} & \multicolumn{2}{|c|}{1933} & \multicolumn{2}{|c|}{1934} & \multicolumn{2}{|c|}{1935} \\
\hline & $\mathbf{B}^{\text {os }}$ & Rent. & $\mathbf{B}^{\text {os }}$ & Rent. & $\mathbf{B}^{\text {os }}$ & Rent. & $\mathbf{B}^{\text {os }}$ & Rent. & $\mathbf{B}^{\text {os }}$ & Rent. \\
\hline \multicolumn{11}{|l|}{ FERRETERÍA } \\
\hline Torres y Sáez & & & 34.792 & $7,0 \%$ & 23.972 & $4,8 \%$ & 26.985 & $5,4 \%$ & 25.721 & $5,1 \%$ \\
\hline $\begin{array}{l}\text { Fernández, Torres } \\
\text { y Cía. }\end{array}$ & 38.303 & $7,3 \%$ & 23.280 & $4,4 \%$ & -2.922 & $-0,6 \%$ & 17.715 & $3,4 \%$ & 20.043 & $3,8 \%$ \\
\hline Suárez Ferrín Hnos & 9.077 & $6,6 \%$ & 3.126 & $2,3 \%$ & & & -1.449 & $-1,1 \%$ & -612 & $-0,4 \%$ \\
\hline \multicolumn{11}{|c|}{ AUTOMÓVILES Y ACCESORIOS } \\
\hline López e Iglesias & 22.241 & $13,4 \%$ & 12.273 & $7,4 \%$ & & & & & & \\
\hline B.J.Carrillo y Jorge & 21.507 & $22,4 \%$ & & & & & & & & \\
\hline $\begin{array}{l}\text { Celestino Pineda } \\
\text { y Cía. }\end{array}$ & 599 & $0,8 \%$ & -22.273 & $-29,7 \%$ & -20.616 & $5-27,5 \%$ & -804 & $-1,1 \%$ & & \\
\hline
\end{tabular}


Finalmente, su carácter de minoristas pero también de intermediarios y almacenistas posibilitaba un espectro más amplio de opciones que las que poseían los establecimientos especializados en una única línea de producto. Por tanto, sus vías de generación de beneficio iban más allá de la estricta enajenación de productos. Algunas de las principales empresas pudieron transitar por este período con un cierto desahogo, aunque la crisis también afectó a sus cuentas de resultados (Cuadro 4.12).

El conjunto de actividades dispersas que integraban el sector de la madera tropieza con dificultades para definirse como un sector propiamente industrial, debido a la heterogeneidad de la oferta y, sobre todo, por tratarse de un sector con una fuerte dependencia del comercio en general, lo que le impedía alcanzar plena autonomía y desarrollo. Un porcentaje muy elevado de los talleres donde se aserraban maderas y se fabricaban cajones eran dependencias anexas de almacenes de maderas. Pero las iniciativas estrictamente industriales configuraban una actividad atomizada y precaria, ya que la mayoría de los fabricantes no comerciantes contaban en sus talleres únicamente con una o dos sierras mecánicas.

En un primer momento, la comercialización de los productos del sector no experimentaron los efectos negativos de la crisis, por cuanto su mercado se situaba principalmente en Galicia y en España, en donde la crisis internacional todavía no había impactado ${ }^{32}$. No obstante, conforme la recesión se iba extendiendo, las consecuencias de la caída de las demandas industriales, de la disminución del ritmo de crecimiento de la construcción urbana, la paralización de la minería, etc. dejaron su huella ${ }^{33}$.

Sin embargo, precisamente la variedad de suministros y de clientes a los que atendían permitió a los empresarios del sector sortear con relativo éxito la coyuntura recesiva, aunque el número de comerciantes registrados se estancase o incluso diminuyese durante los años de la República. El principal problema del sector no era tanto coyuntural sino estructural: la excesiva proliferación de establecimientos de producción y de venta. El sector no se había concentrado suficientemente y apenas se había desarrollado la segunda transformación, con lo que la micro-demanda a nivel local constituía su principal tabla de salvación.

\subsection{Las actividades minoristas sobreviven en un difícil entorno}

Mientras que durante los años treinta el comercio mayorista experimentó una importante crisis, el comercio minorista atravesaba una fase de "auge", pues su número se duplicó entre 1924 y 1931, y se triplicó entre el primer año y 1935, pasando a representar dentro del conjunto del comercio unos porcentajes muy elevados.

\footnotetext{
Aunque la información es incompleta, tanto las empresas fabricantes (Hijos de Emilio Cervigón Carreras, viuda de Antonio Wais) como las dedicadas exclusivamente a la comercialización (Insua y Vizoso, S.L. o Santiago Torrado, C.B.) experimentaron un comportamiento relativamente saneado en sus resultados empresariales, aunque la tendencia de los beneficios es decreciente, dado que las ventas, por efecto de la contracción de los mercados, experimentaron una pronunciada caída. Empresas de pequeño tamaño, como Galán y Aradas, en cambio, soportaron pérdidas de forma continua desde 1932, como consecuencia de la disminución de sus ventas. ARG-DHC (Hacienda). Utilidades.

33 Estudio realizado, op. cit., p. 7. "La madera y la industria de la madera en Galicia", Revista de Economía de Galicia, no 7-8, pp. 61-64 [originalmente editado en 1929].
} 
La Cámara de Comercio atribuía el decrecimiento del comercio mayorista a los cambios en los sistemas de distribución, manifestados en tres aspectos diferentes. En primer lugar, la sustitución del tráfico portuario y ferroviario por el transporte terrestre, mediante la utilización de camiones, lo que contribuyó al debilitamiento de la función distribuidora mercantil de la ciudad. En segundo lugar, la creciente instalación de almacenes en pueblos próximos a A Coruña, así como la ya aludida habilitación de otros puertos del litoral provincial para efectuar operaciones aduaneras, de manera que muchos comerciantes adquirían mercancías por vía marítima y posteriormente la transportaban por vía terrestre ${ }^{34}$.

Por tanto, el comercio continuaba caracterizándose por su minifundismo, pero de manera más acusada que antes de la guerra europea. Lo que López Prado (1968: 197) denominó micro-comercio, tenía una sólida presencia en A Coruña, pero también en las demás ciudades gallegas ${ }^{35}$. Esto se relacionaba en gran parte con la antigüedad de muchos de estos negocios, lo que les permitía conservar todo su sabor tradicional, al ir traspasándose de generación en generación. Sin embargo, repercutía negativamente en la innovación, al existir una cierta resistencia al cambio en algunos de estos comerciantes.

Ahora bien, en los años treinta se aprecia una tendencia que se consolidará en los años sesenta y setenta: la tendencia de los emigrantes a invertir los modestos ahorros obtenidos en su periplo americano en pequeñas tiendas (López Prado, 1968). Lo normal era que la inversión fuese proporcional al pequeño volumen de ahorro disponible. Esta proliferación de comerciantes implica que estas actividades tenían unas dimensiones y una estructura ineficientes (Sande, 1966: 20), aunque en el medio plazo su número experimentase un alza importante. En consecuencia, la sistemática creación de esta clase de comercios servía para atomizar las ventas de los artículos de primera necesidad. Ello dificultaba, además, la posibilidad de contar con unos canales de comercialización más eficientes (López Prado, 1968: 197-198).

Sin embargo, la naturaleza propia de estos negocios provocó un estancamiento de algunos sectores durante esos años. Los años treinta fueron una época de crisis de muchas industrias y de aquellas actividades que mantenían relación con el comercio fuera de la ciudad y, sobre todo, con el comercio internacional (López Prado, 1966: 27). Fueron años de crisis del tráfico portuario (el más afectado, el de pasajeros), de modo que la mayor parte de los negocios marítimos (tanto de servicios como comerciales) atravesaron un período desfavorable, lo que no pareció afectar a los negocios minoristas, cuyo campo de actividad estaba más en contacto directo con la población urbana.

Este crecimiento forma parte de la inercia histórica, pero también de la dinámica del período, que se ajusta al modelo seguido por otras ciudades españolas de rango jerárquico intermedio. Parecen cumplirse en la ciudad los rasgos definitorios del conjunto del sistema de distribución español, caracterizado por un retraso mayor que en otros sectores, especialmente por lo que respecta a la difusión de nuevas formas comerciales (Casares y Briz, 1987).

\footnotetext{
34 Estudio realizado, op. cit., pp. 5-7.

35 Este es un rasgo de largo recorrido. En Galicia, el elemento característico dominante del comercio era su minifundismo, especialmente acentuado en las provincias de Lugo y Ourense. Pero incluso en el resto de España décadas más tarde el gran problema del sector era el excesivo predominio de establecimientos de reducidas dimensiones (Rodríguez Regueiro, 1973: 11-13).
} 


\section{EL SECTOR SERVICIOS Y EL IMPACTO NEGATIVO DE LA CRISIS DE LOS} NEGOCIOS MARÍTIMOS

Durante los años treinta, el sector servicios sufrió una paralización en su evolución. El número de contribuyentes experimentó un crecimiento, pero las cuotas fiscales se estancaron (Cuadro 2.10 y Cuadro 2.11). La explicación más plausible es que las principales actividades (las de mayor peso y mayor cuota, es decir, las que tenían relación directa con los negocios marítimos) atravesaron serias dificultades, mientras que las de menor volumen de negocio mantuvieron sus posiciones e incluso crecieron.

Esta década acarreó un cambio de signo de algunas actividades. Uno de los responsables fue la contracción del movimiento de pasajeros, lo que desincentivó las escalas de las compañías navieras extranjeras ${ }^{36}$. Los negocios portuarios gallegos se hallaban excesivamente supeditados a los condicionantes de la emigración, ligando directamente su suerte a las fluctuaciones económicas internacionales que influían en la movilidad laboral trasatlántica (Vázquez González, 2000a: 939). Por ello, los efectos inducidos de las disminuciones de tráfico citadas se transmitieron a otros sectores, tales como hoteles, agencias de embarque, transportes, etc., alcanzando sus consecuencias a los comerciantes al por menor, como resultado de la disminución de sus ventas ${ }^{37}$. Esta circunstancia resulta coherente con el aparentemente reducido peso (pero de gran alcance) que mantenía el sector exterior en la economía gallega. A pesar de que la relación con el mercado internacional no determinaba de manera trascendental su nivel de actividad, los avatares de la economía mundial irradiaban sus efectos sobre Galicia.

En términos del mercado de mano de obra, la economía gallega funcionaba como una economía abierta (Vázquez González, 2000a: 824). El proceso migratorio trascendía sus efectos exógenos a todo el espacio regional, lo que determinaba que las fluctuaciones migratorias estampasen su huella sobre los grupos portuarios más dependientes de las actividades de importación/exportación y de emigración, pero también sobre el campesinado, a través de una compleja cadena de transmisión.

En A Coruña el fenómeno fue especialmente grave, porque el tráfico de pasajeros se había desplazado durante los años anteriores hacia Vigo (Gráfico 4.2) ${ }^{38}$. Los principales factores que explican ese cambio nacen de las peores condiciones de A Coruña para el trasiego de los emigrantes, del mayor coste de las operaciones en los muelles $\mathrm{y}$, sobre todo, de las menores posibilidades de diversificar la carga, ya que los buques de pasajeros también transportaban mercancías a flete en sus bodegas ${ }^{39}$. Además, en 1929 se otorgó escala facultativa en Vigo a los buques de la Compañía Trasatlántica, lo que perjudicó gravemente los intereses del puerto coruñés ${ }^{40}$.

\footnotetext{
36 Espárrago (1944: 107). Arroyo (2003: 235), quien cita la Memoria de la sede del Banco de Bilbao en A Coruña para el ejercicio de 1930.

37 Estudio realizado, op. cit., p. 15.

38 Vázquez González (1988: 84). En el Gráfico 4.2 se aprecia que la caída no fue demasiado pronunciada en el tráfico total. Pero en ambos puertos se registró una fuerte disminución de los embarques, con una notable subida de los retornados. De hecho, en 1931 entró en Vigo la cifra de desembarcados más alta desde 1922, mientras que el número de embarcados era el más bajo desde 1919 (Cabello, 1931).

39 Estudio realizado, op. cit., p. 16.

40 Galicia industrial y comercial, septiembre de 1931.
} 


\section{Gráfico 4.2. Tráfico de pasajeros en tránsito en A Coruña y Vigo, 1918-36.}

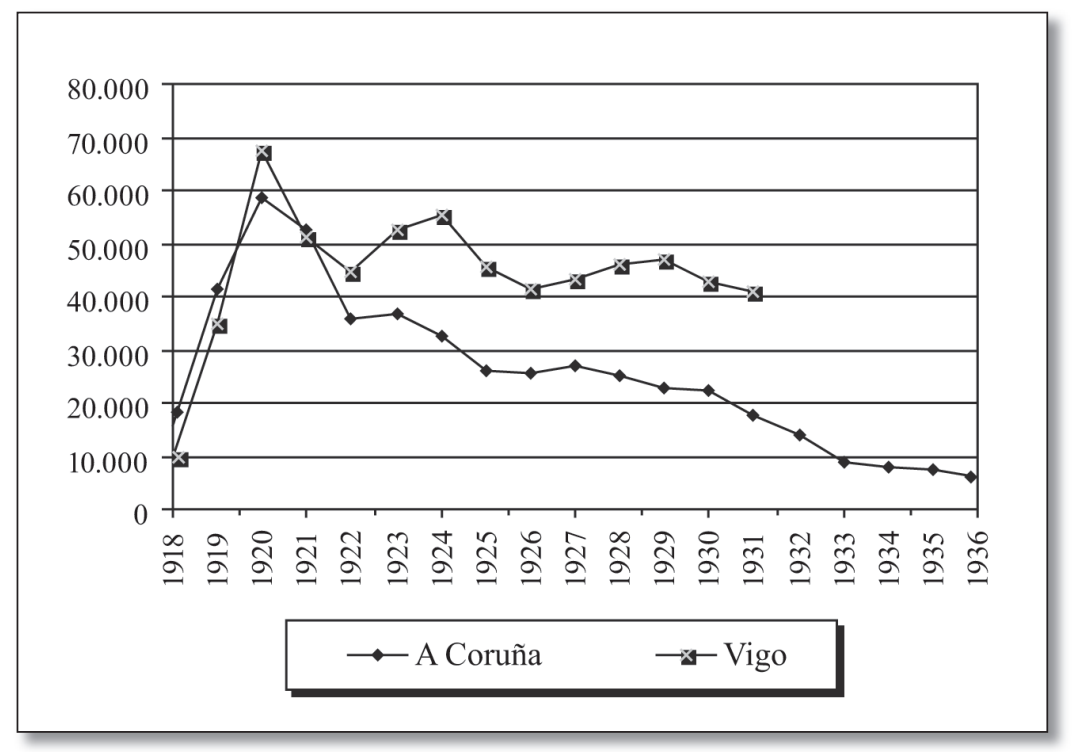

Fuente: Memorias de la Junta de Obras del Puerto de La Coruña y Memoria Comercial de la Cámara Oficial de Comercio, Industria y Navegación, Vigo, 1932.

La caída de este tráfico estuvo acompañada de la del movimiento de mercancías. Si bien entre 1900 y 1930 tuvo lugar un aumento del tráfico mercantil y de pesca, en los años treinta ambos manifestaban una clara paralización. A las causas de este decrecimiento mercantil se refería la Asociación de Consignatarios de La Coruña, que puso de relieve cómo la ciudad se encontraba en condiciones de inferioridad frente a otros puertos de Galicia y del Cantábrico. Desde el inicio de la nueva década, el número de barcos que visitaron el puerto se vio sensiblemente disminuido ${ }^{41}$, lo que puede considerarse un anticipo de lo que habría de ocurrir más adelante, ya que el puerto se constituía como el elemento calibrador fundamental de la mayor o menor presión industrial y comercial dentro de la economía urbana. La razón fundamental que se aducía estaría en el coste del servicio, el más elevado del norte de España ${ }^{42}$.

El efecto multiplicador de la depresión se fue agravando de manera progresiva, toda vez que el mercado internacional fue probablemente el segmento más afectado por la crisis. El bloqueo a la salida de emigrantes y el retorno de muchos de los residentes en América, disminuía los ingresos de numerosos sectores económicos urbanos. A

\footnotetext{
$41 \quad$ López Prado (1966: 27). Según las Memorias de la Junta de Obras del Puerto, la serie de buques que entraron en el puerto con pasajeros evolucionó del siguiente modo: $1922=181$ buques; $1923=250$; $1924=250 ; 1925=269 ; 1926=175 ; 1927=178 ; 1928=178 ; 1929=184 ; 1930=170 ; 1931=135 ;$ $1932=114 ; 1933=118 ; 1934=125 ; 1935=106 ; 1936=76$. Por tanto, se aprecia una clara disminución a partir del inicio de la crisis económica internacional.

42 Estudio realizado, op. cit.
} 
continuación, la economía rural se veía perjudicada por la disminución de ingresos procedentes de la emigración, con lo que se veía reducida su capacidad de demanda agregada. Por otra parte, la deflación incidía en un recorte de las exportaciones, ya de por sí reducidas pero importantes para un campesinado gallego cuya capacidad de respuesta se constreñía por las dificultades de competir vía productividad, debido al retorno a situaciones de saturación del mercado laboral en el campo.

De ahí la continua disminución de la participación del sector servicios. Entre tanto, otras actividades como las de hostelería, hospedajes, etc., u otras que se examinarán más adelante mantuvieron una situación más positiva. Pero éstos eran negocios con cuotas más reducidas, lo que motivaba el aumento del número de contribuyentes globales, sin que fuese acompañado de un incremento en las cuotas.

Cuadro 4.13. Resultados de algunas de las principales empresas de consignación y tránsitos, 1931-35.

\begin{tabular}{|c|c|c|c|c|c|c|c|c|c|c|}
\hline & 1931 & & 1932 & & 1933 & & 1934 & & 1935 & \\
\hline $\begin{array}{l}\text { Hijos de } \\
\text { Benito Ares }\end{array}$ & & & 32.802 & $109 \%$ & 8.460 & $28,2 \%$ & 15.663 & $52,2 \%$ & 12.540 & $41,8 \%$ \\
\hline $\begin{array}{l}\text { Jesús de Labra } \\
\text { y Hermanos } \\
\end{array}$ & 8.082 & $40,4 \%$ & 2.539 & $12,7 \%$ & -1.472 & $-7,4 \%$ & 2.483 & $12,4 \%$ & 2.967 & $14,8 \%$ \\
\hline Herce, S.R.C. & 47.104 & $9,4 \%$ & 28.469 & $5,7 \%$ & 22.076 & $4,4 \%$ & 27.179 & $5,4 \%$ & 25.912 & $5,2 \%$ \\
\hline Vda. Eladio Pérez & -264 & $-0,3 \%$ & 623.380 & $23,4 \%$ & -9.944 & $-9,9 \%$ & -11.124 & $4-11,1 \%$ & $0-21.189$ & $-21,2 \%$ \\
\hline S. de José Pastor & -50.951 & $-5,1 \%$ & -66.426 & $-6,6 \%$ & -65.365 & $-6,5 \%$ & -49.272 & $2-4,9 \%$ & -1.365 & $-0,1 \%$ \\
\hline Rubine e Hijos & & & 49.105 & $3,5 \%$ & 21.620 & $1,5 \%$ & 33.813 & $2,4 \%$ & 28.217 & $2,0 \%$ \\
\hline Labra, Souto y Díaz & 4.806 & $17,2 \%$ & 4.684 & $16,7 \%$ & 4.375 & $15,6 \%$ & 4.109 & $14,7 \%$ & -13.049 & $-46,6 \%$ \\
\hline $\begin{array}{l}\text { Mayor, Sánchez } \\
\text { y Cía. }\end{array}$ & & & -24.360 & & & & & & & \\
\hline Martínez y Antolí & -15.069 & & -7.034 & & & & & & & \\
\hline $\begin{array}{l}\text { Pulpeiro y } \\
\text { Fernández }\end{array}$ & -4.794 & & -42.163 & & & & & & & \\
\hline Agencia Longueira & 9.186 & $15,3 \%$ & 3.020 & $5,0 \%$ & -2.271 & $-3,8 \%$ & -1.774 & $-3,0 \%$ & 313 & $0,5 \%$ \\
\hline López Companioni & & & & & -3.393 & & -6.598 & & -3.133 & \\
\hline
\end{tabular}

Fuente: ARG-DHC (Hacienda). Memorias de las empresas.

Todavía en 1931 se observa un más que notable crecimiento de las actividades de consignación y similares, pero con un descenso en sus cuotas contributivas. Sin embargo, en 1935 se apreciará con claridad la paralización, al dejar de incrementarse el número de estos empresarios, expresión de la fuerte crisis de los negocios marítimos. Analizando algunas de las firmas para las que se dispone de documentación, se ha verificado que las casas dedicadas al negocio de la consignación sufrieron una fuerte 
contracción empresarial, tanto en términos absolutos como con relacción a sus respectivos capitales sociales (Cuadro 4.13). Los años 1932-33 fueron tal vez los más críticos, aunque dentro de una tendencia decreciente de los resultados.

No todas las empresas estaban especializadas únicamente en actividades de consignación, sino que desarrollaban negocios paralelos dentro del sector terciario e incluso labores fabriles (Rubine e Hijos). En el primer caso, el empeoramiento de sus saldos procedió exclusivamente de una drástica reducción de sus cuentas de consignaciones, tránsitos y similares, ya que las partidas de gasto, sobre todo los gastos generales, apenas incidieron en la cuenta de pérdidas y ganancias. La menor componente de la mano de obra en comparación con el comercio o la industria (sectores intensivos en factor trabajo) sin duda influyó en esta circunstancia. Esto ocurría con Jesús de Labra y Hermanos, Herce, S.R.C. o Viuda de Eladio Pérez y Cía., aunque la reducida variación fue común a todas las empresas de este subsector.

Dentro de las diversas partidas de negocio que desarrollaba Sobrinos de José Pastor, la más importante, la de las consignaciones, marcó su déficit. La intermediación en el comercio de compra-venta de madera se mantuvo estable. Sin embargo, el negocio de la consignación sufrió una fuerte contracción. La otra partida origen de quebranto fue el aumento de los intereses abonados a bancos. Por su parte, la cuenta de P y G de Rubine e Hijos era algo más compleja. Con independencia de las partidas correspondientes a fabricación de chocolates (de importancia marginal), se observa una irregular evolución de las utilidades por consignaciones, con tendencia al descenso. Ahora bien, su éxito en esos años se cimentó en la diversificación de sus operaciones ${ }^{43}$.

El otro elemento que continuaba teniendo importancia en los negocios de los empresarios más sobresalientes del sector era la pesca. Como consecuencia de la pérdida del transporte de pasajeros y de la reorientación hacia actividades pesqueras, este negocio cobró gran relevancia en sus operaciones. A Coruña, a principios de los años treinta, necesitaba perentoriamente un muelle pesquero, ya que el número de embarcaciones que trabajaban en el puerto era elevado ${ }^{44}$. Pero la industria pesquera estaba afectada de ciertas carencias y padecía un acusado abandono por parte de las autoridades, que no adoptaron medidas para protegerla de la crisis. Esta fue, probablemente, la causa principal de la caída de las cuotas de estos negocios.

Resulta llamativo el fuerte descenso del sector transporte que tuvo lugar en 1931 y 1935. La causa radica en que desaparecieron de las estadísticas la mayoría de los vehículos terrestres y sólo se conservaron algunos buques ${ }^{45}$. Y su número consiguió mantenerse gracias a la inclusión de otros ingenios (grúas, cabrestantes, etc.) que,

\footnotetext{
43 Las fuentes principales de compensación de estas disminuciones fueron las participaciones en las utilidades de otras empresas y los dividendos generados por acciones en negocios sólidos.

44 A principios de la década, estaban matriculados 25 parejas y 8 bous para la pesca de altura; 16 traineras a vapor para sardina y otras especies; 6 vapores para pesca con palangre de castañeta; 18 ó 20 tarrafas para sardina y otras especies; 25 vapores para bonito; 15 ó 20 motoras para langosta e igual número para congrio. Galicia industrial y comercial, abril de 1931 (Carmona, 1990b: 41).

45 Es preciso tener en cuenta que la documentación empleada no recogía todos los buques existentes en A Coruña, ya que se matriculaban en otros impuestos.
} 
aunque no pertenecían estrictamente a la categoría de vehículos, sí facilitaban la realización de las tareas de carga y descarga de mercancías en el puerto. Aunque el número de empresarios con la consideración de navieros se incrementó de forma importante, sobre todo en 1935, lo que aumentó realmente fue el número de navíos, puesto que sus propietarios eran dueños en muchos casos de varios buques.

Algo similar ocurrió con el sector de la hostelería, que experimentó un fuerte crecimiento en los años treinta. Sin embargo, dicha variación fue un tanto ficticia, debiéndose a que durante los primeros años en la estadística sólo figuraban los principales hoteles, pero no las pequeñas fondas, hospedajes, pensiones, etc., que sí se recogieron en el período republicano y distorsionaron las cifras. De ahí el aumento tan importante de su número, pero no de sus cuotas, que fue considerablemente inferior, ni de sus resultados empresariales, ya que en los casos para los que existe información se aprecia una fuerte contracción en sus resultados empresariales ${ }^{46}$.

Por lo que respecta a los servicios públicos, durante la República la tendencia evolutiva de Aguas de La Coruña no se separó sustancialmente de la línea que venía siguiendo desde el final de la guerra mundial. La principal novedad radicó en el cambio de actitud del Ayuntamiento, menos contemporizadora con la empresa. Las relaciones entre ambas entidades se deterioraron progresivamente, debido a la acumulación de deudas municipales y al creciente desfase entre el consumo estipulado en el contrato de suministro para los servicios del Ayuntamiento y el consumo real. Además, la corporación recibió numerosas quejas desde los barrios periféricos, relativas a la insuficiencia o inexistencia de suministro de agua. Por ello, a partir de entonces se agudizaron las amenazas de municipalización del suministro (que no pasaron del terreno de la mera dialéctica retórica), aunque en el trasfondo se hallaba la ambición del Ayuntamiento de controlar las tarifas y la estrategia de expansión de la compañía (Martínez López et al., 2004: 92, 112).

Las dificultades derivadas de la crisis económica se aprecian en la ralentización del aumento porcentual del número de abonados durante esa década. Con todo, la explotación continuó desenvolviéndose en un marco de crecimiento, en el que el margen representó en torno al $70 \%$ del ingreso de explotación. Pero el principal reto nació del crecimiento urbano, responsable de situaciones de desabastecimiento. El caudal disponible que suministraba la primitiva concesión de principios de siglo se revelaba insuficiente para atender el consumo de la población. La oferta estaba llegando a sus límites, por lo que Aguas de La Coruña inició gestiones en 1935 para lograr aumentar el caudal disponible mediante una nueva concesión. Pero ésta no se consiguió hasta 1939, y el nuevo caudal no estuvo disponible hasta 1941 (Martínez López et al., 2004).

Desde mediados de los años veinte se venían percibiendo signos de estancamiento en la explotación de la Compañía de Tranvías (Piñeiro, 1997). Desde principios de los años treinta se estancó el kilometraje y los gastos de explotación experimentaron

$\overline{46}$ Parisiana, S.A. (Atlantic Hotel): $1931=-12.219,1$ pts.; $1932=-30.771,4 ; 1933=-12.755,4 ;$ $1934=-4.287,6 ; 1935=-7.185,4$. ARG-DHC (Hacienda). Utilidades. 
un ligero crecimiento, mientras que los ingresos oscilaban irregularmente, sin una tendencia clara (Martínez López y Piñeiro, 2001: 26). Hacia 1925 llegaron noticias de que existían proyectos para establecer servicios de autobuses a Sada, a pesar de que la concesión tranviaria atribuía a la compañía la exclusividad en el transporte entre ambas localidades. Sin embargo, en 1932-33 se generalizaron los servicios piratas de autobuses, ejerciendo una competencia presumiblemente desleal con los tranvías, que provocaron fuertes quebrantos a la compañía (Piñeiro, 1997). La crisis de explotación impulsó a la empresa a promover la sustitución de los tranvías por trolebuses, si bien la falta de materiales, unida a la negativa de la Administración a autorizar la importación de los vehículos, retrasaron la inauguración de la primera línea hasta 1951 (Piñeiro, 1997).

La contracción económica de los años treinta incidió en el sistema bancario español. Bastantes bancos atravesaron serias dificultades y algunos tuvieron que cerrar. El año 1931 marca un punto de inflexión, debido a que la atmósfera general de inquietud y expectación ante el ascenso de la República afectó a los círculos empresariales, a la economía en general y a la banca. Pero la situación mejoró en los años siguientes, permitiendo a la banca española salir relativamente bien librada de la depresión (Tortella y Palafox, 1984: 105-110).

La recesión se manifestó también sobre la banca coruñesa, que sufrió una apreciable pérdida de negocio. Por un lado, la crisis tuvo como consecuencia un menor drenaje de ahorro, lo que repercutió en el descenso de giros desde América y en una menor captación de pasivo por los bancos ${ }^{47}$. Por otro, el menor volumen de movimientos repercutió en una merma de la inversión en la plaza, en el mercado de valores y en la puesta en circulación de estos recursos a través de la política crediticia o la intermediación comercial. Además, la depreciación de la peseta incidió en la reducción de las transacciones y en una cierta salida de capitales hacia el extranjero, como forma de afrontar la pérdida del valor de la peseta (Arroyo, 1999: 23, 74).

La crisis derivada de la disminución de las intermediaciones con América repercutió con especial intensidad en las sucursales de los bancos Español del Río de la Plata y Anglo South American Bank, ya que su rol como canalizadores de las operaciones en moneda extranjera procedente de la emigración y de las transacciones comerciales perdió progresivamente fuerza (Arroyo, 1999: 74). Pero para los dos bancos autóctonos, los años treinta trajeron asimismo un escenario de creciente competencia, tanto con la banca española, en plena expansión, como con la banca extranjera.

La coyuntura regresiva de 1931-34 incidió en el Banco de La Coruña, a través de la quiebra de dos casas de banca con las que mantenía relaciones (Arroyo, 2001: 23). Los efectos de la crisis se hicieron notar a partir del cierre de 1931, cortando la progresión en que había entrado el banco a finales de los años veinte. Sin embargo, pronto remontó el vuelo, ya que, tras la pérdida de saldos de pasivo-clientes que se registró hasta $1933^{48}$,

\footnotetext{
Arroyo (1999: 23), citando la Memoria del Banco de Bilbao en A Coruña del ejercicio de 1930.

48 Banco de La Coruña. Memoria presentada a los accionistas en la Junta General celebrada el día 17 de febrero de 1934, y correspondiente al décimo-sexto ejercicio anual, desde $1^{\circ}$ enero al 31 diciembre de 1933, La Coruña, p. 5.
} 
se recuperó con relativa celeridad en los dos ejercicios siguientes ${ }^{49}$. Durante la década, el banco no abrió ninguna otra sucursal ${ }^{50}$. Por el contrario, el Banco Pastor, convertido en el principal banco regional, prosiguió su estrategia expansiva, abriendo diez nuevas sucursales en 1931-35 (Cuadro 3.15).

Los recursos totales del Banco de La Coruña alcanzaron su máximo histórico en 1930, y a partir de ahí la tendencia fue de una continuada caída hasta 1934, recuperándose en el ejercicio previo a la guerra (Cuadro 3.10). En cambio, el Pastor se sostuvo con firmeza hasta 1933, por efecto de su estrategia expansiva hacia el mercado regional. 1934 marcó su primera caída en una década, pero se recuperó nuevamente al año siguiente (Cuadro 3.16).

El saldo inversor del Banco de La Coruña experimentó también una continua caída hasta 1934, recuperándose en 1935, aunque sin alcanzar el nivel de 1930 (Cuadro 3.4). En general, la política del banco fue de cautela, fijándose como prioridades el reforzamiento de la liquidez y de las previsiones ${ }^{51}$. El impago de créditos obligó al Banco de La Coruña a mantener una política de restricción crediticia, así como una revisión sistemática de las garantías admitidas (Arroyo, 2001: 83), mientras consolidaba su carácter de banco mixto, de manera análoga a la gran banca española (Tortella y Palafox, 1984: 107). El Banco Pastor prosiguió su política inversora intensiva hasta 1934, cuando por primera vez desde 1926 vio disminuir su inversión total. Pero, igual que ocurriera con los recursos totales, se recuperó en 1935.

Finalmente, como resultado de la operativa del Banco de La Coruña, los beneficios líquidos tendieron a contraerse fuertemente hasta 1934. A partir de esa fecha, la rentabilidad sobre recursos propios se recuperó nuevamente (Cuadro 3.14). En cambio, el Banco Pastor, además de un recorte menos dramático de sus beneficios, salió un año antes de la crisis, con una recuperación del ritmo de generación de beneficios que se acercaba a los valores de finales de los años veinte. En general, la coyuntura económica había mejorado en los años 1934-35, aunque el panorama seguía siendo inestable ${ }^{52}$.

Por su parte, la evolución de la Caja de Ahorros discurrió por un camino más positivo del que cabría aguardar. En España, los depósitos de las cajas experimentaron un notable crecimiento, hasta su debilitamiento en 1933 (Hernández Andreu, 1980: 27). Sin embargo, el impacto de la crisis financiera internacional no tuvo repercusiones sobre la actividad diaria de la caja coruñesa que, sin embargo, sí experimentó un gran incremento de los recursos con la llegada de la República, pues las alzas salariales y la contención de precios favoreció un cierto incremento del ahorro de las familias.

\footnotetext{
49 Banco de La Coruña. Memoria presentada a los accionistas en la Junta General celebrada el día 23 de febrero de 1935, y correspondiente al décimo-séptimo ejercicio anual, desde $1^{\circ}$ enero al 31 diciembre de 1934, La Coruña, pp. 5-6.

50 "Breve historia del Banco de La Coruña en sus bodas de oro", en Banco de La Coruña. Bodas de oro 1918-1968, La Coruña, Banco de La Coruña, p. 22.

51 Banco de La Coruña. Memoria del ejercicio de 1933, pp. 6-7.

52 Banco de La Coruña. Memoria del ejercicio de 1934, p. 6. Banco de La Coruña. Memoria presentada a los accionistas en la Junta General celebrada el día 22 de febrero de 1936, y correspondiente al décimo-séptimo ejercicio anual, desde $1^{\circ}$ enero al 31 diciembre de 1935, La Coruña, p. 5.
} 
Con todo, a pesar de que los resultados de la entidad habían sido excelentes en los años veinte, a principios de los treinta la marcha ascendente de los beneficios sufrió una desaceleración, y la guerra cortó una recuperación que en 1935 se empezaba a vislumbrar. En conjunto, la depresión tuvo un efecto más suave en la cartera de las entidades que el producido por la guerra europea (Maixé et al., 2003: 142).

\section{LA CRISIS INDUSTRIAL NACIONAL E INTERNACIONAL DEJA SU HUELLA EN UN SECTOR INSUFICIENTEMENTE ASENTADO EN LA CIUDAD}

En España, a partir de 1931 dio comienzo una crisis industrial que se agravó progresivamente en 1933, cuando la caída de la producción tocó fondo (Carreras, 1990: 161). Sin embargo, la depresión no fue tan acusada como en las naciones industrializadas, tal y como revela el indicador del producto industrial de Carreras (1984), que arroja una tendencia descendente, pero no excesivamente alarmante, para el conjunto del período 1930-35 (Comín, 1991: 119). Sin embargo, el comportamiento fue relativamente heterogéneo (Carreras, 1990: 84).

Las industrias que padecieron con mayor fuerza las consecuencias de la depresión fueron las de bienes de equipo, en especial la siderometalúrgica (Hernández Andreu, 1980: 25, 33-34), en paralelo a la crisis de la minería española de esa década. En cambio, el proceso de redistribución de la renta de los años treinta afectó, aparentemente, de manera positiva al consumo y a las industrias ligeras (Tortella y Palafox, 1984: 109). El teórico aumento del poder adquisitivo popular habría expandido la demanda de alimentos, vestido y otros bienes de consumo ${ }^{53}$. A su vez, el crecimiento de estas industrias generó un efecto sobre otros sectores, que también se habrían visto estimulados por la expansión del producto agrario (Tortella y Palafox, 1984: 109). De este modo, la industria textil (aunque no fue ajena a la depresión estructural) experimentó una leve recuperación durante el período republicano ${ }^{54}$. En cambio, la producción de hierro y acero entró en crisis ya en 1930, cuya causa fue la escasa participación del consumo privado en la demanda de productos metalúrgicos en España, agravada por la drástica interrupción de la demanda del sector público para infraestructuras, especialmente de transporte (Hernández Andreu, 1986: 95).

La industria en la provincia de A Coruña no había alcanzado, en palabras del Consejo de Industria, "un desarrollo grande", cebándose la crisis con especial virulencia sobre el sector industrial ${ }^{55}$. En la ciudad se aprecia (Cuadro 2.21 y Cuadro 2.22) cómo fue el único sector que decayó en términos absolutos. Ésta fue una depresión de mayor calado que la de la guerra europea, lo que demuestra la crítica situación que atravesaba el conjunto de la economía productiva urbana ${ }^{56}$.

\footnotetext{
53 Comín defiende la tesis de que el crecimiento de los salarios en la República no aumentó la demanda de bienes de consumo, ya que el incremento del paro pudo disminuir la masa salarial. Además, el consumo podía depender más de la renta permanente que de la corriente (Comín 1991: 130).

54 Hernández Andreu (1986: 96). Sin embargo, a partir de 1934 se observa que la confluencia de las restricciones monetarias y la inversión de la política salarial generó una restricción de la clientela de las industrias de bienes de consumo, que se unieron de este modo a la crisis de las industrias productoras de materias primas exportables (Vilar, 1986: 44).

55 Apuntes para el momento de la industria española de 1930, op. cit., p. 393.

56 Galicia industrial y comercial, enero de 1930 y diciembre de 1930.
} 
El comienzo de la década no fue precisamente alentador, agudizándose el problema con el paso del tiempo ${ }^{57}$. La crisis de los principales sectores industriales gallegos (ganadería, conserva, pesca, madera, etc.) tuvo su reflejo en la propia estructura industrial coruñesa ${ }^{58}$.

Varios fueron los factores que incidieron en la crisis. Entre otros, el bloqueo a la entrada de divisas de los emigrantes (que se sumó a la drástica reducción del flujo migratorio hacia América), la ruptura de relaciones o la disminución de los intercambios comerciales con varias naciones, los problemas derivados del establecimiento de contingentes en distintos países a consecuencia de la crisis, lo que perjudicó a algunas industrias (especialmente la conservera), la lánguida situación de la industria maderera, debido a las importaciones de estos productos del extranjero, la contracción del mercado interior, que coadyuvó una paralización total o parcial de algunas industrias, etc. Una de las consecuencias más dolorosas fue el elevado paro que se registró en esos años. Para remediarlo, se promulgó una ley contra el paro forzoso, gracias a la cual se inició en toda España un relativo relanzamiento de la industria de la construcción.

Resulta significativo que durante este período se produjese una agudización de los conflictos, lo que indudablemente tuvo su origen en la crisis económica. Pero también guarda estrecha relación con el clima social que propició el nuevo régimen democrático instaurado tras la Dictadura, que había recortado drásticamente la libertad de asociación. En ese ambiente, se produjo en A Coruña una extensión de la implantación de las organizaciones sindicales que desembocó en el inicio de una serie de conflictos que se desataron como medio de alcanzar mejoras socioeconómicas (González Probados, 1983).

La situación no era de completa paralización, ya que algunas industrias experimentaron un cierto empuje. Por ejemplo, la industria de la construcción, gracias a la edificación en la zona del Ensanche (que tuvo un fuerte impulso en los años treinta), el crecimiento de la ciudad hacia la periferia, así como otras obras relacionadas con las infraestructuras urbanas. Además, se registró un sustancial avance en la construcción de viviendas baratas ${ }^{59}$.

Una vez iniciada la década, el número de contribuyentes se incrementó, mientras que las tarifas disminuyeron. De aquí se deduce que la crisis era importante, porque afectó a las industrias de mayor tamaño, lo que terminó por reforzar el minifundismo industrial y las dificultades estructurales del sector, al permitir la subsistencia precaria de industrias de reducidas dimensiones y de escasos efectos inducidos. Este rasgo se siguió manteniendo hasta la última fecha censal. La crisis no corrigió los problemas, por lo que las empresas del sector continuaron siendo pequeñas, en algunos casos con un fuerte carácter artesanal, en una época tan avanzada como las vísperas de la Guerra Civil.

\footnotetext{
57 Galicia industrial y comercial, septiembre de 1931.

58 Galicia industrial y comercial, abril de 1935.

59 Para ello, se había constituido en 1923 una asociación destinada a la construcción de casas baratas en la ciudad. Estatuto Reformado de la Asociación de Cooperativas de Casas Baratas de La Coruña, 1923.
} 
Para finalizar, es necesario insistir en que, a pesar de los problemas y deficiencias que se han detectado en la estructura industrial coruñesa, su significación cualitativa para la economía de la ciudad era notable. Aunque el peso global del sector nunca superó la cuarta parte de los empresarios matriculados por contribución industrial, ni el 13-15\% de las cuotas fiscales, su importancia debe ser valorada, máxime en el contexto de la economía gallega, en donde los centros de desarrollo industrial se reducían a los núcleos vigués y ferrolano. En A Coruña, la diversificación industrial era mayor que en esas dos ciudades, aunque siempre a una escala global considerablemente más reducida.

\subsection{Los problemas de contracción de la demanda dominan el panorama interindustrial}

La estructura industrial de A Coruña no se alejaba de los estándares españoles. Hacia finales de los años treinta la estructura industrial nacional se hallaba claramente dominada por productos simples de consumo: industrias alimentarias (bebidas, tabaco, textiles), y otras industrias manufactureras (vestido, calzado, madera y corcho, artes gráficas, etc.). En definitiva, actividades intensivas en mano de obra, y que tendían a cubrir las necesidades de consumo de una población cuyo bajo nivel de ingreso real implicaba una reducida capacidad de compra (Donges, 1976: 30-32).

La distribución sectorial se mantuvo en los años treinta de manera bastante estable. El principal grupo de actividades continuó asentado en la alimentación, que experimentó un crecimiento importante en su participación relativa sobre las cuotas fiscales. No ocurrió así con los valores absolutos, debido al descenso generalizado de las cuotas en todos los sectores industriales. El número de empresarios disminuyó ligeramente su participación, aunque el número absoluto permaneciese estable. Dentro del sector, la evolución fue divergente, ya que crecieron los compuestos mientras la industria conservera sufría una dura crisis. La crisis en el caso de los destilados fue algo menos pronunciada, permaneciendo los molidos en una situación de estancamiento.

En conjunto, la industria agroalimentaria encajaba con el perfil de una región agropecuaria, a pesar de que la industrialización agraria apenas mostrase algunas iniciativas aisladas. La industria conservera vivió posiblemente su época más problemática durante los años treinta. La recesión llevó a la ruina a algunos conserveros, aunque reforzó a los que ya eran más fuertes, es decir, aquéllos que habían obtenido los mayores beneficios de la guerra mundial y que habían crecido horizontal y verticalmente durante los años anteriores (Carmona, 1998: 161-162). Al inicio de la crisis las expectativas eran pesimistas pero, una vez concluido el primer lustro, la desesperanza invadía al sector. Tras el desencadenamiento de la crisis, las empresas más sólidas pudieron sobrellevar sus efectos, sin unos quebrantos insalvables. Los volúmenes de ventas se sostuvieron con dificultad, arrojando todavía resultados moderadamente lucrativos, dados los tiempos difíciles que corrían ${ }^{60}$. Lo peor estaba por llegar.

$\overline{60}$ La Pesquera del Norte de España, S.A. Memoria. Año 1932. 
Forzados por los impagos de las ventas a los países latinoamericanos, los empresarios reorientaron la producción a partir de los años treinta hacia el mercado interior, alternativa favorecida gracias a la mejora en la distribución de la renta, junto con el descenso en los costes de producción, fruto principalmente del abaratamiento de las materias primas, sobre todo el pescado (Carmona, 2001a: 26). Pero la industria entró en crisis por las razones apuntadas con anterioridad, al ser un sector muy dependiente del movimiento pesquero y de un mercado exterior en recesión durante esos años ${ }^{61}$.

En 1932-33 las cifras de exportación se contrajeron fuertemente. Para contrarrestar esta bajada en las ventas, y para poder competir dentro del mercado nacional, las empresas se vieron forzadoas a rebajar los precios de sus productos. Como consecuencia, los beneficios se resintieron (Cuadro 4.14) ${ }^{62}$. Las políticas de contingentes se extendieron en la mayoría de naciones en 1933-35, a lo que se unieron los bloqueos de divisas en la mayoría de los mercados sudamericanos, reduciendo a un margen muy estrecho las exportaciones, e incluso llegando a hacerlas desaparecer ${ }^{63}$. La guerra comercial desatada desembocó en la puesta en marcha de medidas de castigo a otras naciones, que repercutieron negativamente en esta industria, al bloquear algunos de sus principales mercados. Por tanto, la acumulación de stocks y las caídas de los beneficios fueron la norma en vísperas de la Guerra Civil ${ }^{64}$.

Finalmente, una larga nómina de países adoptó medidas tendentes a impedir la entrada de mercancías de otras naciones, mediante la elevación de los derechos de importación o el establecimiento de contingentes. El primero en cerrarse fue el mercado americano ${ }^{65}$, y a continuación cayó el mercado europeo ${ }^{66}$. Todo ello incidió en un aumento de los precios de los productos, con lo que el consumo interior pagó parte de las consecuencias y dio lugar a una agudización de la depresión económica.

El sector también se vio afectado por la política arancelaria que afectaba a otras materias primas necesarias en la industria, por ejemplo, la hojalata. Frente a ello, los empresarios intentaron alcanzar una solución transitoria, consistente en la fórmula de adquirir hojalata de Francia a cambio de que admitieran en ese país, fuera de contingentes, las conservas de pescado gallegas, aunque la propuesta no prosperó ${ }^{67}$.

En 1935 el panorama había empeorado. Los factores que influyeron en la crisis sectorial continuaban presentes. Las dificultades derivadas del elevado proteccionismo externo persistían y a ello habría que añadir la ruptura de las relaciones comerciales con Francia, la irregularidad en la distribución de contingentes y la propia contracción que experimentó el mercado interior, plenamente afectado ya por la crisis internacional ${ }^{68}$.

\footnotetext{
61 "Valor e importancia de la conservería gallega", Industria Conservera, año I, n” 2, 1934, p. 1.

62 La Pesquera del Norte de España, S.A. Memoria. Año 1933.

63 La Pesquera del Norte de España, S.A. Memoria. Año 1934.

64 La Pesquera del Norte de España, S.A. Memoria. Año 1935.

65 Industrias Pesqueras, 1 de mayo de 1932, p. 9. ACTAS Pleno COCINC.

66 El Pueblo Gallego, 7 de agosto de 1932, p. 1.

67 "Defensa de la industria conservera", El Pueblo Gallego, 31 de diciembre de 1932. El Pueblo Gallego, 21 de enero de 1934, p. 1.

68 La economía coruñesa en los últimos años. Memoria comercial de la Cámara Oficial de Comercio, Industria y Navegación de La Coruña de los años 1945 y 1946, La Coruña, p. 96.
} 
Por el contrario, la rúbrica correspondiente a la fabricación de hielo (con destino principalmente al abastecimiento de la flota pesquera y al consumo de los exportadores de pescado), de la que la mejor exponente era la Compañía Frigorífica, S.A., experimentó una marcha ascendente ${ }^{69}$. La demanda de hielo en la ciudad crecía sin interrupción, estimulando el aumento de la escala productiva de esta compañía ${ }^{70}$. El principal handicap residía en que, a pesar del incremento del volumen de ventas, los crecientes gastos de explotación erosionaron los beneficios ${ }^{71}$. Cuadro 4.14 Resultados de algunas de las principales
empresas del sector de la alimentación, 1931-35.

\begin{tabular}{|c|c|c|c|c|c|c|c|c|c|c|}
\hline & \multicolumn{2}{|c|}{1931} & \multicolumn{2}{|c|}{1932} & \multicolumn{2}{|c|}{1933} & \multicolumn{2}{|c|}{1934} & \multicolumn{2}{|c|}{1935} \\
\hline & $\mathbf{B}^{\text {os }}$ & Rent. & $\mathbf{B}^{\text {os }}$ & Rent. & $\mathbf{B}^{\text {os }}$ & Rent. & $\mathbf{B}^{\text {os }}$ & Rent. & $\mathbf{B}^{\text {os }}$ & Rent. \\
\hline \multicolumn{11}{|l|}{ CONSERVAS } \\
\hline \multicolumn{11}{|c|}{ Compañía Frigorífica $108.42531,0 \% 102.252$ 29,2\% 118.885 34,0\% 157.223 22,5\% } \\
\hline $\begin{array}{l}\text { Pérez Cepeda } \\
\text { y Osorio } \\
\end{array}$ & 14.492 & $29,0 \%$ & -5.116 & $-10,2 \%$ & 5.487 & $11,0 \%$ & 449 & $0,9 \%$ & & \\
\hline $\begin{array}{l}\text { Pesquera del Norte } \\
\text { de España }\end{array}$ & & & 44.146 & $15,9 \%$ & 2.147 & $0,8 \%$ & 18.677 & $6,7 \%$ & 7.513 & $2,7 \%$ \\
\hline \multicolumn{11}{|l|}{ COMPUESTOS } \\
\hline $\begin{array}{l}\text { Cooperativa Industrial } \\
\text { Coruñesa }\end{array}$ & & & 282 & $0,1 \%$ & & & 13.530 & $4,5 \%$ & 49.540 & $16,5 \%$ \\
\hline $\begin{array}{l}\text { González y } \\
\text { López Miranda } \\
\end{array}$ & 4.099 & $27,3 \%$ & -953 & $-6,4 \%$ & & & & & & \\
\hline La Unión Industrial & 41.928 & $6,0 \%$ & 43.602 & $6,2 \%$ & 40.618 & $5,8 \%$ & 42.282 & $6,0 \%$ & 39.318 & $5,6 \%$ \\
\hline $\begin{array}{l}\text { Hijos de } \\
\text { J.M. Rodríguez }\end{array}$ & & & 20.297 & $15,3 \%$ & 11.656 & $8,8 \%$ & 2.161 & $1,6 \%$ & 2.519 & $1,9 \%$ \\
\hline Alonso y Cía. & 1.553 & $3,1 \%$ & 2.412 & $4,8 \%$ & -4.693 & $-9,4 \%$ & & & & \\
\hline $\begin{array}{l}\text { Mercantil Cívico } \\
\text { Militar }\end{array}$ & 82.577 & $16,5 \%$ & 77.711 & $15,5 \%$ & 76.335 & $15,3 \%$ & 76.663 & $15,3 \%$ & 76.967 & $15,4 \%$ \\
\hline
\end{tabular}

Fuente: ARG-DHC (Hacienda). Memorias de las empresas.

La industria de los molidos era todavía numerosa, pero estaba caracterizada por la baja calidad del producto final, habiendo fracasado los intentos por establecer empresas a gran escala. Existía un elevado número de pequeños molinos, movidos por energía

\footnotetext{
69 Compañía Frigorífica, S.A. Memoria correspondiente al décimocuarto ejercicio. Año de 1932, La Coruña, pp. 6-7.

70 Compañía Frigorífica, S.A. Memoria correspondiente al duodécimo ejercicio. Año de 1931, La Coruña, pp. 5-6. La venta de hielo ascendió a más de 7.000 tms durante los años treinta, cantidades nunca antes superadas por la empresa: $1931=7.218 \mathrm{tms} ; 1932=7.972 \mathrm{tms} ; 1933=8.474 \mathrm{tms} ; 1934=9.255 \mathrm{tms}$. Memorias de la empresa.

71 Compañía Frigorífica, S.A. Memoria correspondiente al décimotercer ejercicio. Año de 1932, La Coruña, p. 5.
} 
eléctrica ${ }^{72}$. La materia prima para la elaboración de los transformados era de procedencia provincial. Pero la molienda se realizaba sin un proceso de clasificación sofisticado. Con estas perspectivas tecnológicas, el mercado de venta alcanzaba un radio muy reducido, no existiendo exportación fuera de la región ${ }^{73}$. Con todo, no fue el sector más afectado por la crisis, dado su carácter de industria de consumo básico. El principal problema procedía de las dificultades para importar materias primas, dado que la producción de cereales fue deficitaria durante la República.

La industria de los destilados tenía en la fabricación de cerveza de La Estrella de Galicia, uno de sus principales exponentes ${ }^{74}$. El crecimiento de esta empresa se topó con un escenario complicado en los años treinta. Tradicionalmente, había tenido que hacer frente a la inercia del consumo regional, más proclive a los vinos y aguardientes, lo que había condicionado una demanda reducida de su producto. Por su parte, la fábrica de gaseosas de La Unión Industrial sufrió asimismo la caída de la demanda, aunque de manera menos acusada que otras industrias, dado su carácter popular ${ }^{75}$.

La estructura interna del grupo de los compuestos no había experimentado una sustancial transformación. En todo caso, se percibe el surgimiento de varios establecimientos, aunque con las características que los definían en años anteriores. Las fábricas de pastas para sopa tuvieron en otro tiempo una importancia de la que carecían en los años treinta. Las pastas fabricadas en la provincia habían tenido en el pasado un cierto mercado en las antiguas colonias de Cuba, Puerto Rico y Filipinas; pero, perdido éste, la esfera de influencia comercial se limitó al mercado regional ${ }^{76}$.

El sector de los compuestos fue uno de los que experimentó una evolución menos desequilibrada, aunque los resultados de las empresas se vieron perjudicados en algunos casos, por factores de oferta y de demanda. El tono de las memorias de algunas compañías era excesivamente quejumbroso, según se deduce del examen de sus balances y cuentas de resultados. Las expectativas empresariales al inicio de la década no eran halagüeñas. Sin embargo, la evolución posterior de los acontecimientos desmiente en parte el gris escenario que dibujaban los empresarios (Cuadro 4.14).

Por el lado de la oferta, un problema común a las plantas embotelladoras fue la escasez de envases de vidrio, causada por la crisis empresarial de las fábricas españolas ${ }^{77}$. En segundo lugar, los gastos de explotación crecieron como consecuencia del alza en los gastos de personal ${ }^{78}$. En tercer lugar, los transportes atravesaban una

\footnotetext{
72 Apuntes para el momento de la industria española de 1930, op. cit., pp. 400-401.

Ibid., p. 401.

La fábrica tenía invertido un capital de 650.000 pts. Su producción era de unos 5.000 hectolitros, para lo que contaba con una plantilla de 27 empleados. Apuntes para el momento de la industria española de 1930, op. cit., p. 404.

75 Apuntes para el momento de la industria española de 1930, op. cit., pp. 404-405.

76 Apuntes para el momento de la industria española de 1930, op. cit., pp. 405-406.

77 Cooperativa Industrial Coruñesa, S.A. Memoria y balance del quinto ejercicio social, para dar cuenta a la junta general de accionistas que ha de celebrarse el día 25 de febrero de 1934.

78 La Mercantil Cívico Militar. Memoria del Año 1932 presentada a la Junta General de 1933. Año XLII. $17^{\circ}$ del $2^{\circ}$ período social, La Coruña, 1933, p. 9. Esta sociedad fue una de las que mantuvo un comportamiento más positivo, gracias en buena medida a la diversificación de sus negocios, que combinaban la producción con la distribución.
} 
difícil coyuntura, contribuyendo a la contracción de los mercados. Por la vertiente de la demanda, las adversas circunstancias climáticas (veranos lluviosos a principios de los años treinta) perjudicaron el consumo. La merma del mercado urbano y regional exhortó a estas sociedades a practicar políticas de austeridad y control de los gastos generales, al tiempo que los precios de venta se veían sometidos a una visible contención. Sin embargo, una prueba de que la coyuntura no era del todo recesiva reside en que empresas como La Unión Industrial presentan un volumen de ventas en ascenso ${ }^{79}$.

Por lo que respecta a la fábrica de tabacos, durante la década de los treinta continuó la tendencia mecanizadora iniciada unos años antes, ininterrumpida a pesar de (o gracias a) un incendio desencadenado en la planta en 1920. El crecimiento de la producción mantuvo la tendencia de los años veinte, con una breve caída coyuntural al inicio del decenio, que no interrumpió la marcha creciente de las ventas. En 1935 casi se había triplicado la producción de principios de siglo (Alonso Álvarez, 1998: 180-184), lo que demuestra que la fábrica no se vio afectada por la reducción de la demanda en igual medida que los demás sectores industriales locales.

Cuadro 4.15. Resultados de las principales empresas textiles, 1931-35.

\begin{tabular}{|c|c|c|c|c|c|c|c|c|c|c|}
\hline & \multicolumn{2}{|c|}{1931} & \multicolumn{2}{|c|}{1932} & \multicolumn{2}{|c|}{1933} & \multicolumn{2}{|c|}{1934} & \multicolumn{2}{|c|}{1935} \\
\hline & $\mathbf{B}^{\text {os }}$ & Rent. & $\mathrm{B}^{\text {os }}$ & Rent. & $\mathbf{B}^{\text {os }}$ & Rent. & $\mathbf{B}^{\text {os }}$ & Rent. & $\mathrm{B}^{\text {os }}$ & Rent. \\
\hline $\begin{array}{l}\text { Hilados y Tejidos } \\
\text { Vilasantar }\end{array}$ & 120.969 & $8,1 \%$ & 82.448 & $5,5 \%$ & 93.268 & $6,2 \%$ & 126.208 & $8,4 \%$ & 102.362 & $6,8 \%$ \\
\hline Primera Coruñesa & & & 64.927 & $6,5 \%$ & 66.835 & $4,5 \%$ & 15.239 & $1,0 \%$ & 16.528 & $1,1 \%$ \\
\hline Galicia Industrial & 1.529 & $0,2 \%$ & 218.551 & $24,0 \%$ & 260.013 & $28,5 \%$ & 168.295 & $18,5 \%$ & 120.528 & $13,2 \%$ \\
\hline Crecente Hermanos & & & 926 & $92,6 \%$ & & & & & & \\
\hline Feal Hermanos & 6.944 & $46,3 \%$ & -2.874 & $-19,2 \%$ & 1.547 & $10,3 \%$ & 3.699 & $24,7 \%$ & 1.639 & $10,9 \%$ \\
\hline Bamonde Hermanos & 10.790 & $12,3 \%$ & 7.050 & $8,0 \%$ & 6.400 & $7,3 \%$ & 5.950 & $6,8 \%$ & & \\
\hline F.Miranda y Cía., S.L. & & & -1.197 & $-1,0 \%$ & -5.536 & $-4,6 \%$ & 3.468 & $2,9 \%$ & 2.675 & $2,2 \%$ \\
\hline
\end{tabular}

Fuente: ARG-DHC (Hacienda). Memorias de las empresas.

La elaboración de hilados y tejidos se encontraba en un estado insatisfactorio, como consecuencia de la ausencia de un mercado extenso para una producción continua

\footnotetext{
79 La Mercantil Cívico Militar. Memoria del año 1933 presentada a la Junta General de 1934. Año XLIII. $18^{\circ}$ del $2^{\circ}$ período social, La Coruña, 1934, p. 8. La Mercantil Cívico Militar. Memoria del año 1935 presentada a la Junta General de 1936. Año XLV. $20^{\circ}$ del $2^{\circ}$ período social, La Coruña, 1935, p. 8. Memoria que presenta el Consejo de Administración de la Sociedad Anónima La Unión Industrial, a la Junta general que se celebrará el día 27 de febrero de 1934. Memoria que presenta el Consejo de Administración de la Sociedad Anónima La Unión Industrial, a la Junta general que se celebrará el día 25 de febrero de 1935.
} 
y rentable, siendo muy frecuentes los intervalos de paralización ${ }^{80}$. En España, esta industria sufría una fuerte crisis, repercutiendo en la provincia de A Coruña. Además, las fábricas provinciales tuvieron que soportar un elevado coste de la materia prima, debido a la falta de transportes adecuados y al elevado valor de las tarifas aplicadas ${ }^{81}$. Las tres principales sociedades mostraron un comportamiento irregular durante la crisis. Los resultados empresariales sufrieron las consecuencias de las subidas de costes derivadas de la depreciación de la moneda ${ }^{82}$, y de las subidas de los gastos de personal (Cuadro 4.15) ${ }^{83}$. En segundo lugar, los intentos de ampliación de los mercados en España tropezaron con las dificultades del transporte terrestre, aquejado de una fuerte recesión. En tercer lugar, una nota común eran las recíprocas lamentaciones ante la "competencia desleal" de los demás fabricantes de productos textiles ${ }^{84}$.

Un factor favorable al sector en Galicia fue la recesión que éste sufría en Cataluña, lo que permitió a los fabricantes coruñeses abastecer con mayor eficacia el mercado doméstico, aunque a costa de una reducción de los precios de venta ${ }^{85}$. En consecuencia, a pesar del incremento de las ventas, los beneficios no registraron igual evolución, en paralelo con el ritmo de deflación económica. Sin embargo, desde finales de 1931 las consecuencias de la depresión se hicieron sentir en Galicia, afectando inmediatamente al consumo de productos textiles ${ }^{86}$. En primer término, la crisis se diseminó con especial virulencia por el campo gallego, que vio cómo disminuían enormemente las ventas de sus productos, provocando la consiguiente caída de la demanda y la acumulación de stocks empresariales ${ }^{87}$. En segundo lugar, el comercio atravesaba una situación delicada, lo que entorpecía las ventas pero, sobre todo, castigaba el cobro de las mercancías, debido a la falta de liquidez ${ }^{88}$.

Desde 1934, las industrias algodoneras padecieron el recrudecimiento de la crisis industrial española, por efecto de la combinación de varios factores: la restricción de créditos bancarios, las exigencias de pago al contado por parte de los vendedores de materias

\footnotetext{
$80 \quad$ Además de las tres fábricas de tejidos, Primera Coruñesa, Hilados y Tejidos de Vilasantar y Galicia Industrial, existía en A Coruña la empresa F. Miranda y Cía., S.L., dedicada a la producción de redes de algodón para la pesca, la única del norte y noreste de España. Por lo que respecta a las industrias del vestido, además de numerosos talleres, en la capital se localizaba la sociedad Coruñesa de Confecciones, S.A., con un capital de 2.000 .000 pts.; la Sastrería Iglesias, dedicada a la confección de ropa para el Ejército, con un capital de 300.000 pts.; La Alemana-Fábrica de Paraguas, S.L., con un capital de 800.000; finalmente, 2 fábricas de botones, la más importante de las cuales era Algalit, S.L., con un capital de 300.000 pts. La economía coruñesa en los últimos años, op. cit., pp. 109-113.

81 Apuntes para el momento de la industria española de 1930, op. cit., pp. 401-402.

82 Hilados y Tejidos Vilasantar, Sociedad Anónima. Memoria. Año de 1931.

83 Hilados y Tejidos Vilasantar, Sociedad Anónima. Memoria. Año de 1935, p. IV.

84 Galicia Industrial, S.A. Memoria presentada a los Sres. Accionistas en la Junta General ordinaria celebrada el día 31 de marzo de 1932, correspondiente al $4^{\circ}$ ejercicio social. Primera Coruñesa, Sociedad Anónima. Memoria leída y aprobada en la Junta general ordinaria de 25 de febrero de 1934, La Coruña, p. 6.

85 Hilados y Tejidos Vilasantar, Sociedad Anónima. Memorias. Años de 1931-33. Primera Coruñesa, Sociedad Anónima. Memoria leída y aprobada en la Junta general ordinaria de 25 de febrero de 1934, La Coruña, p. 8.

86 Primera Coruñesa, Sociedad Anónima. Memoria leída y aprobada en la Junta general ordinaria de 25 de febrero de 1934, La Coruña, p. 5.

87 Hilados y Tejidos Vilasantar, Sociedad Anónima. Memoria. Año de 1932, pp. i-ii.

88 Hilados y Tejidos Vilasantar, Sociedad Anónima. Memoria. Año de 1932, p. ii-iii.
} 
primas, las ventas a precios no remuneradores, los ofrecimientos a los comerciantes mayoristas de existencias en condiciones ruinosas, etc. Todo ello se resumía en un problema de sobreproducción ${ }^{89}$.

La industria metalúrgica, constituida principalmente por fundiciones y talleres mecánicos, tradicionalmente se había visto afectada por la carestía de las tarifas y por la falta de comunicaciones ${ }^{90}$. En los años treinta, esta industria tenía su mayor fuente de ingresos en la industria base, la pesca, ya que la principal línea de trabajo procedía de las frecuentes reparaciones a las que era necesario someter a los buques.

El mercado continuaba circunscrito a la provincia. Esto provocó una dualidad de comportamiento. Por un lado, al depender de la demanda local, el sector no se vio sometido directamente al embate de la crisis. Sin embargo, las fluctuaciones de la actividad pesquera y los efectos sobre las industrias vinculadas incidieron en el sector. Las principales empresas eran Wonemburger, S.L., La Artística Suárez Pumariega, S.A., Talleres Solórzano, S.A., Miguel Muñoz Ortiz Fernández, Industrias Gallegas, S.A., Talleres de Dolores Sánchez Rodríguez y Ricardo Castro Mosquera ${ }^{91}$.

Al contrario de otros sectores, el problema no radicaba en la oferta y en el encarecimiento de costes (como los laborales o determinados inputs), sino en la disminución de la demanda. En conjunto, sus resultados presentan un perfil irregular, con períodos de pronunciadas caídas de los beneficios, que derivaron en numerosas ocasiones en pérdidas, ocasionadas por la paralización de las actividades industriales vinculadas (Cuadro 4.16).

\section{Cuadro 4.16. Resultados de algunas de las principales empresas metalúrgicas, 1931-35.}

\begin{tabular}{|c|c|c|c|c|c|c|c|c|c|c|}
\hline & \multicolumn{2}{|c|}{1931} & \multicolumn{2}{|c|}{1932} & \multicolumn{2}{|c|}{1933} & \multicolumn{2}{|c|}{1934} & \multicolumn{2}{|c|}{1935} \\
\hline & $\mathbf{B}^{\text {os }}$ & Rent. & $\mathbf{B}^{\text {os }}$ & Rent. & $\mathbf{B}^{\text {os }}$ & Rent. & $\mathbf{B}^{\text {os }}$ & Rent. & $\mathrm{B}^{\text {os }}$ & Rent. \\
\hline $\begin{array}{l}\text { Hijos de M. Muñoz } \\
\text { Ortiz }\end{array}$ & 14.389 & $19,2 \%$ & 10.831 & $14,4 \%$ & 3.673 & $4,9 \%$ & -7.021 & $-9,4 \%$ & & \\
\hline Hijos de Solórzano & 12.934 & $8,8 \%$ & 14.595 & $9,9 \%$ & 27.135 & $18,5 \%$ & 8.737 & $5,9 \%$ & 11.060 & $7,5 \%$ \\
\hline $\begin{array}{l}\text { Celestino Pineda } \\
\text { y Cía. }\end{array}$ & 599 & $0,8 \%$ & -22.273 & $-29,7^{\circ}$ & -20.616 & $-27,5 \%$ & -804 & $-1,1 \%$ & & \\
\hline $\begin{array}{l}\text { Explot. Gral. de } \\
\text { Trapos y Metales } \\
\text { de Galicia }\end{array}$ & & & 439.848 & $-44,0 \%$ & 45.331 & $8,9 \%$ & 52.212 & $10,2 \%$ & 47.001 & $9,2 \%$ \\
\hline
\end{tabular}

Fuente: ARG-DHC (Hacienda). Memorias de las empresas.

\footnotetext{
89 Primera Coruñesa, Sociedad Anónima. Memoria correspondiente al año 1934 leida y aprobada en la Junta general ordinaria de 24 de febrero de 1935, La Coruña, p. 9. Primera Coruñesa, Sociedad Anónima. Memoria correspondiente al año 1935, p. 2. Hilados y Tejidos Vilasantar. Memorias. Años de 1934-35.

90 Circunstancia que afectaba también a la minería, igual que había ocurrido en el pasado. La economía coruñesa en los últimos años, op. cit., pp. 55 y 70.

91 La economía coruñesa en los últimos años, op. cit., pp. 107-108.
} 
Hacia los años treinta, la actividad maderera comenzó a experimentar una fuerte crisis a nivel regional, a consecuencia de su fuerte componente exportadora (Rico, 2000: 434-435). La responsabilidad de la crisis tuvo que ver con factores de oferta y de demanda. Por un lado, existía un problema de dimensionamiento, ya que el número de instalaciones era excesivo para la estructura de la demanda nacional. Por otro, el sector comenzó a sentir la competencia de maderas del exterior (Portugal y Francia), dentro del mismo tramo de oferta que abastecía Galicia. La competencia se vio favorecida en parte por la autorización establecida de entrada de madera extranjera en el país ${ }^{92}$. En cambio, la manipulación de esta mercancía en el puerto de A Coruña no se encontraba en las mejores condiciones, como consecuencia de la existencia de fuertes limitaciones de espacio físico para las operaciones de carga y descarga.

Por la vertiente de la demanda, los pedidos de envases no alcanzaban a la producción. Los envases que requería la industria conservera eran los que daban más vida y proporcionaban mayores rendimientos económicos a los empresarios del sector. La crisis que sufría la industria impactó directamente en la producción y en los resultados de estos talleres. Por ello, la mayoría vivía una vida precaria, encontrándose paralizadas gran parte del año muchas fábricas aserraderos ${ }^{93}$. Finalmente, la relativa paralización de la construcción urbana a finales de la década también tuvo una negativa influencia en el sector ${ }^{94}$.

De todos modos, durante el período de entreguerras se produjo una modificación estructural importante, porque este sector comenzó a desplazar a la alimentación de su posición de privilegio dentro de la industria coruñesa, debido a la continuada creación de empresas. Ésta será casi la única modificación a gran escala en la industria urbana, pues los demás sectores mantuvieron similares porcentajes de participación. Sin embargo, el aumento del número de empresas careció de efectos expansivos, ya que las empresas continuaban siendo de carácter artesanal. Las empresas más destacadas eran Hijos de Benito Ares, S.A. e Hijos de Emilio Cervigón Carreras ${ }^{95}$ (sociedad con un capital de más de un millón de pesetas) ${ }^{96}$.

Dentro del sector del cuero y el calzado, los únicos establecimientos fabriles existentes en Galicia se localizaban en la provincia de A Coruña, que contaba con la empresa más destacada, dedicada a la fabricación de calzado, la ya citada de Ángel Senra. El resto del sector estaba conformado por zapateros, predominando los artesanos que trabajaban en pequeños talleres (Pereira, 1994: 23).

El sector químico en Galicia a principios de los años treinta mostraba una dualidad entre los sectores tradicionales, abastecedores de los mercados locales y de producción

\footnotetext{
92 ACTAS Pleno COCINC, 20 de febrero de 1930.

93 Apuntes para el momento de la industria española de 1930, op. cit., pp. 399-400.

94 Vid. Arroyo (1999: 73), quien cita la Memoria del Banco de Bilbao para el año 1933

95 No ha sido posible localizar información seriada sobre los resultados de las empresas madereras de la capital. Sin embargo, los escasos y fragmentarios datos disponibles permiten conjeturar una evolución irregular, con frecuentes períodos de pérdidas empresariales. ARG-DHC (Hacienda). Utilidades.

96 La industria del mueble, en cambio, apenas había dado sus primeros pasos en Galicia, y no comenzaría a surgir hasta la década de los años cuarenta. Pereira (2002: 127); MOPU. Dirección General de Ordenación y Acción Territorial, Plan Director de Coordinación de Galicia. Sector industrial, Tomo I, p. 20.
} 
artesanal (jabón, velas, lejía, etc.) y otras instalaciones modernas pero poco integradas en el espacio económico gallego (Pereira, 1994: 23). El principal problema que aquejaba al sector en la ciudad fue la fuerte caída de la demanda y de los precios, junto con la elevación del precio de los inputs, lo que se tradujo en la acumulación de stocks y en el empeoramiento de los resultados empresariales ${ }^{97}$.

En A Coruña, destacó, además de los anteriores, el sector de los fertilizantes. El incremento en el consumo agrario influyó lo suficiente como para que se instalase en 1930 en las proximidades de A Coruña el establecimiento de la firma Cros, S.A., inicialmente como centro distribuidor de abonos, que más tarde se transformará en fábrica. La compañía dio inicio a su actividad en 1931, con una producción destinada a la satisfacción de las necesidades gallegas de superfosfatos y otros abonos ${ }^{98}$. Esta fábrica debería haber facilitado la difusión del abonado, pero los efectos de la crisis económica y la elevación de los precios no actuaron en su favor. Buena parte de la culpa la tuvo la política arancelaria que provocó un encarecimiento del abonado químico ${ }^{99}$.

\section{Cuadro 4.17. Resultados de algunas de las sociedades de papel y artes gráficas, 1931-35.}

\begin{tabular}{|c|c|c|c|c|c|c|c|c|c|c|}
\hline & \multicolumn{2}{|c|}{1931} & \multicolumn{2}{|c|}{1932} & \multicolumn{2}{|c|}{1933} & \multicolumn{2}{|c|}{1934} & \multicolumn{2}{|c|}{1935} \\
\hline & $\mathbf{B}^{\text {os }}$ & Rent. & $\mathbf{B}^{\text {os }}$ & Rent. & $\mathbf{B}^{\text {os }}$ & Rent. & $\mathbf{B}^{\text {os }}$ & Rent. & $\mathbf{B}^{\text {os }}$ & Rent. \\
\hline E. Roel de La Torre & & & & & 55.178 & & 50.233 & & 37.673 & \\
\hline Folla y Cía. & 21.656 & $10,8 \%$ & 18.399 & $9,2 \%$ & & & & & -37.067 & $-18,5 \%$ \\
\hline \multicolumn{11}{|c|}{ Soc.Gall.de Publicidad -6.036} \\
\hline Zincke Hermanos & 13.216 & $13,2 \%$ & 14.261 & $14,3 \%$ & 13.101 & $13,1 \%$ & 12.679 & $12,7 \%$ & 13.015 & $13,0 \%$ \\
\hline La Voz de Galicia & & & 72.137 & $24,0 \%$ & 76.083 & $25,4 \%$ & 85.648 & $28,5 \%$ & 97.218 & $32,4 \%$ \\
\hline Grande y Lens & 2.954 & $3,9 \%$ & 2.159 & $2,9 \%$ & 1.285 & $1,7 \%$ & 137 & $0,2 \%$ & -1.198 & $-1,6 \%$ \\
\hline
\end{tabular}

Fuente: ARG-DHC (Hacienda). Memorias de las empresas.

El sector de las imprentas y de la prensa y derivados atravesó momentos también difíciles, reflejados en el aumento de los costes de explotación y las dificultades para acceder a algunos elementos de fabricación (Cuadro 4.17). La elevación de los aranceles y el aumento de los gastos generales fueron las principales partidas responsables ${ }^{100}$. Pero también se aprecia una caída de las utilidades por ventas de mercancías. A pesar

\footnotetext{
97 Explotación de Algas, S.A. Memoria y Balance del Ejercicio que termina en 31 de diciembre de 1935, p. 1.

98 La economía coruñesa en los últimos años, op. cit., p. 71.

99 Galicia industrial y comercial, septiembre de 1931.

100 La Voz de Galicia, S.A. Memorias, 1932-36. En el caso de los diarios, los precios de venta no compensaban suficientemente los costes, dado que estaban sometidos a regulación.
} 
de ello, las empresas más sobresalientes, como La Voz de Galicia, acometieron importantes mejoras de modernización de sus instalaciones ${ }^{101}$.

Este sector encontraba su principal mercado en la edición de la prensa diaria y en publicaciones de diverso tipo, aunque también realizaba labores de impresión muy variadas. Por ello, el marco en el que se desenvolvió la prensa tuvo una marcada incidencia en su evolución empresarial. 1934 marcó un punto de inflexión, ya que el sector debió hacer frente entonces a la contracción del mercado, al incremento de los costes de explotación y a las dificultades para adquirir maquinaria e inputs extranjeros.

La industria eléctrica coruñesa se hallaba prácticamente en los momentos previos a su gran salto cualitativo, que tuvo lugar en la posguerra. El sector eléctrico debería haberse visto afectado por la crisis, en sintonía con el resto de la economía local. No obstante, las características de su oferta productiva, los acuerdos alcanzados entre las principales empresas suministradoras y el oligopolio de facto que ejercían en la región, el carácter cautivo de su demanda, etc. ${ }^{102}$, permitieron a las sociedades suministradoras capear de manera razonablemente beneficiosa la recesión ${ }^{103}$.

\section{Cuadro 4.18. Resultados de las sociedades eléctricas domiciliadas en A Coruña, 1931-35.}

\begin{tabular}{|c|c|c|c|c|}
\hline & & SGGE & FCGE & H. del Pindo \\
\hline \multirow{2}{*}{1931} & $\mathrm{~B}^{\text {os }}$ & & 1.310 .251 & 357.512 \\
\hline & Rent. & & $14,6 \%$ & $29,8 \%$ \\
\hline \multirow{2}{*}{1932} & $\mathbf{B}^{\text {os }}$ & 1.654 .039 & 1.392 .892 & 266.466 \\
\hline & Rent. & $8,3 \%$ & $15,5 \%$ & $22,2 \%$ \\
\hline \multirow{2}{*}{1933} & $\mathbf{B}^{\text {os }}$ & 1.723 .920 & 1.178 .638 & 301.112 \\
\hline & Rent. & $8,6 \%$ & $13,1 \%$ & $25,1 \%$ \\
\hline \multirow{2}{*}{1934} & $\mathbf{B}^{\text {os }}$ & 1.611 .187 & 1.112 .229 & 302.582 \\
\hline & Rent. & $8,1 \%$ & $12,4 \%$ & $25,2 \%$ \\
\hline \multirow{2}{*}{1935} & $\mathrm{~B}^{\text {os }}$ & 1.660 .689 & 1.176 .381 & 142.354 \\
\hline & Rent. & $8,3 \%$ & $13,1 \%$ & $11,9 \%$ \\
\hline
\end{tabular}

Fuente: ARG-DHC (Hacienda). Memorias de las empresas.

\footnotetext{
101 La Voz de Galicia (Sociedad Anónima). Memoria correspondiente al vigésimo quinto ejercicio social, presentada por el consejo de gobierno y administración de la sociedad en junta general de accionistas el 20 de marzo de 1936, La Coruña, 1936, p. 8.

102 Uno de los efectos perversos de la estrategia adoptada por las compañías eléctricas españolas fue la insuficiencia sostenida de la oferta energética frente a la demanda, circunstancia extensible a otras fuentes de energía como el petróleo (Sudrià, 1987: 330).

103 Según el Consejo de Industria, el estado de la industria en la provincia era próspero al inicio de la crisis. En aquel momento existían en funcionamiento 23 centrales de energía hidroeléctrica, con una producción anual de $37.674 .900 \mathrm{Kw} / \mathrm{h}$, una potencia instalada de $30.155 \mathrm{~K}$.V.A. y un total de 393 obreros empleados. Apuntes para el momento de la industria española de 1930, op. cit., p. 412.
} 
La crisis no pareció golpear de inicio con excesiva crudeza a estas compañías. La rentabilidad en 1930 era elevada y los beneficios crecientes (Cuadro 4.18) ${ }^{104}$. Los problemas se agravaron a partir de 1932-33, cuando se produjo una caída de los resultados, aunque siempre con saldos positivos. En cualquier caso, la recesión tampoco fue excesivamente dura, dado que en vísperas de la guerra se aprecian signos de recuperación. El tono de las memorias no muestra una excesiva preocupación durante el primer bienio republicano. Al contrario, a pesar de la crisis industrial, el crecimiento del consumo de alumbrado y del número de abonados, motivado por el crecimiento demográfico de los principales mercados compensó esas pérdidas ${ }^{105}$. El proceso de expansión hacia nuevas áreas continuaba y las cifras de energía distribuida así lo corroboran ${ }^{106}$. Así, en 1931, las FCGE adquirían la explotación eléctrica del Connavia, consistente en dos saltos de agua, centrales y líneas de conducción a Lugo ${ }^{107}$. Esta sociedad y la SGGE entablaron conversaciones con la Electra del Viesgo, fruto de las cuales se firmó un acuerdo entre las tres empresas y sus filiales para el intercambio de fluido, sin entrar en competencia en sus respectivas áreas de actuación ${ }^{108}$.

La política empresarial seguía criterios restrictivos respecto a los gastos corrientes, sin que ello afectase a las necesidades de expansión del negocio. Por ello, los elementos del activo progresaban con normalidad. Las utilidades no se vieron especialmente perjudicadas por los trastornos en el consumo, sino por la elevación de los gastos de personal y algunas partidas de los gastos generales ${ }^{109}$.

A partir de 1933, la crisis comenzó a pasar factura al sector eléctrico. La depresión repercutió vía mercado exterior en la contracción de los negocios urbanos, dando lugar a un retraimiento de la demanda de energía. Los sectores industriales paralizados durante 1931-32 no se habían recobrado del impacto de la crisis ${ }^{110}$. Por otro lado, el panorama social se encontraba muy perturbado. Las numerosas huelgas afectaron al consumo

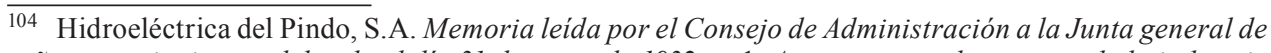
señores accionistas celebrada el día 31 de mayo de 1932, p. 1. Apuntes para el momento de la industria española de 1930, op. cit., p. 410.

105 Memorias de las empresas. El contrato que la Cooperativa Eléctrica Coruñesa había establecido con el Ayuntamiento de A Coruña para garantizar el suministro de alumbrado a la ciudad (posteriormente respetado por la FCGE) se hallaba vencido a principios de los años treinta. En 1933, la FCGE renovó dicho contrato.

${ }^{106}$ La energía vendida por la SGGE creció a un fuerte ritmo durante los años treinta. Frente a los 29,3 millones de Kw/h vendidos durante el trienio 1927-29, en 1930-32 las ventas alcanzaron los 44,6 millones de Kw/h y en 1933-35 los 57,2 millones de Kw/h (Carmona y Pena, 1989: 41).

107 Fábricas Coruñesas de Gas y Electricidad, S.A. ejercicio n 13 , año de 1931. Memoria redactada por el presidente de esta sociedad que presenta el Consejo de Gobierno a la Junta General de Accionistas que habrá de celebrarse el día 31 de marzo de 1932, La Coruña, p. 8.

108 Sociedad General Gallega de Electricidad, S.A. Memoria presentada por el Consejo de Administración a la Junta General de Accionistas convocada para el 30 de abril de 1934. Ejercicio de 1933. La Coruña, p. 5.

109 Ibid., p. 12. Fábricas Coruñesas de Gas y Electricidad, S.A. ejercicio n ${ }^{\circ}$ 14, año de 1932. Memoria redactada por el presidente de esta sociedad que presenta el Consejo de Gobierno a la Junta General de Accionistas que habrá de celebrarse el día 31 de marzo de 1933, La Coruña, p. 12.

110 Sociedad General Gallega de Electricidad. Memoria presentado por el Consejo de Administración a la Junta General de Accionistas convocada para el 30 de abril de 1934. Ejercicio de 1933, La Coruña, p. 6.
} 
de gas y de electricidad y ocasionaron frecuentes interrupciones de la producción, lo que determinó un aumento de los costes, ya que las compañías debían recurrir a motores diésel para impedir los apagones ${ }^{111}$. El problema era fundamentalmente de subdemanda ${ }^{112}$, por lo debieron adoptar en ocasiones políticas de contención de los precios, con el fin de estimular el consumo ${ }^{113}$. Sin embargo, la marcha del negocio mejoró coyunturalmente hasta la guerra, gracias a una mejoría en el rendimiento de las centrales debida al aumento de algunos servicios de distribución ${ }^{114}$.

\footnotetext{
111 Fábricas Coruñesas de Gas y Electricidad, S.A. ejercicio no ${ }^{\circ}$, año de 1933. Memoria redactada por el presidente de esta sociedad que presenta el Consejo de Gobierno a la Junta General de Accionistas que habrá de celebrarse el día 31 de marzo de 1933, La Coruña, p. 10. Sociedad General Gallega de Electricidad. Memoria de 1933, op. cit., p. 6.

112 Hidroeléctrica del Pindo, S.A. Memoria leída por el Consejo de Administración a la Junta general de señores accionistas celebrada el día 10 de abril de 1932, p. 1.

113 A pesar de que con anterioridad el precio de la electricidad en España se hallaba ya congelado en términos nominales desde 1921 (Sequeiros, 1986: 31). De todo modos, las estrechas relaciones entre las empresas gallegas y el mercado escasamente atractivo que atendían impedían que las compañías pugnasen por él bajando las tarifas (Carmona, 1990b: 42).

${ }_{114}$ Como principal hito conviene citar el control que adquirió FCGE sobre la Compañia Madrileña de Alumbrado y Calefacción por Gas, como primer paso para posicionarse en el mercado madrileño. La citada empresa controlaba Gas Madrid, y durante los años de la posguerra los responsables del grupo de FENOSA y del Banco Pastor tendrán intereses en la distribución de energía en Madrid (Mirás, 2003c). Fábricas Coruñesas de Gas y Electricidad, S.A. ejercicio n ${ }^{\circ}$ 17, año de 1935. Memoria redactada por el presidente de esta sociedad que presenta el Consejo de Gobierno a la Junta General de Accionistas que habrá de celebrarse el día 30 de marzo de 1936, La Coruña, p. 12.
} 
4 

En primer lugar, A Coruña experimentó un notorio crecimiento demográfico. El indicador poblacional revela un crecimiento más acelerado que la mayoría de las ciudades de rango jerárquico similar, y muy próximo en términos relativos a las principales ciudades españolas. El principal factor responsable fue la inmigración rural, dado que las pautas endógenas eran relativamente poco dinámicas, en consonancia con lo que ocurría en el conjunto de la sociedad gallega.

La ciudad recibió importantes contingentes, sobre todo de población en edad joven, que alimentaban el mercado laboral, por la vía de la vigorización de la estructura de la población activa. A Coruña se constituyó en el principal centro económico y financiero regional, así como en su principal mercado consumidor, lo que le permitió convertirse en un espacio preferente en Galicia. Sin embargo, la culminación de los momentos de más intensa emigración exterior de la población gallega desembocó en un auténtico éxodo, que A Coruña fue incapaz de reconducir. Al contrario, las fases de mayor aumento de efectivos de la ciudad coinciden con coyunturas de crisis en los mercados internacionales, que bloqueaban la salida de la mano de obra excedente en el campo. En términos comparativos, la ciudad encajó en el patrón habitual, el de las ciudades que acogieron una fracción reducida de sus respectivos emigrantes provinciales, un movimiento que favoreció a las ciudades más activas del período estudiado, es decir, los núcleos en pleno proceso de industrialización. Esto cuestiona la capacidad de atracción sobre el hinterland $\mathrm{y}$, por tanto, el rol de A Coruña como ciudad rectora dentro del sistema urbano regional.

En general, el comportamiento endógeno siguió las pautas de la demografía gallega del período, con algunas diferencias intrínsecas a cualquier núcleo urbano. La marcha de los indicadores no era plenamente equiparable a los estándares españoles en su conjunto, pero el ritmo de transformación se aproximaba a la tendencia de la población nacional, en pleno proceso de modernización socioeconómica. Resulta arriesgado vincular las coyunturas económicas con el comportamiento de las variables demográficas básicas. Pero se aprecian unas respuestas coherentes con la marcha económica de la ciudad. En las situaciones expansivas y en las de crisis, los ritmos de las variables responsables del crecimiento vegetativo se ajustaban razonablemente bien a la evolución económica urbana.

En segundo lugar, la economía coruñesa ha seguido las pautas y los ritmos marcados por la economía española y, con mayor nitidez, por la economía gallega, dentro de la cual se asentaba y sobre la que, a su vez, influía. Aunque en coyunturas concretas, como la guerra mundial, la ciudad parece haberse distanciado de la senda por la que transitaron los espacios más dinámicos del país, esta evolución no se puede calificar de anómala. Por un lado, la economía gallega se benefició puntualmente de la guerra, pero predominaron las secuelas negativas de la transmisión de los efectos de la contienda. Por otro, muchas otras regiones y ciudades españolas no supieron o no pudieron adaptarse a los nuevos requerimientos del mercado mundial, circunstancia por la que permanecieron al margen de la coyuntura especulativa alcista.

La guerra tuvo efectos contradictorios en la economía urbana, ya que constituyó una oportunidad desaprovechada para modernizar las estructuras productivas. La 
aparente paradoja reside en la combinación de aspectos negativos y positivos. En el haber, se aprecia un cierto efecto invernadero, manifestado en un leve pero comparativamente poco importante incremento del número de sociedades constituidas. En el debe, el deterioro de la situación social y la ralentización de la actividad mercantil, industrial y portuaria.

Otra de las singularidades de la economía herculina de este período reside en su relativo alejamiento respecto del patrón general seguido por la economía española al término de la guerra europea. La coyuntura bélica proyecta una sombra que va más allá de 1918, prolongando sus efectos hasta 1920-21. Sin embargo, en A Coruña se detecta una recuperación parcial, aunque insuficiente, una vez que los factores distorsionadores comenzaron a replegarse. En realidad, se trata de un retorno a la normalidad para una ciudad afectada por los desequilibrios que introdujo la crisis económica europea, especialmente aquellos que tenían que ver con el tráfico portuario. Aun cuando determinados elementos de índole social del ciclo bélico todavía continuaban manifestándose, la actividad económica urbana iniciaba lentamente su recuperación.

El período dictatorial se saldó con un balance positivo desde el punto de vista socioeconómico, como correspondió al conjunto de la economía del país. La modernización de la sociedad española se hizo extensiva a la economía regional, irradiando sus efectos sobre la economía de A Coruña.

Durante el período republicano, se observa que en algunos sectores la crisis no fue tan dramática, como debería haber correspondido a un período de fuerte contracción económica. Sin embargo, la economía urbana adoptó una estrategia de ensimismamiento, es decir, de inclinación hacia las actividades comerciales, que eran las que mejor podían garantizar una supervivencia básica a sus habitantes. Esta táctica se asemeja a la de las ciudades pequeñas y medias, especializadas en este tipo de funciones urbanas, con lo que quedó aparcada temporalmente la modernización en sentido estricto, en aras de la supervivencia. Por tanto, se puede hablar de una nueva oportunidad perdida, a cambio de que las consecuencias de la depresión fuesen menos severas que en otras zonas del país.

En tercer lugar, el sector dominante en términos de empleo y en términos empresariales fue el terciario, continuando una tendencia que hundía sus raíces en el siglo XIX. Esto refuerza el argumento de una ciudad terciaria que se ha venido consolidando a través de un largo proceso histórico, y que a lo largo del siglo XX cobra carácter definitivo e irreversible. A lo largo de todo el primer tercio de ese siglo, según las ECI, el comercio y los servicios representaron siempre entre el $75-80 \%$ de las cuotas satisfechas. El sector secundario en su conjunto suponía en torno a un modesto $20 \%$, siendo su participación más débil alrededor de un 15\% (años treinta), coincidente con la crisis industrial del período republicano. Estos porcentajes no deben hacernos creer, sin embargo, que la importancia como ciudad industrial de A Coruña era escasa. A pesar de algunas deficiencias estructurales, la industria en la ciudad tenía una cierta presencia y tradición.

La trascendencia de la función comercial, la más sólidamente asentada en A Coruña, ha tenido su sostén en el tráfico mercantil, lo que ha permitido que dicha función 
haya penetrado con fuerza en su estructura económica. Históricamente, la ciudad ha pertenecido al grupo de ciudades en las que la dotación comercial era especialmente poderosa. Por tanto, no se trata de un caso excepcional, sino de un modelo análogo al de otras ciudades españolas, casi siempre de tamaño pequeño y medio, aunque fortalecido por las funciones portuarias.

La industria carecía de unas dimensiones adecuadas, con una importante presencia de actividades de carácter artesanal, reducidas dimensiones, escasos efectos de arrastre y que atendían una demanda de carácter local. Existía una gran diferencia entre lo que pagaban los contribuyentes del sector industrial y el terciario con respecto al número de sus empresarios. El comercio y los servicios suponían entre el 52 y el $74 \%$ del total de los empresarios, correspondiendo a la industria en general en torno a un $45 \%$.

El crecimiento y la parcial modernización del sector que se detecta desde las últimas décadas del siglo XIX continuaron y, en cierto modo, se aceleraron durante las tres primeras décadas del siglo, aunque a un ritmo más lento que el de otras ciudades, debido al desaprovechamiento de las oportunidades que brindaron las coyunturas expansivas del período. El número de empresas industriales creció. Pero en ningún momento se detecta un shock acelerador del rol que desempeñaba el sector en la economía urbana, del tipo de los que se atisban en procesos de industrialización más explosivos.

Los sectores económicos urbanos siguieron una marcha contrapuesta en las distintas coyunturas que presidieron este período. Los sectores industrial y terciario se resintieron de la negativa coyuntura que supuso la guerra europea y el ciclo posbélico, aunque matizado en el caso de la industria por el buen comportamiento de algunas actividades artesanales. Pero, en general, los servicios y el comercio sufrieron más las consecuencias de la paralización de la actividad económica. Del mismo modo, se recuperaron con mayor vivacidad al acabar ésta y, con mayor claridad, durante los años veinte. Pero durante los años treinta se invirtió la tendencia y se produjo una paralización de la actividad económica, de la que el único sector que pareció mostrarse ausente fue el comercio. Por tanto, la coyuntura pareció influir más sobre el sector terciario y en menor medida sobre la industria, lo que se derivaba probablemente de que en el primer grupo de actividades radicaba el motor en torno al cual giraba la actividad económica urbana.

A Coruña disponía de resortes que le permitían crecer y auparse al cenit de la jerarquía urbana regional. Pero no se puede olvidar que esa posición se sustentaba en una economía con un bajo nivel de desarrollo, y con unos ritmos de crecimiento que tampoco le permitían escalar peldaños a nivel nacional. Aunque han existido ocasionales excepciones, la historia urbana europea no ha sido testigo con excesiva frecuencia de experiencias de ciudades pujantes en entornos económicos insuficientemente desarrollados. No es de extrañar que A Coruña no pudiese situarse más allá de una posición intermedia en la jerarquía urbana nacional.

El principal de los engranajes sobre los que gravitaba la economía era el puerto. Gracias a él, la ciudad desarrolló una serie de funciones que le permitieron equipararse 
en condiciones de igualdad con otras urbes litorales españolas. Una prueba de la interrelación puerto-ciudad era la consonancia entre la significación del puerto coruñés en la jerarquía portuaria nacional con la posición de la ciudad dentro del ranking urbano. En comparación con los espacios portuarios más dinámicos, A Coruña detentaba un papel secundario y excesivamente dependiente de tráficos que generaban menores efectos de arrastre. Sin embargo, el puerto constituía una vía de canalización de riqueza de enorme importancia.

El mar generó riqueza para la ciudad, dentro de un esquema de relaciones que encaja con la dialéctica que se ha identificado en otras ciudades litorales europeas. La relación ciudad-puerto, y sus sinergias, cristalizó en el nacimiento de múltiples negocios (pesca, navegación, intermediación, seguros, etc.), aunque el de A Coruña era un puerto con una estructura propia de servicio a un área escasamente desarrollada $\mathrm{y}$ dependiente.

Capítulo aparte merece el apartado correspondiente a la pesca. Este tipo de actividad era uno de los que caracterizaba con mayor claridad a la economía urbana. Se trataba de un sector básico, dado que generaba numerosos efectos de arrastre sobre un amplio espectro de actividades industriales y terciarias: almacenamiento, intermediación, asentadores, armadores, pertrechos, transformación de la madera, talleres de construcción y reparación de maquinaria, construcción naval, conservas, envases de madera y litografiados, sal, hielo, etc. Además, este sector formó parte, a una escala más modesta que en las Rías Bajas, del entramado empresarial más dinámico de la Galicia de entreguerras. No sólo por el crecimiento productivo y exportador a que dio lugar, sino por el dinamismo tecnológico asociado a los nuevos desafíos que planteaba la expansión de las áreas pesqueras y la acción en los mercados internacionales.

Otro de los anclajes más firmes de la economía se encontraba en el último compartimento del movimiento portuario, la emigración. Desde cualquier ángulo que se enfoque la economía de la ciudad de aquellos años, descubrimos la huella de los efectos de la emigración. Desde mediados del siglo XIX numerosos empresarios coruñeses habían descubierto en la canalización de este tráfico una lucrativa vía de negocio, al amparo de la internacionalización de los mercados de trabajo que se desarrolló como consecuencia de la creciente integración de la economía mundial.

Algunos de esos empresarios trascendieron su época (Pastor, Marchesi, Rubine, etc.), dejando negocios que se prolongaron durante décadas y que se diversificaron, dotando de un creciente protagonismo a sus continuadores. Los apellidos de aquellos pioneros desembocaron en la constitución de nuevas empresas o en la modificación de sociedades ya existentes, dedicadas a un amplio abanico de tareas (consignación, banca, seguros, comercio de importación-exportación, industria, etc.), dando asiento a un tipo de estructura económica sólidamente cimentada en el sector terciario. A un nivel más popular, la riqueza de la emigración se extendía hacia actividades más básicas, al dejar su impronta sobre las actividades de hostelería, de abastecimiento de los buques, el comercio minorista, etc. En última instancia, de la suerte de este movimiento dependían, aunque con intensidad muy distinta, muchos subsectores, especialmente dentro del sector terciario. 
La principal contrapartida negativa de este aluvión demográfico procedía de la escasa capacidad de control real de los agentes económicos urbanos sobre sus ritmos. Por un lado, porque la emigración dependía en último término de las coyunturas de los países de destino, dado que el ritmo de transformación de la economía gallega era insuficiente para sostener una mano de obra excedentaria en el campo. Por otro, porque los principales beneficiarios de este tráfico, los intermediarios urbanos, fueron incapaces o rehusaron desarrollar una actividad naviera propia, que les permitiese erigirse en verdaderos encauzadores de este movimiento. En última instancia, todos ellos terminaron por convertirse en agentes, consignatarios, representantes, etc. de compañías de navegación extranjeras y españolas. Esta actividad les proporcionaba una fuente de liquidez extra para invertir en otros negocios, constituyendo de este modo uno de los segmentos más dinámicos de la burguesía marítima gallega de este período.

No sorprende, por tanto, que encontremos a algunos de los personajes más renombrados de los negocios marítimos involucrados en las principales iniciativas financieras e industriales de la época y, especialmente, en los servicios públicos emergentes. Es decir, en algunos de los sectores punta de la inversión en las ciudades españolas del primer tercio del siglo XX.

A pesar de que, debido a las características propias de la economía regional, el grado de inserción en el mercado mundial era más reducido que el de las áreas españolas más dinámicas, A Coruña no se hallaba en absoluto desconectada del exterior. La oferta de bienes y servicios no era suficientemente competitiva como para integrarse en pie de igualdad con competidores más avezados. Pero hay que tener en cuenta que el puerto era la vía esencial de entrada de mercancías, ya fuesen en régimen de tránsito hacia el mercado regional o hacia el mercado urbano. Cualquier coyuntura que conmoviese las bases de ese delicado dispositivo perjudicaba de inmediato a los agentes involucrados en ese tráfico. Primero a los directamente dependientes del tráfico portuario y, posteriormente, a los sectores vinculados. No sorprende que el cierre de intercambios comerciales afectase pronto a sectores en principio alejados de esa cadena (hostelería, comercio minorista, etc.).

La estructura interna de los sectores económicos no se distanciaba excesivamente de lo que cabría aguardar de una ciudad con un emplazamiento agrario. La primera nota característica era el dualismo. Tanto en la industria como en el terciario coexistían elementos innovadores con otros tradicionales, aunque lo más común era la existencia de unos bajos niveles de modernización. El segundo rasgo consistía en la acentuada fragmentación en un elevado número de pequeños establecimientos, especialmente en el comercio, definido por la abundancia de negocios familiares, en concordancia con la estructura comercial de la mayoría de ciudades españolas. El tercer elemento era el predominio de los sectores destinados a la satisfacción de las necesidades básicas, una circunstancia que se hallaba presente en el aparato comercial de la mayoría de ciudades españolas, y en la estructura industrial de la práctica totalidad de ciudades pequeñas y medias, especialmente las emplazadas en entornos agrarios.

El resto de sectores mantenía una estrecha vinculación con los segmentos dominantes de la estructura productiva regional (pesca, madera, curtidos, etc.). Se observa 
una evolución aparentemente desequilibrada, si se compara con los espacios dinámicos del país, en donde se consolidaron los sectores protagonistas de los procesos de industrialización clásicos. Pero esas historias fueron la excepción y no la norma. A Coruña no resiste la comparación con Bilbao, Barcelona, Madrid, Sevilla, etc., pero sí con ciudades de similar rango y características (San Sebastián, Oviedo, Cádiz, etc.).

Recapitulando, la estructura económica urbana fue el resultado de la confluencia de una serie de factores de demanda y de oferta que condicionaron el devenir de la ciudad. La demanda urbana permitió el nacimiento de sectores que se desarrollaron al abrigo de un consumo creciente, como queda evidenciado en el crecimiento demográfico ya comentado. El mercado de un Área Metropolitana en pleno proceso de formación y del resto de Galicia sirvieron de complemento para determinadas funciones concretas, que requerían mayores umbrales de demanda para garantizar su supervivencia. De ese modo, el incremento de la magnitud del mercado permitió la aparición de las típicas economías de aglomeración que se generan como resultado del agrupamiento en un espacio de un volumen creciente de unidades económicas. Esto es lo que explica los efectos de arrastre de numerosos sectores.

Sin embargo, la incapacidad técnica y financiera para competir en el mercado nacional e internacional redujo el espectro de sectores que se expandieron durante esos años a una banda muy estrecha. Sólo es factible hablar de sector exportador en los casos de la industria conservera y maderera. Aunque las dificultades de transporte interior constituían un poderoso factor limitativo, con todo, se puede deducir que existían problemas de oferta, porque la demanda sí existía, aunque no estimulase un sustancial incremento de la capacidad productiva y una modernización tecnológica a gran escala. Esto explica la incapacidad de A Coruña para hacer frente a los retos que proponía el mercado en coyunturas expansivas. 


\section{Fuentes}

y bibliografía 



\section{Archivo}

Archivo de la Autoridad Portuaria de A Coruña. Memorias de la Junta de Obras del Puerto de La Coruña.

Archivo de la Cámara de Comercio, Industria y Navegación de A Coruña:

- Actas del Pleno de la Cámara de Comercio, Industria y Navegación de La Coruña. 1900-1930.

- Boletín de la Cámara Oficial de Comercio, Industria y Navegación de La Coruña (COCINC). 1916-1917.

- Comercio, Industria y Navegación. Revista de los Intereses Económicos de La Coruña. 1924.

- Correspondencia varia.

- Estudio realizado para conocer las causas del decrecimiento mercantil de La Coruña. 1935.

- Estadística de jornales. 1914-1918.

- Estadística de precios. 1903-1919.

- La economía coruñesa en los últimos años. Memoria comercial de la Cámara Oficial de Comercio, Industria y Navegación de La Coruña de los años 1945 y 1946.

- Matrícula industrial. A Coruña capital. 1914-1935.

- Memoria de la Cámara de Comercio, Industria y Navegación de La Coruña del año 1916.

- Orientación económica y financiera. 1916-1917.

Archivo de la Comandancia de Marina. Lista Oficial de los Buques de Guerra y Mercantes de la Marina Española. 1900-1939.

Archivo de la Compañía de Tranvías de La Coruña.

Archivo de la Confederación Hidrográfica del Norte de España.

Archivo de la Delegación del Banco de España en A Coruña:

- Informe-resumen de las operaciones verificadas durante el año (1899 a 1920) por el Banco de España en La Coruña.

- Informe-resumen leído en la Junta de Señores Accionistas de la sucursal del Banco de España en La Coruña, 7 de febrero de 1915.

Archivo de la Diputación Provincial de La Coruña. Boletín Oficial de la Provincia de La Coruña.

Archivo de la Empresa Municipal de Aguas La Coruña, S.A.

Archivo de la Fundación de los Ferrocarriles Españoles.

Archivo del Ministerio de Economía y Hacienda (Madrid). Memorias presentadas por los Ingenieros industriales de la Investigación de la Hacienda Pública.

- Catálogo Oficial de la Producción Industrial de España, 1938-1942. 
Archivo del Ministerio de Trabajo y Asuntos Sociales (Madrid). Estadística de salarios y jornadas de trabajo referida al período 1914-1930.

Archivo General de la Administración (Madrid).

Archivo Histórico de Protocolos. Ilustre Colegio Notarial de La Coruña. Anuario de la Dirección General de los Registros y del Notariado, 1900-1936.

Archivo Histórico del Reino de Galicia:

- Delegación de Hacienda de A Coruña. Administración de Rentas Públicas. Contribución e impuestos (utilidades). Balances de sociedades y empresas individuales. Legajos 682-683, 767-770-772, 774-783, 1943-1952.

- Delegación de Hacienda de A Coruña. Administración de Rentas Públicas. Contribución e impuestos (utilidades). Expedientes de liquidación de cuotas (arbitrio municipal sobre el producto neto de sociedades). Legajos 826-827.

- Delegación de Hacienda de A Coruña. Administración de Rentas Públicas. Registro de liquidaciones de las tarifas $2^{a}$ y $3^{a}$ de la contribución de utilidades. 1924-1933. Libros 5.233-5.234.

- Delegación de Hacienda de A Coruña. Administración de Rentas Públicas. Registro de liquidaciones de profesionales por utilidades. Tarifa 1 ${ }^{a}$. 1924-1939. Libros 5.237-5.238.

- Delegación de Hacienda de A Coruña. Intervención de Hacienda. Auxiliar de cuentas corrientes por contribución sobre utilidades de la riqueza mobiliaria con los bancos y sociedades por los beneficios que obtienen. 1914-1926, 19271929. Libros 4.535-4.547, 4.564-4.566.

Archivo Histórico Nacional (MADrid).

Archivo Histórico Universitario de la Universidade de Santiago de Compostela. Archivo Municipal de A Coruña:

- Cuentas de suministro de agua para servicios y establecimientos municipales y de obras de abastecimiento de agua. 1923-1937.

- Estados mensuales del consumo de agua en servicios y establecimientos municipales. 1930-1936.

- Expedientes de adjudicación de puestos de mercados. 1914-1936.

- Expedientes de aprovechamiento de aguas públicas. 1901-1966.

- Expedientes de autorización a "Aguas de La Coruña, S.A.” de ejecución de obras de variación y ampliación de la red de distribución de aguas. 1912-1939.

- Expedientes de autorización a "Aguas de La Coruña, S.A." de prestación de suministro de agua a edificaciones situadas fuera del casco de la población. 1929-1936.

- Expedientes de obras municipales de abastecimiento de agua. 1900-1939. 
- Expedientes para la concesión de licencias de obras, varios años.

- Extractos de cuentas de suministro de agua para servicios públicos desde 1916. 1918-1938.

- Libros de Actas del Pleno del Ayuntamiento, varios años.

- Licencias de apertura de establecimientos. 1928-1932.

- Licencias de puestos públicos. 1914-1933.

- Memoria de la Gestión Administrativa del Excmo. Ayuntamiento de La Coruña en el año 1919.

Archivo y Biblioteca del Instituto José CoRnide.

Archivo y Biblioteca del Ministerio de Industria (Madrid):

- Anuario de la Gran Industria de España.

Biblioteca de la Fundación Penzol (Vigo). Industrias Pesqueras. 1932-1936.

Biblioteca de la Real Academia Gallega.

Biblioteca General de la Zona Marítima del Cantábrico. Arsenal Militar Naval (FERRoL).

Biblioteca del Ateneo de A Coruña.

Biblioteca del BANCo de EsPaña (MAdRid).

- Anuario de los valores admitidos a la cotización oficial de la Bolsa de Madrid.

- Anuario Económico Financiero.

- Anuario Financiero de Bilbao. Anuario de los valores mobiliario cotizables y no cotizables en la Bolsa de Comercio de Bilbao.

- Anuario General de España (Bailly-Baillière-Riera). Comercio, Industria, Agricultura, Ganadería, Minería, Propiedad, Profesiones y Elemento Oficial.

Biblioteca del Instituto de Estudios Galegos Padre Sarmiento.

Biblioteca del Museo Arqueológico e Histórico de A Coruña.

Biblioteca del Real Consulado de Comercio de A Coruña.

Biblioteca General del CSIC.

Biblioteca Nacional de España:

- Anuario Bailly-Baillière.

- Anuario de Sociedades Anónimas.

- Anuario de Sociedades Anónimas. Estudio económico-financiero de las existentes en España (Anuario Garciceballos).

- Anuario Económico-Industrial de la Producción Nacional para 1924.

- Anuario Financiero que comprende el historial de valores públicos y de sociedades anónimas de España.

- Anuario Financiero y de Sociedades Anónimas de España. 
- Anuario Garciceballos. Información de Sociedades Anónimas. Economía Nacional. 1919-1920.

- Anuario Marítimo, Comercial, Industrial y de Navegación.

Biblioteca Pública del Estado en La Coruña. Biblioteca Pública del Estado, Catálogo de folletos de Galicia, 1813-1945.

- Biblioteca Pública del Estado, Catálogo de folletos de Galicia. 1833-1929.

Biblioteca Xeral de la Universidade de Santiago de Compostela:

- Estudios Gallegos: 1915-1916.

- Galicia Agraria. 1927-1930.

- Galicia Industrial y Comercial. La Coruña. 1926-1936.

- Vida Gallega. 1933-1935.

Comisaria de Aguas del Norte de España. Proyectos y expedientes de concesiones de aprovechamientos de aguas públicas de La Coruña y Pontevedra. 1901-1939.

Dirección General de Aduanas.

Dirección General de Puertos y Costas:

- Anuario de Pesca Marítima.

- Boletín de Pescas.

Gobierno Civil de La Coruña.

Hemeroteca Municipal de A Coruña.

Instituto Nacional de Estadística (A Coruña):

- Anuario Estadístico de España. 1900-1936.

- Censo de la población de España. 1900-1940.

- Estadísticas de Comercio de Cabotaje de España.

- Estadísticas de Comercio Exterior de España.

- Estadística del movimiento de buques y pasajeros por mar con el exterior.

- Movimiento natural de la población española. 1900-1936.

- Nomenclátor de las ciudades, villas, lugares, aldeas y demás entidades de la provincia de La Coruña. 1900-1940.

Instituto Nacional de Estadística (MADRid). Apuntes para el momento de la industria española de 1930.

Public Record Office. Diplomatic and Consular Reports.

\section{REFERENCIAS}

Abreu, L.F. (1992), "Reconstrucción del ciclo industrial en la economía gallega del siglo XX. Proceso de industrialización en Vigo”, en González LaXe, F. (dir.), Estructura económica de Galicia, Madrid, Espasa-Calpe, pp. 251-295. 
Abreu, L.F. (2002), Iniciativas empresariales en Vigo entre 1866 y 1940, Vigo, Universidad de Vigo.

Alcalá, F. y Sudrià, C. (1989), "The Spanish economy during the First World War: a reassessment", IV Congreso de la Asociación de Historia Económica, Alicante.

AldCroft, D.H. (1961), "Port congestion and the shipping boom of 1919-1920”, Business History, 3 (2), pp. 97-105.

Aldcroft, D.H. (1985), De Versalles a Wall-Street, 1919-1929, Barcelona, Crítica.

Almuedo, J. (1996), Ciudad e Industria. Sevilla 1850-1930, Sevilla, Diputación Provincial de Sevilla.

Alonso Álvarez, L. (1984), "De la manufactura a la industria: la Real Fábrica de Tabacos de La Coruña (1804-1857)", Revista de Historia Económica, II (3), pp. 13-34.

Alonso Álvarez, L. (1998), As tecedeiras do fume. Historia da Fábrica de Tabacos da Coruña, Vigo, A Nosa Terra.

Alonso Álvarez, L. (2000), "El poder empresarial de Galicia en perspectiva histórica”, en OJeA, F. (coord.), Grandes empresas, grandes historias de Galicia, A Coruña, La Voz de Galicia, pp. 9-48.

Alonso Álvarez, L. (2003), “A Fábrica de Tabacos da Coruña: Unha perspectiva dende a Historia empresarial", en De Juana, J. y Castro, X. (eds.), XII Xornadas de Historia de Galicia. Perspectivas plurais sobre a Historia de Galicia, Ourense, Deputación Provincial, pp. 205-237.

Alonso, B. (1991), "Idade contemporánea (século XX)", en VV.AA., Historia de Galicia, Vigo, A Nosa Terra, pp. 223-273.

Alonso, J.A. (1984), “La Banca y la economía de Galicia en el primer tercio del siglo XX”, en García Delgado, J.L. (ed.), España, 1898-1936: estructura y cambio, Madrid, Universidad Complutense, pp. 189-236.

AlvargonzÁlez, R.M. (1977), Gijón: Industrialización y crecimiento urbano, Gijón, Ayalga.

Alvargonzález, R.M., Fernández, A. y Tomé, S. (1992), “Oviedo, capital señorial en la modernización de Asturias (1890-1936)”, en García Delgado, J.L. (ed.), Las ciudades en la modernización de España. Los decenios interseculares, Madrid, Siglo XXI, pp. 149-159.

ArACIL, J.C. (1989), Introducción al transporte marítimo en España, Alicante, Instituto Juan Gil-Albert.

Aracil, R. y Segura, A. (1995), Historia Económica Mundial y de España, Barcelona, Teide.

Arenas, C. (1995), Sevilla y el Estado. Una perspectiva local de la formación del capitalismo en España (1892-1923), Sevilla, Universidad de Sevilla.

ARgüELlES, R. (1931), Los puertos de pesca en España. Ensayos sobre la organización del problema pesquero nacional, Gijón, Tip. La Industria. 
Armas, P. (1990), La organización del espacio lucense, Lugo, Diputación Provincial. Arroyo, E., Machado, R. y Egea, C. (1992), El sistema urbano de la ciudad de Jaén (análisis geográfico), Granada, Universidad de Granada-Ayuntamiento de Jaén.

Arroyo, J.V. (1999), Banca y Mercados en España, 1920-1960: 1. Galicia, Bilbao, Banco Bilbao Vizcaya.

Arroyo, J.V. (2001), El Banco de La Coruña entre 1918 y 1970, Bilbao, Banco Bilbao Vizcaya Argentaria.

Arroyo, J.V. (2003), La Banca en España en el período de entreguerras, 1920-1935. Un modelo de modernización y crecimiento, Bilbao, Banco Bilbao Vizcaya Argentaria.

Bairoch, P. (1988), Cities and Economic Development: From the Dawn of History to the Present, Chicago, University of Chicago Press.

Barreiro Fernández, X.R. (1981), Historia de Galicia, IV. A edade contemporánea, Vigo, Galaxia.

Barreiro Fernández, X.R. (1986), Historia de la ciudad de La Coruña, La Coruña, La Voz de Galicia.

Barreiro Gil, M.J. (1983), “La generalización de la producción de mercancías y la modernización productiva de la agricultura en Galicia, 1876-1976", Revista de Historia Económica, I (2), pp. 133-146.

Barreiro Gil, M.J. (1990), Prosperidade e atraso en Galicia durante o primeiro tercio do século $X X$, A Coruña, Xunta de Galicia.

Bascoy, M.F. (1985), Contribución al estudio de la estructura económica de Galicia: la matrícula industrial de Santiago, 1893-1936, Universidade de Santiago de Compostela, memoria de licenciatura.

Batanero, M. (1976), "Algunos aspectos de la demografía urbana de La Coruña", Revista del Instituto José Cornide de Estudios Coruñeses, 12, pp. 67-83.

BeIRas, X.M. (1970), Estructura y problemas de la población gallega, La Coruña, Banco del Noroeste.

Beiras, X.M. y LóPez, A. (1999), A poboación galega no século XX, Santiago de Compostela, Laiovento.

Bello, L. (1973), Viaje por las escuelas de Galicia, Madrid, Akal (ed. original de 1929). Ben-Ami, S. (1983), La Dictadura de Primo de Rivera (1923-1930), Barcelona, Planeta.

Bernárdez, A. (1917a), "Los negocios de Galicia", Revista Nacional de Economía, año II, nº 7, pp. 668-681.

Bernárdez, A. (1917b), "Galicia en el tercer año de la Guerra", Revista Nacional de Economía, año II, nº 6, pp. 470-476.

Blanco, F.M. (1996), "Un pequeño achegamento á demografía da cidade da Coruña en torno ó ano 1900", Historia Nova IV: contribución dos xoves historiadores de Galicia, Santiago, Asociación Galega de Historiadores, pp. 137-156. 
Bonet, A. (1987), La historiografía urbana en España, Cáceres, Universidad de Extremadura.

Bonet, A. (1989a), "La historiografía urbana en España", en Història urbana i intervenció en el Centre Històric. III ${ }^{a}$ Setmana d'Estudis Urbans a Lleida, Barcelona, Institut Cartogràfic de Catalunya, pp. 37-55.

Bonet, A. (1989b), "Veinte años de historiografía urbana en España", Ciudad y Territorio, 81-82 (3-4), pp. 19-23.

Bonet, A. (1991), El Urbanismo en España e Hispanoamérica, Madrid, Cátedra.

Bonet, A. (1992), "Estudio Preliminar. Oskar Jürgens, arquitecto prusiano y primer estudioso del urbanismo español”, en Jürgens, O., Ciudades españolas. Su desarrollo y configuración urbanística, Madrid, M.A.P. (ed. original de 1926), pp. xi-xviii.

Brey, G. (1989), Economie et mouvement syndical en Galice (1840-1911), Paris, Thèse de Doctorat d'Etat, Université de Pau et des Pays de l'Adour.

Brey, G. (1992), "Mulleres e conflictividade social na Coruña (1874-1910)”, en PereIRA, D. (coord.), Os conquistadores modernos. Movemento obreiro na Galicia de anteguerra, Vigo, A Nosa Terra, pp. 23-46.

BRITTON, S. (1991), "Services and national accumulation”, International Journal of Urban and Regional Research, 15 (3), pp. 421-431.

Bueno, J.I. (2000), Zaragoza, 1917-1936. De la movilización popular a la reacción conservadora, Zaragoza, Institución Fernando Católico el Santo.

Cabello, E. (1931), "El puerto de Vigo", en Cao Moure, J. (ed.), Libro de oro de la provincia de Pontevedra, Vigo, P.P.K.O.

CÁceres, E. (1980), La formación urbana de Las Palmas, Las Palmas, E.T.S. de Arquitectura.

CAPEl, H. (1968), "Estructura funcional de las ciudades españolas en 1950”, Revista de Geografía, II (2), pp. 93-129.

CAPEl, H. (1974), Estudios sobre el sistema urbano, Barcelona, Universidad de Barcelona.

CAPEL, R.M. (1989), "El modelo de mujer en España a comienzos del siglo XX”, en VV.AA., Actas de las VII Jornadas de Investigación Interdisciplinaria. Mujeres y hombres en la formación del pensamiento occidental, Madrid, Universidad Autónoma, vol. II, pp. 311-320.

Carmona, J. (1990a), El atraso industrial de Galicia. Auge y liquidación de las manufacturas textiles (1750-1900), Barcelona, Ariel.

CARmona, J. (1990b), "Crisis y transformación de la base industrial gallega, 18501936”, en Nadal, J. y Carreras, A. (dir. y coord.) (1990), Pautas regionales de la industrialización española, Barcelona, Ariel, pp. 23-48.

CARmona, J. (1994), "Recursos, organización y tecnología en el crecimiento de la industria española de conservas de pescado, 1900-1936", en NADAL, J. y CATALÁN, J. (eds.), La cara oculta de la industrialización española: la modernización de los sectores no líderes, siglos XIX y XX, Madrid, Alianza, pp. 127-162. 
Carmona, J. (1997), "O mar e a industrialización en Galicia”, en Pereira-Menaut, G. (coord), Galicia fai dous mil anos. O feito diferencial galego. I. Historia, vol. 2. Santiago, Museo do Pobo Galego, pp. 251-276.

CArmona, J. (1998), “A «gran empresa» en Galiza: un primeiro achego aos cambios no grupo das maiores empresas non financeiras entre 1930 e 1973", en DE JuANA, J. y Castro, X. (eds.), X Xornadas de Historia de Galicia. Grandes transformacións na historia contemporánea de Galicia, Ourense, Deputación Provincial, pp. 149-174.

Carmona, J. (1999), "Galicia en el desarrollo del sector eléctrico español (19001982)", en Carreras, A. et al. (eds.), Doctor Jordi Nadal: la industrialització $i$ el desenvolupament econòmic d'Espanya, Barcelona, Universitat de Barcelona, vol. II, pp. 1.378-1.397.

CARmona, J. (2001a), "Galicia: minifundio persistente e industrialización limitada", en Germán, L., Llopis, E., Maluquer De Motes, J. y Zapata, S. (eds.), Historia económica regional de España, siglos XIX y XX, Barcelona, Crítica, pp. 13-45.

CARMOnA, J. (2001b), "La historiografía marítima de una región pesquera: Galicia", en Di Vittorio, A. y Barciela, C. (eds.), La storiografia marittima in Italia e in Spagna in età moderna e contemporanea. Tendenze, orientamenti, linee evolutive, Bari, Cacucci.

CARMONA, J. (2003), "Da sardiña ao automóbil: unhas notas sobre a industria viguesa do século XX”, en Vázquez-vicente, X. (ed.), Vigo. Economía e Sociedade, Vigo, Xerais, pp. 35-54.

Carmona, J. y García Lombardero, X. (1985), “De la crisis del Antiguo Régimen a la formación de los primeros sectores industriales. Dos puntos de inflexión en la historia contemporánea de Galicia", en IX Reunión de Estudios Regionales. Crisis, Autonomías y Desarrollo Regional, Tomo II, Santiago, Universidade, pp. 433-452.

Carmona, J. y Pena, J. (1989), “As origens do sector eléctrico na Galiza, 1888-1936", Agália. Quatro Estudios de historia económica de Galiza, monográfico $n^{\circ} 2$, pp. 33-48.

Carmona, J., Espido, A. y Lozano, A. (1995), “Indústria e sociedade na Galiza do século XIX”, Nosa Terra. A Nosa história, Vigo, Galaxia, pp. 72-77.

Carmona, J., Giráldez, J. y MuÑoz, L. (2000), "Galicia”, en Vivir no Atlántico Norte, Santiago de Compostela, Museo do Pobo Galego, pp. 65-83.

CARnero, T. (1992), "La modernización de la ciudad (1895-1935): Cambios y persistencias”, en García Delgado, J.L. (ed.), Las ciudades en la modernización de España. Los decenios interseculares, Madrid, Siglo XXI, pp. 189-196.

CARr, R. (1969), España, 1808-1939, Barcelona, Ariel.

CArré, E. (1929), "Provincia de La Coruña (Tomos I y II)", en CArreras y CAndi, F. (dir.), Geografía General del Reino de Galicia, Barcelona, Editorial de Alberto Martín. Reedición de 1980, La Coruña, Ed. Gallegas S.A. 
CArré, L. (1935), "La Coruña, ciudad de turismo", R.A.I.G. Revista Artística Ilustrada de Galicia, año I, no 4, abril-mayo.

Carreras, A. (1984), "La producción industrial española, 1842-1981: construcción de un índice anual”, Revista de Historia Económica, II (1), pp. 127-157.

Carreras, A. (1985a), "Gasto Nacional Bruto y formación de capital en España, 18491958: primer ensayo de estimación”, en Prados, L. y Martín Aceña, P. (eds.), La nueva historia económica en España, Madrid, Tecnos, pp. 17-51.

Carreras, A. (1985b), "Los ciclos de la economía española”, Enciclopedia de la Economía Española, Barcelona, Orbis, fascículo 16.

CArreras, A. (1990), Industrialización española: estudios de historia cuantitativa, Madrid, Espasa-Calpe.

CArreras, A. (1991), "La industria: atraso y modernización”, en NAdAl, J., CARreras, A. y SudRià, C. (comps.), La economía española en el siglo XX. Una perspectiva histórica, Barcelona, Ariel, 4⿳a ed., pp. 280-312.

Carreras, A. (coord.) (1989), Estadísticas históricas de España, siglos XIX-XX, Madrid, Fundación Banco Exterior.

Carreras, A. y Fontana, J. (1997), "La industrialización: una perspectiva a largo plazo", Papeles de Economía Española, no 73, pp. 35-60.

Casares, J. (1987), "La distribución comercial”, en CASARes, J. (comp.) et al., La economía de la distribución comercial, Barcelona, Ariel, pp. 17-25.

CAsares, J. y Briz, J. (1987), "Una revisión histórica del comercio español”, en CASARES, J. (comp.) et al., La economía de la distribución comercial, Barcelona, Ariel, pp. 94-107.

Casares, J. y Rebollo, A. (1991), “Distribución comercial. La aceleración del cambio: 1966-1991, veinticinco años de revolución comercial en España”, Distribución y Consumo, 1, pp. 10-38.

Casariego, J. (1987), Las Palmas. Dependencia, marginalidad y autoconstrucción, Madrid, I.E.A.L.

Claverol, L. y Vilagrasa, J. (1989), "Pròleg", en Història urbana i intervenció en el Centre Històric. III a Setmana d"Estudis Urbans a Lleida, Barcelona, Institut Cartogràfic de Catalunya, pp. 11-16.

Clemente, E. (1984), Desarrollo urbano y crisis social en Ferrol, Salamanca, C.O.A.G.

Colectivo Xerminal (1990), “Crise económica e loitas sociais na Galicia republicana: o conflicto pesqueiro vigúes en 1932”, en Barreiro Fernández, X.R. et al., O movemento obreiro en Galicia. Catro ensaios, Vigo, Xerais, pp. 139-312.

Colino, A. y Grandío, E. (1994), La Coruña en el siglo XIX, La Coruña, Vía Láctea.

Comín, F. (1991), "La economía española en el período de entreguerras (1919-1935)", en Nadal, J., CARreras, A. y Sudrià, C. (comps.), La economía española en el siglo XX. Una perspectiva histórica, Barcelona, Ariel, 4ª ed., pp. 105-149. 
Comín, F. (1993), "Estado y crecimiento económico en España: lecciones de la historia", Papeles de Economía Española, 57, pp. 32-56.

Comín, F. (2002), “El período de entreguerras (1914-1936)”, en Comín, F., Hernández, M. y Llopis, E. (eds.), Historia Económica de España. Siglos X-XX, Barcelona, Crítica, pp. 285-329.

Costa Rico, A. (1980), O ensino en Galicia, Santiago, Ed. do Cerne.

Costa Rico, A. (1986), "Socialismo e educación na Galiza do primeiro tercio do século XX”, en Castro, X. y De Juana, J. (eds.), II Xornadas de Historia de Galicia, Ourense, Deputación Provincial, pp. 135-164.

DANIELS, P.W. (1991), "Services and urban economic development”, en Fox-PrZEWORSKI, J., Goddard, J. y De Jong, M. (eds.), Urban Regeneration in a Changing Economy. An International Perspective, Oxford, Oxford University Press, pp. 75-95.

De Juana, J. y CAstro, X. (1990), "Población y emigración en la Galicia contemporánea", en De Juana, J. e CAstro, X. (dirs.), V Xornadas de Historia de Galicia, Ourense, Deputación Provincial, pp. 11-68.

De Juana, J. y CAstro, X. (1998), “Unha época de mutacións e permanencias”, en De Juana, J. e Castro, X. (eds.), X Xornadas de Historia de Galicia. Grandes transformacións na historia contemporánea de Galicia, Ourense, Deputación Provincial, pp. 7-10.

De La Puerta, N. (1994), El puerto de Bilbao como reflejo del desarrollo industrial de Vizcaya, 1857-1913, Bilbao, Autoridad Portuaria de Bilbao.

De Terán, F. (1996), "Historia urbana moderna en España. Recuento y acopio de materiales", en SAmbricio, C. (ed.), La historia urbana. Revista Ayer, no 23, pp. 87-107.

De Terán, F. (1999), Historia del urbanismo en España. III. Siglos XIX y XX, Madrid, Cátedra.

Del Cueto, R. (1922), Impresiones sobre la minería en Galicia, La Coruña.

Del Cueto, R. y De Irimo, A.M. (1910), La minería en Galicia (Lugo y La Coruña), La Coruña, Leonardo Rodríguez.

Del Val, M.I. (1997), "Urban growth and royal interventionism in late medieval Castile", Urban History, 24 (1), pp. 129-140.

Delgado, C. (1995), Las pequeñas y medianas capitales de provincia en el proceso de modernización del sistema urbano español, Las Palmas, Universidad.

DíEz NicolÁs, J. (1972), Especialización funcional y dominación en la España urbana, Madrid, Fundación Juan March-Guadarrama.

Donges, J.B. (1976), La industrialización en España. Políticas, logros, perspectivas, Barcelona, Oikos-Tau.

EIRAs, A. (1993), "La emigración gallega a las Américas en los siglos XIX y XX. Nueva panorámica revisada", en EIRAs, A. (ed.), Aportaciones al estudio de la emigración gallega. Un enfoque comarcal, Santiago de Compostela, Xunta de Galicia, pp. $185-215$. 
EIROA, F. (1997), Historia y desarrollo de la pesca de arrastre en Galicia. Siglos XVIII al $X X$, A Coruña, Diputación Provincial de A Coruña.

Escartín, J.M. (2001), La ciutat amuntegada. Indústria del calçat, desenvolupament urbà $i$ condiciuns de vida en la Palma contemporània, Palma de Mallorca, Documenta Balear.

Espárrago, M. (1944), “Aspecto económico de los puertos de la costa gallega”, en FILgueira, J., Arízcun, R. y Espárrago, M., Galicia y el mar, Madrid, Real Sociedad Geográfica, pp. 96-140.

Fernández Clemente, E. y ForCadell, C. (1992), “Crecimiento económico, diversificación social y expansión urbana en Zaragoza, 1900-1930”, en GARCía Delgado, J.L. (ed.), Las ciudades en la modernización de España. Los decenios interseculares, Madrid, Siglo XXI, pp. 433-457.

Fernández Cuenca, E. (1991), El comercio minorista en la ciudad de Alicante, Alicante, Caja de Ahorros Provincial.

Fernández De Castro, I. (1973), La fuerza de trabajo en España, Madrid, Cuadernos para el Diálogo.

Fernández Leiceaga, X. (1998), "Poboación e crescimento económico na Galiza no século XX", en De JuAnA, J. y CAStro, X. (eds.), X Xornadas de Historia de Galicia. Grandes transformacións na historia contemporánea de Galicia, Ourense, Deputación Provincial, pp. 123-147.

Fernández Leiceaga, X. y López Iglesias, E. (2000), Estrutura económica de Galiza, Santiago, Laiovento.

FernÁndez Prieto, L.F. (1992), Labregos con ciencia. Estado, sociedade e innovación tecnolóxica na agricultura galega, 1850-1939, Vigo, Xerais.

Fernández Prieto, L.F. (1998), "Antonte fronte a onte: As orixes da innovación tecnolóxica na agricultura galega", en De Juana, J. y Castro, X. (eds.), X Xornadas de Historia de Galicia. Grandes transformacións na historia contemporánea de Galicia, Ourense, Deputación Provincial, pp. 27-55.

Fernández Prieto, L.F. (2000), “Caracterización da agricultura galega contemporánea: entre o atraso e adaptación ao capitalismo”, en Fernández Prieto, L.F. (dir.), Terra e progreso. Historia agraria da Galicia contemporánea, Vigo, Xerais, pp. 45-60.

Fernández Santander, C. (1987), 1886-1986, Cámara Oficial de Comercio, Industria y Navegación, La Coruña, COCINC.

FERnÁndez Vázquez, M.T. (2002), La industria del curtido en la Galicia contemporánea, Universidade de Santiago de Compostela, tesis doctoral.

Fontana, J. y Nadal, J. (1980), “España 1914-1970”, en Cipolla, C.M. (ed.), Historia económica de Europa (6). Economías contemporáneas, Barcelona, Ariel, pp. 95-163.

Frax, E. (1981), Puertos y comercio de cabotaje en España, 1857-1934, Madrid, Servicio de Estudios del Banco de España. 
Freire, J. (1984), "Pasado, presente y futuro del puerto pesquero de La Coruña", Presente y futuro de La Coruña, La Coruña, Instituto José Cornide de Estudios Coruñeses, vol. II, pp. 129-140.

GÁmir, L. (1975), "Política de transformación de las estructuras comerciales interiores", en GÁmir, L. et al., Política económica de España, Madrid, Guadiana, pp. 375-408.

García Barbancho, A. (1967), Las migraciones interiores españolas. Estudio cuantitativo desde 1900, Madrid, Instituto de Estudios de Desarrollo Económico.

García Delgado, J.L. (1981), “La economía española entre 1900 y 1923”, en TuÑón, M. (dir.), Historia de España. VIII. Revolución burguesa, oligarquía y constitucionalismo (1834-1923), Barcelona, Labor, pp. 407-458.

García Delgado, J.L. (1983a), "El ciclo industrial de la economía española entre 1914 y 1922", Estudios de Historia Social, 24-25, pp. 7-22.

García Delgado, J.L. (1983b), "Prosperidad y crisis en la industria española entre 1914 y 1922. Una reconsideración”, en ANEs, G., RoJo, L.A. y Tedde, P. (ed.), Historia económica y pensamiento social, Madrid, Alianza, pp. 539-560.

García Delgado, J.L. (1984), "La industrialización española en el primer tercio del siglo XX”, en Jover, J.M. (ed.), Historia de España Menéndez Pidal. Los comienzos del siglo XX. La población, la economía, la sociedad (1898-1931), Madrid, EspasaCalpe, pp. 3-171.

García Delgado, J.L. (1986), "Industrialización y nacionalismo económico en la España del primer tercio del siglo XX", en Martínez VARA, T. (ed.), Mercado y desarrollo en la España contemporánea, Madrid, Siglo XXI, pp. 113-130.

García Delgado, J.L. (1991), "Nacionalismo económico e intervencionismo estatal, 1900-1930", en SÁnchez-Albornoz, N. (ed.), La modernización económica de España, 1830-1930, Madrid, Alianza, $3^{\mathrm{a}}$ ed., pp. 176-195.

García Delgado, J.L. (1992), "Madrid en los decenios interseculares: la economía de una naciente capital moderna", en García Delgado, J.L. (ed.), Las ciudades en la modernización de España. Los decenios interseculares, Madrid, Siglo XXI, pp. 405-414.

García Delgado, J.L. y Jiménez, J.C. (1998), "La recuperación económica tras la pérdida de los mercados de ultramar", en Laín, P. y SeCo, C. (eds.), España en 1898. Las claves del Desastre, Barcelona, Galaxia-Gutemberg, pp. 261-276.

García Lombardero, X. (1984), "La economía de Galicia en los siglos XIX y XX", Papeles de Economía Española, 20, pp. 319-333.

García López, A. (2003), La actividad bancaria en Galicia. Desde el Catastro del Marqués de Ensenada a la Ley Cambó, Valladolid, Lex Nova.

GARCíA LóPEZ, J.R. (1989), "El sistema bancario español del siglo XIX: ¿una estructura dual? Nuevos planteamientos y nuevas propuestas", Revista de Historia Económi$c a$, VII (1), pp. 111-132. 
García Márquez, M. (1983), Geografía urbana de Teruel, Teruel, CSIC.

García Martínez, C. (1995), Actividad comercial y espacio urbano: la organización espacial del comercio minorista en la ciudad de Albacete, Universidad de CastillaLa Mancha, tesis doctoral.

García Merino, L.V. (1987), La formación de una ciudad industrial. El despegue urbano de Bilbao, Bilbao, Instituto Vasco de Administración Pública.

García Merino, L.V. (1992), "La consolidación de Bilbao como ciudad industrial", en García Delgado, J.L. (ed.), Las ciudades en la modernización de España. Los decenios interseculares, Madrid, Siglo XXI, pp. 97-127.

García Merino, L.V. (1995), "Prólogo", en Delgado Viñas, C., Las pequeñas y medianas capitales de provincia en el proceso de modernización del sistema urbano español, Las Palmas, Universidad, pp. 7-17.

García Ruiz, J.L. (2002), Los flujos financieros regionales en la España del siglo XX: una perspectiva desde la historia bancaria, Madrid, Fundación Empresa Pública.

García Ruiz, J.L. (2003), Sobre ruedas: una historia crítica de la industria del automóvil en España, Madrid, Síntesis.

GArrido, A. (2003), "Pie de foto para una colección de postales. El crecimiento urbano de A Coruña en la primera mitad del siglo XX", en III Catálogo de la Colección de Postales. Archivo Municipal, A Coruña, Ayuntamiento de A Coruña, pp. 13-20.

Gelabert, J.E. (1995), “Cities, towns and small towns in Castile 1500-1800”, en Clark, P. (ed), Small Towns in Early Modern Europe, Cambridge, Cambridge University Press, pp. 271-293.

Gemmell, N. y Wardley, P. (1990), “The contribution of services to British economy, 1856-1913”, Explorations in Economic History, 27 (3), pp. 299-321.

GERMÁn, L. (1996), “La transformación de la ciudad de Zaragoza 1900-1936”, en VV.AA., Historia de Aragón. II. Historia Económica y Social, Zaragoza, IFC, pp. 459-468.

GiRÁLDEZ, J. (1996), Crecimiento y transformación del sector pesquero gallego, 18801936, Madrid, MAPA.

GiRÁLDEZ, J. (1997a), De las Rías a Terranova: La expansión de la pesca gallega (18801950), Vigo, SIPSA.

Giráldez, J. (1997b), “A explotación dos recursos do mar”, en Pereira-Menaut, G. (coord.), Galicia fai dous mil anos. O feito diferencial galego. I. Historia, vol. 2, Santiago, Museo do Pobo Galego, pp. 235-250.

GirÁldez, J. (2000), “La Artística-Alonarti. Adaptación continua”, en OjEA, F. (coord.), Grandes empresas, grandes historias de Galicia, A Coruña, La Voz de Galicia, pp. 212-213.

Giráldez, J. (2002), “Armadores de Cádiz: competir y cooperar”, Historia Agraria, 28, pp. 91-112. 
Gómez Cruz, C. (1994), La ciutat de Tarragona a l'època de la Dictadura de Primo de Rivera: aspectes de la vida urbana, Tarragona, Cercle d'Estudis Històrics i Socials "Guillem Oliver".

Gómez Martínez, J.A. (2003), "La Sociedad Minera de Villaodrid y el ferrocarril de Puente Nuevo a Ribadeo", III Congreso de Historia Ferroviaria, Gijón.

GonzÁlez Catoyra, A. (1990), Biografías coruñesas, A Coruña, Fundación Caixa Galicia.

GonzÁlez GonzÁlez, M.J. (1987), Diferenciación socioeconómica en la ciudad de León, León, Universidad de León.

GonzÁlez LaXe, F.I. (1984), "La Coruña y su perspectiva histórica pesquera", en Presente y futuro de La Coruña, La Coruña, Instituto José Cornide de Estudios Coruñeses, vol. II, pp. 97-128.

GonzÁlez LAXe, F.I. (1992), "El modelo de funcionamiento de la economía gallega", en GonzÁlez Laxe, F.I. (dir.), Estructura económica de Galicia, Madrid, EspasaCalpe, pp. 19-53.

González Laxe, F.I., De Llano, G. y De Llano, P. (1999), Análisis económico del sistema portuario gallego, A Coruña, Fundación Pedro Barrié de la Maza.

GonzÁlez Portilla, M. (ed.) (2001), Los orígenes de una metrópoli industrial: la Ría de Bilbao, Bilbao, Fundación BBVA.

GonzÁlez Probados, M. (1983), Movemento obreiro e socialismo. A Coruña, 19311933, A Coruña, Ed. do Castro.

GonzÁlez, Ma.C. (2000), "Banco Pastor. Del salazón a las altas finanzas”, en OjeA, F. (coord.), Grandes empresas, grandes historias de Galicia, A Coruña, La Voz de Galicia, pp. 94-101.

GozÁlvez, V. (1987), “Evolución de la población”, en VV.AA. (1987), Atlas sociodemográfico de la ciudad de Alicante, Alicante, Instituto de Estudios Juan Gil-Albert, Diputación Provincial de Alicante, Ayuntamiento de Alicante, pp. 35-38.

Grandío, E. (2000), Años de Guerra. A Coruña, 1936-1939, A Coruña, Vía Láctea.

GuÀRdia, M., Monclús, F.J. y OYón, J.L. (1994), “Un instrumento para la comparación en la historia urbana europea”, en GuÀrdia, M., Monclús, F.J. y OYón, J.L. (eds), Atlas histórico de ciudades europeas, Barcelona, Centre de Cultura Contemporània, pp. xii-Xv.

GuimerÁ, A. (1996), “El sistema portuario español (siglos XVI-XX): Perspectivas de investigación”, en GuimerÁ, A. y Romero, D. (eds.) (1996), Puertos y sistemas portuarios (siglos XIX y XX), Madrid, Ministerio de Fomento-Ente Público Puertos del Estado-CEDEX-CEHOPU-CSIC, pp. 125-142.

HARrison, J. (1983), "The inter-war depression and the Spanish economy", Journal of European Economic History, 2, pp. 295-321. 
Harrison, J. (1988), Historia económica de la España contemporánea, Barcelona, Vicens-Vives, $3^{\mathrm{a}}$ ed.

Hernández Andreu, J. (1980), Depresión económica en España, 1925-1934, Madrid, Instituto de Estudios Fiscales.

Hernández Andreu, J. (1986), España y la crisis de 1929, Madrid, Espasa-Calpe.

Hernández Borge, J. (1980), “Los puertos gallegos en la emigración española a América", Revista de la Excma. Diputación de Pontevedra, nº 0, pp. 41-52.

Hernández Borge, J. (1997), "Los puertos de Vigo y La Coruña en la última fase de la emigración española a América", en Dinámica Litoral-Interior. Actas XV Congreso de Geógrafos Españoles, Santiago de Compostela, A.G.E.-Universidade, vol. II, pp. 813-820.

Instituto de Reformas Sociales (1914), Resumen de las informaciones de los inspectores del trabajo acerca de las consecuencias sufridas por las industrias en España con motivo del actual estado de guerra, Madrid.

Instituto de Reformas Sociales (1916), Coste de la vida del obrero. Estadística de los precios de los artículos de primera necesidad en toda España, desde 1909 a 1915, Madrid.

Instituto de ReFORMAs Sociales (1919a), Informes de los Inspectores del Trabajo sobre la influencia de la Guerra Europea en las industrias españolas (1917-1918), Madrid.

Instituto de Reformas Sociales (1919b), Memoria general de la inspección del trabajo correspondiente al año 1917, Madrid.

Instituto de Reformas Sociales (1920), Aplicación de la jornada máxima de ocho horas: informe de la sección, acuerdos y disposiciones correspondientes, Madrid.

Instituto de Reformas Sociales (1921a), Crisis industrial de las capitales de provincia. Resumen de los informes remitidos por los Inspectores del Trabajo en mayo-junio de 1921, Madrid.

Instituto de Reformas Sociales (1921b), Memoria general de la inspección del trabajo correspondiente al año 1919, Madrid.

Instituto de Reformas Sociales (1923), Memoria general de la inspección del trabajo correspondiente al año 1921, Madrid.

Jefrreys, J.B. (1954), Retail Trading in Britain, 1858-1950, Cambridge, Cambridge University Press.

Labarta, U. (1985), A Galicia Mariñeira, Vigo, Galaxia.

LANvin, B. (1991), "Services and new industrial strategies: What is at stake for developing countries?", en Daniels, P.W. y Moulaert, F. (eds.), The Changing Geography of Advanced Producer Services, London, Belhaven Press, pp. 197-210.

LARrinagA, C. (1997), "Ciudad, economía e infraestructura urbana: San Sebastián a mediados del siglo XIX”, Actas del VI Congreso de la Asociación de Historia Económica, Girona, $7^{\mathrm{a}}$ sesión, pp. 75-80. 
Lindoso, E. (1999), Empresas y empresarios en La Coruña, 1830-1914, Madrid, Fundación Empresa Pública.

Lindoso, E. (2003), "El registro mercantil de A Coruña: una fuente para la historia empresarial decimonónica", en Martín Rodríguez, M. et al. (dirs.), El Registro Mercantil: una fuente para la historia económica, Granada, Universidad de Granada, pp. 31-51.

Lindoso, E. y Mirás, J. (2001), "La trayectoria de una economía urbana, A Coruña (1868-1936)", en Grandío, E., Romero, A.M., Barreiro, X.R. (eds.), El Republicanismo coruñés en la historia, A Coruña, Ayuntamiento de A Coruña, pp. 31-38.

Llordén, F. (1994), Desarrollo económico y urbano de Gijón en los siglos XIX y XX, Gijón, Universidad de Oviedo.

LoIs, R.C. (1996), “As novas formas de urbanización”, en III e IV Semanas Galegas de Historia. A Guerra en Galicia. O Rural e o Urbano na Historia de Galicia, Santiago de Compostela, Asociación Galega de Historiadores, pp. 451-485.

López GonzÁlez, A. (1999), "El impacto espacial del comercio de Lugo sobre su provincia”, en Domínguez, R. (coord.), La ciudad. Tamaño y crecimiento, Málaga, Universidad de Málaga, pp. 111-121.

López Prado, A. (1966), 3 etapas en el proceso socioeconómico de La Coruña, 1900, 1930 y 1965, A Coruña, Instituto José Cornide de Estudios Coruñeses.

López Prado, A. (1968), “Galicia y los problemas del subdesarrollo”, en El Banco de La Coruña. Bodas de oro 1918-1968, La Coruña, Banco de La Coruña, pp. 137-202.

López Prado, A. (1984), "La Coruña y el ahorro gallego, con algunos apuntes sobre la política monetaria y las entidades de crédito", Presente y futuro de La Coruña, La Coruña, Revista del Instituto José Cornide de Estudios Coruñeses, vol. II, pp. 279-334.

Losada, A. (1995), As relacións económicas entre Galicia e os países destino da emigración, Santiago, Xunta de Galicia.

Luengo, F. (1990), Crecimiento económico y cambio social. Guipúzcoa 1917-1923, Bilbao, Universidad del País Vasco.

Magán, J.M. (1997), El desarrollo urbanístico de la ciudad de Albacete, Albacete, Instituto de Estudios Albacetenses.

Maixé, J.C. (dir.), Vilar, M. y Lindoso, E. (2003), El ahorro de los gallegos. Orígenes e historia de Caixa Galicia (1876-2002), A Coruña, Fundación Caixa Galicia.

Máiz, B. (1988), Galicia na Segunda República e baixo o franquismo (1930-1976), Vigo, Galaxia.

Malerbe, P. (1979), "España entre la crisis de posguerra (1920-1921) y la Dictadura", Cuadernos Económicos de I.C.E., nº 10.

Maluquer, J. (1991), "De la crisis colonial a la Guerra Europea: Veinte años de economía española”, en NAdAl, J., CARreras, A. y Sudrià, C. (comps.), La economía española en el siglo XX. Una perspectiva histórica, Barcelona, Ariel, pp. 62-104. 
Martín Aceña, P. (1983), "La crisis financiera española de 1931 y la política monetaria del primer gobierno de la República”, en Anes, G., Rojo, L.A. y Tedde, P. (eds.), Historia económica y pensamiento social, Madrid, Alianza, pp. 611-648.

Martín AceñA, P. (1984), La política monetaria en España, 1919-1935, Madrid, IEF.

Martín AcEÑA, P. (1985), "Desarrollo y modernización del sistema financiero, 18441935”, en Sánchez Albornoz, N. (ed.), La modernización económica de España 1830-1930, Madrid, Alianza, pp. 121-146.

Martín Aceña, P. (1987), “Economía y política económica durante el primer bienio republicano (1931-1933)”, en García Delgado, J.L. (ed.), La II República española. El primer bienio, Madrid, Siglo XXI, pp. 119-134.

Martín Aceña, P. y Pons, Mª.A. (1995), Estructura y rentabilidad de las empresas financieras en España, 1874-1975, Madrid, Fundación Empresa Pública.

Martínez Cuadrado, M. (1974), La burguesía conservadora (1874-1931), Madrid, Alianza.

Martínez De Pisón, E. (1976), Segovia. Evolución de un paisaje urbano, Madrid, Colegio de Ingenieros de Caminos, Canales y Puertos.

Martínez López, A. (1995), "Agricultura e agrarismo no primeiro tercio do século XX”, en Beramendi, J.G. e Roca, M. (eds.), Lois Peña Novo. Obra completa, Santiago, Universidade de Santiago de Compostela, tomo I, pp. 115-134.

MArTínez LóPEz, A. (1997), "El fracaso de la modernización de una industria tradicional: las tenerías gallegas, 1750-1935”, Estudis d'Història Econòmica, 14, pp. 89-115.

Martínez López, A. (2000a), "Perspectiva histórica da gandería galega: Da complementariedade agraria á crise da intensificación láctea”, en FERnández Prieto, L. (dir.), Terra e progreso. Historia agraria da Galicia contemporánea, Vigo, Xerais, pp. 353-381.

Martínez LóPez, A. (2000b), "La ganadería gallega durante el primer franquismo: Crónica de un tiempo perdido, 1936-1960”, Historia Agraria, 20, pp. 197-224.

Martínez López, A. (2001), “Administración local e dotación de servicios: a longa xénese do abastecemento de agua na Coruña", Revista Galega de Administración Pública, 27, pp. 111-126.

Martínez López, A. (2002), "El consumo de carne en las ciudades españolas, 18911935”, IX Simposio de Historia Económica, Barcelona.

Martínez López, A. (dir.) et al. (2004), Aguas de A Coruña: 1903-2003. Cien años al servicio de la ciudad, Madrid, LID-EMALCSA.

Martínez López, A. y Piñeiro, C. (1998), “La actividad empresarial durante el primer franquismo: La Compañía de Tranvías de La Coruña, 1936-1962”, III Encuentro de Investigadores sobre el Franquismo y la Transición Española, Sevilla, pp. 150-164. 
Martínez López, A. y Piñeiro, C. (2001), "Empresas e servicios públicos: a creación dunha infraestructura de transporte urbano, A Coruña 1876-1925", Revista Galega de Economía, 10 (1), pp. 1-29.

Martínez López, A. y Piñeiro, C. (2003), "Nacemento e desenvolvemento dun servicio público esencial: O abastecemento de auga na cidade de A Coruña, 1903-1936", Cuadernos de Estudios Gallegos, L (116), pp. 177-211.

Martínez Suárez, X.L. y Casabella, X. (1989), Catálogo de Arquitectura. A Coruña 1890-1940, Santiago de Compostela, C.O.A.G., $2^{\mathrm{a}}$ ed.

Massó, G. (1967), "Industria conservera de pescados", en Galicia y su desarrollo económico, Bilbao, Banco de Vizcaya, pp. 111-124.

Méndez Romeu, J.L. (1987), "Implantación de la enseñanza graduada en La Coruña", Revista del Instituto José Cornide de Estudios Coruñeses, 23, pp. 121-140.

MirÁs, J. (2003a), La actividad pesquera en el puerto de A Coruña, 1914-1960, A Coruña, Instituto Universitario de Estudios Marítimos.

MiRÁs, J. (2003b), "Un primeiro achegamento ao impacto do porto na vida económica urbana: A Coruña, 1914-1935", Abalar, 1, pp. 56-65.

MiRÁs, J. (2003c), "Servizo público e grupos empresariais no abastecemento de auga á cidade da Coruña. A empresa «Aguas de La Coruña, S.A.»", Murguía. Revista Galega de Historia, 2, pp. 47-59.

MiRÁs, J. (2004a), "La estructura profesional de una ciudad terciaria: A Coruña, 19001960", Geo Crítica/Scripta Nova. Revista electrónica de geografía y ciencias sociales, vol. VIII, no 163, 15 de abril de 2004. http://www.ub.es/geocrit/sn/sn-163.htm.

MirÁs, J. (2004b), "El puerto y la actividad económica en la ciudad de A Coruña, 1914-1935", Geo Crítica/Scripta Nova. Revista electrónica de geografía y ciencias sociales, vol. VIII, no 177. http://www.ub.es/geocrit/sn/sn-177.htm.

MiRÁs, J. (2004c), "El tráfico mercantil portuario en una etapa de transición: A Coruña (1913-1960)", Investigaciones Geográficas, 33, pp. 119-140.

MiRÁs, J. (2004d), "Shifts in the economic structure of a medium-sized Spanish town during the post-war period: La Coruña, 1939-60", Urban History, 31 (3), pp. 357-374.

MiRÁs, J. (2005a) "Comportamiento de los indicadores de crecimiento de la población en una ciudad de rango intermedio. A Coruña 1900-1940", Boletín de la Asociación de Geógrafos Españoles, 40, pp. 375-392.

MiRÁs, J. (2005b), "Changes in the working population and domestic service in a peripheral Spanish town. A Coruña, 1900-1960", The International Journal of Regional and Local Studies, Series 2, 1 (1), pp. 4-20.

MirÁs, J. (2005c), "Evoluzione del settore terziario in una citta' spagnola: La Coruña, 1914-1935", Storia Urbana, 110 (en prensa).

MiRÁs, J. (2005d), "The Spanish tramway as a vehicle of urban shaping: La Coruña from 1903 to 1962", The Journal of Transport History, 26 (2), pp. 20-37. 
Mirás, J. (2005e), "El impacto de la Primera Guerra Mundial en la industria de A Coruña", Revista de Historia Industrial, 29, pp. 143-162.

Mirás, J. (2005f), “Continuidades y transformaciones económicas en las ciudades españolas durante el período de entreguerras", XXV Encontro da Associação de História Económica e Social, Évora.

Mirás, J. (2007), “The Commercial Sector in an early-twentieth century Spanish City. La Coruña 1914-1935”, Journal of Urban History, vol. 32 (en prensa).

Monclús, F.J. (1992), "Planning and History in Spain", Planning Perspective, 7 (1), pp. 101-106.

Monclús, F.J. (1993), recensión en Historia Urbana, no 3, pp. 114-116.

Monclús, F.J. (1995), “Arte urbano y estudios histórico-urbanísticos. Tradiciones, ciclos y recuperaciones", 3ZU. Revista de Arquitectura, 4, pp. 92-101.

Moreno, A. y Escolano, S. (1992), El comercio y los servicios para la producción y el consumo, Madrid, Síntesis.

Morilla, J. (1992), “La economía de Málaga, 1890-1930”, en García Delgado, J.L. (ed.), Las ciudades en la modernización de España. Los decenios interseculares, Madrid, Siglo XXI, pp. 323-343.

Muñoz Abeledo, L. (2002), Los mercados de trabajo en las industrias marítimas de Galicia. Una perspectiva histórica, 1870-1936, Universitat de Barcelona, tesis doctoral.

Muñoz, J., Roldán, S. y Serrano, A. (1978), "La involución nacionalista y la vertebración del capitalismo español”, Cuadernos Económicos de ICE, 5, pp. 13-221.

NADAL, J. (1987a), El fracaso de la Revolución industrial en España, 1813-1914, Barcelona, Ariel, $8^{\mathrm{a}}$ ed. (1 ${ }^{\mathrm{a}}$ ed., 1975).

NADAL, J. (1987b), "La industria fabril española en 1900. Una aproximación”, en NADAl, J., Carreras, A. y SudriÀ, C. (comps.), La economía española en el siglo XX. Una perspectiva histórica, Barcelona, Ariel, pp. 23-61.

NADAl, J. (1988), La población española (siglos XVI al XX), Barcelona, Ariel, $3^{\mathrm{a}}$ ed.

NadAl, J. (dir.) et al. (2003), Atlas de la industrialización de España, 1750-2000, Barcelona, Crítica.

Navajas, F. (1984), "Proyección económica y social de la Fábrica de Tabacos de La Coruña”, en Presente y futuro de La Coruña, La Coruña, Instituto José Cornide de Estudios Coruñeses, vol. II, pp. 141-158.

Nielfa, G. (1984), "Mercado y organización del trabajo en el comercio 1883-1931", Estudios de Historia Social, 30 (III), pp. 137-148.

NiElfa, G. (1989), “Las estructuras comerciales en Madrid, 1900-1931: el minifundismo comercial”, en BAhAmonde, A. y Otero, L.E. (comps.), La sociedad madrileña durante la Restauración, 1876-1931, Madrid, Comunidad de Madrid, pp. 429-458. 
Nogueira, C. (1980a), "Evolución histórica e estructura sectorial da economía industrial”, en Nogueira, C., Soto, L. y López Facal, X., O poder industrial en Galicia, Vigo, Xerais, pp. 11-58.

Nogueira, C. (1980b), "Evolución histórica e estrutura sectorial da economía industrial”, en Durán, J.A. (dir. y coord.), Galicia. Realidade económica e conflicto social, A Coruña, Banco de Bilbao, pp. 205-234.

Nogueira, C., Soto, L. y López Facal, X. (1980), O poder industrial en Galicia, Vigo, Xerais.

NúÑEz SeIXAs, X.M. (1998), Emigrantes, caciques e indianos. O influxo sociopolítico da emigración transoceánica en Galicia (1900-1930), Vigo, Xerais.

NúÑEz, G. (2001), "Modernización de las ciudades españolas durante la crisis política de la Restauración", Ciudad y Territorio. Estudios Territoriales, XXXIII (128), pp. 251-273.

Odriozola, A. y Barreiro, X.R. (1992), Historia de la imprenta en Galicia, La Coruña, Biblioteca Gallega.

OrTiz-VILLAJos, J.M. (1999), “Tecnología y desarrollo regional en España, 1882-1935. Estudio basado en las patentes de invención”, Revista de Historia Económica, XVII (1), pp. 11-50.

Otero Díaz, C. (1972), "Apariencia y realidad del desarrollo económico de Galicia”, en Terceiro, J.B. (ed.), Problemas y soluciones del desarrollo económico de Galicia, Madrid, ZYX, pp. 19-38.

Oyón, J.L. (1993), “Spain”, en Rodger, R. (ed.), European Urban History. Prospect and Retrospect, Leicester, Leicester University Press, pp. 37-59.

OYón, J.L. (ed.) (1998), Urbanismo, ciudad, historia (II). Vida obrera en la Barcelona de entreguerras, 1918-1936, Barcelona, Centre de Cultura Contemporània.

Palafox, J. (1980), "La crisis de los años 30: sus orígenes", Papeles de Economía Española, 1, pp. 30-42.

Palafox, J. (1986), "Comercio exterior y vía nacionalista. Algunas consideraciones", en García Delgado, J.L. (ed.), La crisis de la Restauración. España entre la Primera Guerra Mundial y la Segunda República, Madrid, Siglo XXI, pp. 179-197.

Palazón, S. (1991), "La política inmigratoria en los países de América del Sur: del estímulo a la restricción (1850-1980)", en EIRAS, A. (coord.), Emigración española y portuguesa a América, Alicante, Instituto de Cultura Juan Gil-Albert, pp. 127-136.

PAREJo, A. (2001), "Industrialización, desindustrialización y nueva industrialización de las regiones españolas (1950-2000). Un enfoque desde la Historia Económica", Revista de Historia Industrial, 19-20, pp. 15-75.

Peña Novo, L. (1928), "Presente y porvenir económico de Galicia”, El Pueblo Gallego, 1 de enero de 1928. 
Peña Novo, L. (1929a), Nuevas orientaciones sociales, Vigo, El Pueblo Gallego.

Peña Novo, L. (1929b), “Opiniones. Turismo espiritual”, El Pueblo Gallego, 28 de febrero de 1929.

Peña SaAVedra, V. (1991), Éxodo, organización comunitaria e intervención escolar. La impronta educativa de la emigración transoceánica en Galicia, Santiago de Compostela, Xunta de Galicia, 2 vols.

Pereira, D. (1992a), "Introducción”, en Pereira, D. (coord.), Os conquistadores modernos. Movemento obreiro na Galicia de anteguerra, Vigo, A Nosa Terra, pp. 9-22.

Pereira, D. (1992b), "Asociacionismo e conflictividade na Galiza mariñeira (18701936)", en PereirA, D. (coord.), Os conquistadores modernos. Movemento obreiro na Galicia de anteguerra, Vigo, A Nosa Terra, pp. 151-172.

Pereira, D. (1994), A CNT na Galicia 1922-1936, Santiago, Laiovento.

Pereira, D. (1998), Sindicalistas e rebeldes. Anacos da historia do movemento obreiro na Galicia, Vigo, A Nosa Terra.

Pereira, D. (2001), “O asociacionismo dos pescadores na Galiza de anteguerra: unha ollada de conxunto", en VIII Semana Galega de Historia. Galicia Mare Nostrum: A importancia do mar en Galicia, Santiago, Asociación Galega de Historiadores, pp. 347-385.

Pereira, D. (2002), "Proletariado e loita de clases na Galicia de anteguerra", en Constenla, G. y Domínguez, L. (eds. y coords.), Tempos de sermos: Galicia nos séculos contemporáneos, Vigo, Universidade de Vigo, pp. 123-146.

Pérez De Los Heros, I. (2000), “Torres y Sáez. Tradición ferretera”, en OjeA, F. (coord.), Grandes empresas, grandes historias de Galicia, A Coruña, La Voz de Galicia, pp. 266-267.

Pérez García, J.M. y Noreña, Ma .T. (1992), “Imperialismo europeo, despegue portuario y crecimiento económico en Las Palmas de Gran Canaria, 1882-1931”, en García Delgado, J.L. (ed.), Las ciudades en la modernización de España. Los decenios interseculares, Madrid, Siglo XXI, pp. 462-474.

Pérez Iglesias, M.L. (1985), La ciudad de Pontevedra. Evolución histórica y demográfica, Santiago, Universidade de Santiago de Compostela.

PÉrez MoredA, V. (1985), “La modernización demográfica, 1800-1930. Sus limitaciones y cronología”, en SÁncheZ-Albornoz, N. (ed.), La modernización económica de España, 1830-1930, Madrid, Alianza Editorial, pp. 25-62.

PÉrez RoJos, F.J. (1986), Cartagena 1874-1936 (Transformación urbana y arquitectura), Murcia, Editora Regional de Murcia-Caja Murcia.

PÉrez Serrano, J. (1991), "Demografía y urbanización en Cádiz: dos siglos de relaciones", en GozÁlvez, V. (coord.), Los procesos de urbanización: Siglos XIX y XX, Alicante, Instituto de Cultura Juan Gil-Albert, Diputación de Alicante, pp. 165-174.

Pillet, F. (1984), Geografía urbana de Ciudad Real (1255-1980), Madrid, Akal. 
PiñEIro, C. (1996a), Análise financeira no longo prazo dunha empresa de servicios. A Compañia de Tranvías de La Coruña (1901-1963), Universidade da Coruña, memoria de licenciatura inédita.

PiñeIro, C. (1996b), "Análise financeira no longo prazo dunha empresa de servicios. A Compañía de Tranvías de La Coruña (1901-1963)”, Revista Galega de Economía, 5 (1), pp. 181-198.

PiñeIro, C. (1997), "Las empresas concesionarias de servicios públicos en Galicia. Economía, financiación empresarial y electrificación de la red tranviaria coruñesa en los años veinte", Galicia en Clave Económica, 2, pp. 101-119.

PoRTo, A.S. (1986), La Institución Libre de Enseñanza en Galicia, Sada-A Coruña, Ed. do Castro.

Pose, J.M. (1992), La economía y la sociedad compostelanas a finales del siglo XIX, Santiago, Universidade de Santiago de Compostela.

Pozueta, J. et al. (1985), Santander. El puerto y su historia, Santander, Junta del Puerto de Santander.

Prados, L. (2003), El progreso económico de España, 1850-2000, Madrid, Fundación BBVA.

Precedo, A. (1987a), Galicia: estructura del territorio y organización comarcal, Santiago, Xunta de Galicia.

Precedo, A. (1987b), "La estructura terciaria del sistema de ciudades en España", Estudios Territoriales, 24, pp. 53-76.

Precedo, A. (1990a), La Coruña, metrópoli regional, La Coruña, Caixa Galicia.

Precedo, A. (1990b), La red urbana, Madrid, Síntesis.

Precedo, A. (1998), Geografía humana de Galicia, Barcelona, Oikos-Tau.

Precedo, A. (dir.) (1991), Orense. Centro de equilibrio, La Coruña, Caixa Galicia.

Precedo, A. (dir.) (1995), El Área Urbana de Ferrol. La crisis de un modelo urbano, La Coruña, Caixa Galicia.

Precedo, A., Rodríguez, R. y Villarino, M. (1988), Vigo, área metropolitana, La Coruña, Caixa Galicia.

Pueyo, J. (2003), "Oligopolio y competencia en la banca española del siglo XX: concentración económica y movilidad intra-industrial, 1922-1995", Revista de Historia Económica, XXI (1), pp. 147-198.

Racionero, L. (1978), Sistemas de ciudades y ordenación del territorio, Madrid, Alianza.

Ramos Hidalgo, A. (1987), "Zonificación urbana", en VV.AA., Atlas sociodemográfico de la ciudad de Alicante, Alicante, Instituto de Estudios Juan Gil-Albert, Diputación Provincial de Alicante, Ayuntamiento de Alicante, pp. 11-22. 
Rebollo, A. (1987), “Grandes almacenes y almacenes populares”, en CASARES, J. (comp.) et al., La economía de la distribución comercial, Barcelona, Ariel, pp. 216-223.

ReHER, D.s. (1989), "Urban growth and population development in Spain, 1787-1930”, en Lawton, R. y Lee, R. (eds.), Urban Population Development in Western Europe from the Late-Eighteenth to the Early-Twentieth Century, Liverpool University Press, pp. 190-219.

REHER, D.S. (1994), “Ciudades, procesos de urbanización y sistemas urbanos en la Península Ibérica, 1550-1991”, en GuÀrdia, M., Monclús, F.J. y OYón, J.L. (eds), Atlas histórico de ciudades europeas, Barcelona, Centre de Cultura Contemporània, pp. 1-29.

Renouvin, P. et al. (1995), La Primera Guerra Mundial, Barcelona, Oikos-Tau.

Revenga, E. (1980), "La transición demográfica en España”, Revista Española de Investigaciones Sociológicas, 10, pp. 233-240.

Rico, E. (2000), "Montes, industria de serra e tráfico de madeira en Galicia. A provincia de Pontevedra no período 1875-1936", en Fernández Prieto, L. (dir.), Terra e progreso. Historia agraria da Galicia contemporánea, Vigo, Xerais, pp. 405-440.

Rivas Moreno, F. (1916), El problema de las subsistencias en La Coruña, Zaragoza, Tipografía El Heraldo.

Rivera, A. (1985), Situación y comportamiento de la clase obrera en Vitoria (19001915), Bilbao, Universidad del País Vasco.

Rodríguez Lestegás, F. (1989), Valor y usos del suelo urbano, Santiago, Universidade.

Rodríguez Osuna, J. (1985), Población y territorio en España. Siglos XIX y XX, Madrid, Espasa-Calpe.

Rodríguez Regueiro, M. (1973), El comercio mayorista y minorista en el sector de la alimentación, La Coruña, Cámara de Comercio.

Rojo, J. (1980), El sistema financiero en Galicia: estructura y evolución (1964-1978), Universidade de Santiago de Compostela, tesis doctoral.

Roldán, S. y García Delgado, J.L., con la colaboración de JuAn MuÑoz (1973), La formación de la sociedad capitalista en España, 1914-1920, Madrid, CECA, 2 vols.

Román, M. (1997), Historia de La Voz de Galicia (1882-1939), Vigo, Universidad de Vigo.

Romaní, A. (1981), La pesca de bajura en Galicia, A Coruña, Ed. do Castro.

Romero Masiá, A. (1997), A Fábrica de Tabacos da Palloza. Producción e vida laboral na decana das fábricas coruñesas, A Coruña, UGT.

Romero, J. (1995), "Bibliografía sobre terciarización urbana, comercio y consumo", Revista de Geografía, XXIX (2), pp. 115-131.

Rubio, M. (1916), Memoria de valoraciones para el año 1913. Provincia de La Coruña, Madrid, Establecimiento Tipográfico de Antonio Marzo. 
SÁez, A. (1975), Población y actividad económica en España, Madrid, Siglo XXI.

Sagredo, F. et al. (1976), La Caja de Ahorros-Monte de Piedad de La Coruña y Lugo (1876-1976), La Coruña.

San Vicente, M. (1954), "Importancia estratégica del puerto de La Coruña en el movimiento emigratorio nacional", Orientación Económica y Financiera, XII, 53, pp. 10-13.

SÁNCHEZ JimÉnEZ, J. (1992), “Málaga, 1890-1930: Las transformaciones sociales de una ciudad en crisis", en García Delgado, J.L. (ed.), Las ciudades en la modernización de España. Los decenios interseculares, Madrid, Siglo XXI, pp. 345-375.

SANDE, R. (1966), La Coruña económica y financiera, 1938-1965, A Coruña, Instituto José Cornide de Estudios Coruñeses.

Santos Gayoso, E. (1990), Historia de la prensa gallega, 1800-1986, La Coruña, Ed. do Castro.

Santos Ledo, M.J. (1984), "Proceso de transición demográfica y crecimiento de los principales núcleos satélites del área metropolitana de La Coruña”, en III Coloquio Ibérico de Geografía, Barcelona, Universidad, pp. 410-414.

SEQueIros, J.G. (1981), Elementos para el análisis estructural de la economía gallega. Sobre el desarrollo del Capitalismo en su periferia próxima, Universidade de Santiago de Compostela, resumen tesis doctoral.

Sequeiros, J.G. (1985), "Hábitat y desarrollo urbano en Galicia, 1857-1980", en IX Reunión de Estudios Regionales. Crisis, Autonomías y Desarrollo Regional, Santiago de Compostela, Asociación Española de Ciencia Regional, tomo I, pp. 275-296.

Sequeiros, J.G. (1986), El desarrollo económico de Galicia. II. Industrialización y Mercado Interior, Santiago, Universidade de Santiago de Compostela.

Serrano, J.M. (1986), "La política arancelaria española al término de la primera guerra mundial: proteccionismo, Arancel Cambó y tratados comerciales", en García Delgado, J.L. (ed.), La crisis de la Restauración: España entre la Primera Guerra Mundial y la Segunda República, Madrid, Siglo XXI, pp. 199-223.

Sinde, A.I. (1999), "El transporte de pescado en España y el problema de los vagones frigoríficos: 1890-1950", en Muñoz, M., Sanz, J. y Vidal, J., Siglo y medio de ferrocarril en España. Economía, industria y sociedad, Madrid, Fundación de Ferrocarriles Españoles, pp. 771-786.

Sinde, A.I., DiéGuez, M ${ }^{\mathrm{a}}$.I. y Fernández, Mª.T. (2002), “El proceso de difusión tecnológica en la pesca de altura del norte de España", Historia Agraria, 28, pp. 113-136.

Sorribes, J. (1992), "La transición urbana: Método y resultados. Valencia 1874-1931", García Delgado, J.L. (ed.), Las ciudades en la modernización de España. Los decenios interseculares, Madrid, Siglo XXI, pp. 197-222.

Souto, X.M. (1990), Vigo. Cen anos de Historia urbana (1880-1980), Vigo, Xerais. 
Sudrià, C. (1987), "Un factor determinante: la energía”, en Nadal, J., CARreras, A. y SudRì̀, C. (comps.), La economía española en el siglo XX. Una perspectiva histórica, Barcelona, Ariel, pp. 313-363.

SudRiÀ, C. (1990), "Los beneficios de España durante la Gran Guerra. Una aproximación a la Balanza de Pagos española, 1914-1920", Revista de Historia Económica, VIII (2), pp. 363-396.

TEIXIDOR, M.J. (1982), València, la construcció d'una ciutat, València, Institució Alfons el Magnànim-Diputació de València.

TENA, A. (1985), “Una reconstrucción del comercio exterior español, 1914-1935. La rectificación de las estadísticas oficiales", Revista de Historia Económica, III (1), pp. 77-122.

Tobal, C. (1997), “Distribución espacial del terciario portuario”, en Dinámica LitoralInterior. Actas XV Congreso de Geógrafos Españoles, Santiago de Compostela, A.G.E.-Universidade, vol. II, pp. 701-708.

Tовоso, P. (2002), Grandes almacenes y almacenes populares en España. Una visión histórica, Madrid, Fundación Empresa Pública.

Tortella, G. (1994), El desarrollo de la España contemporánea. Historia económica de los siglos XIX y XX, Madrid, Alianza.

Tortella, G. (2000), La revolución del siglo XX, Madrid, Taurus.

Tortella, G. y Palafox, J. (1983), “Banca e industria en España, 1918-1936”, Investigaciones Económicas, 20, pp. 33-66.

Tortella, G. y Palafox, J. (1984), “Banking and industry in Spain, 1918-1936”, Journal of European Economic History, 13 (2), pp. 81-111.

Trespalacios, J. (1992), Estudio del sector comercial en la ciudad de Oviedo, Oviedo, Universidad de Oviedo, Documento de Trabajo 052/1992.

TRINIDAD, F. (2001), Los trabajadores gaditanos en la coyuntura de la Primera Guerra Mundial (1914-1923), Cádiz, Universidad de Cádiz.

Troitiño, M.A. (1984), Cuenca: Evolución y crisis de una vieja ciudad industrial, Madrid, MOPU.

VAlCÁrCel, A. (1923), "La Coruña y su puerto", en Catálogo de La Coruña. La Coruña a través de un siglo. 1923-1924, Vigo, Ed. P.P.K.O, pp. 56-62.

VALDALiso, J.M. (1997), La navegación regular de cabotaje en España en los siglos XIX y XX. Guerras de fletes, conferencias y consorcios navieros, Vitoria, Gobierno Vasco-Departamento de Transportes y Obras Públicas.

Valdaliso, J.M. (2003), "Los libros de buques del Registro Mercantil y sus posibilidades para la historia económica, 1886-1986", en MArTín RodríGUEz, M. et al. (2003), El registro mercantil: una fuente para la historia económica, Granada, Universidad de Granada. 
Valiña, M. (2000), "Hijos de Rivera. Cerveza con estrella”, en Ojea, F. (coord.), Grandes empresas, grandes historias de Galicia, A Coruña, La Voz de Galicia, pp. 196-199.

VÁzquez GonzÁlez, A. (1988), "La emigración gallega. Migrantes, transporte y remesas", en Sánchez Albornoz, N. (ed.), Españoles hacia América. La emigración en masa, 1880-1930, Madrid, Alianza, pp. 80-105.

VÁzQuez GonZÁlez, A. (1990), "Algúns aspectos do transporte de emigrantes galegos a América (1850-1930)", V Xornadas de Historia de Galicia, Ourense, Deputación Provincial, pp. 121-134.

VÁzquez GonzÁlez, A. (1992), "Emigración e transporte de galegos hacia América, 1900-1930”, en Alonso Álvarez, L. (coord.), Os intercambios entre Galicia e América Latina. Economía e Historia, Santiago, Universidade, pp. 77-110.

VÁzquez GonzÁlez, A. (2000a), La emigración gallega a América, 1830-1930, Universidade de Santiago de Compostela, tesis doctoral.

VÁzquez GonzÁLEZ, A. (2000b), "El ocaso de la armaduría gallega y la emergencia de los nuevos señores del transporte emigratorio a América: los consignatarios (1847-1880)", en Cagiao, P. (ed.), Galicia nos contextos históricos. Sémata, 11, pp. 235-256.

Vázquez González, A. (2001), "Los nuevos señores del entramado comercial de la emigración a América por puertos gallegos: Los consignatarios de las grandes navieras transatlánticas, 1870-1939”, VII Congreso de la Asociación de Historia Económica, Zaragoza.

VÁzquez VaAmonde, Ma.C. (1996), La metalurgia en Galicia de los siglos XVIII al $X X$ : ferrerias, fundiciones y forjas, Universidade de Santiago de Compostela, tesis doctoral.

Velasco, C.F. (2002), "Galiza na II República”, en Constenla, G. y Domínguez, L. (eds. y coords.), Tempos de sermos. Galicia nos séculos contemporáneos, Vigo, Universidade de Vigo, pp. 227-248.

VICEDO, E. (ed.) (1999), Empreses i institucións econòmiques contemporánies a les terres de Lleida, 1850-1990, Lleida, Institut de Estudis Ilerdencs.

VidAL Bendito, T. (1991), "El papel de la urbanización en la modernización demográfica de España”, en GozÁlvez, V. (coord.), Los procesos de urbanización: Siglos $X I X$ y XX, Alicante, Instituto de Cultura Juan Gil-Albert, Diputación de Alicante, pp. 37-48.

VIDAL, J. (1987), Comerciantes y políticos. Alicante (1875-1900), Alicante, Instituto de Estudios Juan Gil-Albert.

Vilar, P. (1986), La Guerra Civil Española, Barcelona, Crítica, $4^{\mathrm{a}}$ ed.

Vilela, X.L. (1997), La Divisa del progreso. Historia de la Sociedad de Seguros Mutuos contra Incendios de Casas de La Coruña (1835-1997), A Coruña, Ed. Imperio. 
Villares, R. (1982), La propiedad de la tierra en Galicia: 1500-1936, Madrid, Siglo XXI.

Villares, R. (1984), "El indiano gallego. Mito y realidad de sus remeses de dinero", Indianos. Monografía de los Cuadernos del Norte, n², pp. 29-34.

Villares, R. (1991), Historia de Galicia, Madrid, Alianza.

Villares, R. (1992), "As remesas de diñeiro dos emigrantes”, en Galicia e América. Cinco séculos de Historia, Santiago, Consello de Cultura Galega, pp. 254-255.

Villares, R. (1996a), Historia da emigración galega a América, Santiago, Xunta de Galicia.

Villares, R. (1996b), "La historiografía gallega actual”, en Agirreazkuenaga, J. y Urquijo, M. (eds.), Perspectivas de historia local: Galicia y Portugal, Bilbao, Universidad del País Vasco, pp. 11-26.

Villares, R. (1996c), "Idade contemporánea”, en VV.AA., Nova Historia de Galicia, A Coruña, Ed. Tambre, pp. 353-447.

Villares, R. (1998), Historia de Galicia, Vigo, Obradoiro.

VILlARES, R. (2000), “A agricultura galega, 1870-1930. Unha época de grandes transformacións", en FERnÁndez PRIETO, L. (dir.), Terra e progreso. Historia agraria da Galicia contemporánea, Vigo, Xerais, pp. 61-82.

Villares, R. y Fernández, M. (1996), Historia da emigración galega a América, Santiago, Xunta de Galicia.

Walton, J.K. (2002), "Planning and seaside tourism: San Sebastian, 1863-1936”, Planning Perspectives, 17, pp. 1-20.

Williamson, J.G. (1982), "Was the Industrial Revolution worth it? Disamenities and death in 19th century British towns", Explorations in Economic History, 19 (3), pp. 221-245. 


